\title{
DETERMINAÇÃO DA PERMEABILIDADE EM MADEIRAS BRASILEIRAS DE FLORESTAS PLANTADAS
}

\author{
Marcio Rogério da Silva
}

Dissertação apresentada ao Programa de Pós-Graduação Interunidades Ciências e Engenharia de Materiais, da Universidade de São Paulo, para obtenção do título de Mestre em Ciências de Engenharia de Materiais.

Orientador: Carlito Calil Junior

\section{SÃO CARLOS}


Ficha catalográfica elaborada pelo Serviço de Biblioteca e Informação IFSC/USP.

Silva, Marcio Rogério da

Determinação da permeabilidade em madeiras brasileiras de florestas plantadas / Marcio Rogério da Silva; orientador Carlito Calil Junior. São Carlos, 2007.

$135 \mathrm{f}$.

Dissertação (Mestrado - Área de concentração: Ciência e Engenharia de Materiais) - Escola de Engenharia de São Carlos/Instituto de Física de São Carlos/ Instituto de Química de São Carlos da Universidade de São Paulo.

1. Permeabilidade a ar. 2. Permeabilidade à liquido. 3. Espécie de reflorestamento. 4. Equipamento alternativo. 5. Fluxo em madeira. I. Título. 


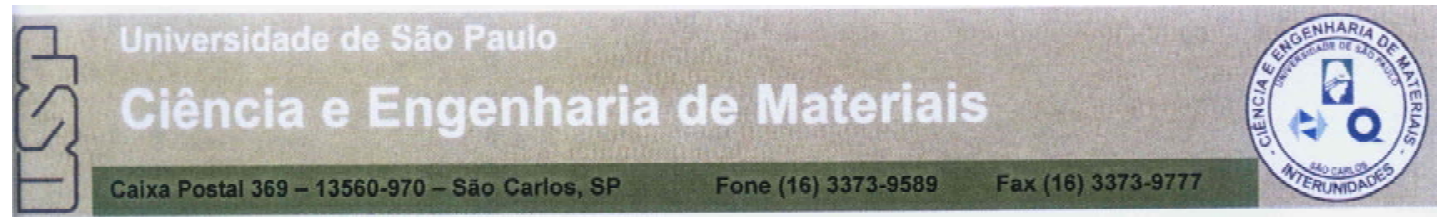

MEMBROS DA COMISSÃO JULGADORA DA DISSERTAÇÄO DE MESTRADO DE MARCIO ROGÉRIO DA SILVA, APRESENTADA AO PROGRAMA DE PÓS-GRADUAÇÃO EM CIÊNCIA E ENGENHARIA DE MATERIAIS DO INSTITUTO DE FISICA DE SÃO CARLOS, UNIVERSIDADE DE SÃO PAULO, EM 20.03.2007.

\section{COMISSÃO JULGADORA:}

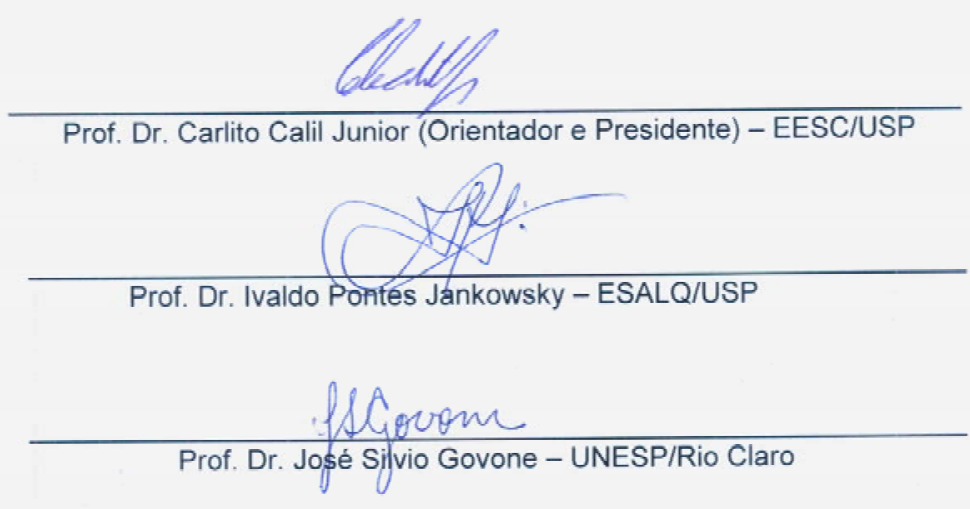


Aos meus pais Joaquim e Dalila, ao meu irmão Marcos, pelo amor, dedicação e compreensão durante todas as horas.

\section{AGRADECIMENTOS}


A Deus, pois dele tudo vem.

Ao Prof. Carlito Calil Junior, meu orientador, pela incansável e valiosa orientação e principalmente pelo apoio, amizade e confiança, depositados em mim, sem os quais esse trabalho não teria sido realizado.

Ao prof. Antônio Alves Dias, prof. Francisco Antônio Rocco Lahr, prof. Ivaldo Pontes Jankowsky, prof. José Silvio Govone e prof. Antônio Aprígio da Silva Curvelo, pela ajuda nos momentos dificeis, companheirismo e amizade.

A todos os amigos do LaMEM, em especial: Alexandre Mina, Élen Morales, Júlio Molina, Gilmara Machado, Maximiliano Azambuja, Pedro Segundinho, André Christóforo, André Zangiácomo, Edna Moura e Maria Fátima (Fati), pois me auxiliaram e são companheiros nas horas fáceis quanto nas horas dificeis.

A todos os amigos que conquistei dentro e fora da universidade, em especial: Roberta, Alexandre, Marquim, Uelton, Marcelo, Oilson, Idemar, Rose e Márcio, pois contribuíram em minha caminhada.

A todos os funcionários e técnicos do LaMEM, Sílvio, Samuel, Cido, Arnaldo, Tânia, Bragatto, Roberto e Jaime, pelo inestimável apoio.

A todos que contribuíram de forma direta ou indireta para a conclusão deste trabalho.

\section{SUMÁRIO}




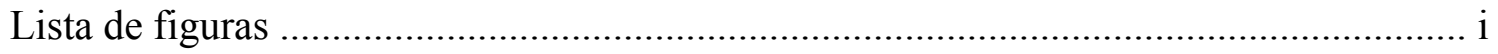

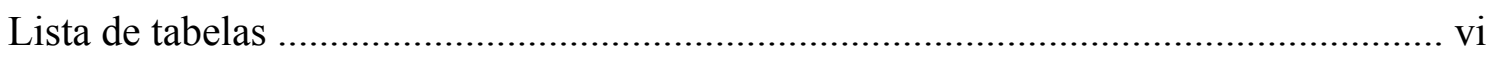

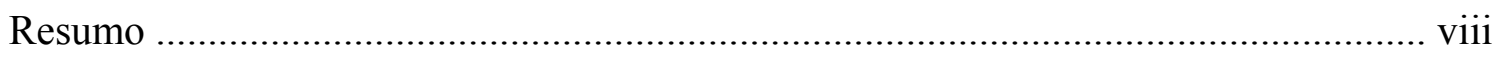

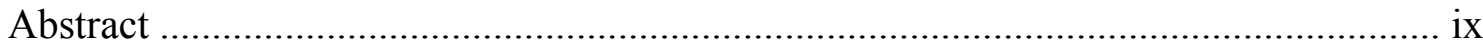

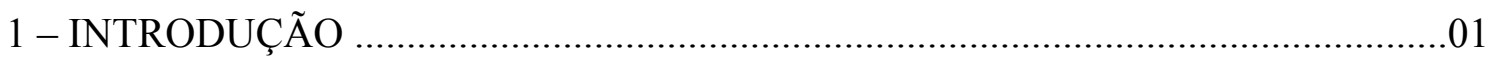

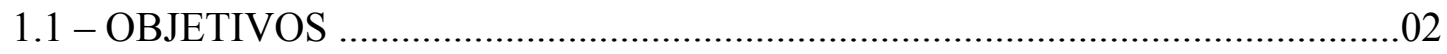

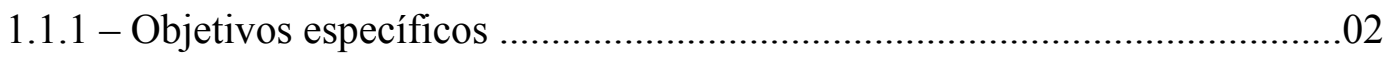

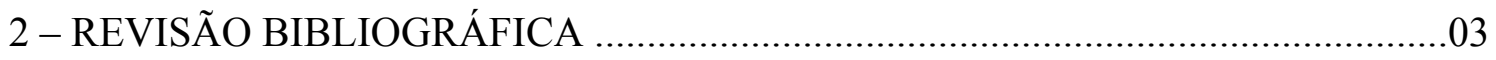

2.1 - Elementos constituintes da madeira ................................................................

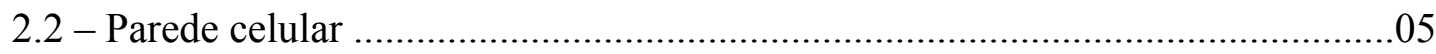

2.3 - Microestrutura nas coníferas (gimnospermas) ……………………………........

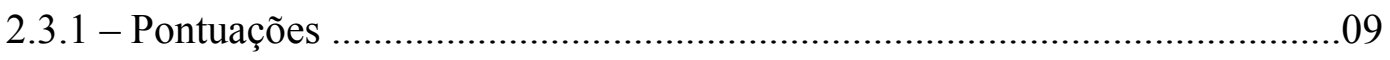

2.3.2 - Fatores que influenciam a permeabilidade nas coníferas ............................11

2.3.3 - Caminho do fluxo de fluidos nas coníferas ...............................................15

2.4 - Microestrutura nas dicotiledôneas (angiospermas) .............................................18

2.4.1 - Caminho dos fluidos nas dicotiledôneas (angiospermas) ………………....22

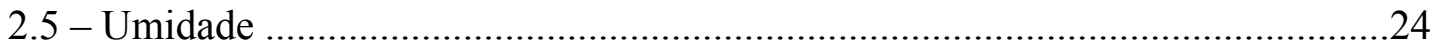

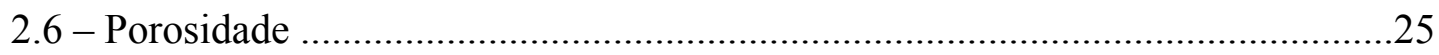

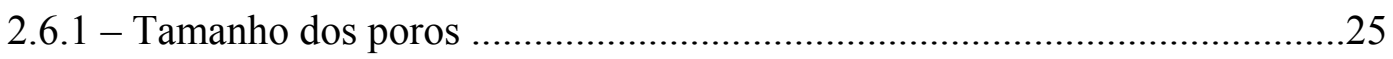

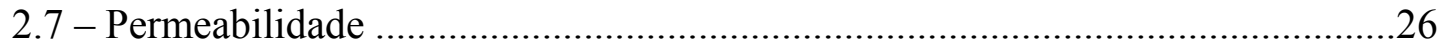

2.7.1 - Métodos que podem ser utilizados na determinação da permeabilidade ..28

2.7.2 - Modelo de fluxo para coníferas ..............................................................29

2.7.3 - Modelo de fluxo para dicotiledôneas ..........................................................31

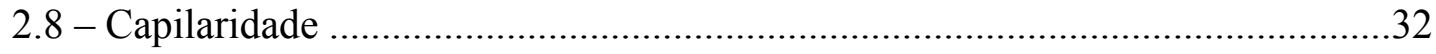

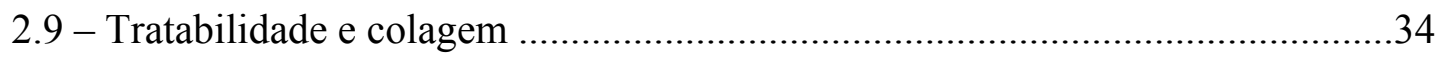

2.10 - Conclusão da revisão bibliográfica ……………………………………….....36 


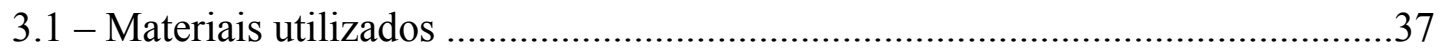

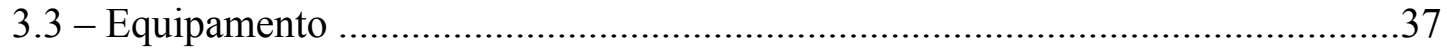

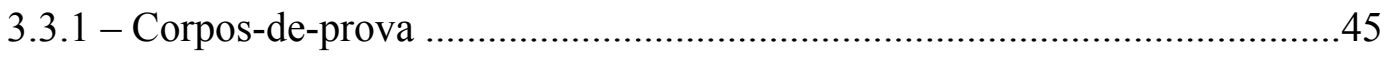

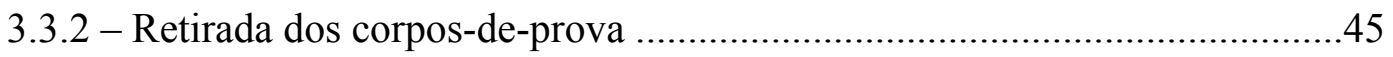

3.2.3 - Impermeabilização dos corpos-de-prova ..................................................46

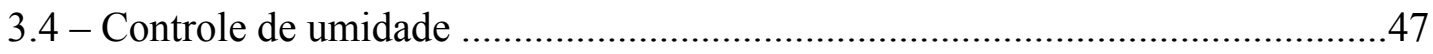

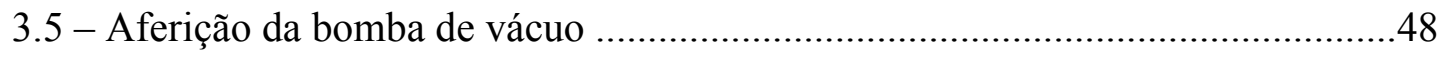

3.6 - Tipos de fluidos utilizados na determinação da permeabilidade .........................49

3.7 - Microscopia eletrônica de varredura ……………….................................50

3.8 - Análise química da madeira de E. citriodora, E. grandis e Pinus elliottii ........51

3.8.1 - Preparação da madeira para análise química ..............................................51

3.8.2 - Determinação do teor de cinzas ..................................................................53

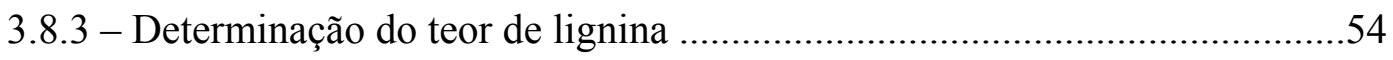

3.8.4 - Determinação do teor de holocelulose - celulose e poliose ........................56

3.9 - Caracterização simplificada ………………………………………………....56

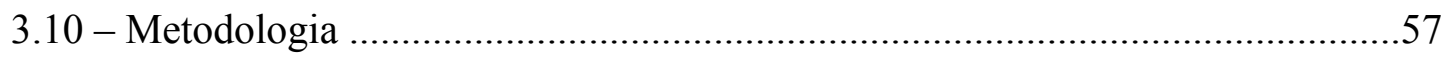

3.10.1 - Amostra a ser ensaiada ……………………................................5

3.10.2 - Descrição metodológica dos ensaios para fluxo gasoso ………………....59

3.10.3 - Descrição metodológica dos ensaios para fluxo líquido ...........................62

3.11 - Análise estatística dos resultados .......................................................................63

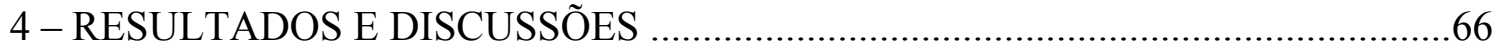

4.1 - Microscopia eletrônica de varredura ……………………………………......66

4.2 - Resultados da analise química …………………………………………….......77

4.3 - Resultados da permeabilidade em função do fluxo e resultados da análise

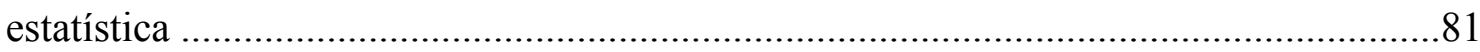

4.4 - Caracterização simplificada ............................................................................93 
5 - CONCLUSÕES

6 - REFERÊNCIAS BIBLIOGRÁFICAS

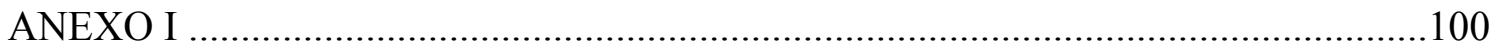

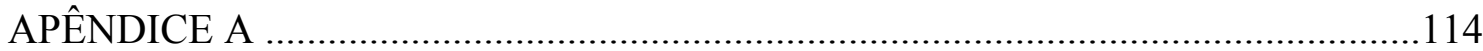

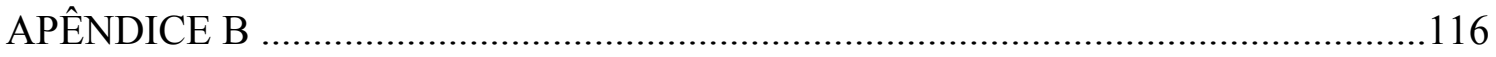

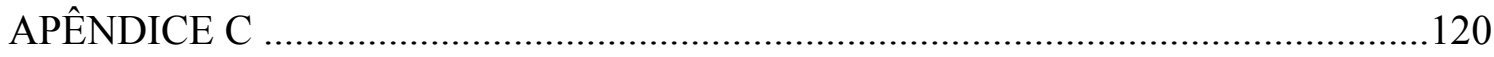




\section{LISTA DE FIGURAS}

\section{Capítulo 2}

Figura 2.1 - Representação esquemática da estrutura fibrilar da parede celular. Fonte - Lepage (1986)

Figura 2.2 - Estrutura da parede celular de um traqueídeo (conífera) ou de fibras libriformes e vasos (folhosas)

Figura 2.3 - Diagrama do lenho de uma conífera nos três planos de observação. Fonte - Lepage (1986)

Figura 2.4 - Tipos de traqueídeos do lenho das coníferas. Fonte - Lepage (1986) .8

Figura 2.5 - Tipos de pares de pontuações. A, par de pontuação areolada, presente somente nas coníferas; $\mathrm{B}$, par de pontuação simples e C, par de pontuação semiareolada. Fonte - Lepage (1986)

Figura 2.6 - Menbrana do par de pontuações areolada de Eastern Hemlock. Fonte Siau (1971)

Figura 2.7 - A, Pontuação areolada com torus aspirado (encostado à parede celular, bloqueando a passaagem de líquidos); B, vista frontal do torus mostrando o retículo de sustenção ou margo. 12

Figura 2.8 - Aspiração em madeira de lenho precoce no limite dos pares de pontuações entre traqueídeos do cerne de Pinus shortleaf. Seção tangencial. Fonte Siau (1971)

Figura 2.9 - Aspiração em madeira de lenho tardio no limite dos pares de pontuações entre traqueídeos do cerne de Pinus elliotti. Seção tangencial. Fonte - Siau (1971).

Figura 2.10 - Membrana da aspiração no limite dos pares de pontuações de madeira de lenho precoce de Virginia pine. Fonte - Siau (1971).

Figura 2.11 - Forte incrustação e membrana aspirada no limite dos pares de pontuações de madeira de lenho precoce nas pontuações do cerne de Pinus rígida. Fonte - Siau (1971). 
Figura 2.12 - Estrutura da parede primária da superfície de torus visto pela abertura de dentro do traqueídeo. Fonte - Siau (1971). 14

Figura 2.13 - Modelo do fluxo em coníferas. Plano tangencial mostrando pontuações nas superfícies radiais das terminações afiliadas aos traqueídeos. Fonte Siau (1971) .16

Figura 2.14 - Difusão de umidade nos traqueídeos. Fonte - Ilmara et al (1996)...17

Figura 2.15 - Diagrama do lenho de uma dicotiledônea nos três planos de observação. Fonte - Lepage (1986) .18

Figura 2.16 - Tipos de placa de perfuração. Fonte: Lepage (1986) …………….....20

Figura 2.17 - Vasos com tilas. Fonte: Lepage (1986). .21

Figura 2.18 - Modelo generalizado do fluxo para angiospermas. A importância relativa do fluxo é indicada pelo tamanho da flecha.

Figura 2.19 - Corpo-de-prova permeável ilustrando a significância dos termos na lei de Darcy

Figura 2.20 - Modelo de escoamento longitudinal para dicotiledôneas com vasos abertos. Fonte Siau (1971). 31

\section{Capítulo 3}

Figura 3.1 - Vista superior da estrutura de madeira. .38

Figura 3.2 - Vista frontal da estrutura de madeira. .38

Figura 3.3 - Vista frontal do suporte de madeira. .39

Figura 3.4 - Vista superior do suporte de madeira. .39

Figura 3.5 - Junta cônica com as torneiras de teflon. .40

Figura 3.6 - Vista superior do conjunto de rolhas. 40

Figura 3.7 - Conjunto de rolhas acopladas. Rolha de teflon com oliva .41

Figura 3.8 - Fixador de rolha de borracha. .41

Figura 3.9 - Conjunto de rolhas em posição de acoplamento. .42

Figura 3.10 - Medidores de deslocamento de fluidos. .43

Figura 3.11 - Equipamento montado para ensaios de permeabilidade .44

Figura 3.12 - Peças constituintes do dispositivo apresentadas individualmente....44 
Figura 3.13 - Corpo-de-prova utilizado nos ensaios a líquido e gás. .45

Figura 3.14 - Madeira antes do desdobro. .45

Figura 3.15 - Retirada dos corpos-de-prova na direção e perpendicular às fibras da madeira. 46

Figura 3.16 - Seqüência de usinagem para os corpos-de-prova. ..........................46

Figura 3.17 - Recobrimento de um corpo-de-prova...........................................47

Figura 3.18 - Etapas da impermeabilização. .....................................................47

Figura 3.19 - Calibrador de bomba de vácuo. ................................................... 48

Figura 3.20 - Deslocamento da coluna de mercúrio.........................................49

Figura 3.21 - Processo de desobstrução dos elementos anatômicos. ......................50

Figura 3.22 - Corte das amostras de Pinus e Eucayptus para realização do MEV.51

Figura 3.23 - Amostras metalizadas com ouro (a). Amostras no microscópio para análise (b).

Figura 3.24 - Processo de retirada dos extrativos (A). Ocorrência do refluxo no Soxhlet (B) .52

Figura 3.25 - Amostras após calcinação. .53

Figura 3.26 - Máquina universal de ensaio AMSLER (a) e DARTEC (b) .57

Figura 3.27 - Combinações de teste para realização dos ensaios. .58

Figura 3.28 - Combinações de teste para realização dos ensaios. 59

Figura 3.29 - Adaptação para determinação do fluxo. .60

Figura 3.30 - Vedação do corpo-de-prova e da rolha evitando vazamento. 60

Figura 3.31 - Cola quente aplicada até próximo ao topo do corpo-de-prova (a). Em (b), amostra pronta a ser ensaiada... .62

\section{Capítulo 4}

Figura 4.1 - Corte transversal do CAL com os elementos anatômicos obstruídos, com aumento de vinte e cem vezes.

Figura 4.2 - Corte transversal do CAL com os elementos anatômicos desobstruídos, com aumento de vinte e cem vezes .68 
Figura 4.3 - Corte radial do CAT com elementos anatômicos obstruídos, com aumento de vinte e cem vezes.

Figura 4.4 - Corte radial do CAT com elementos anatômicos desobstruídos, com aumento de vinte e cem vezes

Figura 4.5 - Corte transversal do CCL com os elementos anatômicos obstruídos, com aumento de vinte e cem vezes

Figura 4.6 - Corte transversal do CCL com os elementos anatômicos desobstruídos, com aumento de vinte e cem vezes .70

Figura 4.7 - Corte radial do CCT com os elementos anatômicos obstruídos, com aumento de vinte e cem vezes .70

Figura 4.8 - Corte radial do CCT com os elementos anatômicos desobstruídos, com aumento de vinte e cem vezes. .70

Figura 4.9 - Corte transversal do GAL com os elementos anatômicos obstruídos, com aumento de vinte e cem vezes .71

Figura 4.10 - Corte transversal do GAL com os elementos anatômicos desobstruídos, com aumento de vinte e cem vezes..... .71

Figura 4.11 - Corte radial do GAL com os elementos anatômicos obstruídos, com aumento de vinte e cem vezes.

Figura 4.12 - Corte radial do GAL com os elementos anatômicos desobstruídos, com aumento de vinte e cem vezes .72

Figura 4.13 - Corte transversal do GCL com os elementos anatômicos obstruídos, com aumento de vinte e cem vezes

Figura 4.14 - Corte transversal do GCL com os elementos anatômicos desobstruídos, com aumento de vinte e cem vezes .73 Figura 4.15 - Evidência da baixa permeabilidade a água destilada no cerne do $E$. grandis.

Figura 4.16 - Corte radial do GCL com os elementos anatômicos obstruídos, com aumento de vinte e cem vezes.

Figura 4.17 - Corte radial do GCL com os elementos anatômicos desobstruídos, com aumento de vinte e cem vezes. .74 
Figura 4.18 - Corte transversal do PL com os elementos anatômicos obstruídos, com aumento de vinte e cem vezes. . .75

Figura 4.19 - Corte transversal do PL com os elementos anatômicos desobstruídos, com aumento de vinte e cinqüenta vezes.

Figura 4.20 - Corte radial do PT com os elementos anatômicos obstruídos, com aumento de vinte e cem vezes .76

Figura 4.21 - Corte radial do PL com os elementos anatômicos desobstruídos, com aumento de vinte e cem vezes. .76

Figura 4.22 - Box-Plot de permeabilidade gasosa na direção longitudinal às fibras.

Figura 4.23 - Box-plot de permeabilidade liquida com água destilada na direção longitudinal às fibras.

Figura 4.24 - Box-plot de permeabilidade liquida com óleo de Neen na direção longitudinal às fibras. .88

Figura 4.25 - Box-plot de permeabilidade liquida para os dois tipos de fluidos analisados na direção longitudinal às fibras. 


\section{LISTA DE TABELAS}

Tabela 1 - Aumento da permeabilidade em porcentagem para fluxo gasoso após desobstrução dos elementos anatômicos. 66

Tabela 2 - Composição química dos principais constituintes da madeira. .............77

Tabela 3 - Medidas estatísticas dos resultados da análise química do E. citriodora. .78

Tabela 4 - Medidas estatísticas dos resultados da análise química do E.grandis....78

Tabela 5 - Medidas estatísticas dos resultados da análise química do Pinus elliottii.

Tabela 6 - Resultados estatísticos de permeabilidade para as amostras que apresentaram vazão a umidade de $12 \%$.

Tabela 7 - Resultados da $\mathrm{K}_{\mathrm{g}}$ em $\mathrm{cm}^{3} / \mathrm{cm}$.atm.s, Rj, H e p, na direção longitudinal às fibras.

Tabela 8 - Diferença entre a média dos postos pelo método de Dunn para $\mathrm{K}_{\mathrm{g}}$ na direção longitudinal às fibras.

Tabela 9 - Resultados da $\mathrm{K}$ em $\mathrm{cm}^{3} / \mathrm{cm}$.atm.s com água destilada, $\mathrm{Rj}, \mathrm{H}$ e p, na direção longitudinal às fibras.

Tabela 10 - Resultados da $\mathrm{K} \mathrm{em} \mathrm{cm}^{3} / \mathrm{cm}$.atm.s, com preservativo à base de óleo de Neen, $\mathrm{Rj}, \mathrm{H}$ e $\mathrm{p}$, na direção longitudinal às fibras. .86

Tabela 11 - Diferença entre a média dos postos pelo método de Dunn para os resultados de $\mathrm{K}$ à base de água destilada na direção longitudinal às fibras. .86

Tabela 12 - Diferença entre a média dos postos pelo método de Dunn para os resultados de $\mathrm{k}$ com preservativo à base de óleo de Neen na direção longitudinal às fibras.

Tabela 13 - Resultados da $\mathrm{K}$ em $\mathrm{cm}^{3} / \mathrm{cm}$.atm.s, com água destilada (Àgua) e preservativo a base de óleo de Neen (Neen), $\mathrm{Rj}, \mathrm{H}$ e $\mathrm{p}$, na direção longitudinal às fibras.

Tabela 14 - Diferença entre a média dos postos pelo método de Dunn para os resultados de k com água destilada e preservativo à base de óleo de Neen, na direção longitudinal às fibras. .90 
Tabela 15 - Resultados da $\mathrm{K}_{\mathrm{g}} \mathrm{em} \mathrm{cm} / \mathrm{cm}$.atm.s na direção longitudinal às fibras. 92

Tabela 16 - Principais propriedades físicas da madeira . .........................................93 


\section{RESUMO}

Este trabalho tem por finalidade o estudo da permeabilidade da madeira, com ênfase nas espécies de florestas plantadas do gênero de Pinus elliotti, Eucalyptus grandis e Eucalyptus citriodora. Com a sua determinação, avalia-se o quanto uma dada espécie de madeira é permeável a preservativos (tratamentos químicos) e o quanto ela é permeável a aplicação de adesivos estruturais (confecção de peças estruturais em Madeira Laminada Colada - MLC). A avaliação da permeabilidade é um fator fundamental para definição do tratamento preservativo da madeira. Para isto foi projetado e construído um equipamento alternativo, para uso laboratorial, visando determinar a permeabilidade e analisar qual espécie dentre as estudadas seriam mais permeáveis a fluidos líquidos e gasosos em madeiras brasileiras de florestas plantadas. $\mathrm{O}$ equipamento construído permite a determinação do escoamento de fluidos em corposde-prova cilíndricos de madeira, em todas as suas direções ortogonais.

Os resultados obtidos mostram que o equipamento é adequado para a determinação da permeabilidade a líquido ou gás em madeiras, onde na direção longitudinal, o alburno E. grandis é a parte do lenho mais permeável a líquido e gás, seguido do alburno do $E$. citriodora, Pinus elliottii e cerne do E. grandis. Com exceção do Pinus elliottii na direção transversal, as demais espécies não apresentaram vazão nesta direção.

Palavras-chave: permeabilidade a ar, permeabilidade a líquido, fluxo, madeira, espécie de reflorestamento e equipamento alternativo. 


\begin{abstract}
This work aims to study permeability of wood especially in reforestation species like Pinus elliotti, Eucalyptus grandis and Eucalyptus citriodora in order to evaluate how much a given wood species is permeable to preservatives (chemical treatments) and how much it is permeable to application of structural adhesives (making of structural pieces in Glued Laminated - MLC). Evaluation of permeability is a fundamental factor when defining the preservative treatment to able applied in the wood, so an alternative equipment has been especially designed and built aiming to determine its permeability and analyze which one of the studied Brazilian reforestation species would be more permeable to liquid and gaseous fluids. This laboratorial equipment has allowed determination of fluid drainage in cylindrical samples of wood in all of its orthogonal directions.

Obtained results have shows that it is appropriate for determining liquid or air permeability of wood where, in longitudinal direction, E. grandis sapwood has been the most permeable part, followed by E. citriodora sapwood, Pinus elliottii and E. grandis heartwood. None of the species has presented any flow in traverse direction, except Pinus elliottii.
\end{abstract}

Keywords: air permeability, liquids permeability, flow, wood, reforestation species and alternative equipment. 


\section{1 - INTRODUÇÃO}

A redução da disponibilidade de espécies de madeiras nativas, os elevados custos de exploração e transporte, associado ao fortalecimento dos conceitos de preservação ambiental, ampliam a necessidade do desenvolvimento de alternativas viáveis para a utilização racional da madeira.

Frente a estas dificuldades, foi necessário buscar, como fonte alternativa, madeiras de florestamento dos gêneros Pinus e Eucalyptus, que se encontra em quantidades apreciáveis, nas regiões Sul, Sudeste e Nordeste do Brasil, devido inicialmente a políticas públicas de incentivos fiscais para o florestamento.

Madeiras vindas de fontes de florestamento, principalmente dos gêneros Pinus e Eucalyptus, apresentam um crescimento muito rápido e conseqüentemente tendem a ter baixa durabilidade natural contra a ação de organismos xilófagos, sendo assim, há necessidade de preservá-las. Além do mais, com o crescente aumento no consumo de madeira, faz com que estas espécies sejam abatidas cada vez mais cedo, sendo necessário fabricar peças estruturais com adesivos cada vez mais eficazes.

Contudo, é necessário conhecer as propriedades físicas e químicas destas madeiras para que, em sua utilização, seja obtida a máxima eficácia de suas características, e assim reduzindo custos na produção e evitando o desperdício e prováveis prejuízos. Uma característica física importante a ser conhecida nas espécies de florestamento do gênero Pinus e Eucalyptus é a permeabilidade, propriedade esta que pode indicar o deslocamento de fluidos na madeira e assim prever se a espécie é permeável a tratamentos químicos e adesivos na confecção de peças estruturais. A baixa permeabilidade na madeira pode resultar em tratamentos defeituosos e conseqüentes prejuízos.

Hansmann (2002) diz que a permeabilidade da madeira para líquidos e gases, desempenha um importante papel em um número de processos técnicos como o tratamento da madeira com preservativos químicos, no processo de polpação ou na secagem da madeira. Condições e tempo de processamento são direcionados pela permeabilidade, sendo ela um fator crucial para se obter produtos de qualidade. A maior 
permeabilidade da madeira indica a maior facilidade com que ela pode ser tratada ou processada.

De acordo com Sjostrom (1981) conhecer a estrutura porosa (elementos anatômicos e pontuações) da madeira é de grande importância para compreensão do fenômeno que está associado com a impregnação de madeira.

De acordo com Krabbenhoft e Damkilde (2004), o transporte de água na madeira é um problema importante, pois suas propriedades mecânicas dependem do teor de umidade da peça e o teor de umidade na madeira está relacionado com o ambiente circunvizinho. Um outro processo em que o deslocamento de fluidos é importante é o tratamento da madeira com preservativos artificiais.

\section{1 - OBJETIVOS}

O presente trabalho tem como objetivo o estudo teórico e experimental da permeabilidade em madeiras de florestamento.

\subsection{1 - Objetivos específicos}

- Indicar a diferença de tratabilidade entre Eucalyptus grandis, Eucalyptus citriodora e Pinus elliotti;

- Determinar a diferença de tratabilidade entre alburno e cerne no Eucalyptus grandis e Eucalyptus citriodora;

- Investigar a diferença de permeabilidade em duas das direções ortogonais: direção longitudinal e transversal;

- Apresentar um aparelho de fácil construção para determinação da permeabilidade a líquido e a gás;

- Verificar se existe equivalência estatística entre os grupos ensaiados;

- Determinar um modelo matemático para a permeabilidade de Pinus e Eucalyptus. 


\section{2 - REVISÃO BIBLIOGRAFICA}

\section{1 - Elementos constituintes da madeira}

De acordo com Lepage (1986), as células de madeira são constituídas principalmente de celulose, polioses e lignina. De forma simplificada pode-se dizer que a celulose forma um esqueleto imerso numa matriz constituída de hemicelulose e lignina, sendo a lignina um material aglutinante.

De acordo com Calil et al (2003), a celulose é um polissacarídeo linear, de alto peso molecular, não-solúvel em água, sendo o composto químico mais abundante no planeta. Trata-se do componente fundamental da estrutura celular da madeira. Apresenta cadeia longa e sem ramificações, caracterizando-se por regiões cristalinas em grande parte de seu comprimento, entrecortadas por zonas amorfas. Siau (1971) fala que aproximadamente um terço do volume de celulose amorfa é capaz de adsorver moléculas de água resultando em inchamento lateral.

O menor elemento constituinte do esqueleto celulósico é considerado, por muitos autores, como sendo uma fibrila elementar. Esta fibrila é formada por um feixe paralelo de 36 moléculas de celulose ligadas entre si por meio de pontes de hidrogênio. A união das fibrilas elementares origina as microfibrilas e estas formam as macrofibrilas que, por fim, dá origem à fibra de celulose, Figura 2.1.

De acordo com Hellmeister (1973) a justaposição das cadeias de celulose não é contínua. A análise, utilizando raios-X, permite reconhecer e medir regiões que apresentam inúmeras cadeias de celulose alinhadas e interligadas. Essas regiões, denominadas "cristalitos" ou micelas, correspondem às microfibrilas observadas ao microscópio eletrônico.

De acordo com Siau (1971), estudos de raios-X fornecem evidência para a cristalinidade parcial da microfibrila. A fração de cristalinidade determinada na celulose em polpa de madeira foi de $65 \%$ a $70 \%$.

Os cristalitos têm um comprimento de aproximadamente $600 \AA$ (angstron), com dimensões laterais de aproximadamente $100 \AA$ por $40 \AA$. Deste modo cada cristalito contém aproximadamente 100 cadeias de celulose. O comprimento das cadeias de 
celulose nativa é de 10000 unidades glicosídicas e é próximo de 100 vezes a de um cristalito. Uma cadeia de celulose passa através de muitos cristalitos e regiões amorfas. Estes fatos podem ser sumarizados no modelo de franja micelar de uma porção de microfibrilas, figura 2.1 .

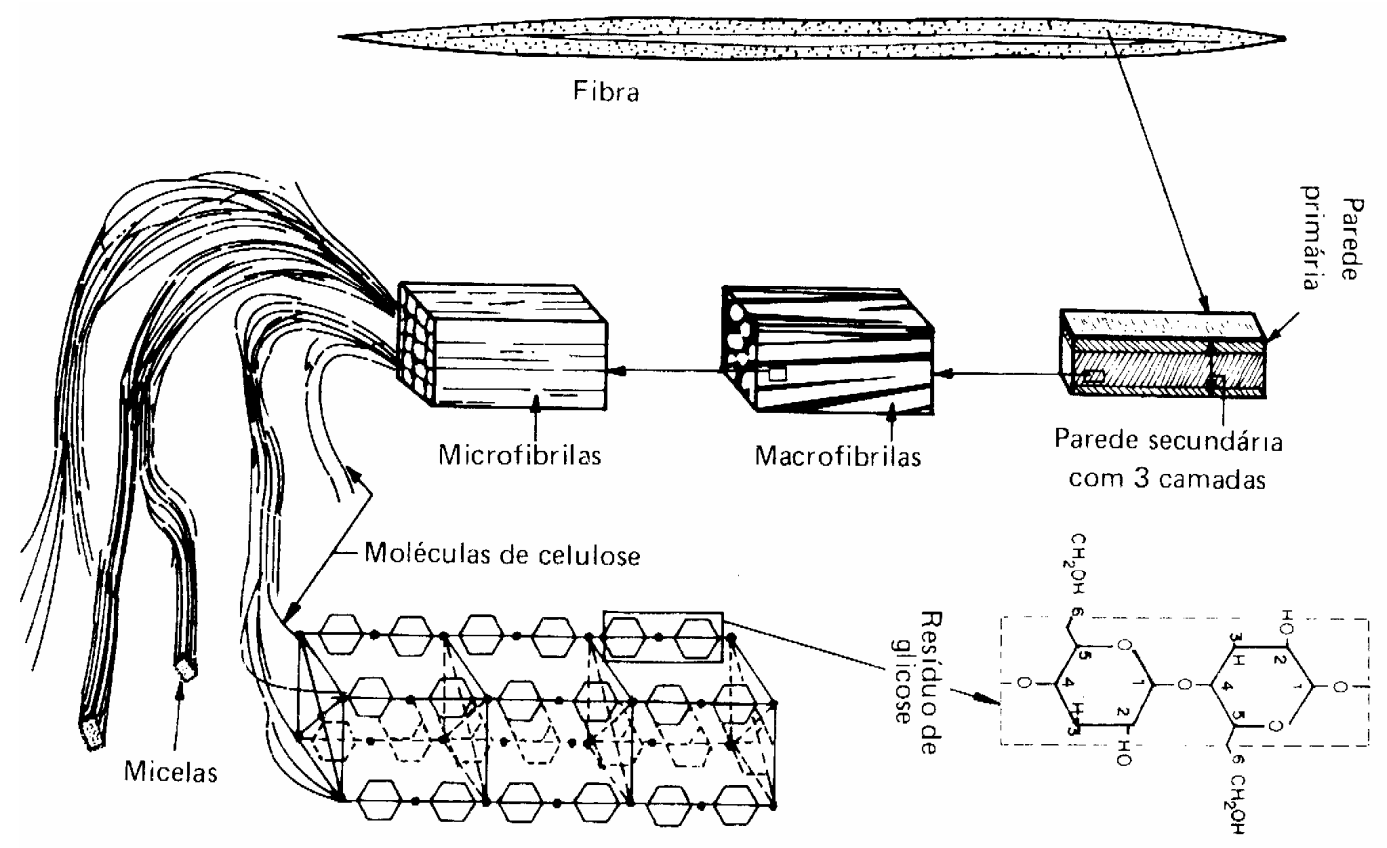

Figura 2.1 - Representação esquemática da estrutura fibrilar da parede celular. Fonte - Lepage (1986)

De acordo com Calil et al (2003), hemiceluloses são polímeros amorfos constituídos de uma cadeia central à qual se somam cadeias laterais. Além de atuar como uma "matriz" na qual estão imersas as cadeias de celulose, as hemiceluloses são componentes bastantes higroscópicos e atraem moléculas de água das paredes celulares. A associação de um grupo de cadeias de celulose "envolvidas" por moléculas de hemicelulose pode ser chamada de microfibrila. A lignina é definida como uma macromolécula de natureza aromática e tridimensional, de elevado peso molecular, amorfo, que trabalha como material incrustante em torno das microfibrilas, conferindo rigidez às paredes celulares dos elementos anatômicos, tornando-as resistentes a solicitações mecânicas. 


\section{2 - Parede celular}

Quando se fala em parede celular, seja de um traqueídeo de uma conífera ou de um vaso ou fibra de uma folhosa, sabe-se, através da microscopia eletrônica, que ela é formada por camadas individuais dispostas segundo um arranjo concêntrico.

De acordo com Lepage (1986), a lamela média é localizada entre traqueídeos (coníferas) ou de fibras libriformes e vasos (dicotiledôneas), servindo de elemento de ligação entre os elementos anatômicos e consiste essencialmente de lignina, apresentando substâncias pécticas, principalmente no estágio inicial de sua formação.

Para Siau (1971), a espessura da lamela média entre traqueídeos para madeira de lenho tardio pode variar de aproximadamente $1 \mu \mathrm{m}$, na parte mais fina, para 3 ou $4 \mu \mathrm{m}$, nos cantos da célula.

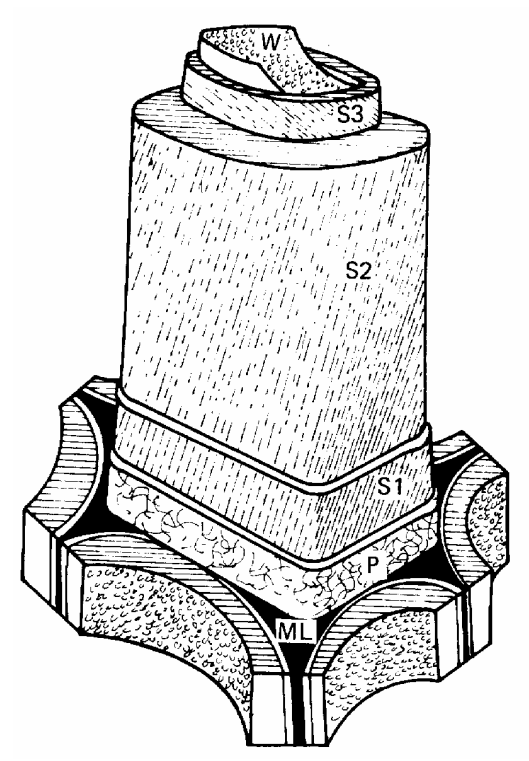

$$
\begin{aligned}
& \text { ML - lamela média; } \\
& \mathrm{P} \text { - parede primária; } \\
& \mathrm{W} \text { - zona verrugosa. } \\
& \text { Parede secundária: } \\
& \text { - } \mathrm{S}_{1} \text { - camada externa; } \\
& \text { - } \mathrm{S}_{2} \text { - camada secundária média; } \\
& \text { - } \mathrm{S}_{3} \text { - camada secundária interna; }
\end{aligned}
$$

Figura 2.2 - Estrutura da parede celular de um traqueídeo (conífera) ou de fibras libriformes e vasos (dicotiledôneas).

Lepage (1986) observa que a camada externa de material celulósico é a parede primária $(\mathrm{P})$, que tem uma espessura de aproximadamente $0,1 \mu \mathrm{m}$ na árvore viva, contendo celulose, hemicelulose, pectina e proteína imersas numa matriz de lignina.

Conforme Siau (1971), a parede primária pode conter de 5 a 10 por cento de celulose com forte orientação microfibrilar. 
A parede secundária consiste de três camadas que, por conveniência, são chamadas de $S_{1}, S_{2}$ e $S_{3}$, sendo $S_{1}$ e $S_{3}$ delgadas, e $S_{2}$ espessa. Na camada $S_{1}$, a mais externa, com aproximadamente 0,1 a $0,3 \mu \mathrm{m}$ de espessura, o arranjo das microfibrilas forma um ângulo entre $50^{\circ}$ e $70^{\circ}$ em relação ao eixo da célula considerada.

A camada intermediária $S_{2}$ forma a porção principal da célula, com espessura variando de 1 a $5 \mu \mathrm{m}$. O ângulo microfibrilar varia entre $10^{\circ}$ e $30^{\circ}$ em relação ao eixo, diminuindo com o aumento do comprimento da fibra.

De acordo com Siau (1971), a camada $\mathrm{S}_{2}$ contém aproximadamente 50 por cento de celulose. A absorção de água nesta camada causará um inchamento transversal (tangencial e radial), desde que a água penetre nas cadeias. O pequeno valor do inchamento longitudinal para madeira é provavelmente ao inchamento nas camadas $\mathrm{S}_{1} \mathrm{e}$ $\mathrm{S}_{3}$. As camadas $\mathrm{S}_{1}$ e $\mathrm{S}_{3}$ contribuem para a estabilidade dimensional da madeira comprimindo a camada $\mathrm{S}_{2}$ e deste modo, prevenindo o estufamento das fibras quando estas estão inchadas com água.

A camada interna $S_{3}$ da parede secundária tem $0,1 \mu \mathrm{m}$ de espessura. $\mathrm{O}$ ângulo das microfibrilas varia muito, conforme a espécie de madeira considerada, oscilando entre $50^{\circ}$ e $90^{\circ}$.

Para Lepage (1986), a zona verrugosa é uma membrana amorfa delgada localizada na superfície interna da camada $\mathrm{S}_{3}$, fazendo fronteira com o lúmen central oco. Essa zona é encontrada em quase todas as coníferas e em algumas folhosas, e possui depósitos verrugosos constituídos de material semelhante à lignina com pequenas quantidades de hidratos de carbono e substâncias pécticas.

A camada verrugosa de algumas espécies é importante por causa da sua influência na difusão através da parede celular.

\section{3 - Microestrutura nas coníferas (gimnospermas)}

As células originadas do câmbio seguem dois esquemas de especialização: um para as coníferas (gimnospermas) e um para as dicotiledôneas (angiospermas).

As coníferas distinguem-se por duas formações básicas: traqueídeos e raios fusiformes. As células iniciais fusiformes são responsáveis pela formação de todo o 
sistema axial do caule (fibras, traqueídeos, parênquima axial, e elementos de vaso) e as células iniciais radiais originam o sistema radial (traqueídeo radial, parênquima radial), Figura 2.3.

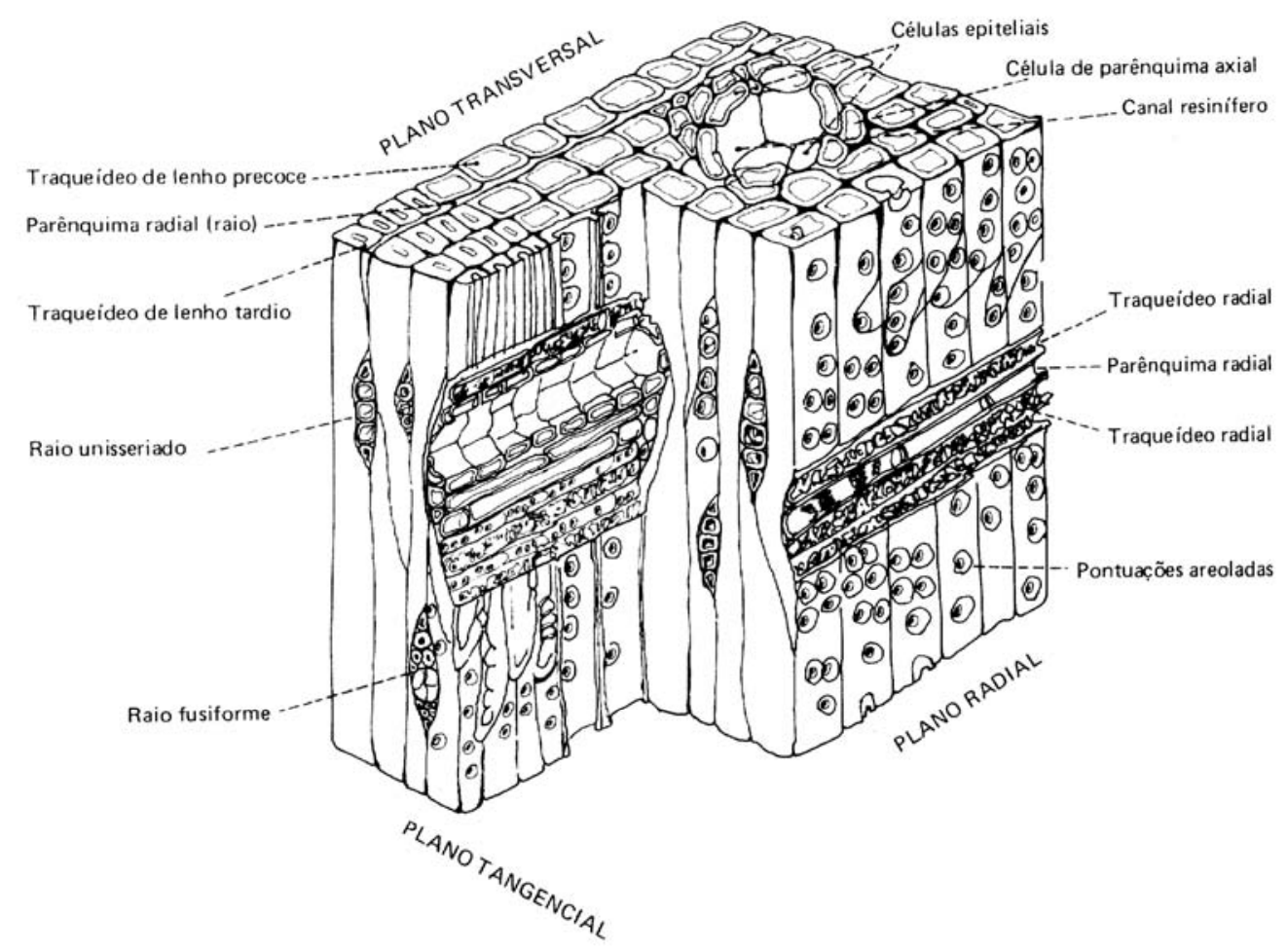

Figura 2.3 - Diagrama do lenho de uma conífera nos três planos de observação. Fonte Lepage - (1986).

De acordo com Hellmeister (1973), os traqueídeos são células alongadas de até 5 mm de comprimento e $60 \mu \mathrm{m}(0,06 \mathrm{~mm})$ de diâmetro, com seção transversal vazada de forma quadrada a sextavada com extremidades biceladas fechadas. Entre traqueídeos adjacentes, na direção vertical, na parede secundária, formam-se válvulas especiais denominadas pontuações aureoladas, que regulam a passagem da seiva bruta de uma célula para a seguinte.

Os traqueídeos radiais se comunicam com os traqueídeos longitudinais através de pontuações simples que são de menor tamanho em relação à pontuação areolada.

Os traqueídeos podem constituir até $95 \%$ da madeira das coníferas e têm a função de conduzir a seiva bruta (no alburno), ser depósito de substâncias polimerizadas (no cerne), de resistir às solicitações mecânicas.

Conforme Siau (1971), o número de pontuações por traqueídeo pode variar de 50 a 
300 pontuações em traqueídeo de lenho precoce, sendo menor em traqueídeo de lenho tardio. Segundo Sjostrom (1981), os traqueídeos de lenho precoce, apresentam aproximadamente 200 pontuações areoladas. O diâmetro radial nos traqueídeos é maior em traqueídeo de lenho precoce e com traqueídeo de lenho tardio tendo paredes celulares mais grossas, Figura 2.4. O diâmetro tangencial pode variar de $15 \mu \mathrm{m}$ para 80 $\mu \mathrm{m}$, de acordo com as espécies e o comprimento pode ir de $1.200 \mu \mathrm{m}$ até $7.500 \mu \mathrm{m}$. Valores médios de diâmetro e de comprimento podem ser considerados como $33 \mu \mathrm{m} \mathrm{e}$ $3.500 \mu \mathrm{m}$ respectivamente, com uma relação comprimento para diâmetro de aproximadamente 100 .

A composição volumétrica das coníferas é a seguinte, Siau (1971):

- traqueídeos longitudinal $\quad 93 \%$

- raios lenhosos $\quad 01 \%$

- canais resiníferos longitudinais $06 \%$

As porcentagens citadas acima destacam a importância que os traqueídeos desempenham no fluxo de fluidos nas coníferas.

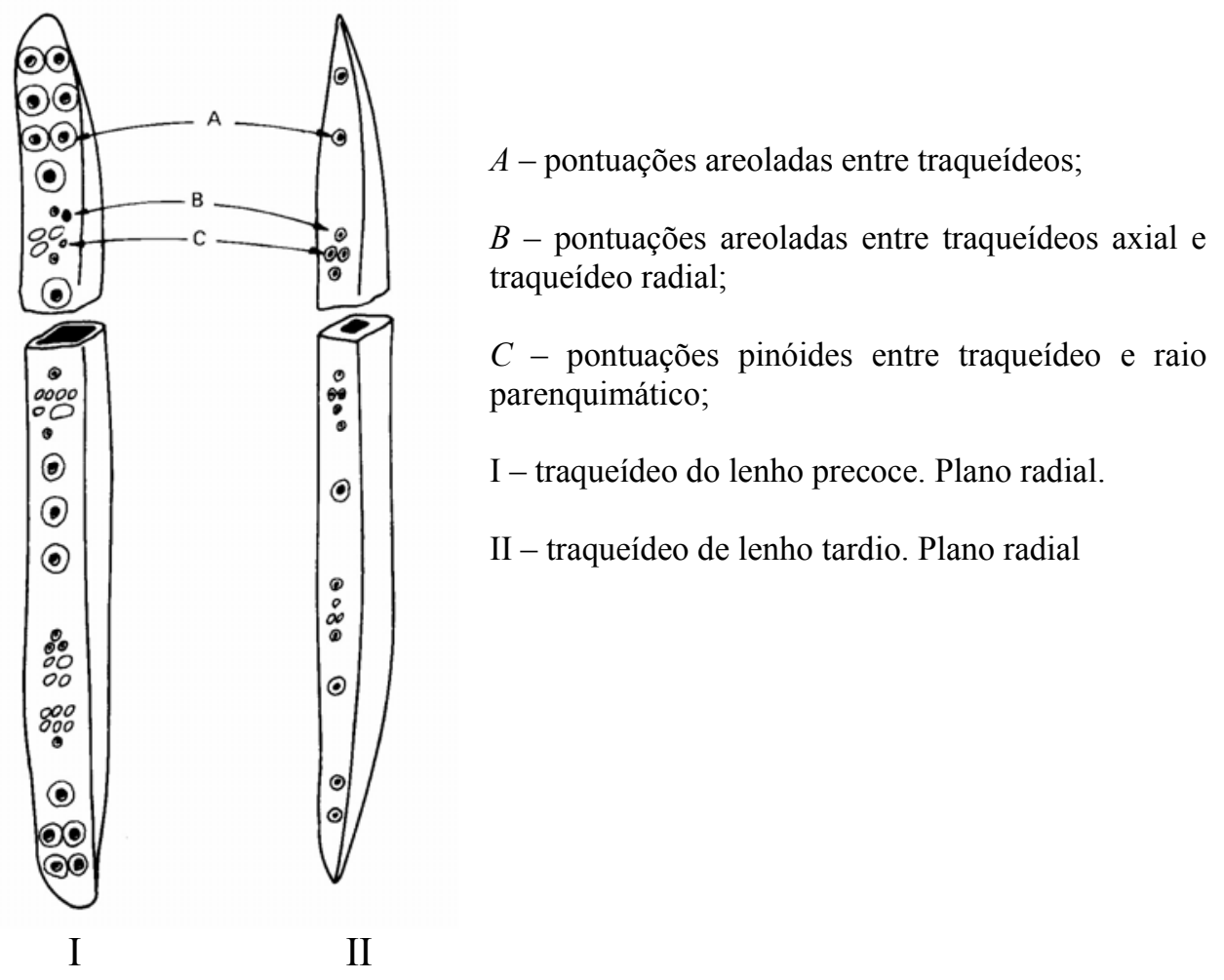

Figura 2.4 - Tipos de traqueídeos do lenho das coníferas. Fonte - Lepage (1986). 
Calil et al (2003) afirmam que os raios fusiformes são células alongadas e achatadas, de diâmetro bem maior que os traqueídeos e posicionam-se horizontalmente da casca à medula. Podem constituir até $10 \%$ da madeira das coníferas e têm a função principal de conduzir a seiva elaborada da casca para a medula, depositando-a nas regiões do cerne.

As coníferas ainda apresentam na sua constituição, parênquima longitudinal, parênquima radial e células epiteliais ao redor dos canais resiníferos que podem ser encontrados no grupo de Southern Pine e em algumas outras espécies, sendo que os canais resiníferos não são considerados como células $\mathrm{e}$, sim, como espaços intercelulares.

\subsection{1 - Pontuações}

De acordo com Sjostrom (1981) a condução de água em uma árvore é possível por causa das pontuações, que são recessos ou aberturas na parede celular secundária entre células adjacentes, Figura 2.5. Duas pontuações complementares normalmente ocorrem em células vizinhas e deste modo, formando um par de pontuações.

O transporte de água no lúmen de células adjacentes ocorre através das membranas da pontuação, que consiste de uma parede primária e lamela média. Pares de pontuações são típicos de traqueídeos nas coníferas e fibras e vasos nas dicotiledôneas. Em coníferas a membrana da pontuação pode ser pressionada contra a pontuação areolada e deste modo prevenindo o transporte de água, desde que o torus seja impermeável.

Pares de pontuações areoladas são geralmente encontrados entre prosenquimatosas ou em células condutoras como traqueídeos longitudinais e traqueídeos radiais. O diâmetro total da câmara da pontuação nas pontuações areolada de uma conífera tem aproximadamente uma extensão de 6 para $30 \mu \mathrm{m}$, sendo que pontuações em madeira de lenho tardio são menores em relação à madeira de lenho precoce

De acordo com Taylor (1978), torus é o engrossamento central das pontuações aureoladas, consistindo de material da parede primária.

O diâmetro do torus é de um terço para metade do diâmetro total da câmara, e que o diâmetro da abertura é aproximadamente metade do diâmetro do torus. 


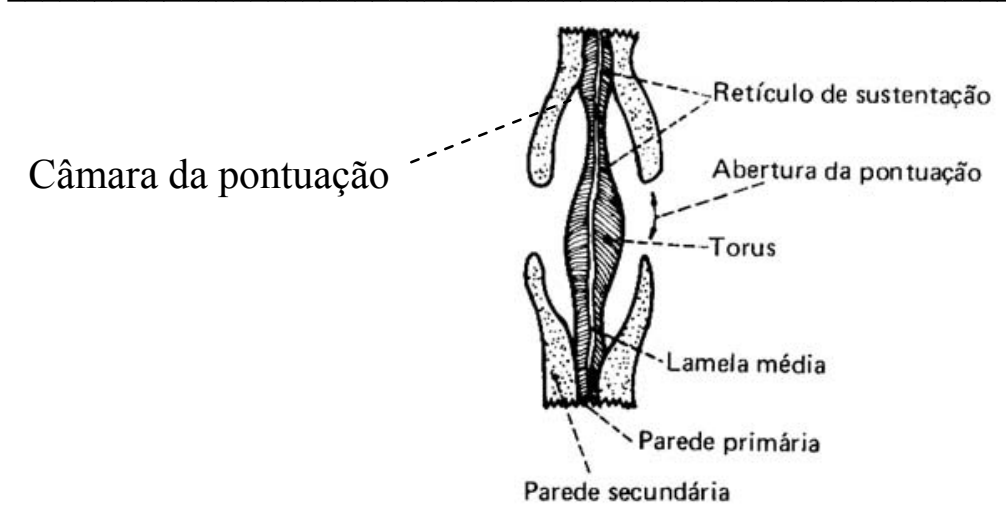

A

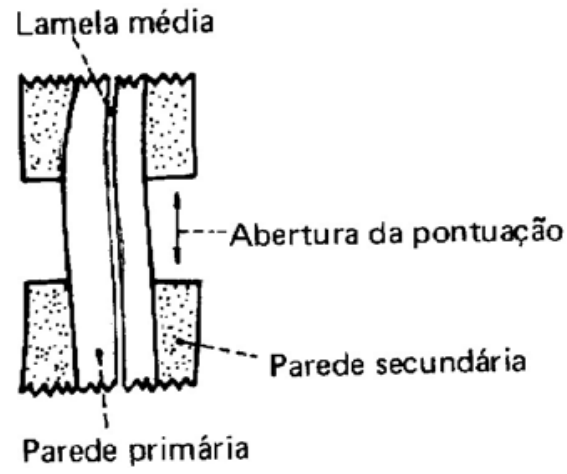

B

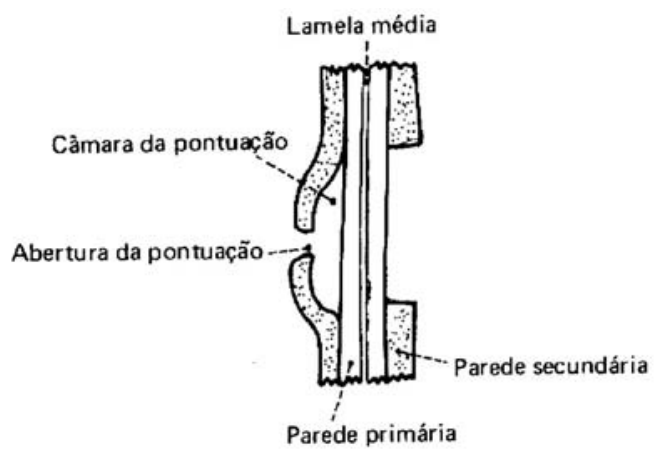

C

Figura 2.5 - Tipos de pares de pontuações. A, par de pontuação areolada, presente somente nas coníferas; B, par de pontuação simples e C, par de pontuação semi-areolada. Fonte - Lepage (1986)

Usualmente ele não aparenta abertura, mas, ocasionalmente, alguns pequenos orifícios são encontrados no torus de algumas espécies. A membrana ao redor do torus é chamada de margo ou membrana de sustentação, e consiste de fios de microfibrilas radiando o torus de forma circular para a borda da pontuação da câmara, como mostrado em Figura 2.6. A abertura entre as microfibrilas permite a passagem dos fluidos e pequenas partículas que atravessam a membrana da pontuação.

A Figura 2.6 refere se a um torus seco com solvente de acetona para prevenir aspiração. É uma réplica da superfície radial. A parede celular foi dividida entre as células, para visualizar o diâmetro da câmara. O interior da câmara atrás da membrana é provavelmente perdido. Os fios microfibrilares do margo são vistos claramente sem 
nenhuma incrustação. Dentro do diâmetro da câmara, $18 \mu \mathrm{m}$; diâmetro do torus, $9 \mu \mathrm{m}$; abertura no margo, até $3 \mu \mathrm{m}$.

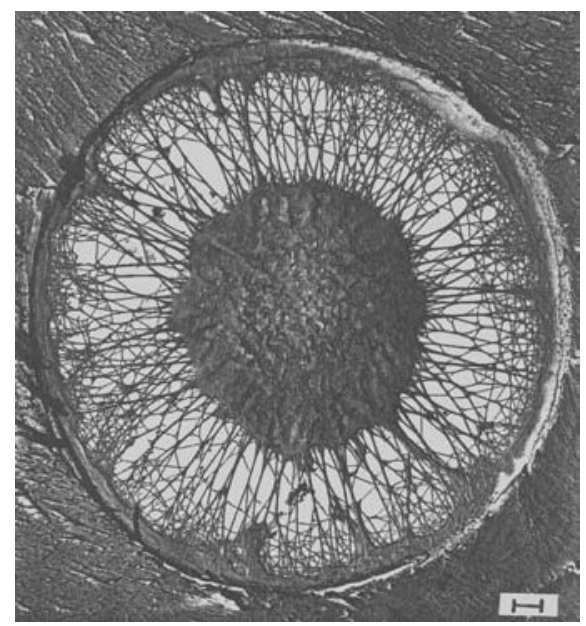

Figura 2.6 - Membrana do par de pontuações areolada de Eastern Hemlock. Fonte - Siau (1971).

Medida do fluxo e outros métodos de medição indicam que a abertura das pontuações tem um raio efetivo entre 0,01 e $4 \mu \mathrm{m}$.

\subsection{2 - Fatores que influenciam a permeabilidade nas coníferas}

Há três mudanças nos pares de pontuações na madeira das coníferas que podem acontecer para favorecer a redução da permeabilidade, particularmente no cerne.

De acordo com Magalhães (2004), a primeira é a aspiração, em que a secagem rápida de madeira de Pinus com emprego de altas temperaturas, em estufa de processamento contínuo. Durante o processo de secagem rápida, é comum ocorrer à aspiração das pontuações, principalmente nas regiões com parede celular de pequena espessura, baixa densidade e resistência mecânica, própria do lenho inicial, Figura 2.7. A aspiração da pontuação ocorre quando ainda existe água livre no lúmen das células. A retirada dessa água causa uma pressão que é proporcional ao inverso do diâmetro capilar. Assim, a membrana da pontuação, composta pelo torus e o margo, sofre uma pressão no sentido de comprimi-la contra a auréola, causando um selamento da pontuação aureolada. Na junção entre a membrana e a auréola, após a aspiração da pontuação, passam a atuar as forças de atração do tipo ligação de hidrogênio. Via de regra, para se desfazer a aspiração, o melhor é uma total rehidratação da madeira. A 
aspiração da pontuação pode causar uma diminuição na permeabilidade da madeira em até dez vezes. Em muitas aplicações industriais em que se necessita de impregnações com monômeros, ceras ou parafinas, a baixa permeabilidade da madeira resulta em tratamentos defeituosos e conseqüentes prejuízos.

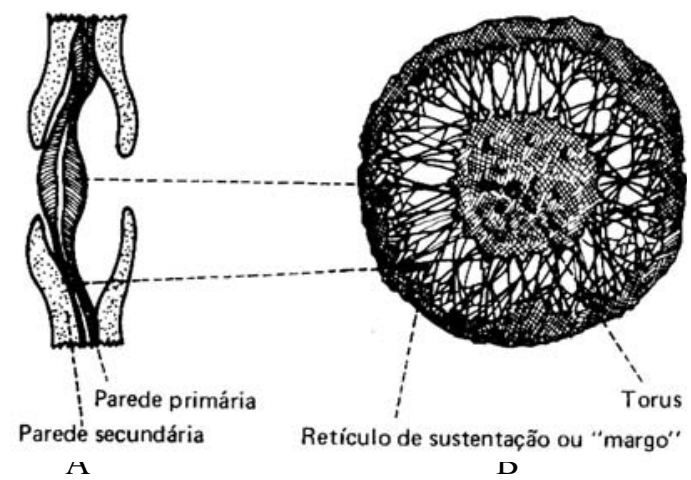

Figura 2.7 - A, Pontuação areolada com torus aspirado (encostado à parede celular, bloqueando a passagem de líquidos; B, vista frontal do torus mostrando o retículo de sustenção ou margo. Fonte Lepage (1986).

Conforme Siau (1971), a aspiração da pontuação é a condição côncava do torus (ou seja, quando o torus está aderente à abertura da pontuação), como mostrado na Figura 2.8, Figura 2.9, Figura 2.10 e Figura 2.11, devendo ser resultado das forças capilares que ocorrem durante a secagem.

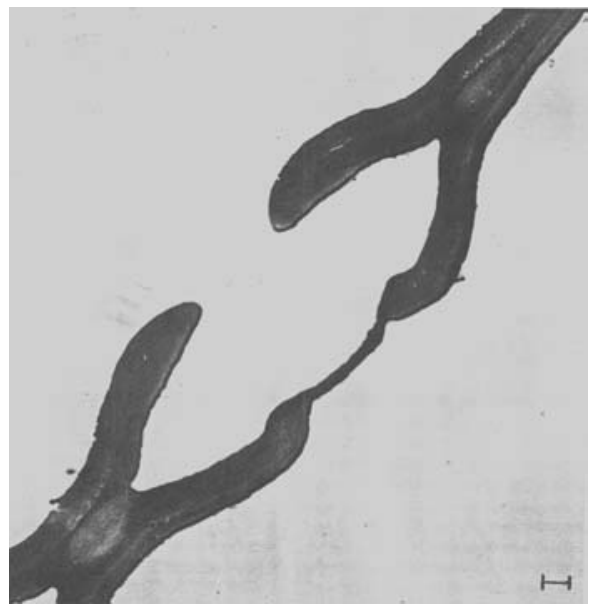

Figura 2.8 - Aspiração em madeira de lenho precoce no limite dos pares de pontuações entre traqueídeos do cerne de Pinus shortleaf. Seção tangencial. Fonte - Siau (1971). 


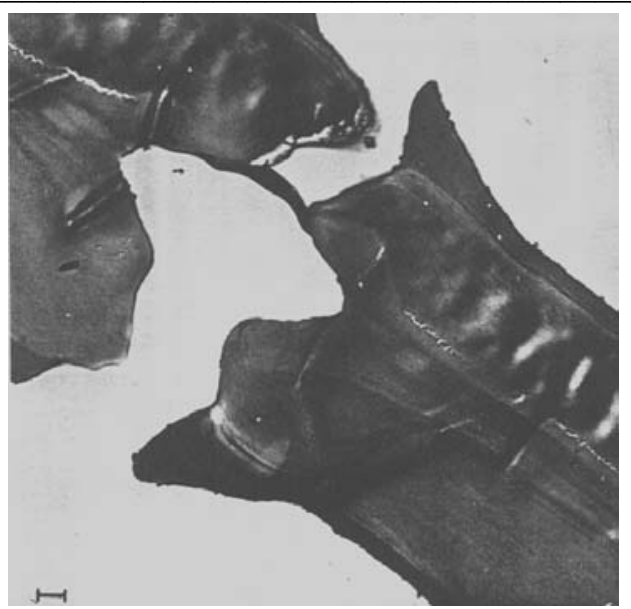

Figura 2.9 - Aspiração em madeira de lenho tardio no limite dos pares de pontuações entre traqueídeos do cerne de Pinus elliottii. Seção tangencial. Fonte - Siau (1971).

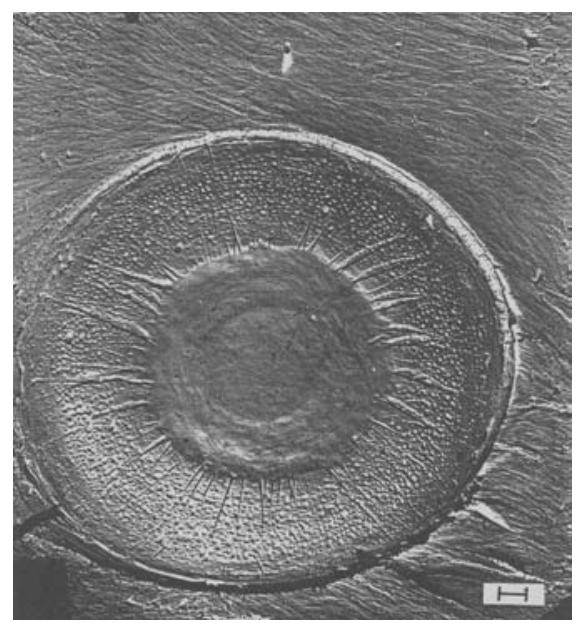

Figura 2.10 - Membrana aspirada no par de pontuação areolada em madeira de lenho precoce, Virginia pine. Fonte - Siau (1971).

A segunda condição é a oclusão das pontuações com extrativos, onde a permeabilidade da madeira pode ser aumentada pela retirada dos extrativos com água quente e álcool.

A terceira é a incrustação com substâncias como lignina que são insolúveis em água quente e álcool. Este material pode ser removido e degradado pelo tratamento com cloreto de sódio diluído com acido acético.

Uma incrustação severa e uma membrana aspiralada no limite dos pares de pontuações é mostrada em Figura 2.11. 


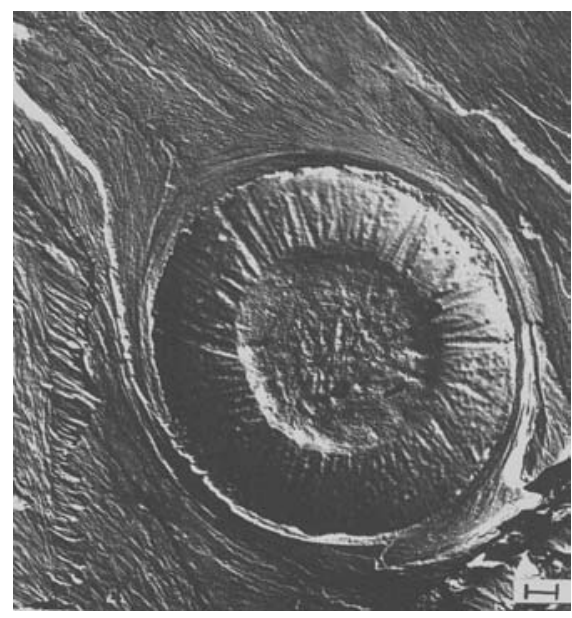

Figura 2.11 - Forte incrustação e membrana aspirada no limite dos pares de pontuações de madeira de lenho precoce nas pontuações do cerne de Pinus rígida. Fonte - Siau (1971).

A estrutura da parede celular ao redor uma abertura na pontuação e na parte interna do lúmen é mostrada em Figura 2.12 . A forte orientação da estrutura microfibrilar do torus é evidenciada, junto com porções das camadas $\mathrm{S}_{1}, \mathrm{~S}_{2}$ e $\mathrm{S}_{3}$ ao redor da abertura.

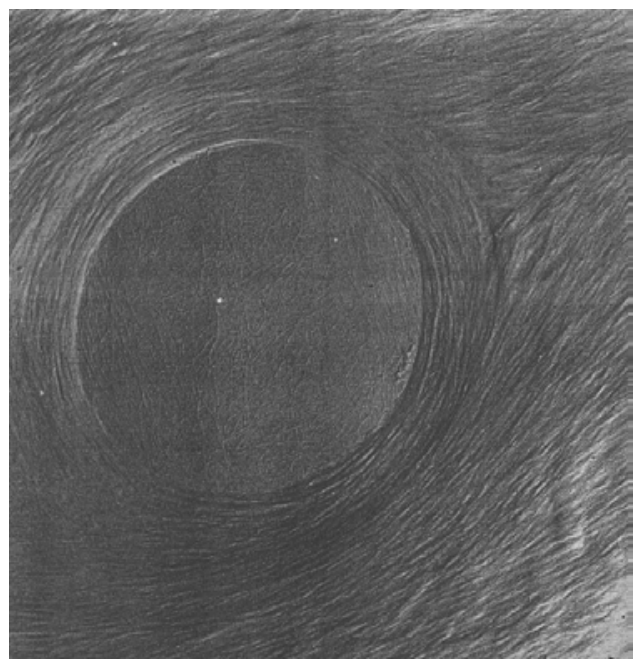

Figura 2.12 - Estrutura da parede primária da superfície de um torus visto pela abertura de dentro do traqueídeo. Fonte - Siau (1971).

De acordo com Magalhães (2004), a permeabilidade depende da posição no tronco da árvore assim como se a madeira é de lenho precoce ou lenho tardio. A permeabilidade longitudinal de madeira de Pinus taeda é menor na parte inferior do que 
na parte superior da árvore. Madeira de lenho tardio também apresenta maior permeabilidade do que madeira juvenil, não sendo apenas uma função da densidade. Submetendo peças de madeira maciça ainda verde de Pinus elliotti, com dimensões nominais de 3,0 x 3,0 x 10,0 cm e isentas de defeito, a tratamento mecânico de compressão uniaxial na direção radial, haverá um aumento na permeabilidade ao ar nas direções longitudinal e tangencial, sendo que na direção tangencial a permeabilidade aumentou em mais de 50\%. Em contrapartida, na direção radial, quanto maior for a severidade da deformação menor será a permeabilidade ao ar da madeira tratada.

Em madeira de Pinus radiata, quanto mais drástica a secagem, maior será a permeabilidade, pois o principal mecanismo de transporte de líquidos são os canais de resina e, assim, a aspiração da pontuação deixa de ser importante. Entretanto, em algumas espécies, como o Pinus caribea hondurensis, uma secagem drástica provoca rachaduras externas e internas, além da aspiração da pontuação.

\subsection{3 - Caminho do fluxo de fluidos nas coníferas.}

Lepage (1986) afirma que cerca de 93\% do volume da madeira das coníferas são constituídos por traqueídeos longitudinais, que se dispõem ao longo da grã da árvore. Estes têm um centro oco e geralmente vazio, por isso os fluidos podem entrar no lúmen diretamente por suas extremidades afiladas, fluir livremente na madeira através dos traqueídeos e passar para o lúmen dos traqueídeos adjacentes pelas pontuações areoladas onde as extremidades dos mesmos se sobrepõe Figura 2.13

De acordo Siau (1971), a abertura das pontuações é muito pequena em comparação com o diâmetro dos traqueídeos e é, entretanto, responsável pela maior parte de resistência do escoamento do fluxo. Deste modo é o número de pares de pontuações que essencialmente determinam à permeabilidade da madeira.

Desde que os raios e canais resiníferos formem uma pequena fração do volume, estes contribuem para o fluxo global, podendo ser de importância secundária. Quando estes caminhos de fluxo são negligenciados, um modelo de fluxo muito simples para coníferas resulta em que o fluido escoa de traqueídeo para traqueídeo nas suas terminações finais através dos pares de pontuações. 
Siau (1971) diz que a permeabilidade longitudinal nas coníferas é muito maior que a permeabilidade tangencial, pois há bem menos pontuações através das paredes para passagem por unidade de comprimento na direção longitudinal que na direção tangencial, Figura 2.13

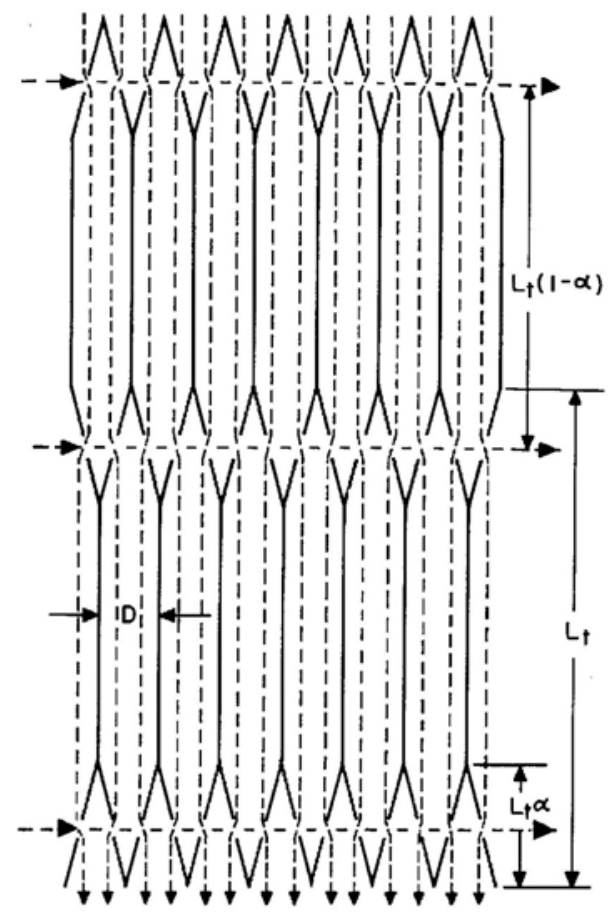

Figura 2.13 - Modelo do fluxo em coníferas. Plano tangencial mostrando pontuações nas superfícies radiais das terminações afiliadas aos traqueídeos. Fonte - Siau (1971

Segundo Ilmari et al (1996), em membranas porosas, a umidade transportada em fase de vapor é a combinação de sua difusão através dos vazios intracelulares e absorção de umidade na parede celular. A estrutura celular das coníferas consiste de traqueídeos, paredes celulares e pontuações. Nas coníferas, a direção da difusão entre células adjacentes é através das aberturas das pontuações.

A umidade transportada aumenta na estrutura celular da madeira, quando o número de pontuações aumenta. Correspondentemente, o conteúdo de umidade é mais baixo quando a espessura das paredes celulares aumenta. Deste modo a direção da difusão através das pontuações é maior em madeira de lenho tardio onde a densidade local é alta. A difusão em madeira de lenho precoce é aproximadamente 10 vezes maior, se 
comparada com a madeira de lenho tardio, mostrando a importância da densidade, observada em uma extensão moderada em reais resultados de teste na madeira.

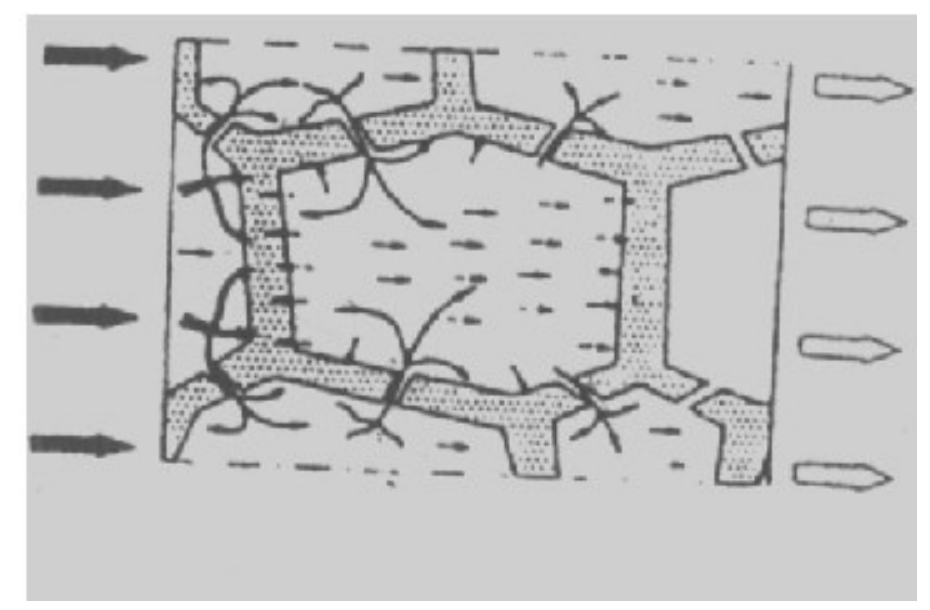

Figura 2.14 - Difusão de umidade nos traqueídeos. Fonte - Ilmara et al (1996).

De acordo com Lepage (1986), para o fluxo na direção radial, os fluidos podem entrar através dos raios na superfície tangencial, fluírem ao longo das células radiais, por difusão, passando de uma a outra através da membrana das pontuações simples nas extremidades das células radiais. Das células radiais, os fluidos podem difundir-se através da membrana das pontuações semi-aureoladas (campo de cruzamento) e caminhar para o lúmen dos traqueídeos longitudinais adjacentes. Para o fluxo na direção tangencial ou acompanhando os anéis de crescimento, os fluidos podem entrar nas células da madeira pela superfície radial. Em virtude das pontuações que ligam um lúmen ao outro estar concentradas nas paredes radiais dos traqueídeos, os fluidos podem fluir livremente como um líquido, através das membranas das pontuações areoladas dos traqueídeos adjacentes.

Siau (1971) propôs um modelo em que todas as pontuações são localizadas na superfície radial e nas terminações finais dos traqueídeos, como mostrado em Figura 2.13. Todo traqueídeo tem quatro pares de pontuações que são entendidas para serem do mesmo tamanho. É claro que ambos os escoamentos longitudinal e tangencial são controlados no final dos pares de pontuações. É assumido que a relação dos traqueídeos longitudinais serem cem vezes maior que a sua largura. A permeabilidade na direção 
longitudinal é muito maior que na direção tangencial, pois o número de caminhos paralelos são maiores por unidade de área e menos paredes cruzadas para serem atravessadas em série por unidade de comprimento na direção do fluxo.

De acordo com Siau (1971), vários experimentos foram realizados por diversos pesquisadores sobre a permeabilidade das coníferas. Foi demonstrado em alguns experimentos que a maior penetração de fluidos ocorreu em madeira de lenho tardio, devido à maior habilidade que as paredes das pontuações da madeira de lenho tardio apresentam em resistir à aspiração e porque as membranas das pontuações desse lenho são mais espessas e mais rígidas.

\section{4 - Microestrutura nas dicotiledôneas (angiospermas)}

A madeira das dicotiledôneas distingue-se por três formações básicas: vasos, fibras e raios heterocelulares, Figura 2.15.

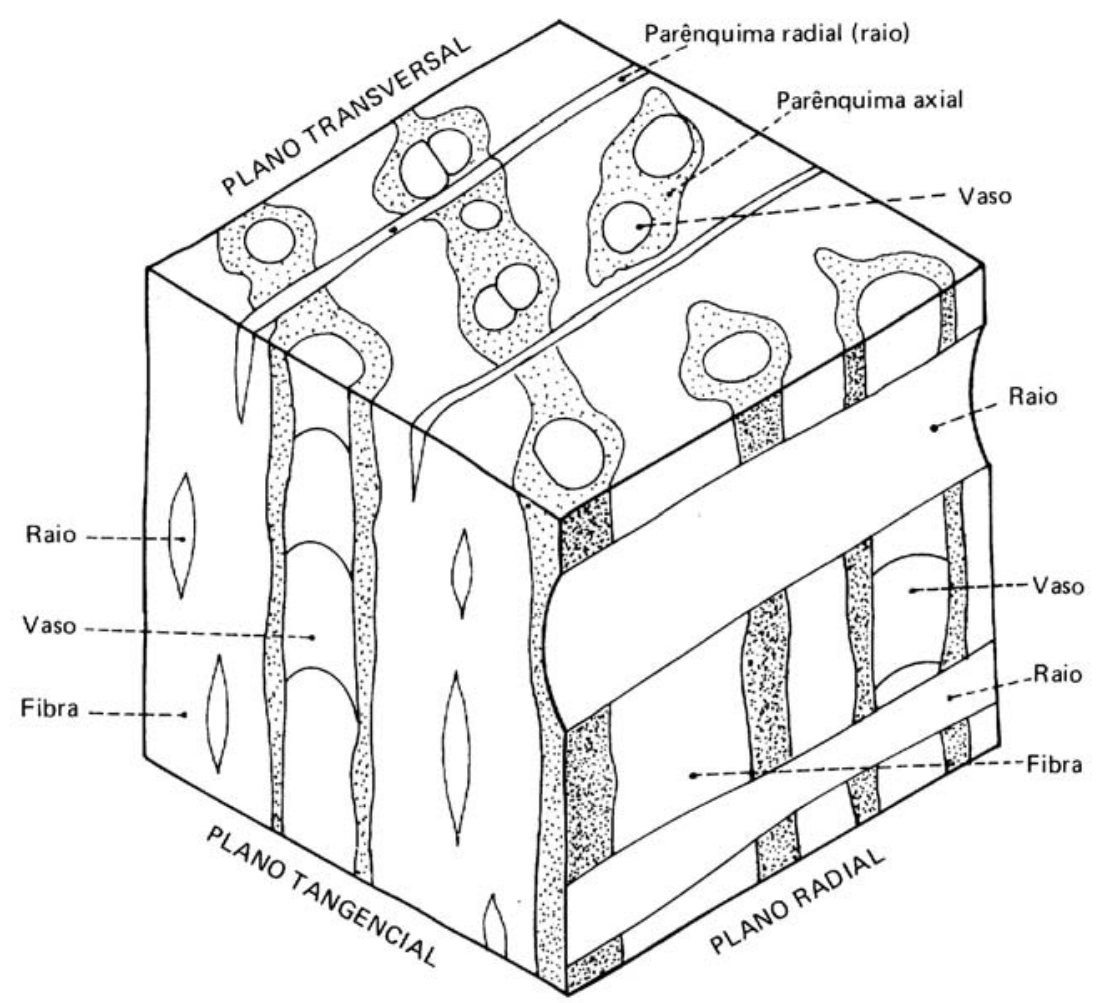

Figura 2.15 - Diagrama do lenho de uma dicotiledônea nos três planos de observação. Fonte - Lepage (1986). 
Conforme Hellmeister (1973), os vasos são constituídos por células alongadas, sobrepostas e ligadas topo a topo, com até $1 \mathrm{~mm}$ de comprimento e $300 \mu \mathrm{m}(0,3 \mathrm{~mm})$ de diâmetro, com seção transversal arredondada e vazada. Os vasos vistos em seção transversal são chamados de poros.

Os vasos podem constituir até $50 \%$ da madeira das dicotiledôneas, têm a função de transporte da seiva bruta (no alburno) e são depósitos de substâncias polimerizadas (no cerne).

Em quase todas as nossas espécies de madeira de dicotiledôneas, os vasos podem ser observados à vista desarmada, em seção transversal, como minúsculos furos, e, em seção longitudinal, como pequenas ranhuras alongadas.

Segundo Lepage (1986), os elementos de vaso apresentam uma área de comunicação entre si, que é chamada de placa de perfuração, Figura 2.16. Esta pode ser simples, quando possui uma só perfuração, e multiperfurada, com mais de uma perfuração. As placas multiperfuradas podem ser escalariformes, se as perfurações forem alongadas e paralelas. Os remanescentes da placa, entre abertura é chamada reticulada, com aspecto de um retículo.

Os elementos de vasos também apresentam comunicações com outros elementos que os circundam, através de pontoações. Entre dois elementos vasculares justapostos, as pontoações são sempre areoladas.

Quando os elementos de vasos vasculares estiverem em contato com células parenquimáticas, as pontuações serão do tipo semi-areoladas.

As pontoações areoladas que ocorrem nas paredes dos elementos vasculares podem aparecer isoladas ou contíguas e podem apresentar forma arredondada e elíptica, em fenda e escalariforme. Quanto à disposição, podem ser alternadas, opostas ou do tipo misto.

Nas dicotiledôneas, o parênquima axial é dividido em dois tipos, de acordo com a sua relação espacial com os poros:

- apotraqueal, quando não definitivamente associado com os poros;

- paratraqueal, quando está consistentemente associado com os poros. 


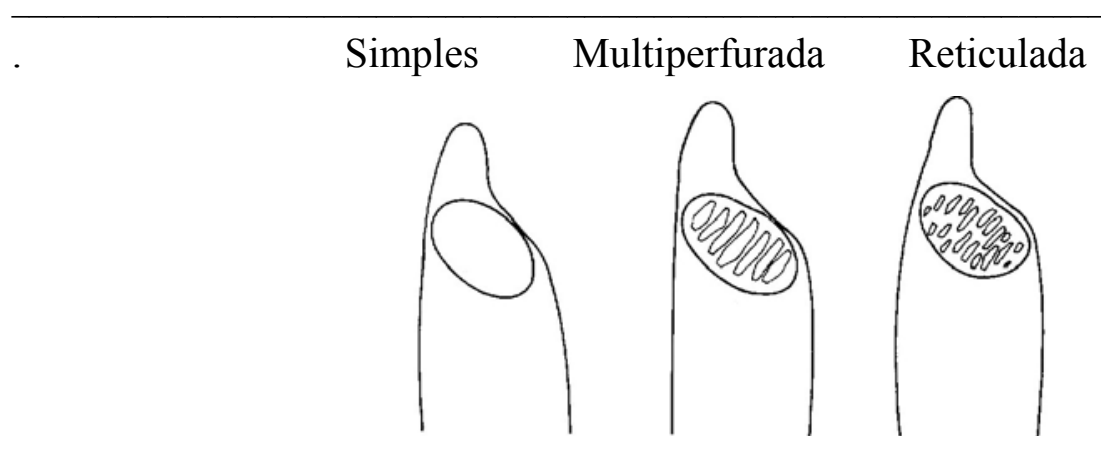

Plano radial
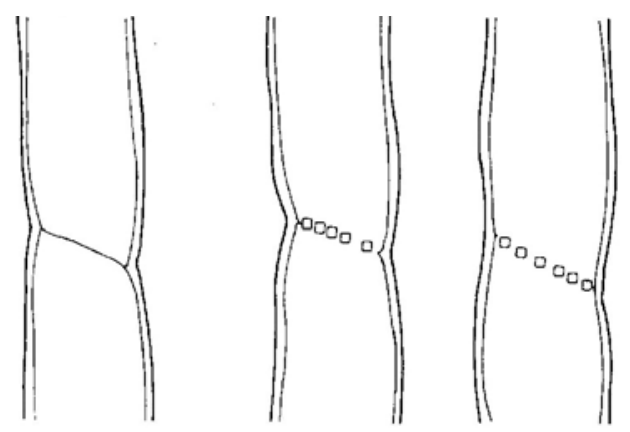

Plano tangencial

Figura 2.16 - Tipos de placa de perfuração. Fonte: Lepage (1986).

O parênquima radial nas dicotiledôneas apresenta grande variação de largura, podendo ser uni, bi, tri, tetrasseriados, etc.

De acordo com Lepage (1986), nas madeiras de dicotiledôneas, os vasos podem ser distribuídos em três tipos de porosidade:

- em anéis porosos formando concentração de poros no lenho precoce, com diâmetro maior do que no tardio. No Brasil são raros os casos de madeiras que apresentam tendência de formação de anéis porosos, enquanto, em países de clima frio, esta distribuição de vasos é típica.

- difusa, quando os vasos estão distribuídos regularmente através das camadas de crescimento. A maioria das madeiras brasileiras apresenta porosidade difusa.

- semi-difusa, quando os vasos se distribuem de um modo intermediário entre a porosidade em anéis porosos e a difusa.

Os poros podem ou não conter obstruções como depósitos de óleo-resina, calcário, tilas etc. 
As tilas são membranas semelhantes a bolas que entram nos vasos a partir das células do parênquima adjacente, através dos pares de pontoações. As tilas são encontradas no cerne de certas espécies de madeira e chegam a obstruir total ou parcialmente o lúmen dos vasos. Sendo assim, as tilas, gomas e outros depósitos podem impedir ou diminuir grandemente a permeabilidade do cerne de muitas madeiras de dicotiledôneas, Figura 2.17.

Tilas de paredes finas Tilas esclerosadas

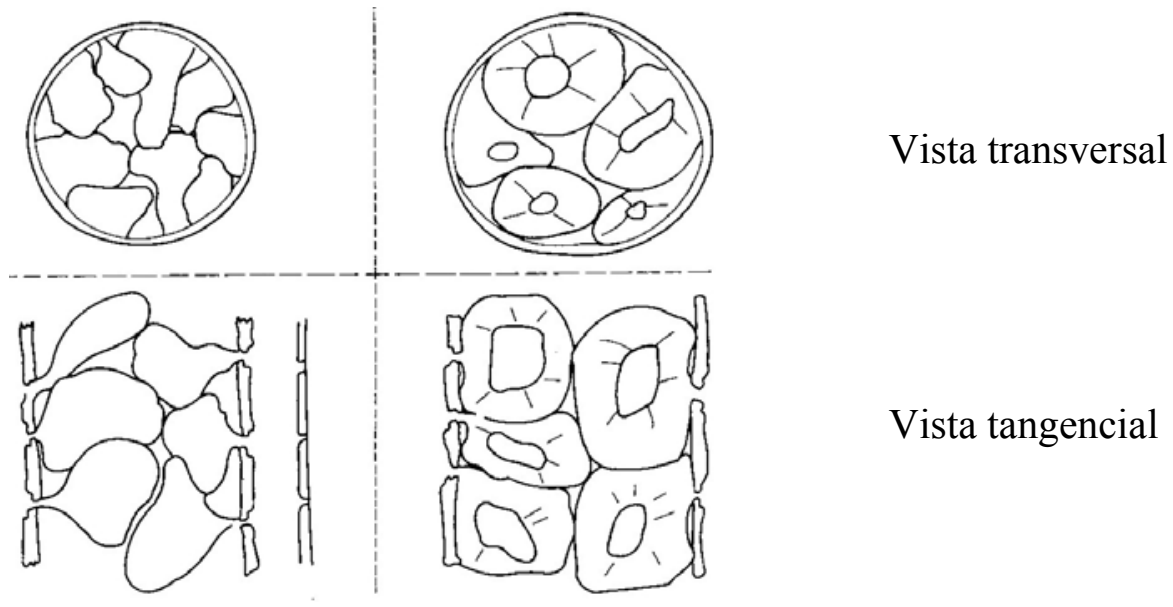

Figura 2.17 - Vasos com tilas. Fonte: Lepage (1986).

Conforme Calil et al (2003), fibras são células longas com até 1,5 mm de comprimento, seção transversal vazada e arredondada, paredes com espessura sistematicamente superior à dos vasos. As fibras são elementos fechados, não possuindo comunicação através das extremidades. Podem constituir, dependendo da espécie, até $50 \%$ da madeira das dicotiledôneas, sendo as principais responsáveis por sua resistência mecânica e por sua rigidez.

Os principais tipos de fibras encontrados na madeira das dicotiledôneas são as seguintes:

- fibra-libriforme: é uma célula alongada, com extremidades afiladas, com paredes de espessura variável e com pontuações simples. É o tipo mais abundante nas dicotiledôneas. 
- fibrotraqueídeo: é um traqueídeo semelhante à fibra libriforme, com extremidades aguçadas, paredes geralmente espessas com pontuações areoladas e abertura em fenda;

- fibra gelatinosa: é uma fibra com a porção interna da parede lignificada e de aparência gelatinosa;

- fibra septada: é uma fibra cujo lúmen está subdividido por paredes delgadas e transversais.

Para Lepage (1986), as fibras variam em comprimento, largura e espessura da parede, não só entre as espécies de madeira, como também numa mesma árvore, ao longo do caule e da medula para a casca.

Os raios medulares são idênticos aos que aparecem nas coníferas.

Lúmen celular, ou simplesmente lúmen, é a denominação dada ao espaço interno dos elementos anatômicos.

\subsection{1 - Caminho dos fluidos nas dicotiledôneas (angiospermas)}

De acordo com Lepage (1986), os vasos podem contribuir com 5 a $60 \%$ do volume de madeira e comumente constituem o caminho longitudinal do fluxo de menor resistência. Como os vasos são elementos com extremidades abertas, a penetração de fluidos ao longo da grã de algumas madeiras das dicotiledôneas é muito mais rápida e mais extensa do que para dentro (através dos raios) nas fibras que circundam os vasos. A resistência ao fluxo em qualquer tipo de placa de perfuração dos vasos é pequena, porque as aberturas são grandes e as placas são relativamente finas. Assim, os vasos se comportam como um tubo capilar aberto e comprido. Sjostrom (1981) diz que o transporte de água nos vasos das dicotiledôneas, é mais efetivo que nos traqueídeos das coníferas.

Lepage (1986) diz ainda que as passagens de fluido entre vasos, traqueídeos e fibrotraqueídeos são realizadas através das pontuações areoladas e entre células parenquimáticas e fibras libriformes, através de pontuações simples; entre vasos traqueídeos e fibrotraqueídeos e as demais células é feita através de pontuações semiareoladas. Não existe torus nas pontuações das dicotiledôneas e as membranas são 
contínuas através da câmara da pontuação inteira e não causam aspiração devido à ausência do torus.

Para Lepage (1986), as fibras podem constituir cerca de 50\% do volume de madeira em algumas espécies de dicotiledôneas, principalmente de libriformes e/ou fibrotraqueídeos. Os fluidos são capazes de atingir as fibras a partir dos vasos e células do parênquima e através dos pares de pontuações em suas paredes adjacentes. Os traqueídeos das dicotiledôneas são geralmente de paredes finas e são facilmente penetráveis através de suas pontuações areoladas, porém representam uma baixa fração volumétrica e, portanto, são de pouca importância como caminhos de fluidos.

De acordo com Lepage (1986), o parênquima longitudinal pode variar de 1 a $18 \%$ nas madeiras americanas e até cerca de 50\%em algumas madeiras tropicais. Pode ser mais permeável do que a fibra. As células do parênquima radial variam de 5 a 30\% nas madeiras americanas e têm uma contribuição menor no fluxo total do que nas coníferas, apesar de a fração volumétrica média ser maior nas dicotiledôneas. A proporção de fluxo de fluido através do alburno é maior do que através do cerne e a proporção através de madeiras com anéis porosos é maior do que nas madeiras com poros difusos. A presença de tilas nos vasos reduz significativamente a permeabilidade nas madeiras das dicotiledôneas, principalmente no cerne. Portanto, o fluxo de fluidos nas dicotiledôneas é muito mais complexo e variável do que nas coníferas.

Um modelo generalizado para o fluxo das dicotiledôneas é representado abaixo. 


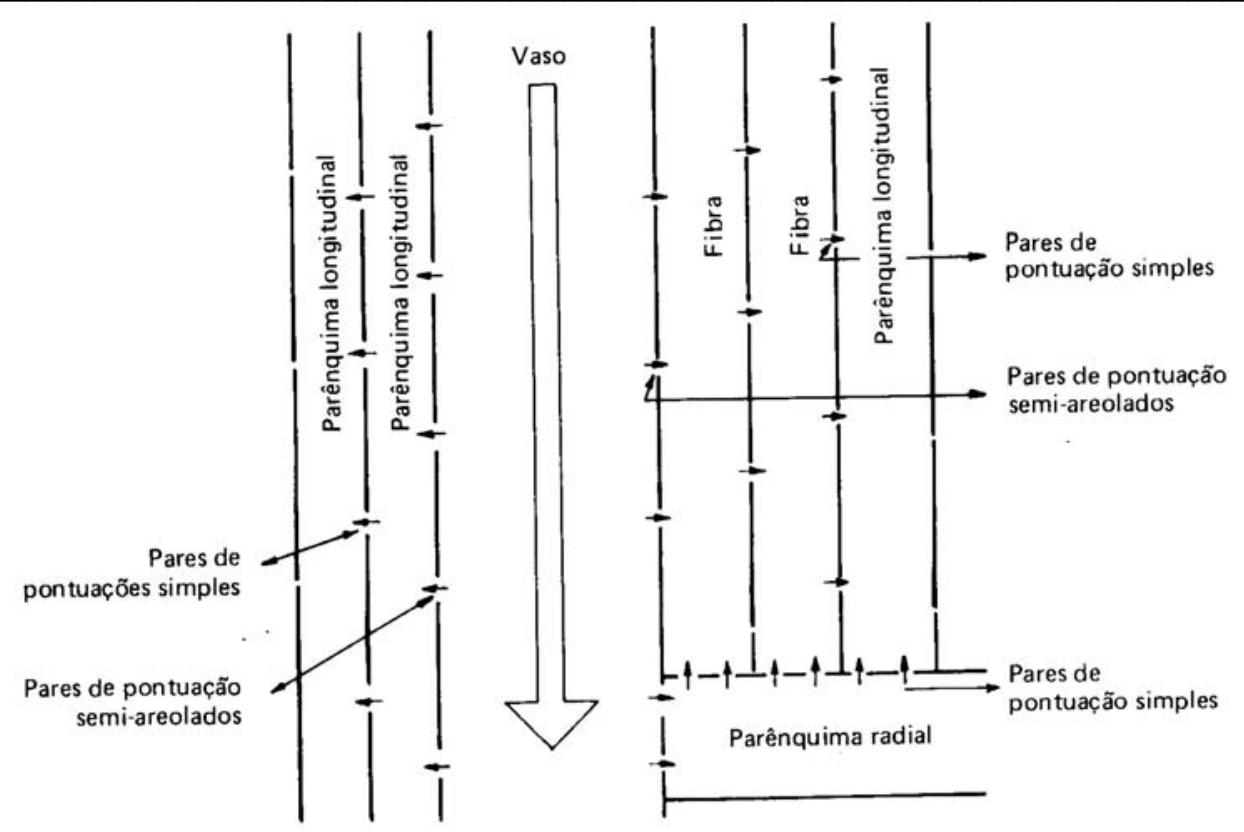

Figura 2.18 - Modelo generalizado do fluxo para dicotiledôneas. A importância relativa do fluxo é indicada pelo tamanho da flecha

Siau (1971) nota que a passagem de preservativos oleosos, em carvalho vermelho, não encontrou diferença na penetração de fibras de lenho tardio e de lenho precoce como foram encontradas nas madeiras de coníferas.

\section{5 - Umidade}

De acordo com Lepage (1986), acima do ponto de saturação das fibras, um aumento do teor de umidade diminui a fração de vazios na madeira. Abaixo do ponto de saturação das fibras, aumentos de umidade geralmente diminuem a permeabilidade da madeira a gases. A explicação pode ser dada pela redução do tamanho dos poros causada pelo inchamento da membrana das pontuações. Essa redução atinge o máximo no ponto de saturação das fibras, provavelmente, pela condensação de umidade nos pequenos capilares das membranas das pontuações, bloqueando a passagem de gases pela madeira.

A NBR 7190/1997 adota, como valor de referência, a umidade de 25\% para o ponto de saturação das fibras, enquanto Calil et al 2003 adotam como ponto de saturação das fibras, um valor de umidade entre $20 \%$ e $30 \%$. 


\section{6 - Porosidade}

Segundo Siau (1971), porosidade é a fração de volume vazio na madeira. Este termo é as vezes confundido com permeabilidade que se refere à facilidade como que o fluxo flui através da madeira.

A porosidade pode ser calculada segundo a expressão:

$\mathrm{V}_{\mathrm{a}}=1-\mathrm{G}\left(0,685+0,01 \mathrm{M} / \mathrm{G}_{\mathrm{S}}\right)$

onde:

$\mathrm{V}_{\mathrm{a}}=$ fração de vazios (porosidade);

$\mathrm{G}=$ densidade básica da madeira $\left(\mathrm{g} / \mathrm{cm}^{3}\right)$;

$\mathrm{M}=$ teor de umidade da madeira ( $\mathrm{M}$ está abaixo do ponto de saturação das fibras);

$\mathrm{G}_{\mathrm{S}}=$ densidade aparente da madeira $(\mathrm{a} \mathrm{M} \%),\left(\mathrm{g} / \mathrm{cm}^{3}\right)$;

$0,685=$ volume específico do material lenhoso $\left(\mathrm{cm}^{3} / \mathrm{g}\right)$.

Quando o conteúdo de umidade (M) estiver acima do ponto de saturação das fibras, o termo $0,01 \mathrm{M} / \mathrm{G}_{\mathrm{S}}$ pode ser substituído por $0,01(30) / 1,115$ ou 0,270 . Então:

$$
\mathrm{V}_{\mathrm{a}}=1-\mathrm{G}[0.955+0,01(\mathrm{M}-30)] .
$$

Segundo Lepage (1986), o termo 0,685 G corresponde à fração de volume do material lenhoso, enquanto $\mathrm{MG} / \mathrm{G}_{\mathrm{S}}$ equivale à fração de volume de água de ligação. Essa fração de volume é equivalente à quantidade máxima de preservativo absorvido pela madeira. Geralmente, não é fator limitante no tratamento comercial de madeira, a menos que o teor de umidade seja elevado.

\subsection{1 - Tamanho dos poros}

Para Lepage (1986), a importância desse fator é dada pela equação de Poiseuille, que estabelece que:

$Q=\frac{\pi \cdot R^{4} \cdot \Delta P}{8 \cdot n \cdot L}$ 
onde:

$\mathrm{Q}=$ vazão, $\mathrm{cm}^{3} / \mathrm{seg}$;

$\mathrm{R}=$ raio do poro, $\mathrm{cm}$;

$\Delta \mathrm{P}=$ diferencial de pressão, dina $/ \mathrm{cm}^{2}$;

$\mathrm{n}=$ viscosidade do líquido, $($ dina $\mathrm{seg}) / \mathrm{cm}^{2}$;

$\mathrm{L}=$ comprimento da madeira na direção do fluxo, $\mathrm{cm}$.

\section{7 - Permeabilidade}

De acordo com Lepage (1986), a permeabilidade da madeira correlaciona-se bem com sua respectiva tratabilidade.

Siau (1971) observa que a condição fixa para o escoamento de fluidos através da madeira tem obedecido à lei de Darcy. Condição fixa de escoamento existe quando fluxo e gradiente são constantes em espaço e tempo. Fluxo é a taxa de escoamento por unidade

de área da seção transversal, expresso em $\left[\mathrm{cm}^{3}\right.$ (fluido) $/ \mathrm{cm}^{2}$ (área)seg]. Gradiente é a diferença de pressão causando o escoamento por unidade de comprimento da espécie na direção do escoamento, expresso em $(\mathrm{atm} / \mathrm{cm})$ ou $\left(\operatorname{dina} /\left(\mathrm{cm}^{2} \mathrm{~cm}\right)\right]$. Assim a condição para a lei de Darcy é que a permeabilidade é igual ao fluxo dividido pelo gradiente. Deste modo a permeabilidade é a medida da facilidade com que um fluido escoa através de um material poroso debaixo da influência de um gradiente de pressão. A lei de Darcy pode ser escrita para fluido incompressível:

$$
k=\frac{\text { fluxo }}{\text { gradiente }}=\frac{V / t A}{\Delta P / L}=\frac{V L}{t A \Delta P}
$$

onde:

$\mathrm{k}=$ permeabilidade, $\mathrm{cm}^{3}$ (líquido) $\mathrm{cm} /$ dina seg;

$\mathrm{V}=$ volume do líquido fluindo através da espécie, $\mathrm{cm}^{3}$;

$\mathrm{L}=$ comprimento da espécie na direção do fluxo, cm;

$\mathrm{t}$ = tempo do fluxo, seg;

$\mathrm{A}$ = área da seção transversal da espécie perpendicular para direção do fluxo, $\mathrm{cm}^{2}$;

$\Delta \mathrm{P}=$ diferença de pressão entre a entrada e a saída final da espécie, dina $/ \mathrm{cm}^{2}$. 


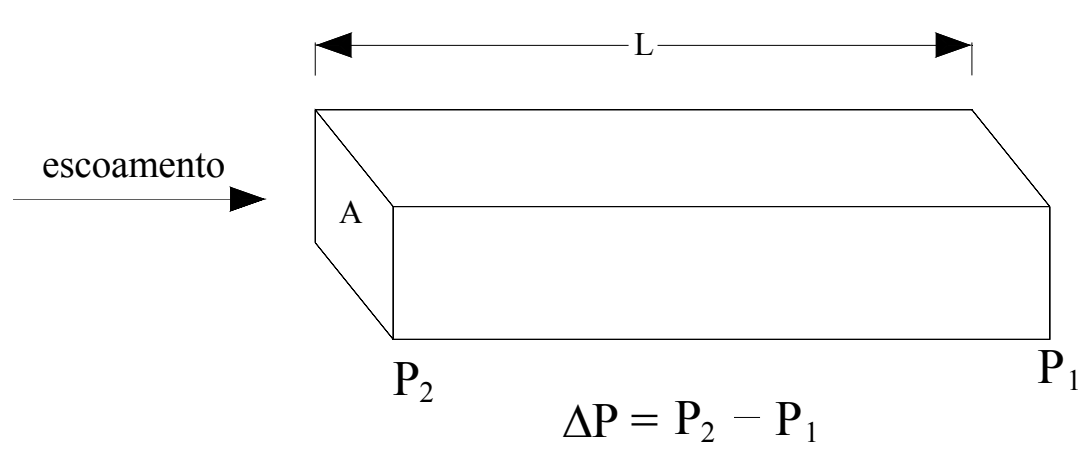

Figura 2.19 - Corpo-de-prova permeável ilustrando a significância dos termos na lei de Darcy.

Segundo Jankowsky (1986), a lei de Darcy é válida após o líquido ter penetrado na madeira e com diferencial de pressão constante (fluxo em estado estável).

Lepage (1986) diz que, para eliminar a influência do fluido, é muito usada a permeabilidade específica.

A permeabilidade específica é o produto da permeabilidade pela viscosidade. Assim, estes valores são independentes da medida do fluido e é somente uma função do tamanho e número de aberturas na estrutura de madeira segundo Siau (1971).

$\mathrm{K}=\mathrm{k} \cdot \mathrm{n}$

onde:

$K=$ permeabilidade especifica, $\mathrm{cm}^{2}$;

$k=$ permeabilidade, $\mathrm{cm}^{3}$ (fluido) $\mathrm{cm} /$ (dina seg);

$n=$ viscosidade do fluido, dina $\mathrm{seg} / \mathrm{cm}^{2}$.

De acordo com Lepage (1986), a permeabilidade longitudinal pode ser mais de 1000 vezes maior do que essa mesma grandeza medida nas direções radial ou tangencial. Entretanto, nas aplicações práticas, a relação estabelecida entre penetrações é de aproximadamente 100 vezes. A explicação para tal discrepância reside no fato de que a lei de Darcy é valida para condições ideais, diferentes daquelas observáveis numa operação de impregnação de madeiras. Nessas condições para pressões efetivas da ordem de $100 \mathrm{Kpa}$ e viscosidade de 0,05 a 1 poise, estabeleceu-se o seguinte modelo:

$$
F_{V L}=0,470 \log \left[k_{g}\left(\frac{P}{n}\right) 0,42\right]-0,89
$$


Por esse modelo, verifica-se que a relação de penetração é proporcional a raiz quadrada da relação de permeabilidade. Então, a relação de penetração de 100:1 corresponderia a uma relação de permeabilidade de $10^{4}: 1$, que está de acordo com as relações observadas.

Quando a lei de Darcy é aplicada para escoamento gasoso, (fluido compressível), a expansão do gás e as mudanças resultantes no gradiente ao longo da espécie devem ser consideradas. A lei de Darcy para escoamento gasoso pode ser escrita:

$$
K_{g}=\frac{V L P}{t A \Delta P \bar{P}}
$$

onde:

$K_{g}=$ permeabilidade a gás, $\mathrm{cm}^{3}$ (gás) $/(\mathrm{cm}$ atm seg);

$V=$ volume do fluxo de gás através da espécie, $\mathrm{cm}^{3}$ (gás);

$P=$ pressão em que o volume é medido, atm;

$L=$ comprimento da espécie na direção do fluxo, cm;

$\Delta P=$ diferença de pressão, atm;

$t=$ tempo, seg;

$A=$ área da seção transversal, $\mathrm{cm}^{2}$;

$\bar{P}=$ média da pressão na espécie, atm.

\subsection{1 - Métodos que podem ser utilizados na determinação da permeabilidade}

Siau (1971) descreve três métodos para medir a permeabilidade em madeiras:

- O primeiro consiste no método de deslocamento de subida de água, onde um vácuo parcial é aplicado na a saída final do corpo-de-prova, que puxa o ar do tubo causando um deslocamento de água para cima no tubo. Este método é satisfatório para madeiras com alta e baixa permeabilidade

- O segundo consiste no método de deslocamento de descida de água, onde a água é inicialmente puxada acima do ponto 1 por vácuo dentro de um tubo. Quando o vácuo é desligado o ar vai escoando através do corpo-de-prova e permitindo que a água abaixe. Este método é satisfatório para medida de alta e muito alta permeabilidade. 
- O terceiro é o método do rotâmetro (fluxômetro), no qual é utilizado o aparato do primeiro método descrito acima, mas o tubo que registra o deslocamento de água é substituído pelo rotâmetro. $\mathrm{O}$ método utiliza estado fixo de escoamento desde que a taxa de fluxo e gradiente seja constante. A equação de Darcy pode ser reescrita para este método:

$$
K_{g}=\frac{152 Q L P a}{A \Delta P_{m}\left(2 P_{a}-\Delta P_{m}\right)}
$$

onde:

$Q=$ taxa de escoamento do gás, $\mathrm{cm}^{3} / \mathrm{seg}$, como determinado para o gráfico de calibração fornecido com o rotâmetro;

$P_{a}=$ pressão atmosférica, $\mathrm{cm}$ de mercúrio;

$\Delta P_{m}=$ leitura inicial do manômetro, $\mathrm{cm}$ de mercúrio.

\subsection{2 - Modelo de fluxo para coníferas}

O fluxo de fluidos através das coníferas é essencialmente por meio dos traqueídeos, que são interconectados por pares de pontuações areoladas. Siau (1971) propôs um modelo em que todas as pontuações são localizadas na superfície radial e nas terminações finais dos traqueídeos, Figura 2.13. É assumido que todas as aberturas das pontuações tenham o mesmo tamanho. Para simplificação, todo traqueídeo deve ter quatro pares de pontuações que são compartilhados por traqueídeos adjacentes. Está claro que ambos os fluxos longitudinal e tangencial são controlados pelos pares de pontuações areoladas.

$\mathrm{Na}$ seguinte análise matemática do modelo, a relação da permeabilidade longitudinal para permeabilidade transversal irá ser derivada. A relação de comprimento para o diâmetro do traqueídeo seja 100. A quantidade $\alpha$ representa a relação de traqueídeo que se sobrepõe. Estes valores podem ser estendidos de um máximo de 0,5 para zero. Está claro, na Figura 2.13, que a permeabilidade longitudinal é muito maior que a permeabilidade tangencial devido ao número de caminhos paralelos por unidade de área e menos paredes celulares para serem atravessados em séries por unidade de 
comprimento na direção do fluxo. Deste modo, a permeabilidade na direção longitudinal para as coníferas pode ser escrita:

$k_{L} \alpha \frac{2 L_{t}(1-\alpha)}{D^{2}}$

onde:

$\mathrm{kL}=$ permeabilidade longitudinal;

$\mathrm{D}=$ diâmetro dos traqueídeos, $\mathrm{cm}$;

2 = número de caminhos paralelos por traqueídeos;

$\mathrm{Lt}=$ comprimento dos traqueídeos, $\mathrm{cm}$;

$\alpha=$ fração dos traqueídeos que se sobrepõem.

Na direção tangencial, o número de caminhos paralelos por $\mathrm{cm} 2$ da área da seção transversal $=1 / \operatorname{DLt}(1-\alpha)$; número de pares de pontuações em série por $\mathrm{cm}$ de largura $=2 / \mathrm{D}$, então:

$$
k_{T} \alpha \frac{1}{2 L_{t}(1-\alpha)}
$$

onde:

$\mathrm{kT}=$ permeabilidade tangencial

Entretanto:

$$
\frac{k_{L}}{k_{t}}=\frac{4 L_{t}^{2}(1-\alpha)^{2}}{D^{2}}
$$

Desde que Lt/D tenha um valor igual a 100, a equação 11 pode ser reescrita:

$$
\frac{k_{L}}{k_{T}}=40000(1-\alpha)^{2}
$$

O modelo discutido acima negligencia o escoamento através dos raios, embora haja evidências de escoamento considerável através destas células em algumas espécies, contribuindo para o fluxo na direção radial, segundo Siau (1971). 


\subsection{3 - Modelo de fluxo para dicotiledôneas}

De acordo com Siau (1971), quando uma dicotiledônea apresenta vasos abertos, estes se comportam como vasos capilares abertos ao longo de todo comprimento de uma espécie de madeira. O grande diâmetro dos vasos (se comparado com a abertura das pontuações) faz o escoamento através das fibras e do parênquima longitudinal insignificante por comparação. Deste modo, estes caminhos são negligenciados e um modelo simplificado é descrito na Figura 2.20.

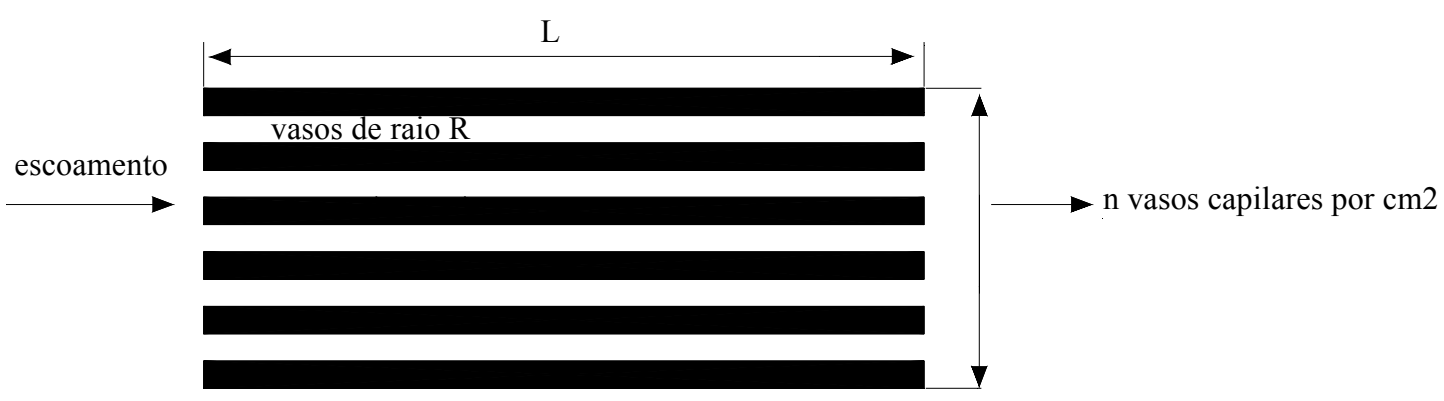

Figura 2.20 - Modelo de escoamento longitudinal para dicotiledôneas com vasos abertos. Fonte Siau (1971).

Se houver $\mathrm{N}$ vasos capilares paralelos em uma espécie de madeira, a equação 3 pode ser reescrita aplicando o modelo da Figura 2.20 e escreve-se uma equação para a permeabilidade longitudinal nas dicotiledôneas, expressa em termos de atmosferas:

$k_{L}=\frac{q_{v} \cdot R^{2}}{8 \eta} \times 1,013 \times 10^{6}$

onde:

$k_{L}=$ permeabilidade longitudinal, $\mathrm{cm}^{3}$ (fluido)/(dina seg);

$q_{v}=$ fração de volume dos vasos em difusão porosa das dicotiledôneas;

$R=$ raio dos vasos, $\mathrm{cm}$;

$n=\mathrm{N} / \mathrm{A}=\mathrm{n}^{\mathrm{o}}$ de vasos por $\mathrm{cm}^{2}$ da seção transversal.

A equação 13 indica que a permeabilidade longitudinal de uma dicotiledônea é dependente somente da quantidade e raio dos vasos e a viscosidade do fluido. 


\section{8 - Capilaridade}

A ação capilar dos líquidos se deve à tendência dos líquidos de subir pelas paredes de tubos capilares (tubos muitos finos) e é uma conseqüência da tensão superficial.

Quando o conteúdo de umidade na superfície e no núcleo de uma peça de madeira for maior que o ponto de saturação das fibras, o movimento de umidade ocorre através do fluxo capilar como resultado das forças de tensão superficial. Siau (1971) define tensão superfícial como a energia de superfície por unidade de área.

Forças intermoleculares nos líquidos são responsáveis por fenômenos de capilaridade (subida de líquidos em tubos capilares).

Quando temos líquido em um tubo capilar, a tensão superficial exerce uma força de subida, desde que haja adesão entre o líquido e a superfície interior do capilar, ou seja, a força de adesão entre o líquido e a parede do capilar é maior que a força de coesão do líquido. Neste caso o liquido tende a se espalhar na maior área possível do capilar devido ao líquido estar entrando em contato com uma superfície hidrofílica, Forma assim um menisco com a forma côncava. Podemos citar como exemplo, água dentro de um tubo capilar de vidro. Quando a tensão superficial exerce uma força de descida, significa que não há adesão entre o líquido e a superfície interior do capilar, ou seja, a força de adesão entre o líquido e a parede do capilar é menor que a força de coesão do líquido. Neste caso, o líquido tende a reduzir sua área de contato com o capilar por estar entrando em contato com uma superfície hidrofóbica tomando a forma de um menisco convexo. Podemos citar como exemplo, o mercúrio dentro de um tubo capilar de vidro.

Siau (1971) descreve um aparato capaz de mostrar a permeabilidade específica da espécie Western Hemlock medida com gás ou um líquido não polar como mercúrio, apresentam resultados iguais.

As forças capilares são governadas pela equação abaixo:

$$
P_{0}-P_{1}=\frac{2 \gamma}{R_{i}}
$$


onde:

$P_{0}-P_{1}=$ diferencial de pressão, $1 \mathrm{~b} / \mathrm{in}^{2}$;

$R_{i}=$ raio da interface líquido gás, $\mathrm{cm}$;

$\gamma=$ tensão superficial, dina $/ \mathrm{cm}$.

A quantidade máxima de tensão capilar é determinada pelo tamanho da abertura da pontuação no sistema.

Stamm apud Siau (1971), usou a equação 15 para calcular o raio da abertura das pontuações em coníferas.

$$
P_{0}-P_{1}=\frac{21.4}{R}
$$

onde:

$R=$ raio de capilaridade, $\mu \mathrm{m}$.

Colapso ocorre na madeira quando a tensão capilar excede a força compressiva perpendicular para a grã. No processo de secagem, as tensões de secagem é um importante fator para o colapso da madeira, a superfície da tábua sofre uma secagem inicial encolhendo mais que o centro e exercendo uma força compressiva que contribui para o colapso. A tensão capilar foi reconhecida como a principal causa do colapso segundo Siau (1971).

Os fatores responsáveis pelo colapso na madeira durante a secagem são descritos abaixo:

- tamanho da abertura das pontuações: pequenas pontuações são relacionadas cm baixa permeabilidade e alta tensão capilar. As pontuações podem ou não podem estar aspiradas;

- tensão superficial do líquido que esta secando da madeira: a alta tensão superficial tende para causar colapso, devido a altas tensões capilares;

- densidade de madeira: a baixa densidade esta relacionada com paredes celulares finas, o que faz com que a madeira tenha baixa resistência compressão; 
- temperatura da madeira: em elevadas temperaturas, a redução da resistência, faz a madeira mais susceptível para entrar em colapso.

\section{9 - Tratabilidade e colagem}

De acordo com Lepage (1986), a permeabilidade da madeira relaciona-se bem com sua respectiva tratabilidade. Sendo assim, madeiras com alta permeabilidade são susceptíveis a tratamentos químicos.

Segundo Déon (1989), a proteção ideal será obtida à medida que o produto utilizado for bom e o método de aplicação apto a fazer penetrar este último profundamente na madeira. "E é aqui que intervém o fator permeabilidade". A permeabilidade de uma madeira é como a dureza, a densidade, a durabilidade natural etc., uma propriedade da madeira, propriedade que indica aproximadamente a aptidão que uma essência tem de se deixar penetrar por um produto. Esta permeabilidade determinará a qualidade de impregnação efetivamente obtida pela aplicação dos tratamentos de preservação, qualidade variável segundo a natureza desses tratamentos e os fenômenos de penetração. Portanto, convém, na prática, levando-se em conta o nível de preservação a atingir, determinar o procedimento mais apropriado em função da durabilidade e da permeabilidade da espécie considerada, esse procedimento correspondendo, por sua vez, a um tipo de produto e ao seu processo de aplicação. Além disso, para uma mesma espécie, o grau de permeabilidade varia frequentemente segundo a parte considerada, cerne e alburno, este último sendo mais permeável aos produtos de preservação.

Essas considerações, e igualmente a prática, mostram que as diferentes madeiras se comportam de maneira muito variada. Certas espécies apresentam uma baixa durabilidade natural e uma permeabilidade quase nula e portanto o problema de sua conservação é insolúvel. Por outro lado, encontram-se essências de boa resistência natural e de permeabilidade excelente para as quais a proteção ideal precedentemente evocada é atingida. Entre esses dois extremos, todas as possibilidades estão abertas.

É por isso que, quando se deve escolher um modo de tratamento, é preciso considerar os pontos seguintes: 
- uso da madeira a tratar e riscos de ataques corridos;

- natureza da madeira a tratar (durabilidade natural, permeabilidade e umidade no instante do tratamento).

As madeiras menos densas são mais susceptíveis a se impregnar que as madeiras densas e uma madeira leve não é forçosamente bem impregnável. Pode-se dizer que o grau de permeabilidade não esta ligada à densidade, segundo Déon (1989). Um exemplo é o AIÉLÉ (de densidade 0,5) que não aceita à impregnação.

As espécies de madeiras são divididas em coníferas e dicotiledôneas, e podem apresentar diferentes arranjos nos seus elementos anatômicos constituintes, com reflexo na tratabilidade. As madeiras são agrupadas em quatro classes, (Lepage, 1986), de acordo com a maior ou menor facilidade com que o cerne é penetrado:

- Grupo 1: cerne facilmente penetrado;

- Grupo 2: cerne moderadamente penetrado;

- Grupo 3: cerne de penetração difícil;

- Grupo 4: cerne de penetração muito difícil.

Albuquerque and Latorraca (2005) falam que as propriedades da madeira possuem um nítido efeito nas ligas adesivas e, geralmente as dicotiledôneas apresentam mais dificuldades do que as coníferas. As propriedades anatômicas de madeira possuem uma significativa influência na colagem de madeiras, a exemplo da densidade, permeabilidade e porosidade que ocorre em: lenhos inicial e tardio, cerne e alburno, e lenho juvenil e lenho adulto. A importância das propriedades anatômicas da madeira esta voltada aos seus efeitos no movimento do adesivo para o interior da estrutura da madeira, ou seja, a penetração.

A porosidade se relaciona com a densidade, que influenciam na penetração dos adesivos na madeira. A porosidade pode ser considerada como o inverso da densidade, do ponto de vista da liga adesiva, desde que esta se relacione com as aberturas da madeira relativas à passagem de líquidos ou gases. 


\subsection{0 - Conclusão da revisão bibliográfica}

A determinação do fluxo pode ser realizada de três maneiras. O método adotado para a realização desta pesquisa foi o método do rotâmetro (fluxômetro), pela praticidade de trabalho.

A permeabilidade é severamente distinta em relação às coníferas e dicotiledôneas. Isto se deve ao fato de os elementos anatômicos das mesmas serem significativamente diferentes. Um outro fator que prejudica a permeabilidade é a presença de tilas e aspirações das pontuações.

Tanto para as coníferas quanto para as dicotiledôneas, a permeabilidade pode ser também determinada em função dos elementos anatômicos, juntamente com a viscosidade do fluido a ser trabalhado.

Concluímos que a permeabilidade está associada à distinção dos elementos anatômicos e a sua respectiva tratabilidade, mas não à densidade da madeira. 


\section{3 - MATERIAIS E MÉTODOS}

A descrição do material e as etapas para realização do trabalho experimental são descritas abaixo.

\section{1 - Materiais utilizados}

As madeiras foram obtidas através de doações de empresas que fornecem madeira para construção civil. Já o equipamento e os fluidos foram adquiridos pelo Laboratório de Madeiras e Estruturas de Madeira (LaMEM).

Foram utilizadas três espécies diferentes de madeiras de florestamento, sendo elas: Pinus elliottii, Eucalyptus grandis e Eucalyptus citriodora.

\section{2 - Equipamento}

Para realização dos ensaios de permeabilidade foi projetado e construído um equipamento para determinação de fluxo líquido e gasoso em madeiras. O equipamento é constituído por uma estrutura de madeira, suporte de madeira, conjunto de rolhas, junta cônica, fluxômetros, buretas, mufa e uma bomba de vácuo.

Inicialmente será apresentada a planta das partes que constituem o equipamento para sua fabricação. A primeira parte montada é a estrutura de madeira, que permite a sustentação das demais peças constituintes do equipamento, com exceção da bomba de vácuo, que fica ao chão.

Esta estrutura é constituída por barras cilíndricas de madeira dispostas verticalmente e horizontalmente, Figura 3.1. As barras cilíndricas foram unidas umas às outras por pinça universal mufa, o que proporciona o ajuste entre a distância das barras verticais, em função da disposição das demais peças constituintes do equipamento, de acordo com o tipo de ensaio a ser realizado.

A barra cilíndrica indicada nas laterais da estrutura de madeira, figura 3.1, é utilizada para proporcionar estabilidade dimensional. A estrutura de madeira é apoiada em uma mesa com dimensões de 122 x $80 \mathrm{~cm}$. 


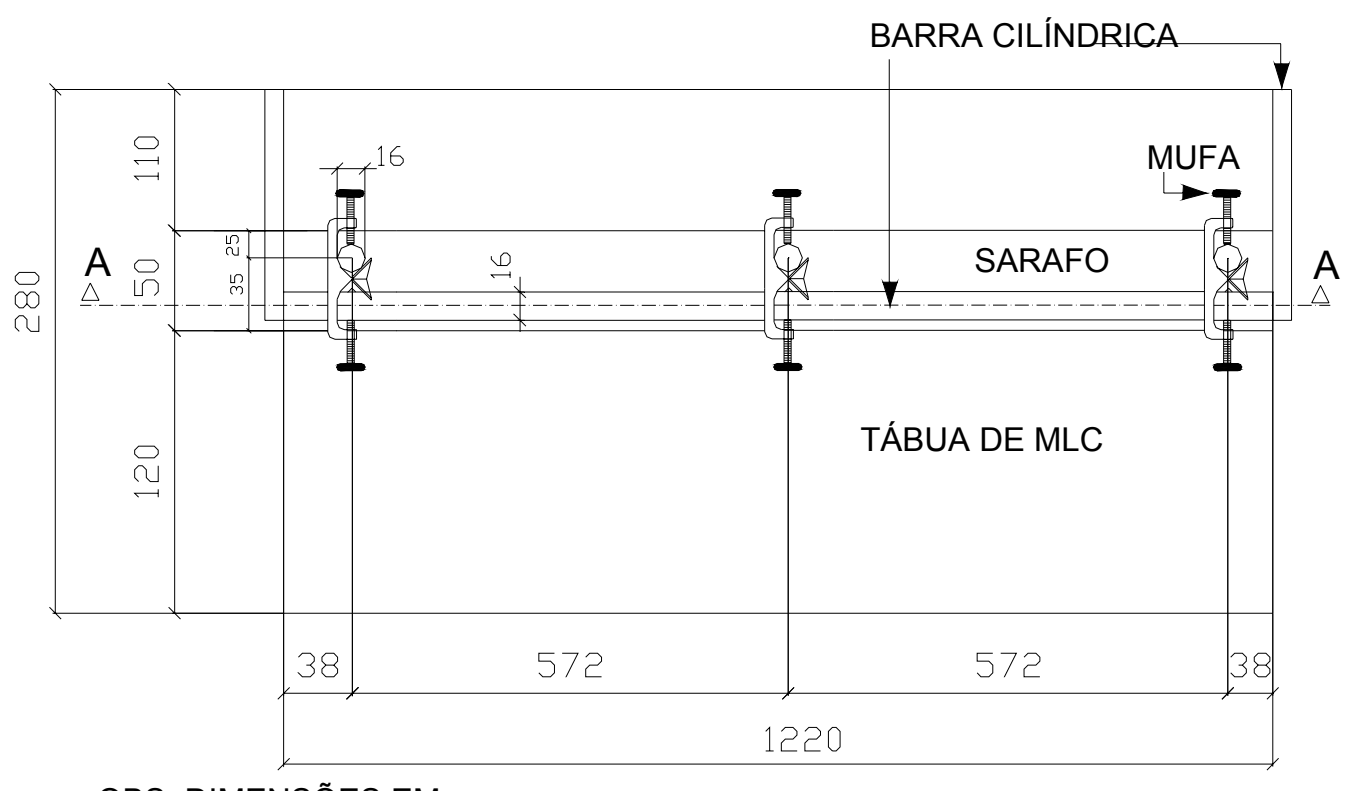

OBS: DIMENSÕES EM mm.

Figura 3.1 - Vista superior da estrutura de madeira.

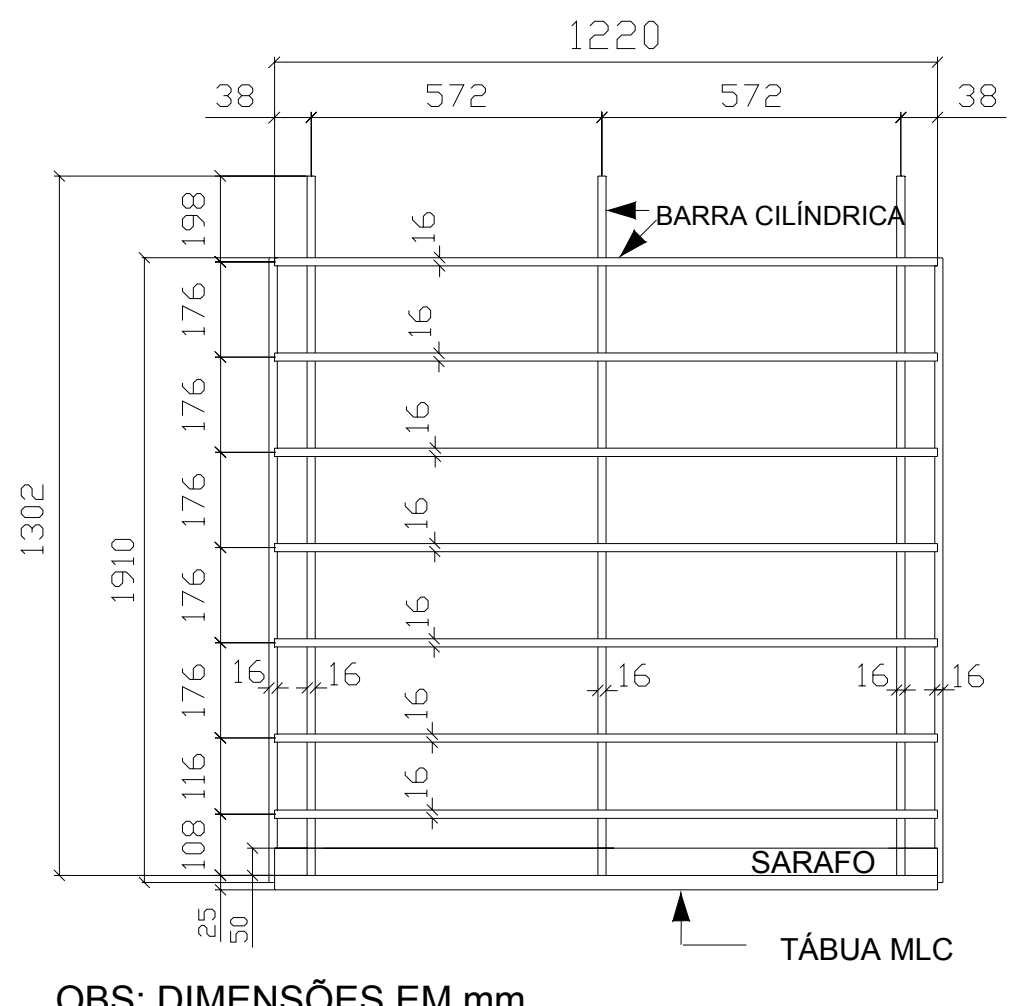

OBS: DIMENSÕES EM mm.

Figura 3.2 - Vista frontal da estrutura de madeira. 
Na Figura 3.3 e Figura 3.4, vemos o suporte de madeira que é fixado à estrutura de madeira por pinça universal mufa para prender a junta cônica.

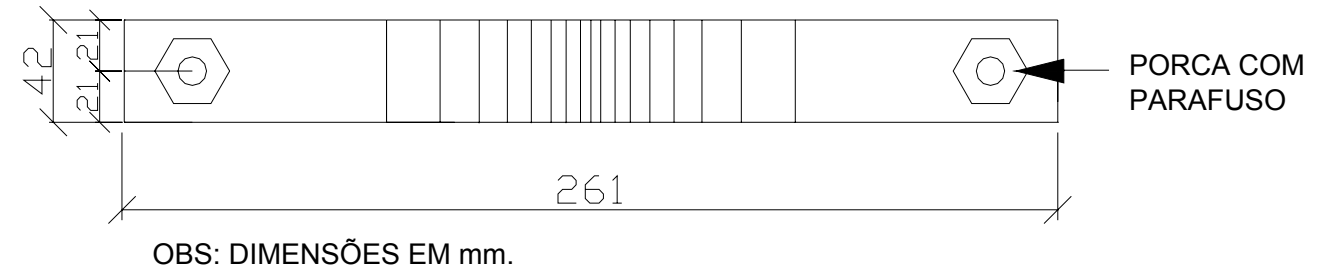

Figura 3.3 - Vista frontal do suporte de madeira.

A parte interna do suporte de madeira foi revestida com carpete para evitar o atrito direto da junta cônica com o suporte de madeira, Figura 3.4.

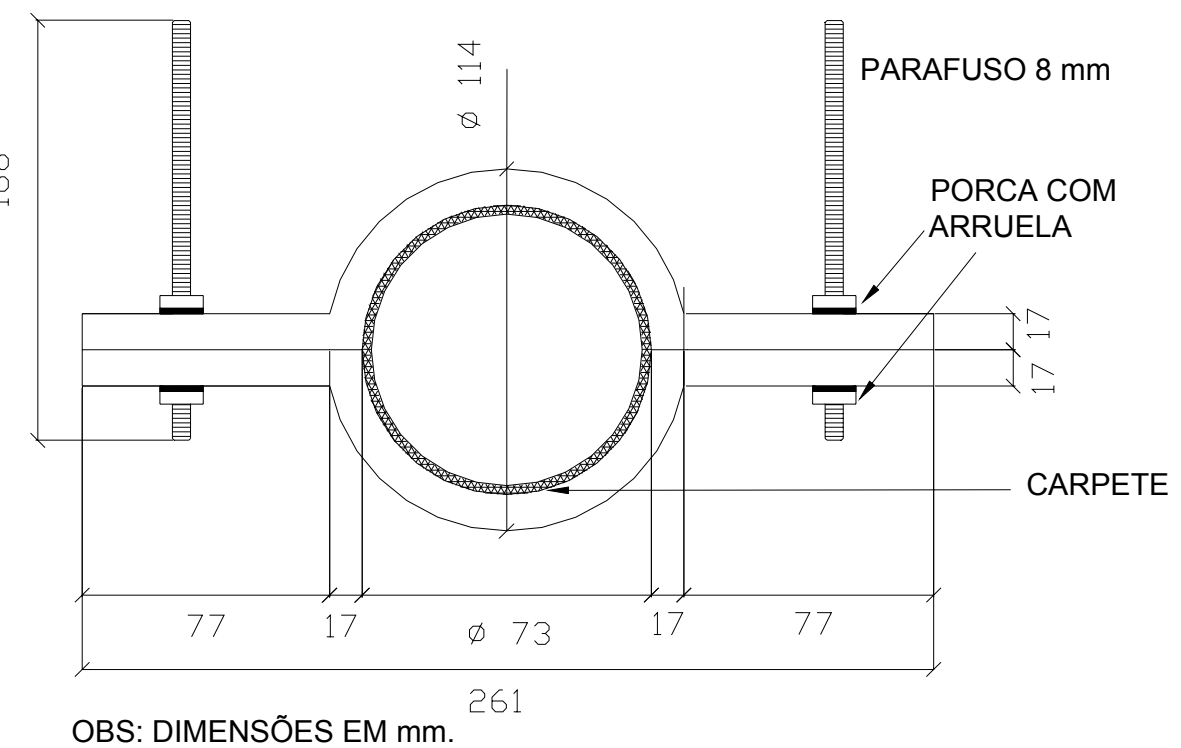

Figura 3.4 - Vista superior do suporte de madeira.

A junta cônica $(71 / 60 \mathrm{~mm})$ possui paredes de $5 \mathrm{~mm}$ de espessura e serve de apoio para conjunto de rolhas. A junta cônica recebe o vácuo produzido pela bomba de vácuo por meio de uma torneira de teflon de $8 \mathrm{~mm}$, e após a realização do ensaio, libera o vácuo por outra torneira de teflon de $8 \mathrm{~mm}$, Figura 3.5 . 


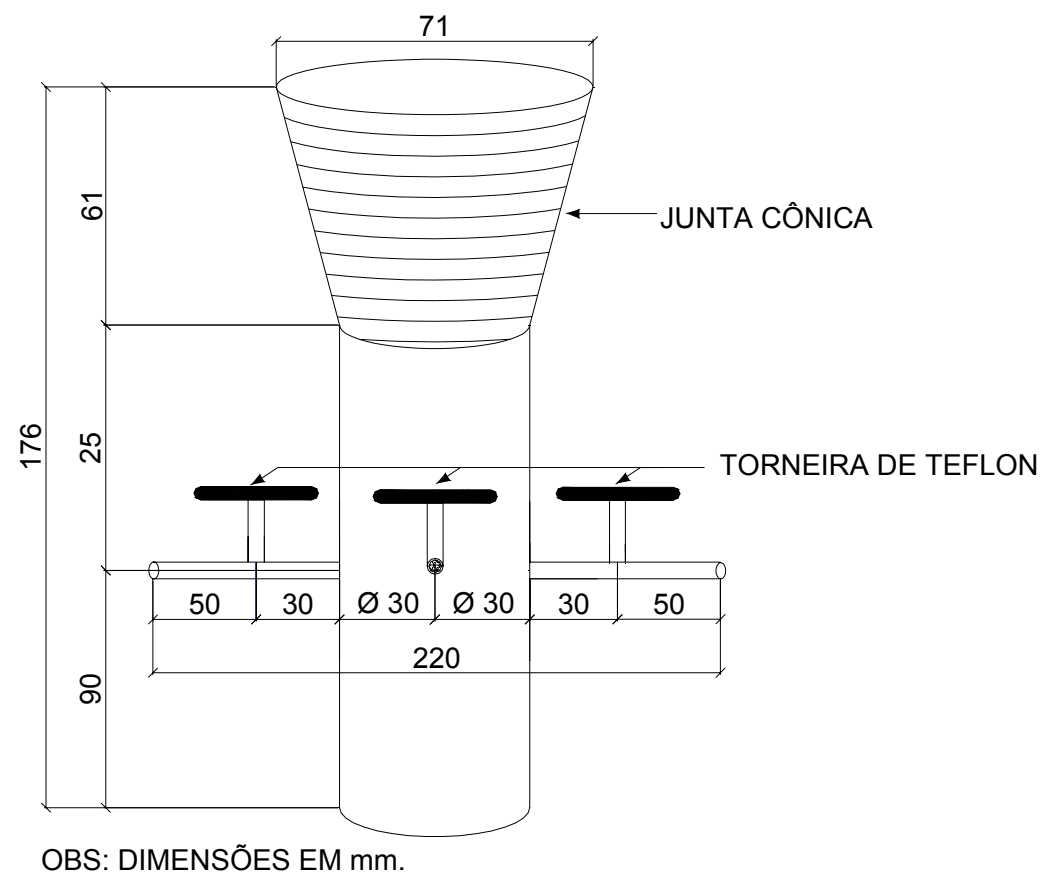

Figura 3.5 - Junta cônica com as torneiras de teflon.

Para permitir o deslocamento de fluidos através dos corpos-de-prova e vedar a junta cônica, foi desenvolvido um conjunto de rolhas constituído por: rolha cônica de resina de mamona, rolha cônica de borracha e rolha cilíndrica de teflon Figura 3.6.

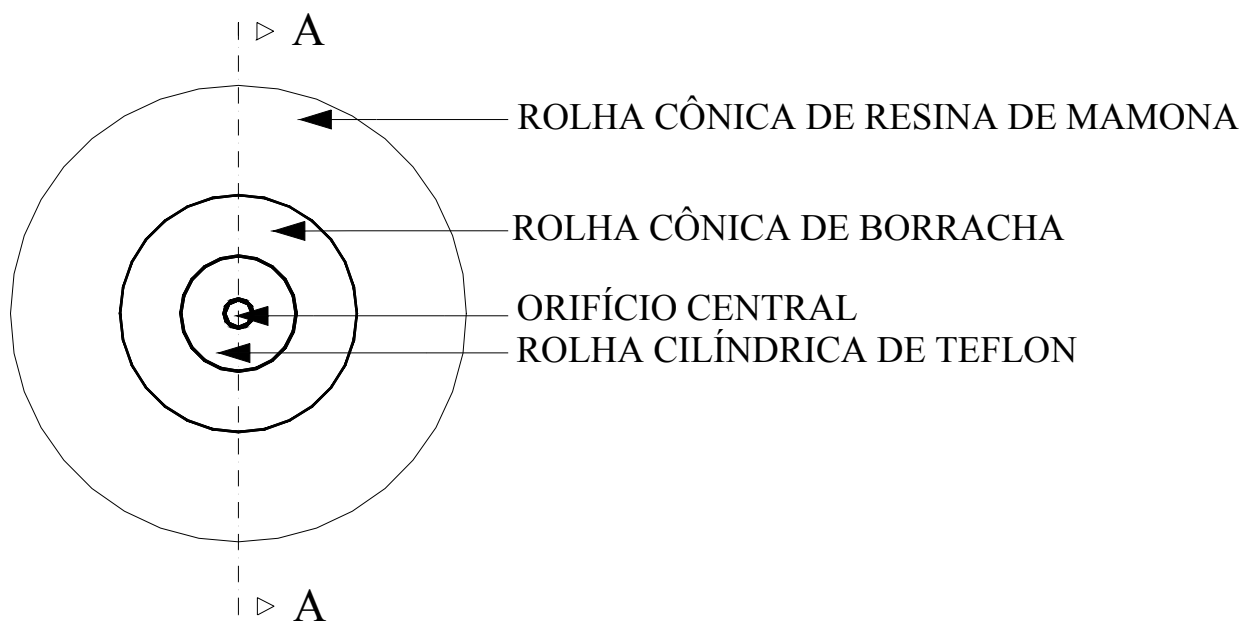

Figura 3.6 - Vista superior do conjunto de rolhas.

O conjunto de rolhas é acoplado sendo que: a rolha cônica de resina de mamona, sendo a maior, fixa as duas rolhas cônicas de borracha. A rolha cônica de borracha, que 
fica na parte inferior da rolha de resina de mamona, irá fixar o corpo-de-prova e a rolha cônica de borracha, que fica na parte superior da rolha de resina de mamona, irá fixar a rolha cilíndrica de teflon, Figura 3.7. Há também duas rolhas cilíndricas de teflon sendo que: a primeira, constituída por uma oliva na parte superior, e é utilizada para medir o fluxo gasoso; a segunda rolha é constituída apenas por um orifício central para encaixe da bureta; e é utilizada na determinação do fluxo líquido.

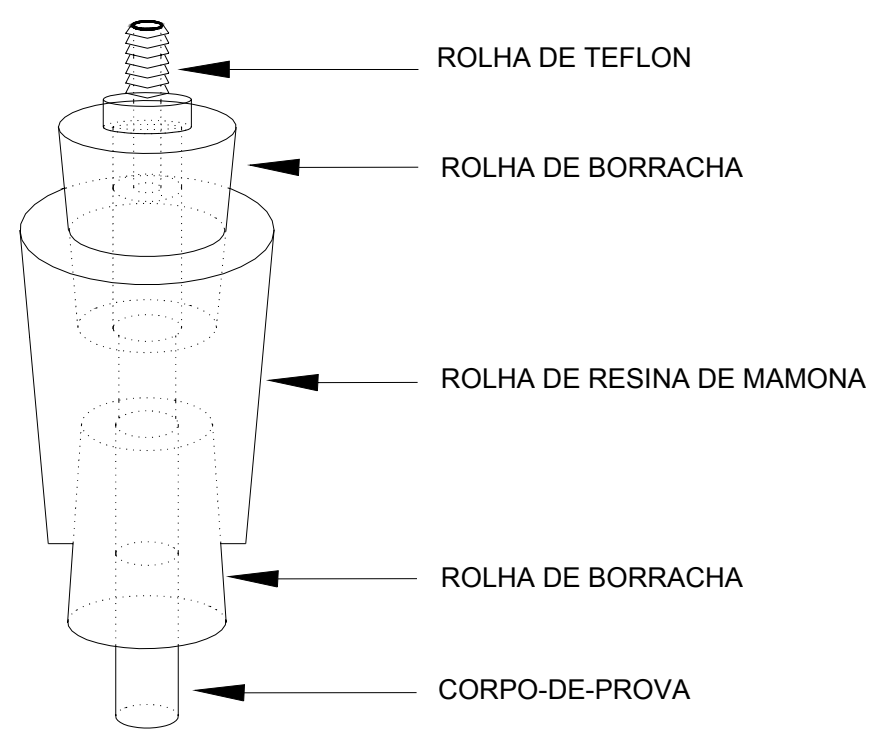

Figura 3.7 - Conjunto de rolhas acopladas. Rolha de teflon com oliva.

O fixador de rolha de borracha foi desenvolvido com a finalidade de proporcionar um melhor ajuste entre a rolha de borracha que acomoda o corpo-de-prova na rolha de resina de mamona. Foi fabricado com madeira maciça de Eucalyptus, com $22 \mathrm{~mm}$ de espessura.

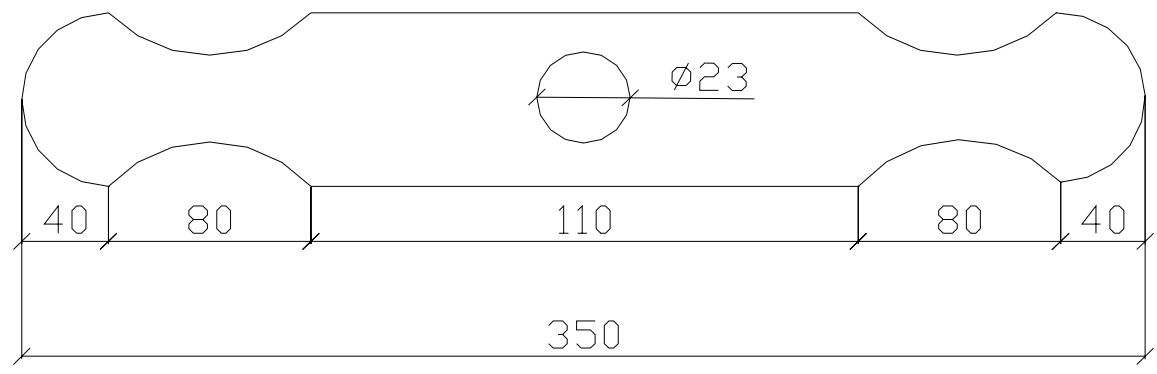

Obs: dimensões em mm.

Figura 3.8 - Fixador de rolha de borracha.

A figura 3.9 apresenta todo o conjunto de rolhas e suas respectivas dimensões. 


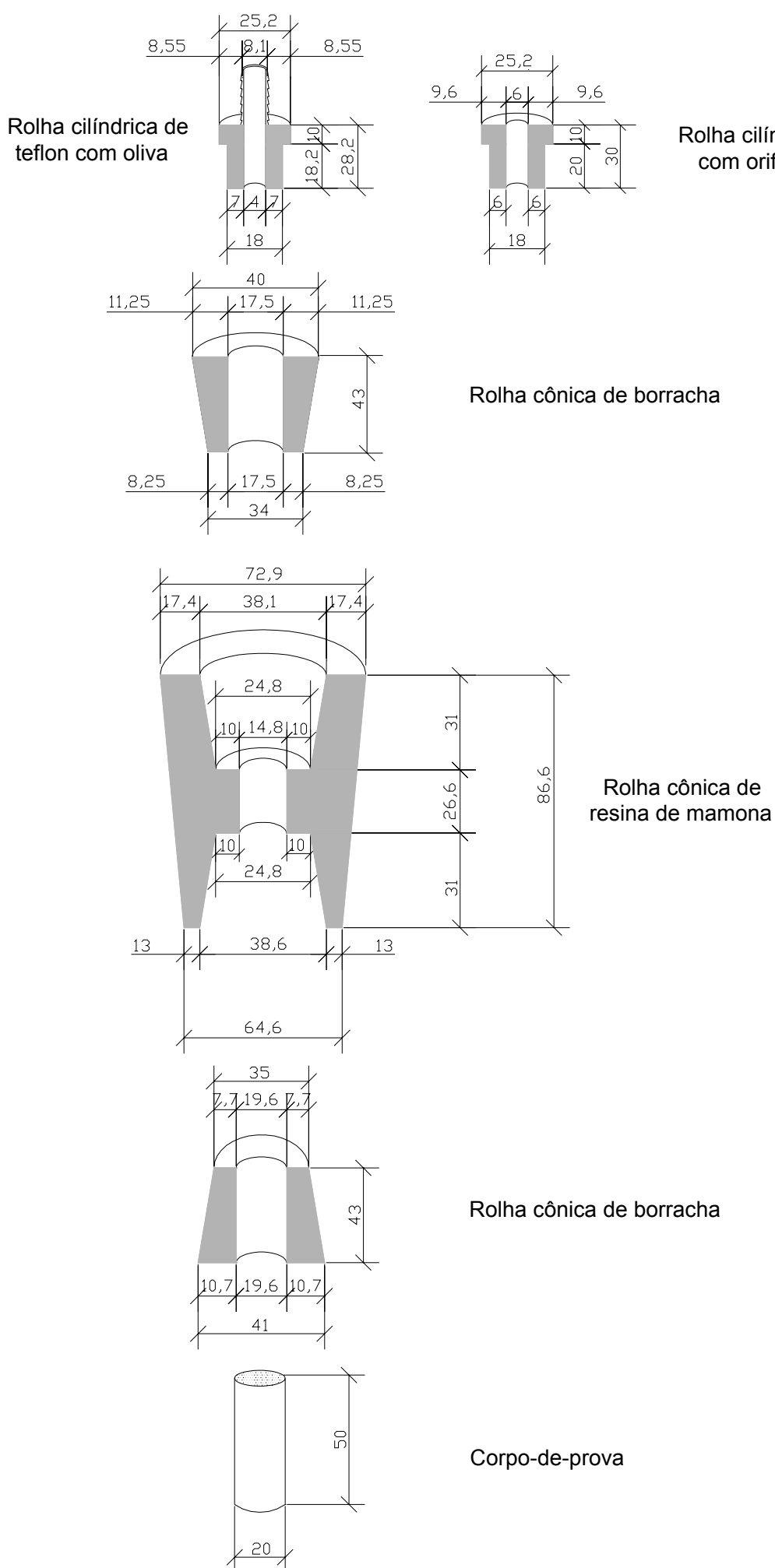

Obs: dimensões em mm.

Figura 3.9 - Conjunto de rolhas em posição de acoplamento. 
Os fluxômetros têm finalidade de medir o fluxo de ar através dos corpos-de-prova. O dispositivo montado é constituído por três fluxômetros, com fluxo de: 20 a 180 ml/min, 10 a 100 l/h e de 100 a 1100 l/h, Figura 3.10 a. Há ainda duas buretas com a finalidade de medir o fluxo de líquidos através dos corpos-de-prova, com capacidade de armazenamento de $25 \mathrm{ml}$ e $50 \mathrm{ml}$, Figura $3.10 \mathrm{~b}$.

Os fluxômetros e as buretas são fixados na estrutura de madeira por uma pinça universal.

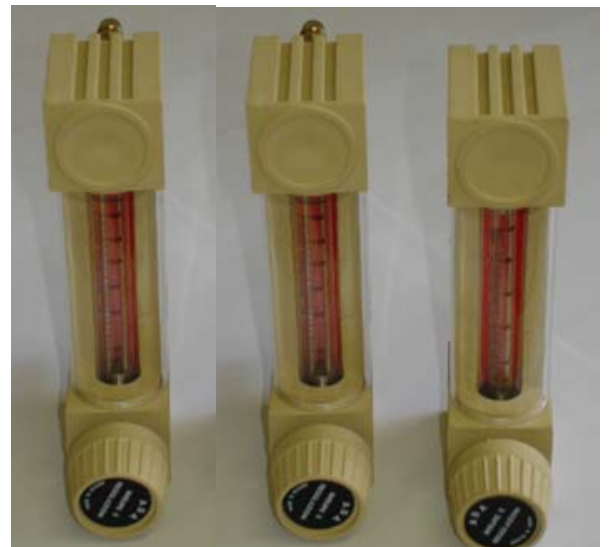

a) Fluxômetros

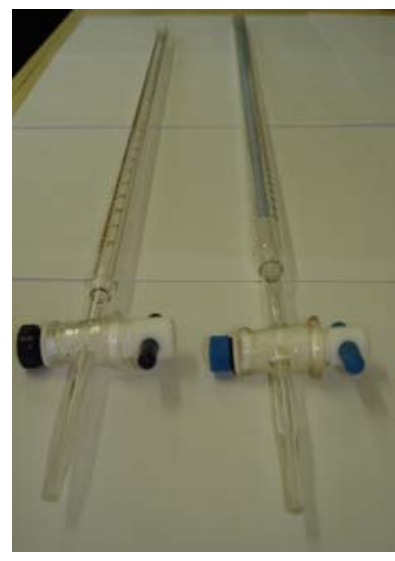

b) Buretas

Figura 3.10 - Medidores de vazão de fluidos.

Para proporcionar a ligação entre as peças que constituem o equipamento foi utilizada uma mangueira de silicone de $6 \times 10 \mathrm{~mm}$. Esta mangueira permite a ligação entre a bomba de vácuo e uma das torneiras de teflon de $8 \mathrm{~mm}$ da junta cônica e também a ligação entre a rolha de teflon com oliva e o fluxômetro, para realização de ensaio gasoso.

Para realização de ensaios com líquidos, a rolha cilíndrica de teflon com oliva é substituída pela rolha cilíndrica de teflon com orifício central, pois é nesta que se encaixará a bureta. A bureta apresenta, para saída do líquido uma ponta muito fina, por ser um instrumento de precisão e por este motivo, houve a necessidade de cortar sua ponta para que não haja nenhuma influência no deslocamento do líquido.

Uma visão geral do equipamento pronto para realização de ensaios de permeabilidade é mostrado na Figura 3.11. 


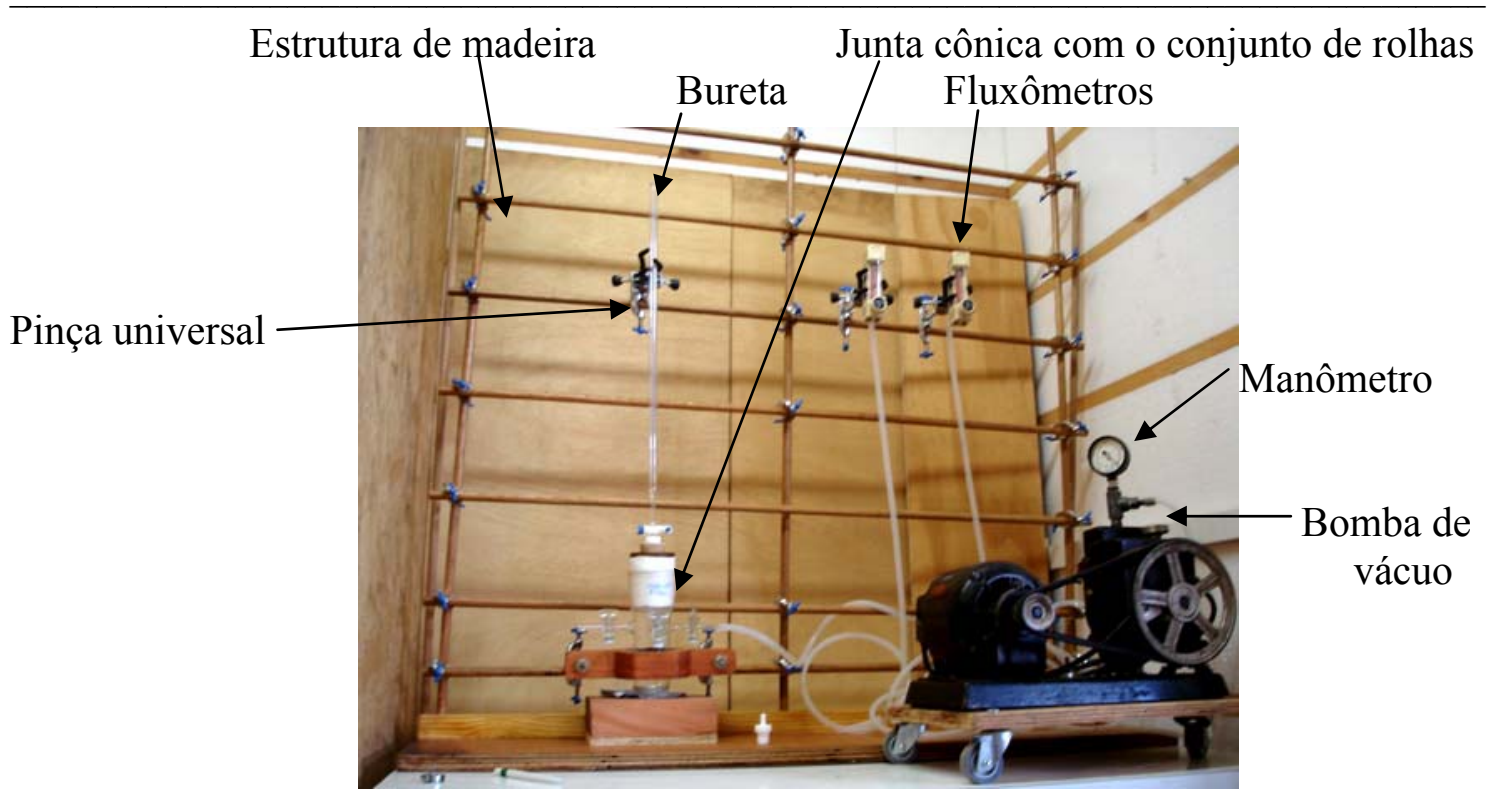

Figura 3.11 - Equipamento montado para ensaios de permeabilidade.

A Figura 3.12 é mostrada a junta cônica com o suporte de madeira (a), a rolha de resina de mamona (b), as rolhas de borracha acima e rolhas de teflon à frente (c) e o conjunto de rolhas acoplado com corpo-de-prova (d).

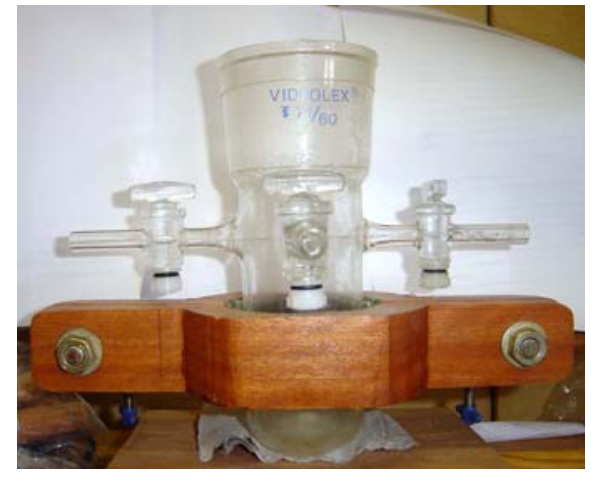

a

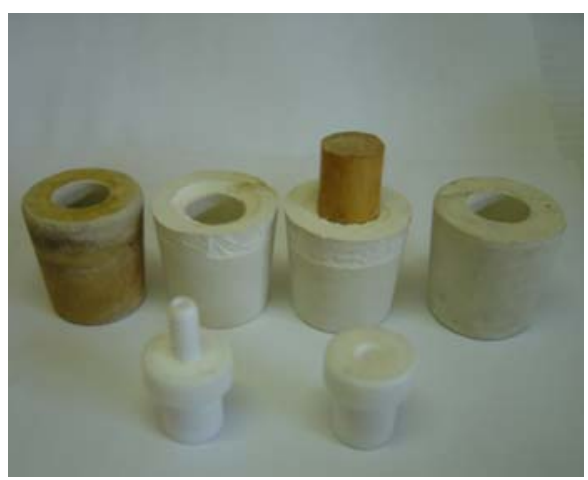

C

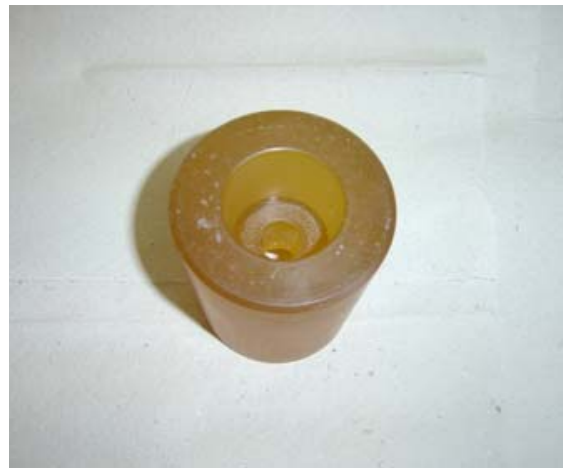

b

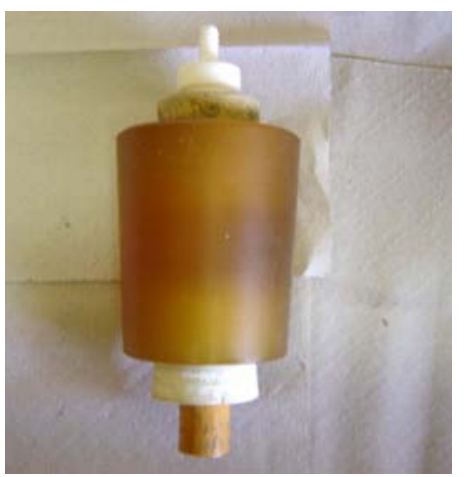

d

Figura 3.12 - Peças constituintes do equipamento apresentadas individualmente. 


\section{3 - Corpos-de-prova}

As dimensões utilizadas para cada corpo-de-prova, tanto para espécie de Pinus como de Eucalyptus foram de 20x50 mm.

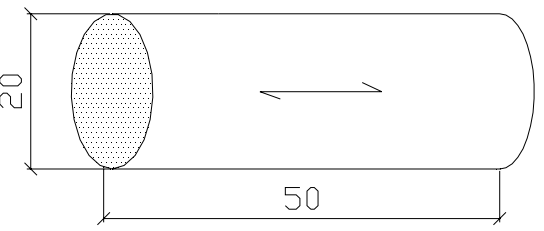

Figura 3.13 - Corpo-de-prova utilizado nos ensaios de permeabilidade a líquido e gás.

Os corpos-de-prova são introduzidos aproximadamente até a metade do seu comprimento na rolha de borracha.

\subsection{1 - Retirada dos corpos-de-prova}

Os corpos-de-prova de Eucalyptus citriodora foram obtidos da parte inferior do tronco de uma árvore com aproximadamente 25 anos de idade e com diâmetro médio de $31 \mathrm{~cm}$. O cerne possuía um diâmetro médio de $21 \mathrm{~cm}$ e o alburno uma espessura média de $4 \mathrm{~cm}$, Figura 3.14 b. Os corpos-de-prova de Eucalyptus grandis foram obtidos da parte superior de uma árvore com aproximadamente 100 anos de idade, onde o cerne apresentava um diâmetro média de $30 \mathrm{~cm}$ e o alburno um diâmetro média de $5 \mathrm{~cm}$, Figura 3.14 a. Para o Pinus elliottii, os corpos-de-prova foram retirados de vigas de madeira de dimensões de $15 \times 5 \times 200 \mathrm{~cm}$.

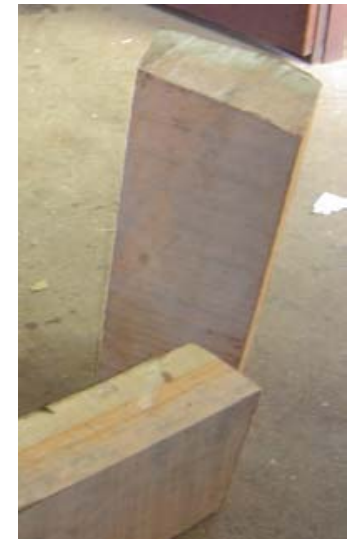

a) Eucalyptus grandis

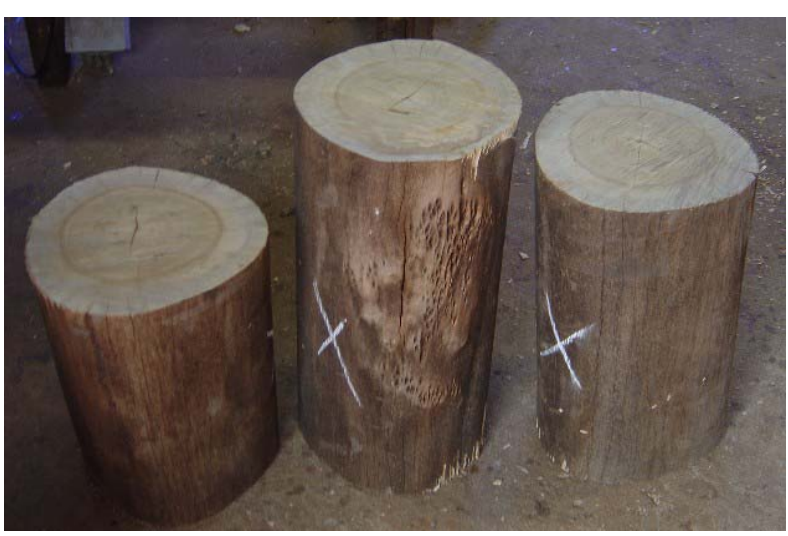

b) Eucalyptus citriodora

Figura 3.14 - Madeira antes do desdobro. 
A Figura 3.15 apresenta a direção em relação às fibras nas madeiras de que foram retirados os corpos-de-prova para ensaios de permeabilidade.

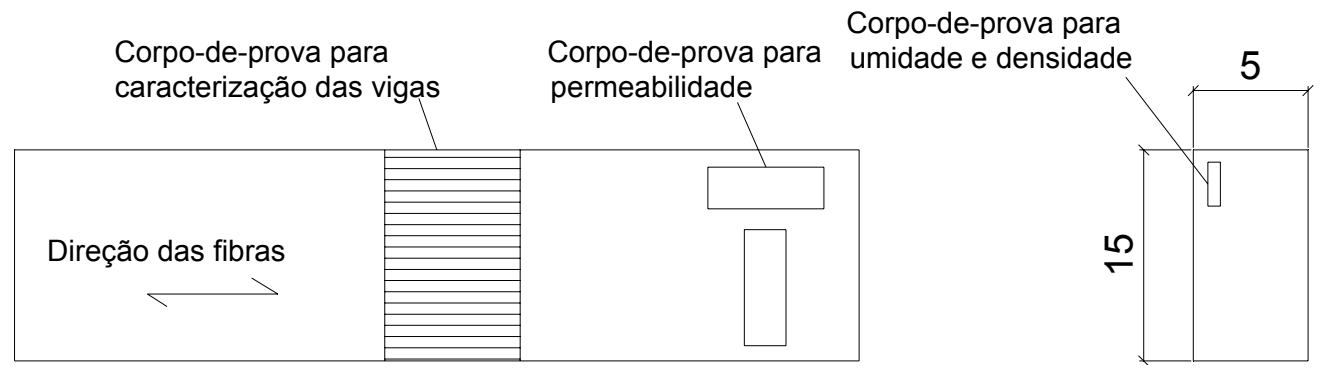

Figura 3.15 - Retirada dos corpos-de-prova na direção e perpendicular às fibras da madeira.

As dimensões dos corpos-de-prova ainda na forma prismática que foram levados ao torno para finalização de sua confecção, são as mesmas tanto para o alburno quanto para o cerne nas dicotiledôneas. Os corpos-de-prova prismáticos são desdobrados nas dimensões de 22x135 mm, em seguida levados ao torno, onde adquirem forma cilíndrica para posterior impermeabilização, Figura 3.16.

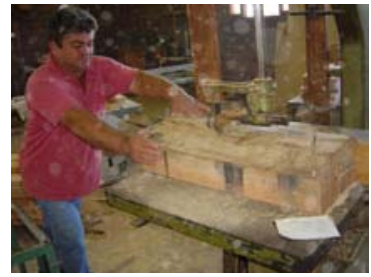

a) Desdobro da madeira

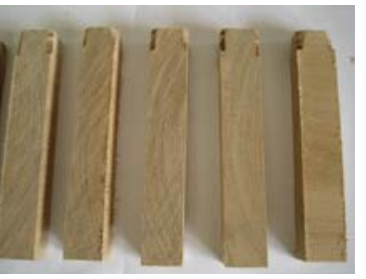

b) Corpo-de-prova retangular

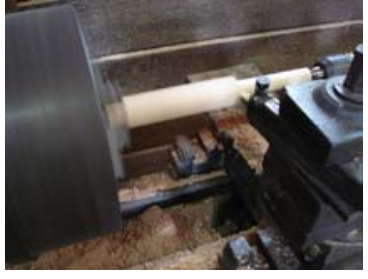

c) Torneamento

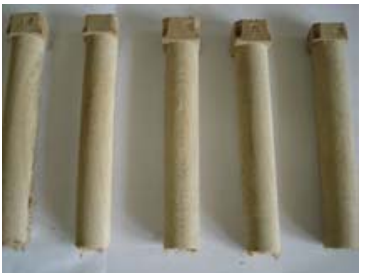

d) Corpo-de-prova cilíndrico

Figura 3.16 - Seqüência de usinagem para os corpos-de-prova.

\subsection{2 - Impermeabilização dos corpos-de-prova}

Para garantir a permeabilidade somente na direção ortogonal desejada, os corposde-prova tiveram suas laterais impermeabilizadas com adesivo epóxi, Figura 3.17.

$\mathrm{O}$ adesivo foi aplicado antes que o corpo-de-prova fosse cortado no seu comprimento final, pois, se cortado antes da aplicação da resina, esta poderia escoar no topo ou na base do corpo-de-prova e este podendo absorver a resina e prejudicando o deslocamento do fluxo. 


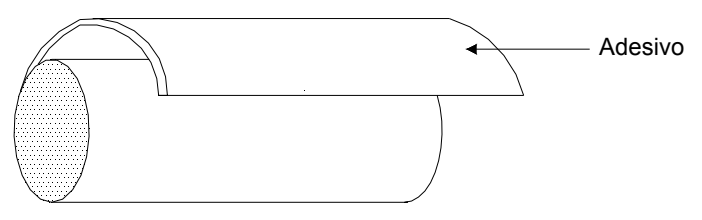

Figura 3.17 - Recobrimento de um corpo-de-prova.

O adesivo epóxi foi aplicado com facilidade, após sua preparação (mistura dos componentes A e B), com o uso de uma pequena pá, com movimento retilíneo. O tempo de secagem do adesivo é de aproximadamente 5 minutos, o que exige bastante agilidade, pois sua viscosidade aumenta rapidamente (cerca de 2 a 3 minutos), dificultando o espalhamento, Figura 3.18 a.

Após a aplicação do adesivo nos corpos-de-prova, os mesmos foram colocados dentro de um sistema isolado (caixa de isopor), para secagem do adesivo, assim evitando o contato do corpo-de-prova com o meio ambiente, ou seja, com ganho ou perda umidade, Figura 3.18 b.

A preparação do adesivo foi feita parcialmente em pequenas quantidades para garantia de um tempo satisfatório de aplicação.

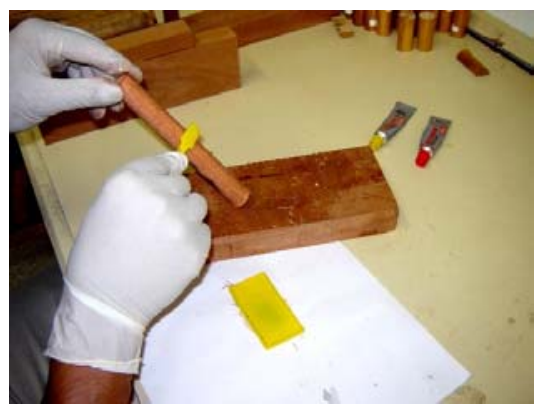

a) Aplicação do adesivo

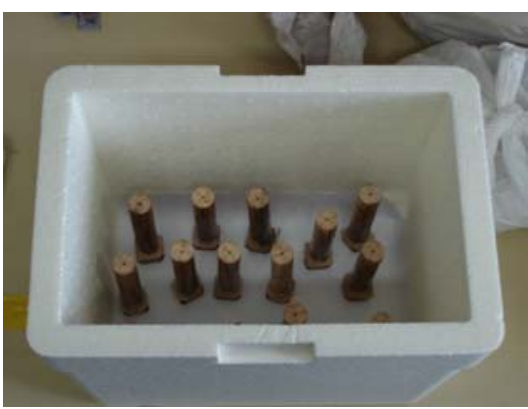

b) secagem do adesivo

Figura 3.18 - Etapas da impermeabilização.

\section{4 - Controle de umidade}

Como descrito na revisão bibliográfica, abaixo do ponto de saturação das fibras, aumentos de umidade geralmente diminuem a permeabilidade da madeira a gases. Sendo assim, adotou-se $12 \%$ como umidade padrão para realização dos ensaios, $\mathrm{U}_{1}=12 \% \pm 2 \%$. 
Após a secagem do adesivo, os corpos-de-prova foram cortados com $50 \mathrm{~mm}$ de comprimento e, posteriormente, levados à estufa, por um período de 16 horas aproximadamente, a $45^{\circ} \mathrm{C}$, para controle de umidade.

Quando a massa correspondente à faixa de umidade esperada foi atingida, os corpos-de-prova foram colocados em sacolas plásticas de polietileno, onde permaneceram por um período de 7 dias para homogeneização da massa de água em seu volume.

\section{5 - Aferição da bomba de vácuo}

Para determinação do fluxo, utilizou-se uma bomba de vácuo DUO-SEAL com manômetro de mola de $760 \mathrm{mmHg}$ acoplado à bomba.

A aferição da bomba de vácuo foi realizada no departamento de Hidráulica e Saneamento, Universidade de São Paulo - USP, São Carlos. Para aferição do equipamento utilizou-se um calibrador de bomba de vácuo, onde se verificou se a leitura do manômetro era equivalente à leitura do calibrador da bomba de vácuo.

O calibrador para bomba de vácuo é constituído de duas colunas (mangueiras) cheias de mercúrio, em uma base de metal, com uma escala graduada em $\mathrm{cm}$, Figura 3.19.

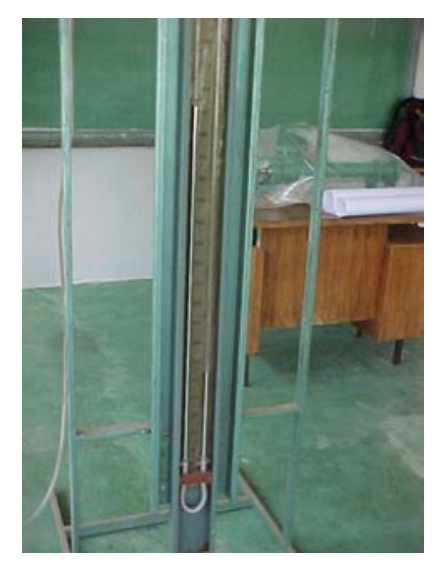

Figura 3.19 - Calibrador de bomba de vácuo.

Quando se promove o vácuo em umas das colunas, há um deslocamento do mercúrio para cima e, conseqüentemente, na outra coluna o mercúrio se desloca para baixo. A diferença em $\mathrm{cm}$ entre o máximo e o mínimo registrado por essas colunas de 
mercúrio é que irá indicar o valor do vácuo produzido pela bomba de vácuo. A coluna de mercúrio que se deslocou para cima apresentou uma leitura máxima de $920 \mathrm{~mm}$, enquanto a coluna que se deslocou para baixo apresentou uma leitura mínima de $260 \mathrm{~mm}$, Figura 3.20 .

Foi constatado que o equipamento se encontrava em perfeitas condições de funcionamento, e que o vácuo registrado pelo calibrador de bomba de vácuo e pelo manômetro de mola da bomba de vácuo eram equivalentes em $660 \mathrm{mmHg}$.
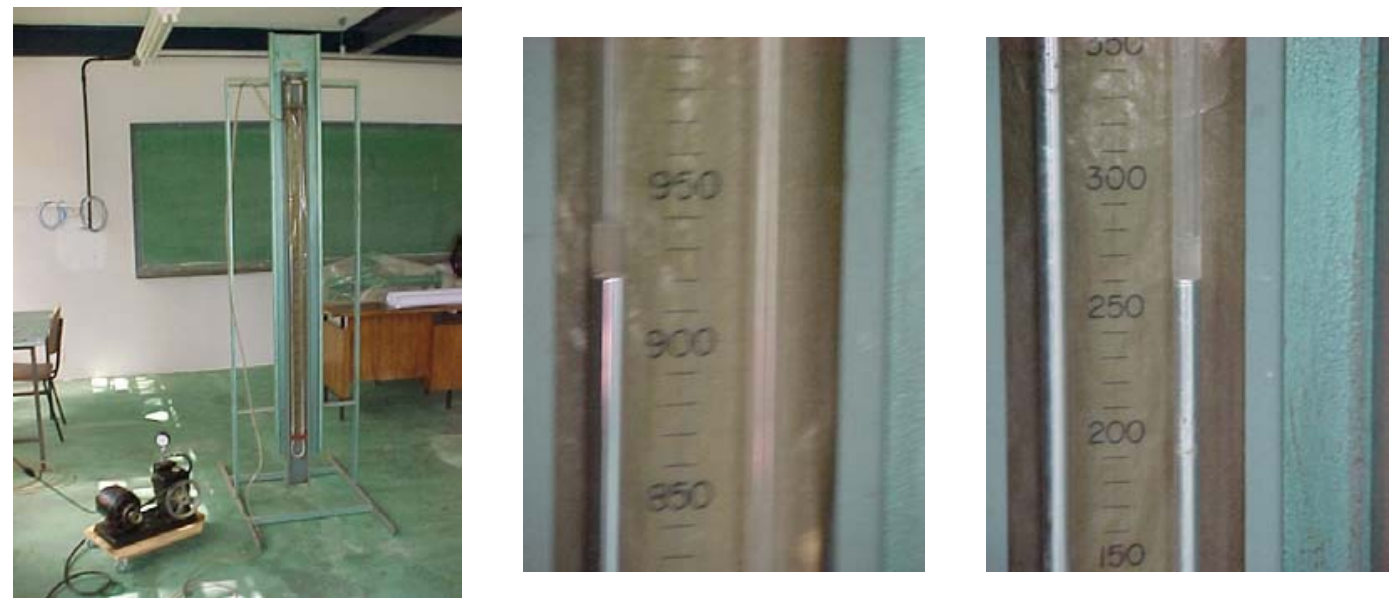

Figura 3.20 - Deslocamento da coluna de mercúrio.

\section{6 - Tipos de fluidos utilizados na determinação da permeabilidade}

Para realização dos ensaios de permeabilidade foram utilizados os seguintes fluidos: ar atmosférico, água destilada e preservativo à base de óleo de Neen.

O preservativo a base de óleo de Neen esta sendo desenvolvido pelo IQSC instituto de Química de São Carlos juntamente com o LaMEM - Laboratório de Madeiras e de Estruturas de Madeira, Machado et al (2006).

O preservativo natural à base de óleo de Neen é obtido através da extração do óleo de Neen por meio de prensagem de suas sementes. O preservativo é uma emulsão de óleo em água. Para se preparar uma emulsão de óleo em água estável é necessária uma terceira fase, constituída por um emulsificante ou tensoativo. Emulsão é uma dispersão, cuja fase dispersa é composta por gotículas de um líquido distribuído num veículo no qual é imiscível. As emulsões que têm fase interna oleosa e fase externa aquosa são conhecidas como emulsões de óleo em água, que podem ser designadas como O/A. A 
emulsão de Neen em água destilada foi obtida com a utilização do tensoativo Reopex B. A preparação dessa emulsão foi necessária porque o óleo de Neen tem caráter apolar, ao passo que o Reopex B se solubiliza em água destilada (caráter polar), e sendo assim o Reopex B favorece o processo de emulsificação. Torna-se, então, possível a administração, numa única mistura de substâncias hidro e lipossolúveis, ou seja, o processo de emulsificação possibilita a preparação de misturas relativamente estáveis e homogêneas de dois líquidos imiscíveis. O processo de emulsificação, com as características físico-químicas do preservativo natural, é descrito por Machado et al (2006).

\section{7 -Microscopia eletrônica de varredura}

No decorrer dos ensaios, constataram-se problemas de fluxo decorrentes do corte dos corpos-de-prova, na dimensão de ensaio $(5 \mathrm{~cm})$, devido que a serra macerava (colapsava) os elementos anatômicos da madeira. Foi necessário desobstruir os elementos anatômicos no topo e na base dos corpos-de-prova, com uma lâmina afiada (estilete), Figura 3.21. Para melhor evidenciar este comportamento dos elementos anatômicos, foi realizada a microscopia eletrônica de varredura - MEV, no IFSC Instituto de Física de São Carlos - Universidade de São Paulo - USP.
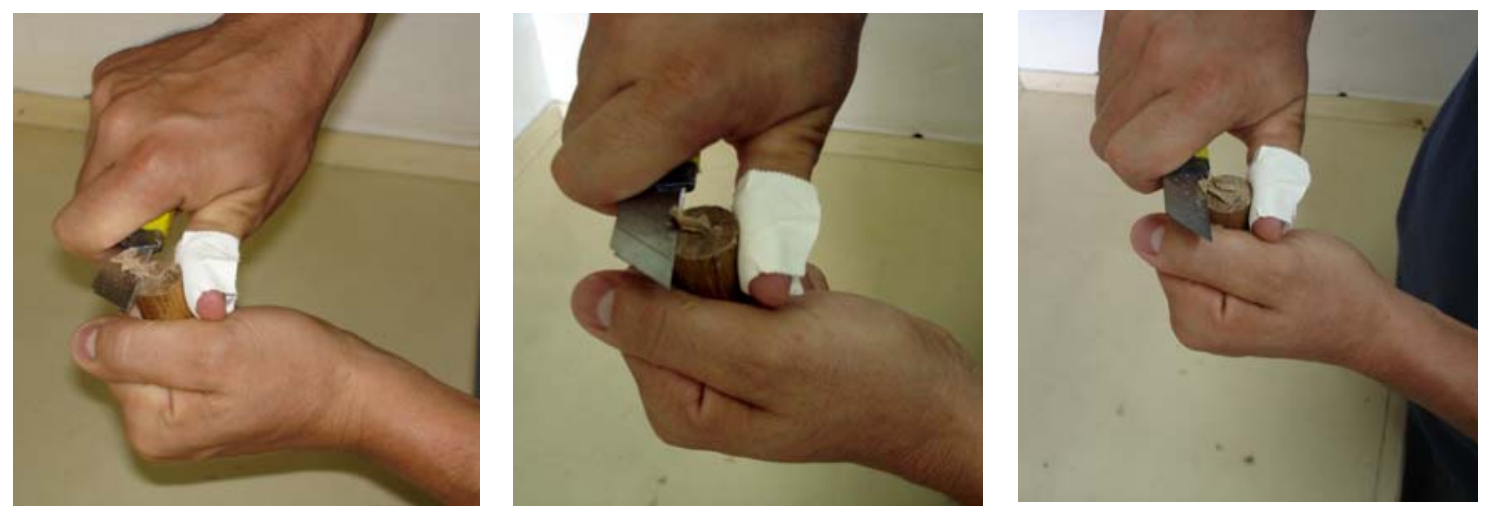

Figura 3.21 - Processo de desobstrução dos elementos anatômicos.

As amostras utilizadas na realização do MEV foram preparadas a partir de corposde-prova prontos para serem medidos quanto ao deslocamento do fluxo. As amostras 
foram retiradas com $20 \mathrm{~mm}$ de diâmetro por de $3 \mathrm{~mm}$ de espessura de corpos-de-prova colapsados e corpos-de-prova desobstruídos, Figura 3.22.

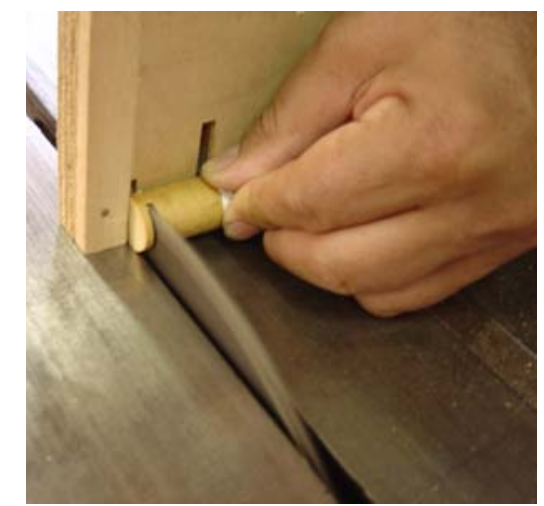

Figura 3.22 - Corte das amostras de Pinus e Eucalyptus para realização do MEV.

As amostras foram colocadas em uma estufa, por um período de 48 horas, a $80^{\circ} \mathrm{C}$, para que ficassem bem secas. Após a secagem, elas foram metalizadas com ouro e, em seguida levadas ao microscópio eletrônico de varredura para análise, Figura 3.23.

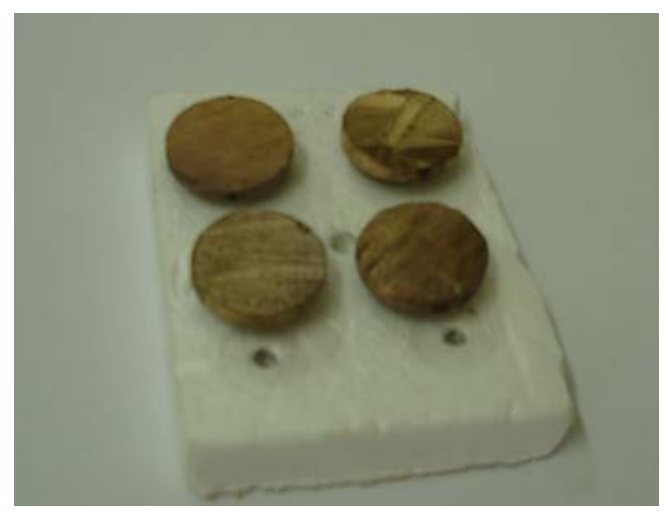

a

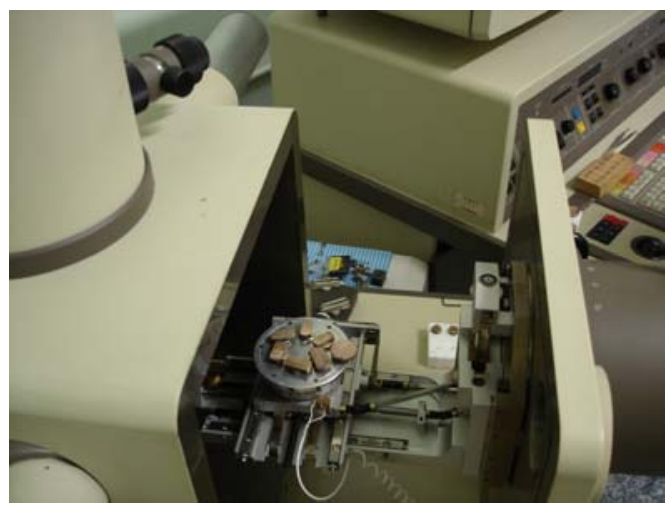

b

Figura 3.23 - Amostras metalizadas com ouro (a). Amostras no microscópio para análise (b).

\section{8 - Análise química da madeira de E. citriodora, E.grandis e Pinus elliotti}

\subsection{1 - Preparação da madeira para análise química.}

A preparação das amostras para análise química foi realizada de acordo com a norma TAPPI T 264 cm-97, no laboratório de Físico-Química do Instituto de Química de São Carlos - IQSC, Universidade de São Paulo - USP. 
Numa primeira etapa, a madeira foi submetida a um processo de moagem, obtendose 10 gramas de amostra com granulometria de 42 mesh, por meio de peneiramento. Este processo foi realizado com o objetivo de promover um maior contato superficial da madeira com os reagentes usados na análise.

$\mathrm{O}$ teor de umidade da madeira foi medido usando uma balança OHAUS modelo MB200, onde aproximadamente $1 \mathrm{~g}$ de madeira é submetido ao aquecimento por 3 horas, a $105^{\circ} \mathrm{C}$. Para análise química da madeira foi necessário trabalhar com as amostras em duplicata.

$5 \mathrm{~g}$ de amostra foram submetidas à extração em solventes organo-solúveis em um extrator tipo Soxhlet, havendo não menos que quatro refluxos por hora, consistindo em três etapas: 1) Extração com $200 \mathrm{ml}$ etanol 95\% por 4 horas, com objetivo de remover os extrativos solúveis neste meio; 2) 1:1 (v/v) partes de ciclo-hexano/etanol, por 8 horas, com objetivo de remover os extrativos organo-solúveis; 3) água em ebulição por 3 horas. A Figura 3.24 ilustra o processo de retirada dos extrativos.

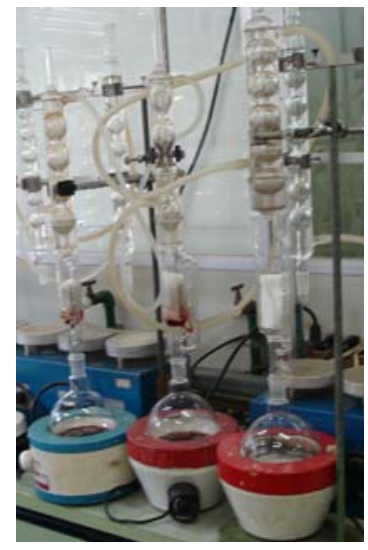

A

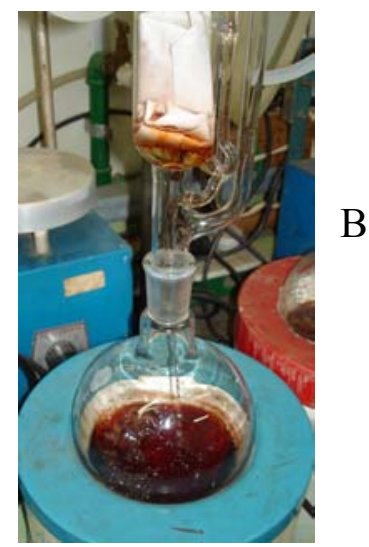

Figura 3.24 - Processo de retirada dos extrativos (A). Ocorrência do refluxo no Soxhlet (B).

Após a extração, a amostra foi lavada com etanol $95 \%$, seca ao ar e, posteriormente, em estufa com temperatura máxima de $60^{\circ} \mathrm{C}$, até obter massa constante. A porcentagem de extrativos é calculada segundo a expressão, em termos de massa seca:

$$
\% \text { Extrativos }=\frac{m_{i}-m_{f}}{m_{i}} .100
$$


onde:

$m_{i}=$ massa inicial;

$m_{f}=$ massa final.

\subsection{2 - Determinação do teor de cinzas.}

Segundo Machado (2000), os teores de cinzas são determinados de acordo com a norma TAPPI T $211 \mathrm{~cm}-85$ com objetivo de se obter a porcentagem de material inorgânico da amostra. Para determinação do teor de cinzas, utilizaram-se cadinhos de porcelana previamente calcinados em mufla a $600^{\circ} \mathrm{C}$, por 3 horas. Após queima, os cadinhos foram resfriados em dessecador. Foi colocado 1,0 g de amostra nos cadinhos que foram levados à mufla, na temperatura de $575^{\circ} \pm 25^{\circ} \mathrm{C}$, por 4 horas. As amostras calcinadas, Figura 3.25, foram colocadas em dessecador para resfriamento. A determinação das massas foi realizada em balança analítica.

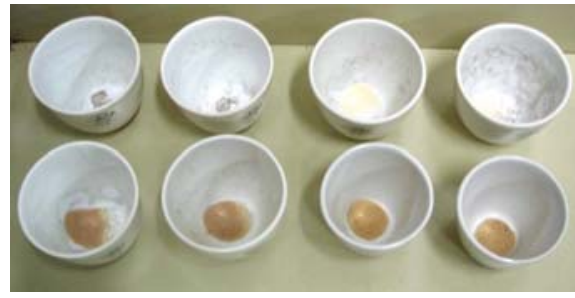

Figura 3.25 - Amostras após calcinação.

O teor de cinzas foi determinado segundo a expressão:

$$
\% C z=\frac{m_{r} \cdot 100}{m}
$$

onde:

$\% C_{z}=$ teor de cinzas $(\%)$;

$m_{r}=$ massa $(\mathrm{g})$ de cinzas;

$m=$ massa $(\mathrm{g})$ de amostra seca antes da queima. 


\subsection{3 - Determinação do teor de lignina}

Os teores de lignina foram determinados pelo somatório dos teores de lignina Klason insolúvel e lignina solúvel.

1) Lignina Klason insolúvel

O teor de lignina Klason insolúvel foi determinado segundo a norma TAPPI T 222 om-98. Pesou-se $1 \mathrm{~g}$ de material pré-extraído, ou seja, livre de extrativos e transferiu-se para um erlenmeyer juntamente com $15 \mathrm{ml}$ de $\mathrm{H}_{2} \mathrm{SO}_{4} 72 \%(\mathrm{~d}=1,631 \mathrm{~g} / \mathrm{ml})$, por 2 horas, sobre agitação magnética. Posteriormente, diluiu-se a solução ácida para $3 \%$, transferindo para um balão de extração com $560 \mathrm{ml}$ de água destilada, totalizando um volume de $575 \mathrm{ml}$ e submeteu-se ao refluxo por 4 horas. Filtrou-se o resíduo em funil de vidro sinterizado de porosidade $10-15 \mathrm{M}$, previamente tarado e foi colocado para secagem em estufa a $105 \pm 3^{\circ} \mathrm{C}$, até massa constante. $\mathrm{O}$ filtrado foi utilizado para determinação do teor de lignina solúvel e de polissacarídeos (celulose e polioses).

O teor de lignina insolúvel foi calculado segundo a expressão:

$$
L i=\frac{m_{r}}{m_{a}} \cdot 100
$$

onde:

$$
\begin{aligned}
& L i=\text { lignina insolúvel na amostra (\%); } \\
& m_{r}=\text { massa de resíduo }(\mathrm{g}), \text { base seca; } \\
& m_{a}=\text { massa da amostra }(\mathrm{g}), \text { base seca. }
\end{aligned}
$$

\section{2) Lignina Klason solúvel}

O filtrado produzido pelo método da lignina Klason insolúvel foi analisado por meio de espectroscopia na região ultravioleta (UV/VIS) conforme Machado (2000). Foi utilizado um espectrofotômetro marca Beckamn, modelo DU-7. As absorbâncias foram medidas em 215 e $280 \mathrm{~nm}$, tomando como referência uma solução de ácido sulfúrico diluído nas mesmas proporções. A concentração de lignina solúvel é calculada segundo a expressão:

$$
L_{s}=\frac{4,53 \cdot A_{215}-A_{280}}{300}
$$


onde:

$L_{s}=$ concentração em $\mathrm{g} / \mathrm{L}$ de lignina solúvel;

$A_{215}=$ valor de absorbância em $215 \mathrm{~nm}$;

$A_{280}=$ valor de absorbância em $280 \mathrm{~nm}$.

Essa equação foi obtida utilizando-se os valores da absortividade da lignina de madeira e a absortividade dos produtos obtidos da degradação de glicídios, tais como glicose, xilose, manose e glicuranolactona, presentes no filtrado. A partir dessas informações e utilizando a lei de Lambert-Beer, as seguintes equações podem ser escritas:

$$
\begin{aligned}
& A_{280}=0,68 \mathrm{Gs}+18 \mathrm{Ls} \\
& A_{215}=0,15 \mathrm{Gs}+70 \mathrm{Ls}
\end{aligned}
$$

Onde a $A_{280}$ e $A_{215}$ são os valores de absorbância da solução; 0,68 e 0,15, as absortividades dos produtos oriundos da degradação dos glicídios; 18 e 70, as absortividades da lignina em 215 e $280 \mathrm{~nm}$ segundo Machado (2000). Respectivamente, Gs e Ls são as concentrações em g/L dos produtos da degradação dos glicídios (Gs) e da lignina solúvel (Ls) no filtrado. Resolvendo as equações obtém-se a expressão de concentração de lignina solúvel em g/L no filtrado, equação 19.

Realizando a conversão de unidades de g/L para \%, tem-se a equação:

$$
\% L s=\left(\frac{L_{s} \cdot V \cdot d i l}{P S}\right) .100
$$

onde:

$\% L s=$ porcentagem de lignina solúvel;

$L_{s}=$ lignina solúvel $(\mathrm{g} / \mathrm{L})$;

$V=$ volume final (L);

$d i l=$ diluição em ácido $3: 1(\mathrm{v} / \mathrm{v})$;

$P S=$ peso $\operatorname{seco}(\mathrm{g})$ 


\subsection{4 - Determinação do teor de holocelulose - celulose e polioses}

O filtrado produzido pelo método de lignina Klason insolúvel foi utilizado para a determinação do teor de holocelulose, celulose e polioses, através de análises por cromatografia líquida de alta eficiência (CLAE). Uma pequena amostra da solução foi filtrada em membrana "Sep Pak $\mathrm{C}_{18}$ ' e, em seguida, analisada quanto aos teores de celobiose, glicose, xilose, arabinose, ácido acético e ácido fórmico por CLAE, num cromatógrafo líquido marca Shimadzu modelo LC-10, acoplado a um registrador Shimadzu modelo C-R7A, com detector de índice de refração modelo RID-6A, detector de UV/VIS modelo SPD-10AV, forno modelo CTO-10A, usando uma coluna Aminex HPX-87H BIO-RAD. A fase móvel foi $\mathrm{H}_{2} \mathrm{SO}_{4} 0,005 \mathrm{~mol} / \mathrm{L}$ com fluxo de $0,6 \mathrm{ml} / \mathrm{min}$, a $45^{\circ} \mathrm{C}$ segundo Machado (2000).

As concentrações de celobiose e glicose foram convertidas em celulose, as de xilose e arabinose convertidas em hemicelulose e a de ácido acético convertida em grupos acetila. As massas foram divididas pelo peso seco do material inicial e multiplicado pelo fator de hidrólise que foi obtido através de uma relação matemática de massa molar, dentro das relações estequiométricas das equações de hidrólise dos açúcares na biomassa. Os fatores de conversão de glicose e celobiose para celulose são de 0,90 e 0,95 , respectivamente. De maneira similar, xilose e arabinose foram convertidas a hemicelulose, usando-se o fator de 0,88 . O fator de conversão do ácido acético a grupo acetila é 0,72 .

\section{9 - Caracterização simplificada}

Para espécies de madeira usuais, pode-se fazer a classificação simplificada com base nos ensaios de compressão paralela às fibras, de acordo com Calil et al (2003).

A realização dos ensaios de caracterização simplificada, umidade e densidade foram realizadas de acordo com a NBR 7190/97.

A determinação da porosidade foi realizada de acordo com Siau (1971), segundo a equação: $\mathrm{V}_{\mathrm{a}}=1-\mathrm{G}\left(0,685+0,01 \mathrm{M} / \mathrm{G}_{\mathrm{S}}\right)$.

$\mathrm{Na}$ caracterização simplificada foram utilizados seis corpos-de-prova prismáticos isentos de defeito, com seção transversal de $5 \mathrm{~cm}$ e comprimento de $15 \mathrm{~cm}$, com umidade 
de $12 \%$ e velocidade constante de carregamento $10 \mathrm{MPa} / \mathrm{min}$, ou seja, aproximadamente $42 \mathrm{kgf} / \mathrm{seg}$.

Para determinação da umidade e massa específica foram utilizados três corpos-deprova prismáticos isentos de defeito com seção nominal de 2,0 x 3,0 x 5,0 cm

Na realização dos ensaios mecânicos utilizou-se a Máquina Universal AMSLER, com capacidade para $250 \mathrm{KN}$, Figura 3.26 a, para corpos-de-prova com seção nominal de 5 x $15 \mathrm{~cm}$ e a Máquina Universal Dartec com capacidade para $100 \mathrm{KN}$, Figura 3.26 b, para corpos-de-prova com seção nominal de $3 \times 9 \mathrm{~cm}$, provenientes do alburno. Ambas se encontram nas dependências do LaMEM (Laboratório de Madeiras e de Estruturas de madeira), USP - Universidade de São Paulo.

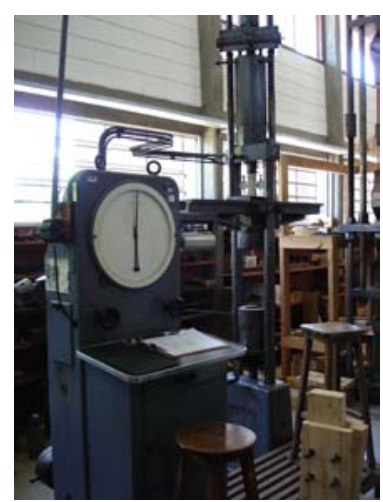

a

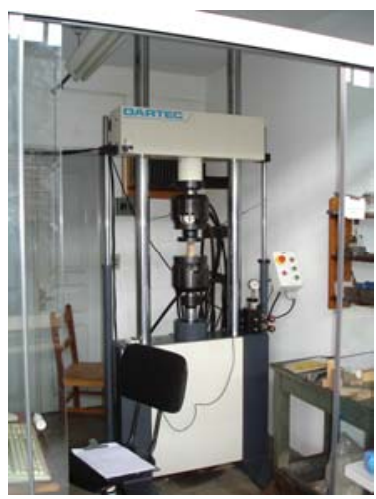

b

Figura 3.26 - Máquina universal de ensaio AMSLER (a) e DARTEC (b)

\subsection{0 - Metodologia}

Visto que não se encontrou nenhuma norma na literatura brasileira ou internacional para execução dos ensaios de permeabilidade, a definição do tipo de adesivo, do formato e das dimensões dos corpos-de-prova e a metodologia para execução dos ensaios foram feitos com base nas informações obtidas na revisão bibliográfica.

A seqüência de execução dos ensaios de permeabilidade foi o seguinte:

$\left.1^{\circ}\right)$ Ensaio de permeabilidade a gás (ar atmosférico).

$2^{\circ}$ ) Ensaio de permeabilidade a líquido (água destilada e preservativo à base de óleo de Neen). 


\subsection{1 - Amostra a ser ensaiada}

A determinação do número de corpos-de-prova utilizados para realização dos ensaios, tanto a gás como a lìquido foi feita com base em um planejamento fatorial.

No planejamento fatorial, todas as combinações possíveis dos níveis dos fatores são testadas. Fator é a variável a ser investigada para determinação do seu efeito sobre a resposta, enquanto que níveis correspondem aos valores especificados dos fatores.

Devido à dificuldade de obtenção de uma umidade pontual fixa para os corpos-deprova de madeira, foi considerada uma faixa de umidade: U1. Essa faixa corresponde ao seguinte intervalo: $\mathrm{U} 1=12 \% \pm 2 \%$.

O vácuo utilizado atinge um máximo de $660 \mathrm{mmHg}$ e este não sofre alteração pois, quanto maior for o vácuo, mais significativos serão os resultados.

$\mathrm{Na}$ espécie Eucalyptus foi verificada a permeabilidade tanto do alburno como também do cerne, onde se considerou, para este caso, duas das direções ortogonais com relação às fibras da madeira: transversal e longitudinal.

Assim, no planejamento fatorial, o cerne e o alburno correspondem aos dois fatores a serem investigados com dois níveis cada: direções transversal e longitudinal.

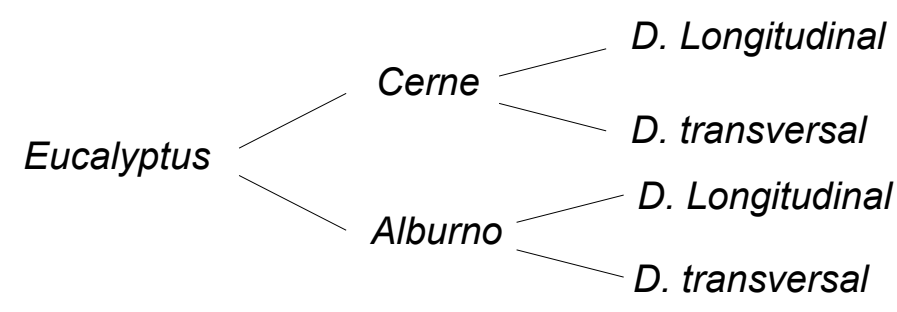

Figura 3.27 - Combinações de teste para realização dos ensaios.

Para cada combinação de deslocamento de fluido foram consideradas de dez a vinte replicações, sendo que as replicações dependem da disponibilidade de madeira. Nestas condições, se houver vinte replicações, haverá oitenta corpos-de-prova para cada espécie de madeira de Eucalyptus.

Na espécie de Pinus, considerou-se, para este caso, duas das direções ortogonais com relação às fibras da madeira: transversal e longitudinal.

Assim, no planejamento fatorial, para a madeira de Pinus corresponde a um fator a ser investigado com dois níveis cada: direções transversal e longitudinal. 
Pinus

\section{Longitudinal}

D. transversal

Figura 3.28 - Combinações de teste para realização dos ensaios.

Para cada combinação de deslocamento de fluido foram consideradas de dez a vinte replicações dependendo da disponibilidade de madeira. Nestas condições, se tivermos vinte replicações, totalizaremos quarenta corpos-de-prova para o Pinus.

\subsection{2 - Descrição metodológica dos ensaios para fluxo gasoso}

A realização dos ensaios para fluxo gasoso se procedeu da seguinte maneira: inicialmente se montou o corpo-de-prova no conjunto de rolhas, como descrito na página 40, Figura 3.7. Em seguida, colocou-se o conjunto de rolhas por cima da junta cônica e aplicou-se o vácuo para registro do fluxo através do corpo-de-prova. Foram registrados os valores do fluxo e, após a realização do ensaio, o sistema foi desmontado e montado novamente para verificar se, na repetição do ensaio com o mesmo corpo-de-prova, os valores obtidos eram equivalentes.

Os corpos-de-prova foram ensaiados na mesma direção e em sentido oposto. Observou-se, na mesma direção, uma alta variabilidade na repetição dos ensaios no mesmo corpo-de-prova da ordem de 50 a $300 \%$ e em relação à direção oposta uma variabilidade um pouco menor, mas da ordem de 30 a 97\%. Essa variabilidade foi mais acentuada em ensaios onde os corpos-de-prova apresentavam baixo fluxo. $\mathrm{O}$ tempo inicial previsto para registro do fluxo foi de 5 minutos, onde se constatou uma pequena variabilidade do fluxo em função do tempo, da ordem de $2 \%$ aproximadamente.

Como não existe uma metodologia normatizada para este tipo de ensaio, resolveuse o problema com base nos ensaios preliminares e, após inúmeras tentativas, a solução encontrada foi parar de trabalhar com a junta cônica e utilizar uma mangueira cristal de $20 \mathrm{~mm}$ de diâmetro por $25 \mathrm{~cm}$ de comprimento, com espigão $\mathrm{Fg} 1 / 2 \times 1 / 4$.

Procedeu-se da seguinte maneira: a montagem do conjunto de rolhas continuou a mesma descrita na página 40, mas ao invés de ligar-se a mangueira de silicone de vácuo à junta cônica, ela foi ligada na rolha de teflon com oliva. No corpo-de-prova foi 
introduzida uma das extremidades da mangueira cristal e, na outra extremidade, colocou-se o espigão $\mathrm{Fg} 1 / 2 \times 1 / 4$, onde se ligou a mangueira de silicone que estava ligada ao fluxômetro, Figura 3.29. Sendo assim, o sistema não trabalhava mais no sentido de expulsar a rolha de borracha que fixa o corpo-de-prova e sim no sentido de compressão.

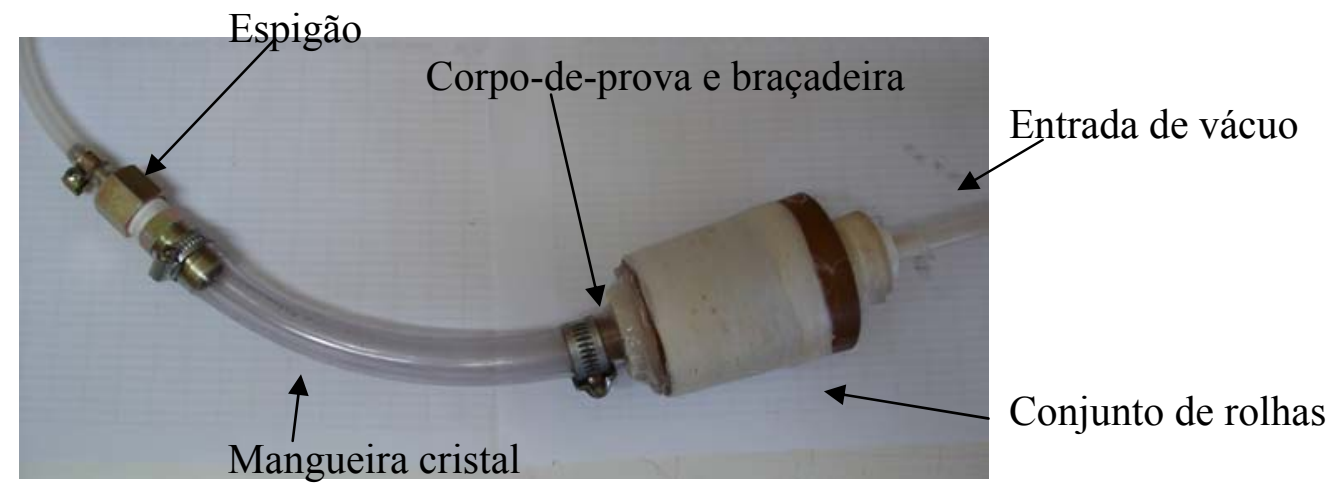

Figura 3.29 - Adaptação para determinação do fluxo.

Antes de introduzir a mangueira no corpo-de-prova, passou-se cola quente próximo à rolha de borracha, Figura 3.30 (1). Após a mangueira ser introduzida no corpo-de-prova, com a cola ainda quente, foi colocada uma braçadeira por cima da mangueira de cristal, Figura 3.30 (2) e, por fim, utilizou-se cola quente ao redor das rolhas de borracha e da rolha de resina de mamona, Figura 3.30 (3). Todas essas medidas foram realizadas com o intuito de se evitar ao máximo qualquer tipo de vazamento.

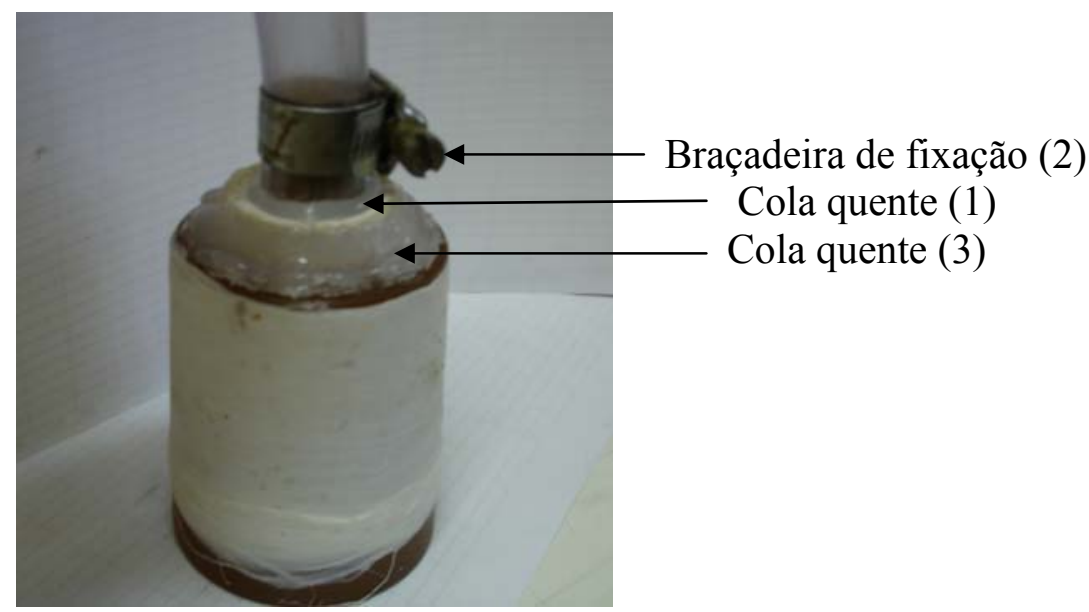

Figura 3.30 - Vedação do corpo-de-prova e da rolha evitando vazamento. 
Após todos esses cuidados, os resultados obtidos na repetição dos ensaios para a mesma direção, na determinação do fluxo gasoso, foram satisfatórios e os ensaios puderam ser concluídos. Em relação ao tempo para registro do fluxo, observou-se que 5 minutos era muito tempo. Como após a estabilização dos ensaios não houve mais nenhum registro de diferença do fluxo em função do tempo, considerou-se somente a leitura por 2 minutos.

Depois de serem estabelecidos os valores exatos de fluxo para os corpos-de-prova, retornou-se à montagem inicial do sistema para resolver o problema de vazamento, sendo resolvido com o uso de fita teflon, vaselina e cola quente. A cola foi aplicada com movimento retilíneo, ou seja, desde a base da rolha de borracha até próximo do topo do corpo-de-prova a fim de se obter uma maior área de contato de superfície entre o corpode-prova e a rolha de borracha, Figura 3.31 a, e entre a rolha de borracha e a rolha de resina de mamona. Foi necessário esperar a cola resfriar bem para que a mesma não se desprendesse, Figura 3.31 b. Para acelerar o processo de resfriamento da cola quente, joga-se água fria na cola quente, evitando que o topo do corpo-de-prova seja molhado. A fita teflon foi aplicada em quatro camadas ou mais ao redor da rolha de resina de mamona. As camadas de fita foram distribuídas uniformemente e, após sua distribuição, passou-se bastante vaselina a fim de evitar que a rolha de resina de mamona se fixasse (se prendesse) na junta cônica. Se ocorrer esta fixação da junta cônica e da rolha de resina de mamona, recomenda-se colocar todo o conjunto dentro de freezer por aproximadamente 30 minutos, pois como a rolha de resina de mamona e o vidro da junta cônica apresentam coeficiente de dilatação diferente, elas se desprenderão naturalmente.

Após estas medidas o dispositivo inicial registrou os mesmos valores de deslocamento de fluxo comparado com o sistema utilizando a mangueira cristal. 


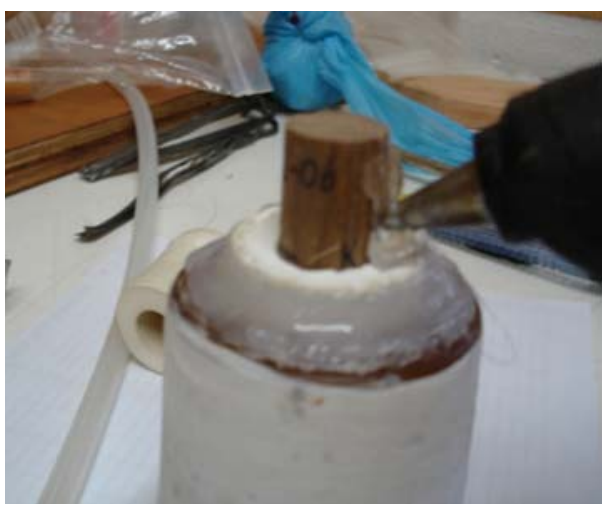

a

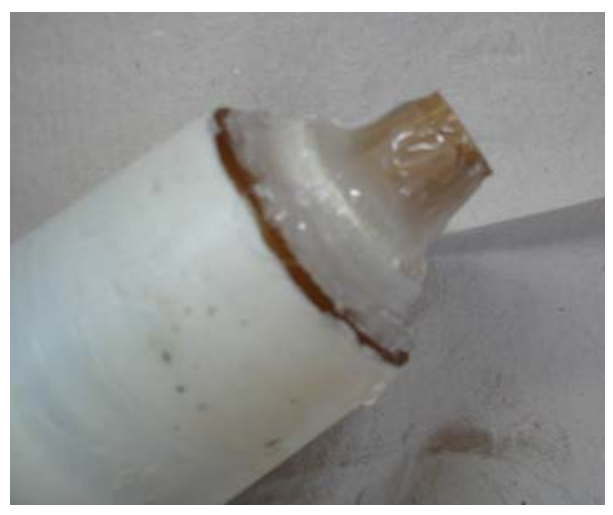

b

Figura 3.31 - Cola quente aplicada até próximo ao topo do corpo-de-prova (a). Em (b), amostra pronta a ser ensaiada.

\subsection{3 - Descrição metodológica dos ensaios para fluxo líquido.}

$\mathrm{O}$ tempo que uma quantidade conhecida de fluido líquido demora para percolar o corpo-de-prova foi registrado com o auxílio de um cronômetro digital.

Para fixação dos corpos-de-prova, procedeu-se como descrito para os ensaios gasosos, Figura 3.31. Após fixação dos corpos-de-prova, trocou-se a rolha de teflon com a oliva pela rolha de teflon com orifício central, Figura $3.12 \mathrm{c}$. Para evitar vazamento na ponta da bureta, utilizou-se uma fina camada de fita teflon. A bureta foi fixada por uma pinça universal para minimizar o risco de quebrar, figura 3.11.

Posteriormente encheu-se a bureta com fluido desejado e abriu-se um pouco a torneira da bureta, para que o corpo-de-prova fique cheio do fluido. Rapidamente completou-se a bureta com o fluido analisado e então abriu-se novamente a torneira. Quando o menisco do fluxo passou pela escala graduada na marca de $20 \mathrm{ml}$, iniciou-se o registro do tempo e quando o menisco do fluxo passou pela escala graduada na marca de $50 \mathrm{ml}$, cessou o registro do tempo. Este procedimento só é valido para corpos-de-prova de alta vazão e desde que realizado com a bureta de $50 \mathrm{ml}$.

É importante ser ágil no momento em que se completa a bureta, pois a madeira é um material hidrófilo.

Para madeiras de menor vazão, não é necessário utilizar o procedimento descrito acima, basta colocar aproximadamente $10 \mathrm{ml}$ a mais de fluido em relação a um ponto desejado na bureta e abrir a torneira. Inicialmente o fluido líquido desce rapidamente, devido ao ar atravessar a madeira com facilidade; quando o fluido líquido chega no 
corpo-de-prova, por ele ser incompressível, estabiliza-se o deslocamento do fluxo. Para registro do tempo, espera-se o fluido percolar todo o corpo-de-prova e somente após é iniciado o registro do tempo, ou seja, quando o fluxo está estabilizado através do corpode-prova.

O cerne do Eucalyptus grandis apresenta uma baixa vazão e, por este motivo, a quantidade de líquido que percolou o corpo-de-prova para registro do tempo foi de $0,5 \mathrm{ml}$. Somente após o fluido ter cruzado todo o corpo-de-prova é que se iniciou o registro do tempo

\subsection{1 - Análise estatística dos resultados}

Para análise estatística dos resultados, empregou-se a metodologia a seguir.

Consideram-se os valores de permeabilidade para cada tipo de fluido na direção longitudinal ou radial às fibras, como populações. Estas são independentes (nãocorrelatas), pois são obtidas a partir de ensaios de corpos-de-prova diferentes, para cada tipo de solicitação.

Análises prévias dos valores de cada espécie, e também em conjunto, não demonstraram normalidade ou homogeneidade de variância. Desta forma, escolheu-se a prova não-paramétrica de Kruskal-Wallis ao invés da correspondente prova paramétrica F (análise de variância paramétrica). Sua finalidade é averiguar se $\mathrm{k}$ amostras independentes são provenientes de uma mesma população ou de populações idênticas, ou provêm de populações distintas, de acordo com Campos (1979), onde k é um número inteiro maior ou igual a 2.

Segundo Morales (2002), cada uma das n observações é substituída por um posto, isto é, todos os escores de todas as $\mathrm{k}$ amostras combinadas são dispostos em uma única série de postos. Ao menor valor de permeabilidade atribui-se o posto 1, ao seguinte o posto 2, e assim sucessivamente até o n-ésimo posto. A seguir, calcula-se a soma dos postos em cada uma das amostras. A prova de Kruskal-Wallis verifica se estas somas são tão díspares que não seja provável se refiram elas a amostras extraídas da mesma população. 
Utiliza-se a estatística $H$ definida pela expressão 23 , que tem distribuição quiquadrado com K-1 graus de liberdade, desde que o tamanho das amostras não seja muito pequeno.

$$
H=\frac{12}{N(N+1)} \sum_{j=1}^{K} \frac{R_{j}^{2}}{n_{j}}-3(N+1)
$$

onde:

$\mathrm{k}=$ número de amostras;

$\mathrm{n}_{\mathrm{j}}=$ número de casos das amostras $\mathrm{j}$;

$\mathrm{N}=\sum n_{j}$

$\mathrm{R}_{\mathrm{j}}=$ soma dos postos na amostra (coluna) $\mathrm{j}$;

$\sum_{j=1}^{K}=$ somatório entre todas as $\mathrm{k}$ amostras (colunas).

Fixa-se um nível de confiança $\alpha$ e calcula-se a probabilidade ${ }^{\sum_{j=1}^{K}} \mathrm{p}$ associada ao grau de liberdade $(\mathrm{gl}) \mathrm{K}-1$ e a estatística calculada $\mathrm{H}$. A hipótese de nulidade $\mathrm{H}_{0}$ é rejeitada se o valor de $\mathrm{p}$ for inferior ao valor de $\alpha$.

Neste estudo foram considerados $\mathrm{N}=316, \mathrm{k}=4, \mathrm{gl}=3$ e foi adotado $\alpha=0,05$.

Assim, adotando o valor de $\alpha=0,05$, se $\mathrm{p}$ for menor que 0,05 , rejeita-se $\mathrm{H}_{0}$ e os valores de permeabilidade nos ensaios a gás e líquido não podem ser considerados estatisticamente equivalentes. Se $\mathrm{p}$ for maior que 0,05 , aceitamos $\mathrm{H}_{0}$ e os valores de permeabilidade a gás e líquido podem ser considerados estatisticamente equivalentes.

Quando, neste método não-paramétrico rejeita-se a hipótese nula $\mathrm{H}_{0}: \mathrm{t}_{1}=\mathrm{t}_{2}=\ldots=$ $t_{k}$, então se conclui que pelo menos dois dos tratamentos considerados diferem entre si. Utiliza-se, então, o método de comparações múltiplas (método de Dunn), que tem como finalidade localizar, quando existem, as diferenças significativas entre os pares de tratamentos e é um complemento ao método não-paramétrico de Kruskal-Wallis, segundo Campos (1979). 
Utilizam-se comparações envolvendo todos os pares de tratamentos, para grandes amostras, segundo Campos (1979).

Primeiro, para cada par i e $\mathrm{j}$ de tratamentos, são calculados os valores de $R_{i}$ e $R_{j}$, que representam as somas dos postos atribuídos a estes tratamentos, na classificação das $\mathrm{N}$ observações referentes aos $\mathrm{k}$ tratamentos. Depois são calculados os valores de $\bar{R}_{i}=\frac{R_{i}}{n_{i}}$ e $\bar{R}_{j}=\frac{R_{j}}{n_{j}}$, onde $\mathrm{n}_{\mathrm{i}}$ e $\mathrm{n}_{\mathrm{j}}$ são os números de repetições dos tratamentos $\mathrm{i}$ e $\mathrm{j}$ respectivamente. Determinam-se as diferenças $\left.\right|^{\overline{R_{i}}-\overline{R_{j}}} \mid$ e compara-se com a d.m.s. (diferença mínima significativa), calculada pela expressão 24:

$$
\text { d.m.s. }=Q \sqrt{\frac{K .(N+1)}{12}}
$$

A diferença em módulo maior que o valor de d.m.s. indica que os $\mathrm{t}_{\mathrm{i}}$ e $\mathrm{t}_{\mathrm{j}}$ são não equivalentes. Os valores de Q estão apresentados na Tabela 1C, no apêndice.

Para amostras grandes, os valores de Q podem ser aproximados por valores z da tabela normal, expressão 25:

$$
\left.d . m . s=z_{\propto /[k(k-1)]} \sqrt{\frac{N(N+1)}{12}\left(\frac{1}{n_{i}}\right.}+\frac{1}{n_{j}}\right)
$$

onde ${ }_{\propto /[k(k-1)]}$ é um limite superior da distribuição normal, $\left(\mathrm{z}_{\text {crítico }}\right)$. 


\section{RESULTADOS E DISCUSSÕES}

Neste capítulo são apresentados e discutidos os resultados do registro do fluxo para o equipamento fabricado e a metodologia estatística, entre outros.

Quando o corpo-de-prova não apresentou vazão nos ensaios de permeabilidade, foi utilizado o símbolo $(* *)$ e quando não houve possibilidade de fabricação do corpo-deprova por indisponibilidade de madeira, utilizamos o símbolo (*).

\section{1 - Microscopia eletrônica de varredura}

Os elementos anatômicos, quando obstruídos, prejudicam severamente a permeabilidade e com o MEV foi possível ver como se comportam os elementos anatômicos antes e após desobstrução. Na microscopia utilizou-se um aumento de 20 a 100 vezes.

A Tabela 1 apresenta a diferença da permeabilidade a gás em $\mathrm{cm}^{3} / \mathrm{cm}$.atm.seg antes e após a desobstrução dos elementos anatômicos e o quanto a permeabilidade aumentou em porcentagem após desobstrução dos elementos anatômicos.

Tabela 1 - Aumento da permeabilidade em porcentagem para fluxo gasoso após desobstrução dos elementos anatômicos.

\begin{tabular}{|c|c|c|c|}
\hline \multirow{2}{*}{ Amostra } & $\mu$ do fluxo obstruído & $\mu$ do fluxo desobstruído & \multirow{2}{*}{$\begin{array}{c}\text { \% do aumento da } \\
\text { permeabilidade }\end{array}$} \\
\cline { 2 - 4 } & $\mathrm{K}=\mathrm{cm}^{3} / \mathrm{cm}$. atm.seg & $\mathrm{K}=\mathrm{cm}^{3} / \mathrm{cm} . \mathrm{atm} . \mathrm{seg}$ & $71.00 \%$ \\
\hline CAL & 352.55 & 602.69 & $53.15 \%$ \\
\hline GAL & 453.75 & 694.91 & $21.23 \%$ \\
\hline GCL & 20.07 & 24.33 & $4.53 \%$ \\
\hline PL & 141.88 & 148.31 & - \\
\hline PT & 24.57 & 24.65 & \\
\hline
\end{tabular}

As espécies de madeira nas suas respectivas direções ortogonais, que não se encontram descritas nesta tabela, apresentaram permeabilidade nula tanto para os elementos anatômicos colapsados quanto para os elementos anatômicos desobstruídos pelo estilete. A desobstrução dos elementos anatômicos se mostrou altamente significativa na direção longitudinal às fibras para o alburno de Eucalyptus citriodora e 
alburno de Eucalyptus grandis, e em menor intensidade para o Pinus elliottii. Na direção transversal às fibras, a permeabilidade não se mostrou afetada pela obstrução dos elementos anatômicos para o Pinus elliottii.

A seguir serão apresentadas as fotos do MEV para todas as espécies e direções ortogonais estudadas neste trabalho, sendo:

- $\mathrm{CAL}=$ Eucalyptus citriodora alburno longitudinal;

- CAT = Eucalyptus citriodora alburno transversal;

- CCL = Eucalyptus citriodora cerne longitudinal;

- CCT = Eucalyptus citriodora cerne transversal;

- GAL = Eucalyptus grandis alburno longitudinal;

- GAT = Eucalyptus grandis alburno transversal;

- GCL = Eucalyptus grandis cerne longitudinal;

- GCT = Eucalyptus grandis cerne transversal;

- PL = Pinus elliottii longitudinal;

- PT = Pinus elliottii transversal.

A barra abaixo, no canto direito das fotos do MEV, indica o comprimento de $500 \mu \mathrm{m}$, para fotos com aumento de vinte vezes; de $203 \mu \mathrm{m}$, para fotos com aumento de cinqüenta vezes; e de $101 \mu \mathrm{m}$, para fotos com aumento de cem vezes.
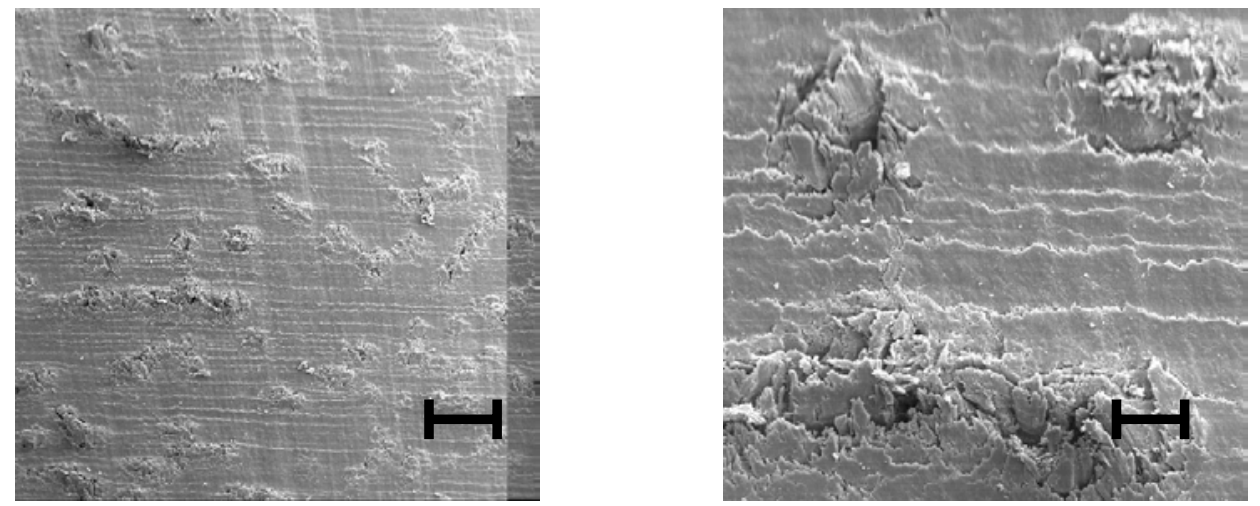

Figura 4.1 - Corte transversal do CAL com os elementos anatômicos obstruídos, com aumento de vinte e cem vezes.

Observa-se na Figura 4.1 os elementos anatômicos do CAL obstruídos pela serra que dividiu os corpos-de-prova no seu comprimento final, pois a serra consegue macerar 
e forçar o pó de serra para dentro dos elementos anatômicos. O mesmo ocorre nas Figuras 4.3, 4.5, 4.7, 4.9, 4.11, 4.13, 4.16, 4.18 e 4.20.
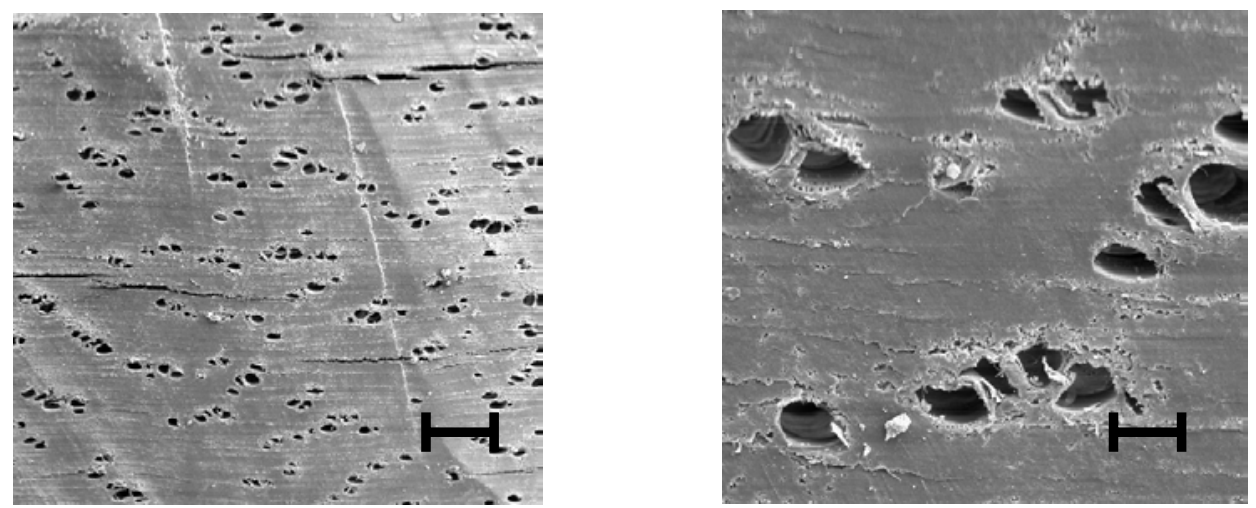

Figura 4.2 - Corte transversal do CAL com os elementos anatômicos desobstruídos, com aumento de vinte e cem vezes.

Para a Figura 4.2, os vasos no CAL estão desobstruídos pelo estilete, mas não é possível observar a desobstrução do parênquima longitudinal e das fibras, apesar de eles apresentarem uma importância bem menor em relação ao deslocamento de fluidos. A mesmo conclusão é obtida para a Figura 4.10. As fotos apresentadas na Figura 4.2 e Figura 4.6 contêm trincas, mas estas ocorreram devido a secagem da amostra para a realização da MEV.
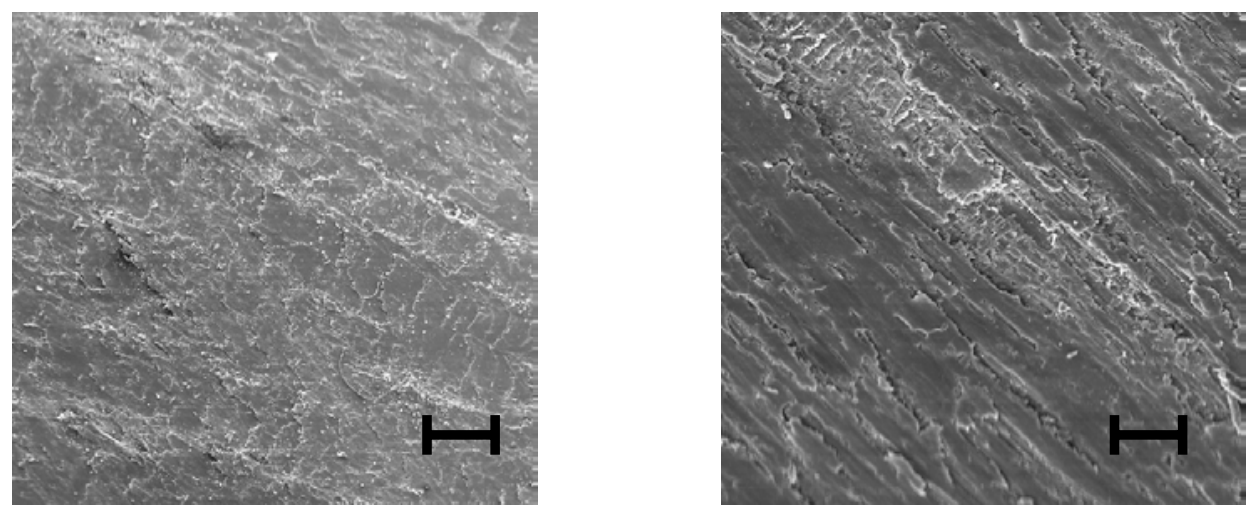

Figura 4.3 - Corte radial do CAT com elementos anatômicos obstruídos, com aumento de vinte e cem vezes.

Na Figura 4.4 e Figura 4.12, não é possível observar os raios na direção radial; são encontrados apenas vasos longitudinais abertos ao meio. 

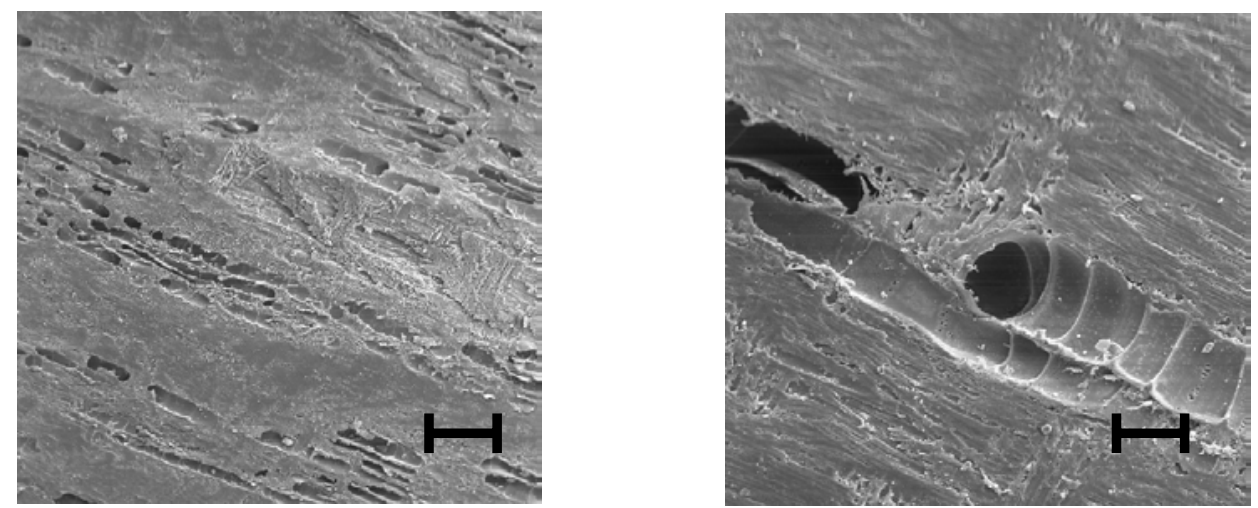

Figura 4.4 - Corte radial do CAT com elementos anatômicos desobstruídos, com aumento de vinte e cem vezes.

A Figura 4.5 e Figura 4.6 apresentam riscos com diferentes sentidos e intensidade. Isto se deve ao fato de que, no momento da desobstrução dos corpos-de-prova, não era possível fazer um corte único com o estilete, e com isto, acabou sendo realizados vários cortes na amostra e, com maior intensidade, em madeiras de alta densidade.
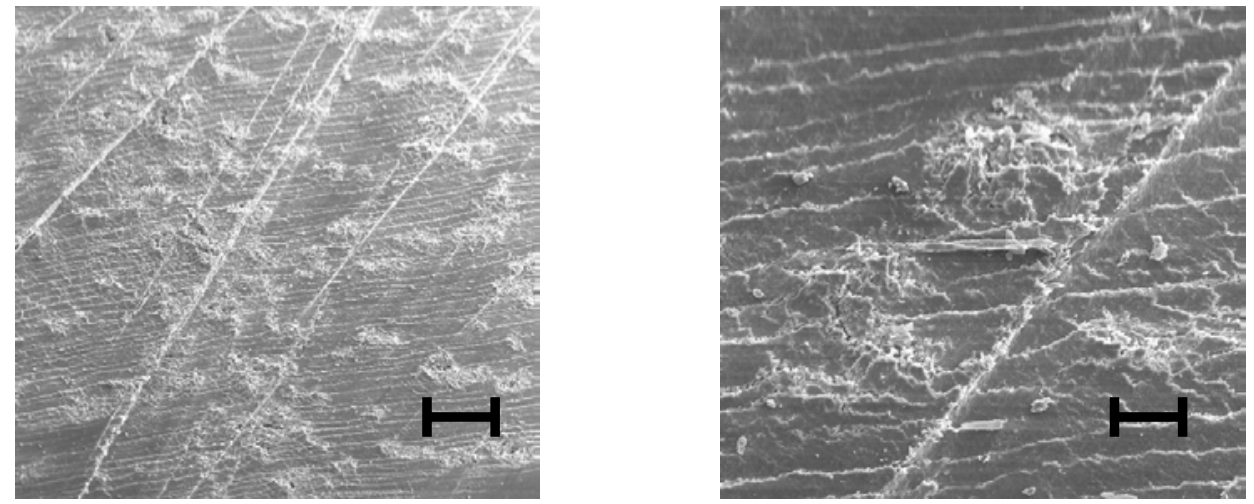

Figura 4.5 - Corte transversal do CCL com os elementos anatômicos obstruídos, com aumento de vinte e cem vezes.

Na Figura 4.6, é possível observar que mesmo após ter sido passado o estilete para desobstruir os vasos, os mesmos se encontram obstruídos, pois o cerne está obstruído por tiloses, que prejudicam a permeabilidade e, dependendo da sua intensidade, podem até tornar a mesma nula. 

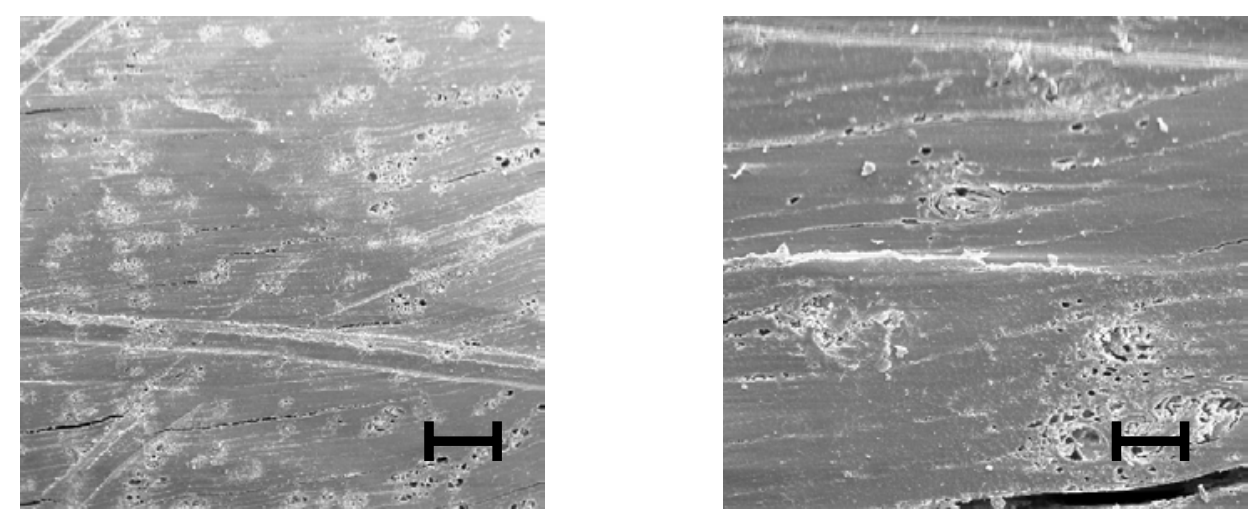

Figura 4.6 - Corte transversal do CCL com os elementos anatômicos desobstruídos, com aumento de vinte e cem vezes.
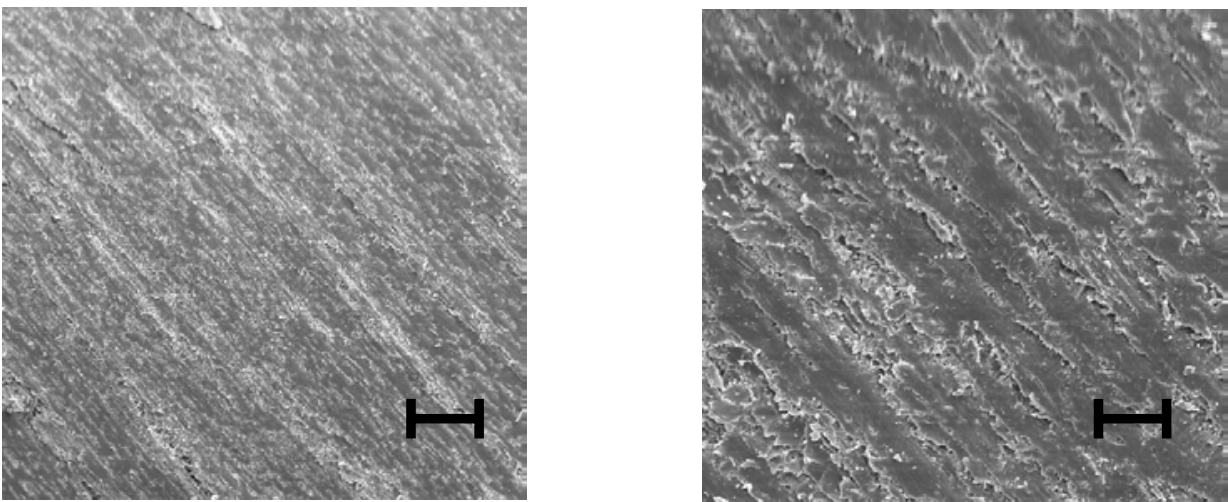

Figura 4.7 - Corte radial do CCT com os elementos anatômicos obstruídos, com aumento de vinte e cem vezes.
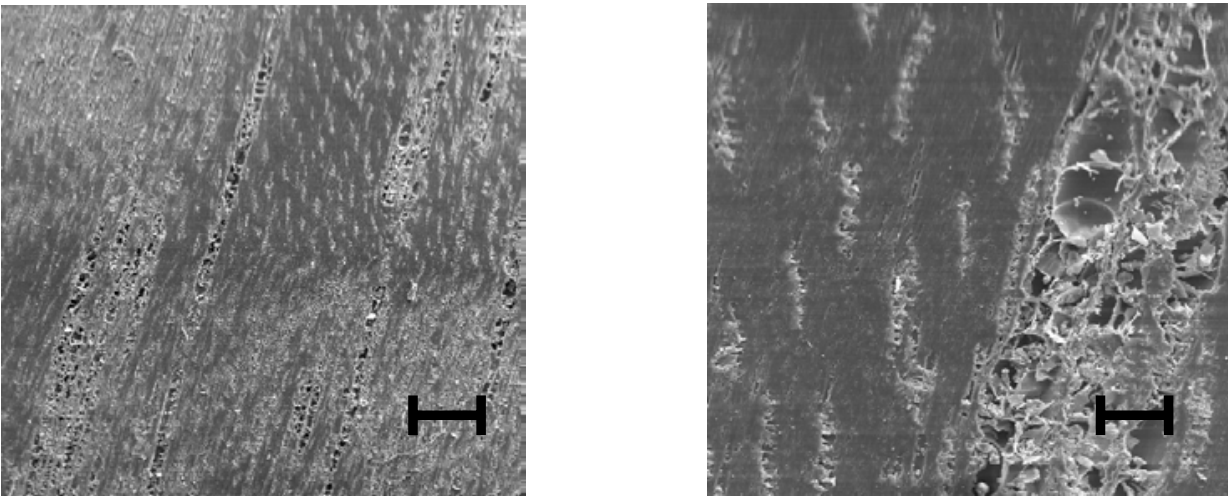

Figura 4.8 - Corte radial do CCT com os elementos anatômicos desobstruídos, com aumento de vinte e cem vezes. 
Uma observação muito importante pode ser feita em relação à Figura 4.8 (CCL) e Figura 4.17 (GCL), onde não é possível constatar a presença de raios na direção transversal, mas podemos observar claramente a presença de tiloses dentro dos vasos longitudinais e, em menor intensidade para a amostra da Figura 4.17 (GCL). Isto justifica o fato do GCL ter uma baixa permeabilidade e do CCL ter permeabilidade nula.
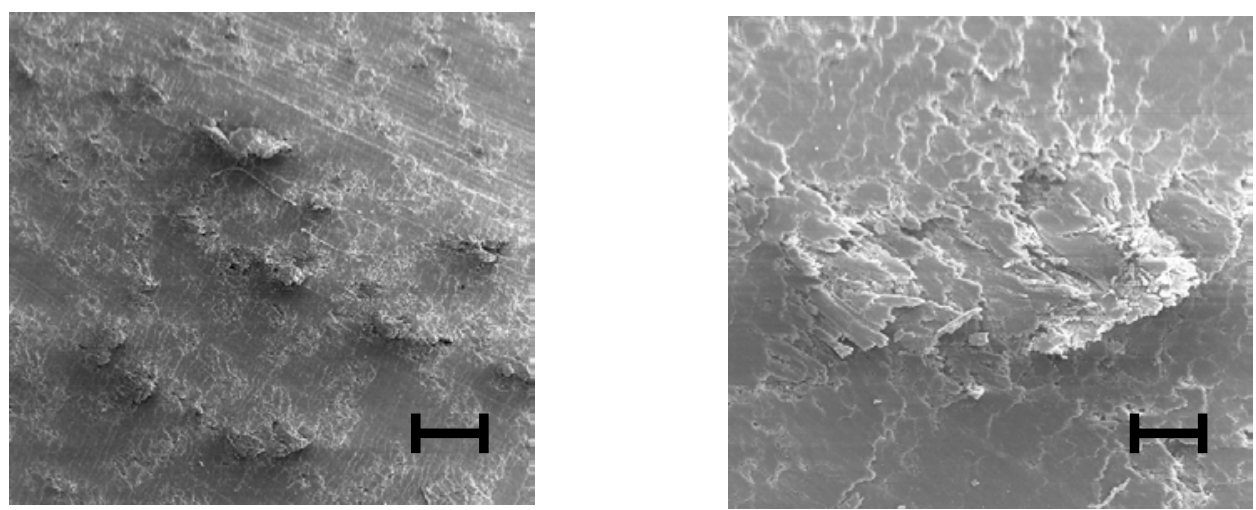

Figura 4.9 - Corte transversal do GAL com os elementos anatômicos obstruídos, com aumento de vinte e cem vezes.
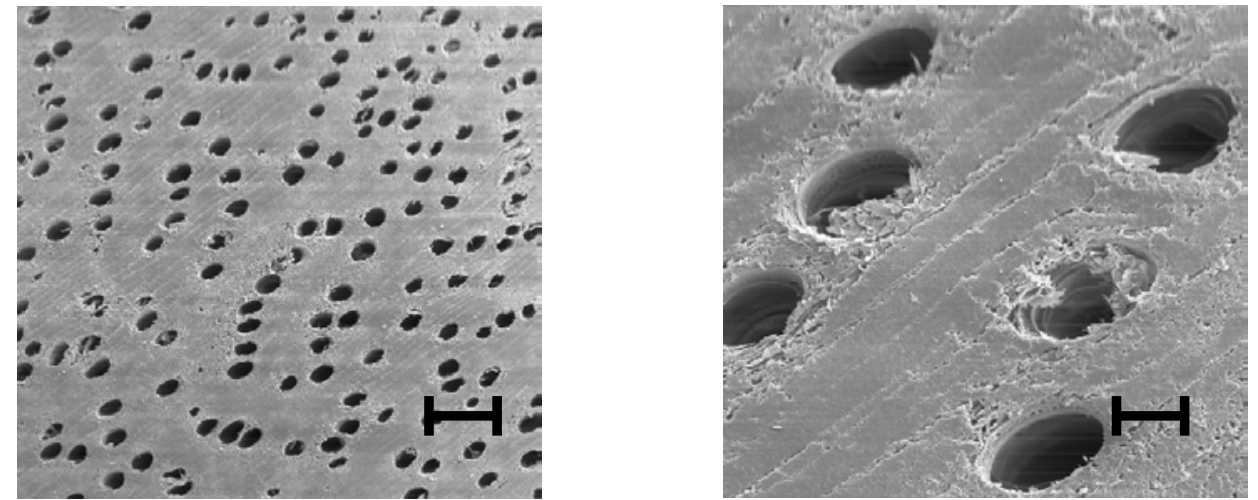

Figura 4.10 - Corte transversal do GAL com os elementos anatômicos desobstruídos, com aumento de vinte e cem vezes. 

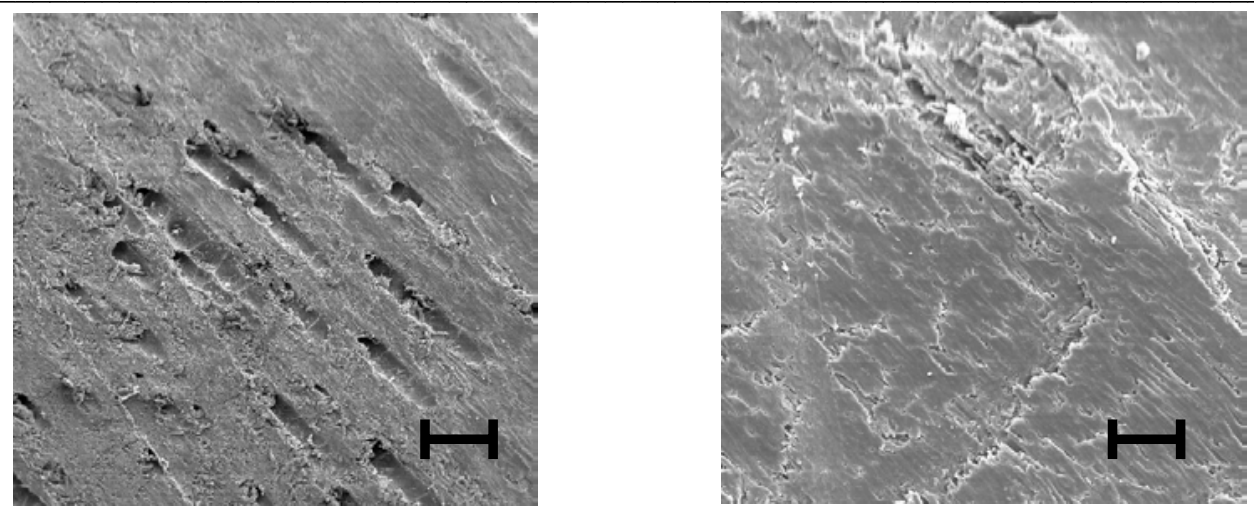

Figura 4.11 - Corte radial do GAT com os elementos anatômicos obstruídos, com aumento de vinte e cem vezes.
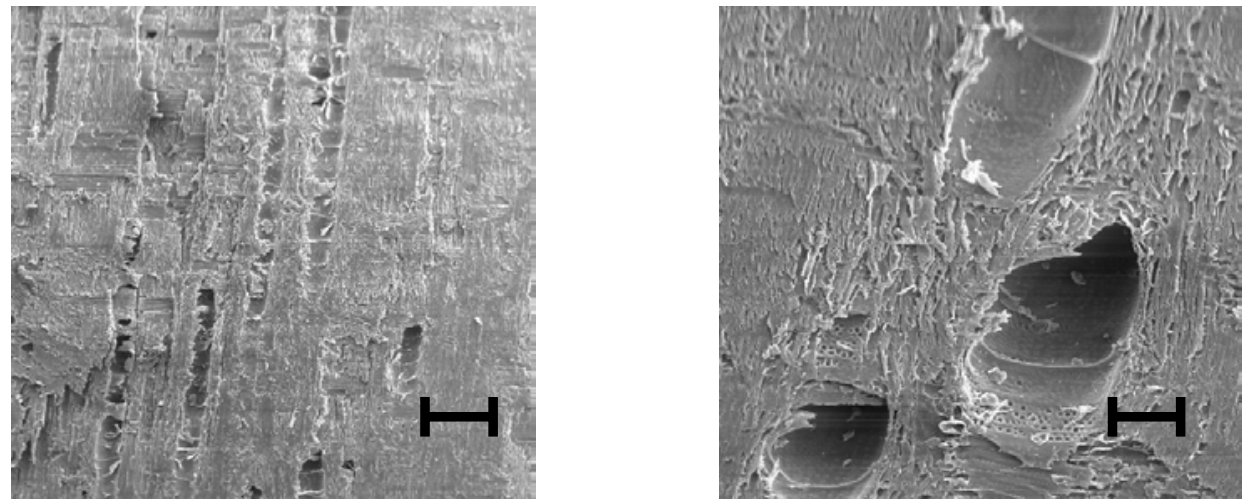

Figura 4.12 - Corte radial do GAT com os elementos anatômicos desobstruídos, com aumento de vinte e cem vezes.
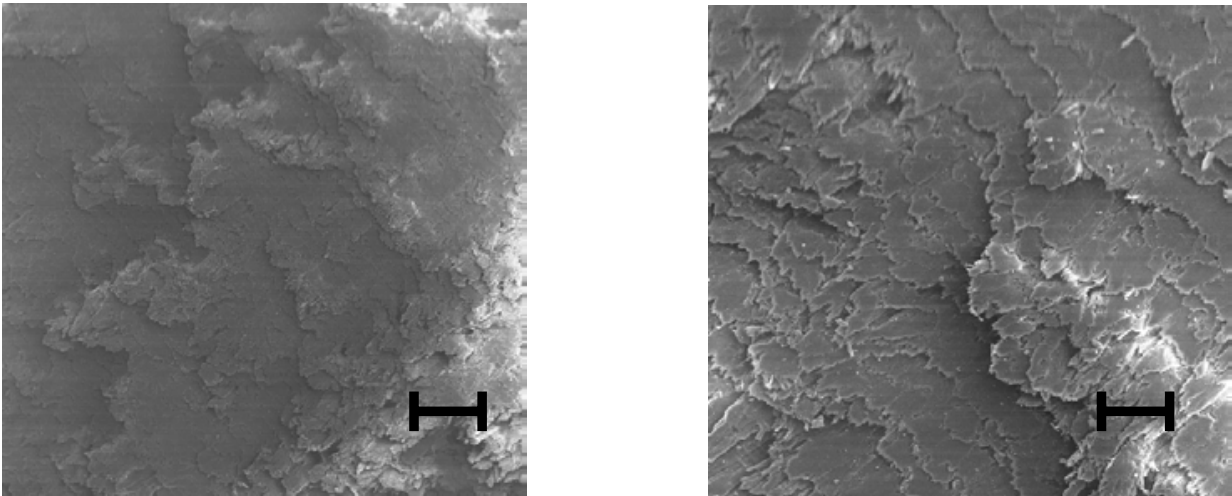

Figura 4.13 - Corte transversal do GCL com os elementos anatômicos obstruídos, com aumento de vinte e cem vezes. 
O cerne do Eucalyptus grandis na direção longitudinal apresenta baixa permeabilidade e isto pode ser explicado claramente pela Figura 4.14, onde são observados vasos obstruídos, vasos parcialmente obstruídos e vasos completamente obstruídos por tilas. Este fato também justifica a baixa permeabilidade do GCL nos ensaios com líquido e o fato de a permeabilidade não ter ocorrido no todo do corpo-deprova, ou seja, só ocorreu em partes, como mostrado na Figura 4.15. Esta amostra é a única dentre as dicotiledôneas em que é possível observar os parênquimas longitudinais.
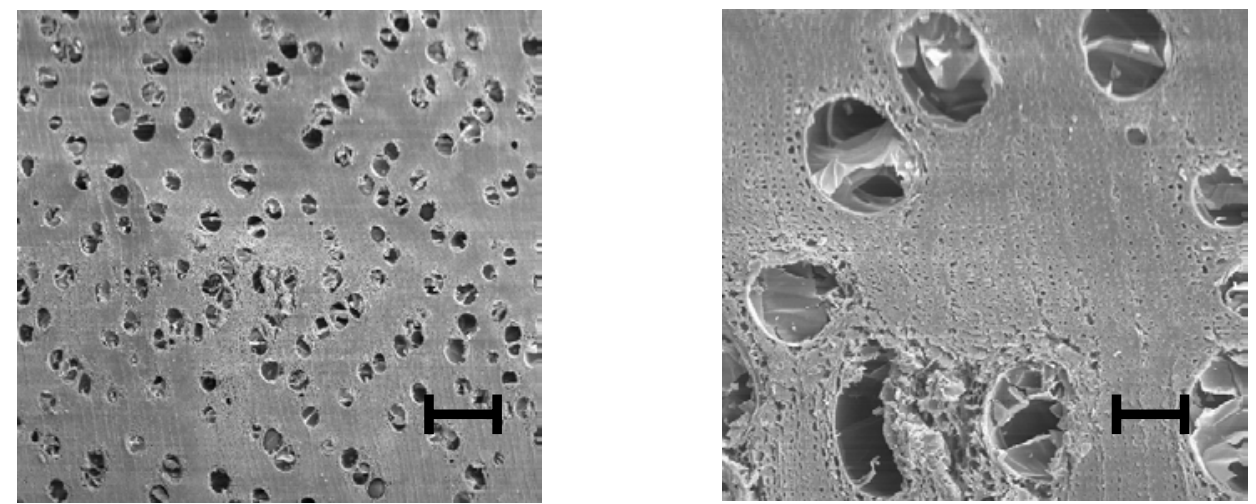

Figura 4.14 - Corte transversal do GCL com os elementos anatômicos desobstruídos, com aumento de vinte e cem vezes.

A baixa permeabilidade líquida a água destilada é evidenciada no cerne do $E$. grandis, na Figura 4.15 a, onde se observa na saída do corpo-de-prova a formação de bolhas de ar devido ao fato do fluido percolar o corpo-de-prova muito lentamente. $\mathrm{Na}$ Figura $4.15 \mathrm{~b}$, observa-se uma mancha escura no centro do corpo-de-prova e com isto conclui-se que o fluxo se processa apenas em parte e não em toda a área do corpo-deprova. 


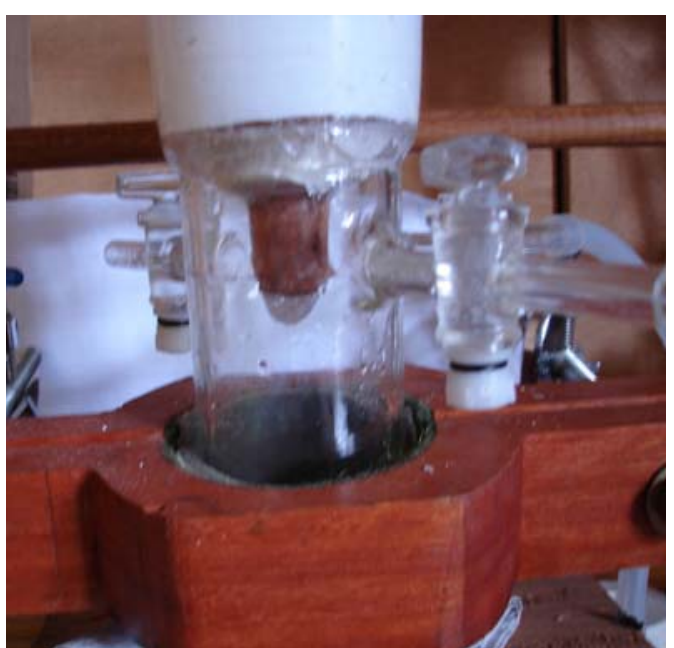

a

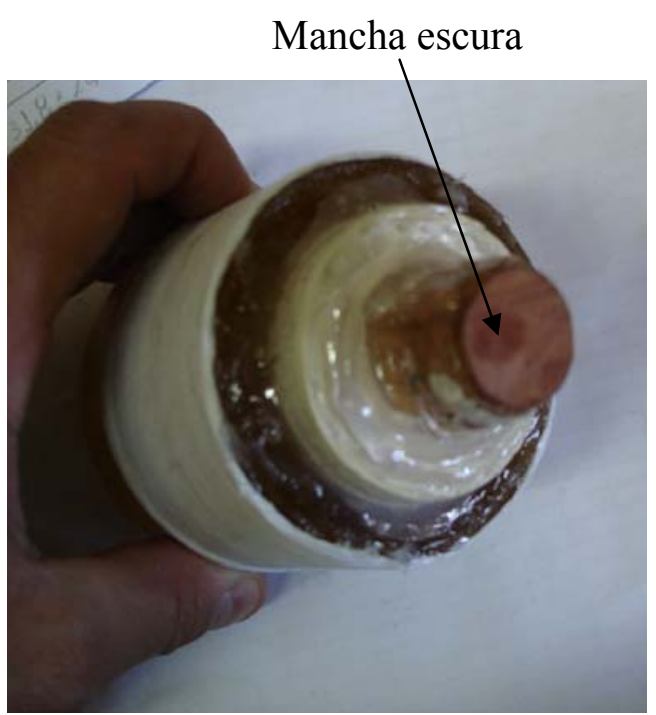

b

Figura 4.15 - Evidência da baixa permeabilidade a água destilada no cerne do E. grandis.
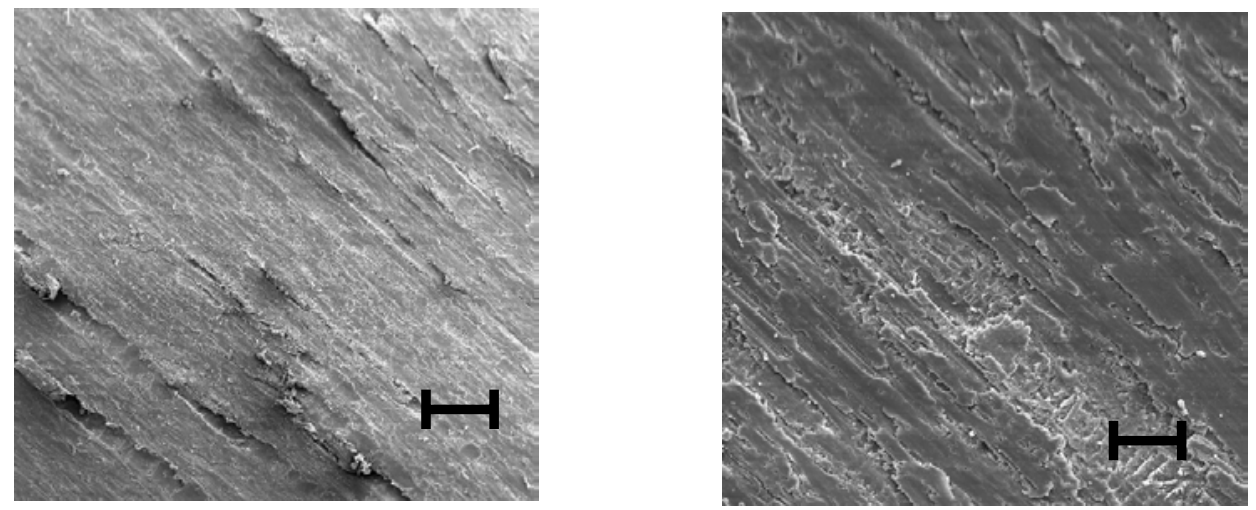

Figura 4.16 - Corte radial do GCL com os elementos anatômicos obstruídos, com aumento de vinte e cem vezes.
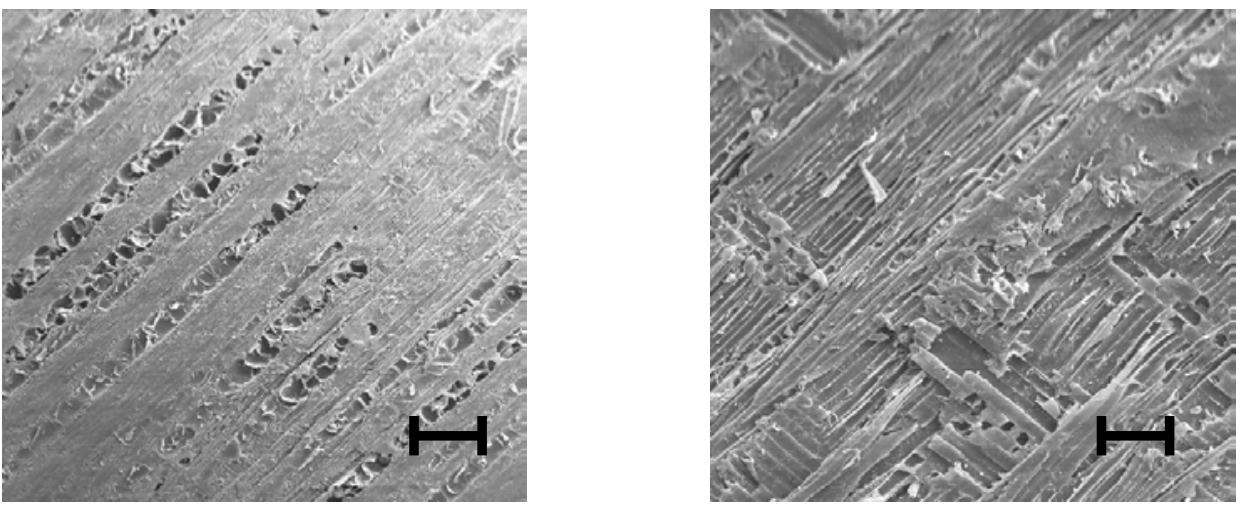

Figura 4.17 - Corte radial do GCL com os elementos anatômicos desobstruídos, com aumento de vinte e cem vezes. 

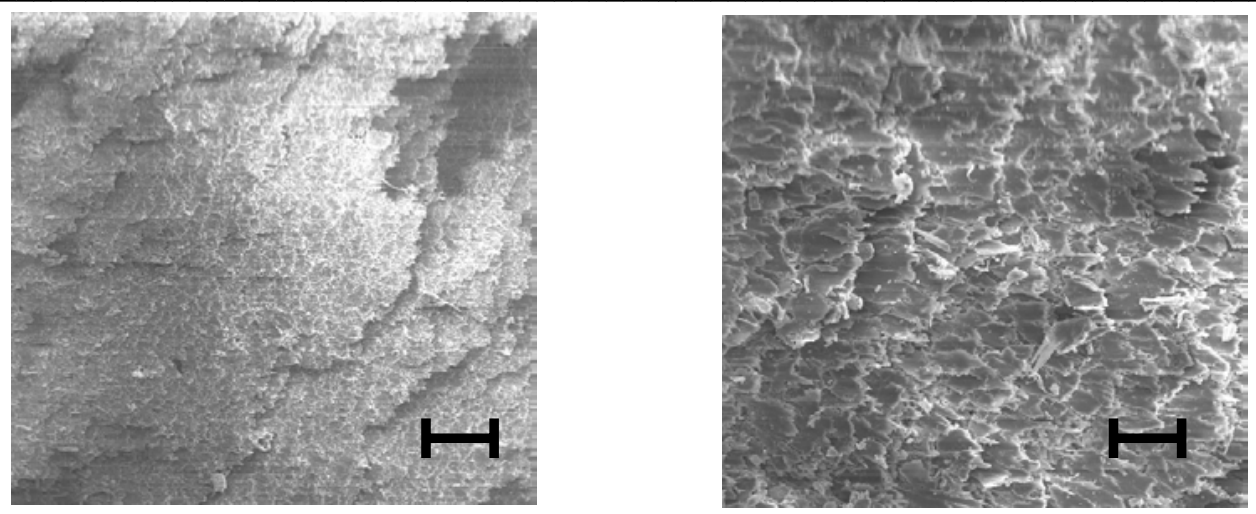

Figura 4.18 - Corte transversal do PL com os elementos anatômicos obstruídos, com aumento de vinte e cem vezes.

$\mathrm{Na}$ Figura 4.19 (PL) na $\mathrm{MEV}$, são encontrados os canais resiníferos e os traqueídeos longitudinais, onde há canais resiníferos obstruídos por tilas e traqueídeos colapsados pelo estilete. A permeabilidade nesta madeira (conífera) não é exclusivamente baseada nos canais resiníferos, visto que os traqueídeos longitudinais desempenham um importante papel na condução do fluxo e, com isto, conclui-se que nesta amostra a permeabilidade foi prejudicada pela maneira que foi adotada para desobstrução dos corpos-de-prova porque temos traqueídeos colapsados. Já para as dicotiledôneas, não foi encontrada nenhuma evidencia na MEV de obstrução dos vasos pela lâmina, visto que elas têm maior densidade.
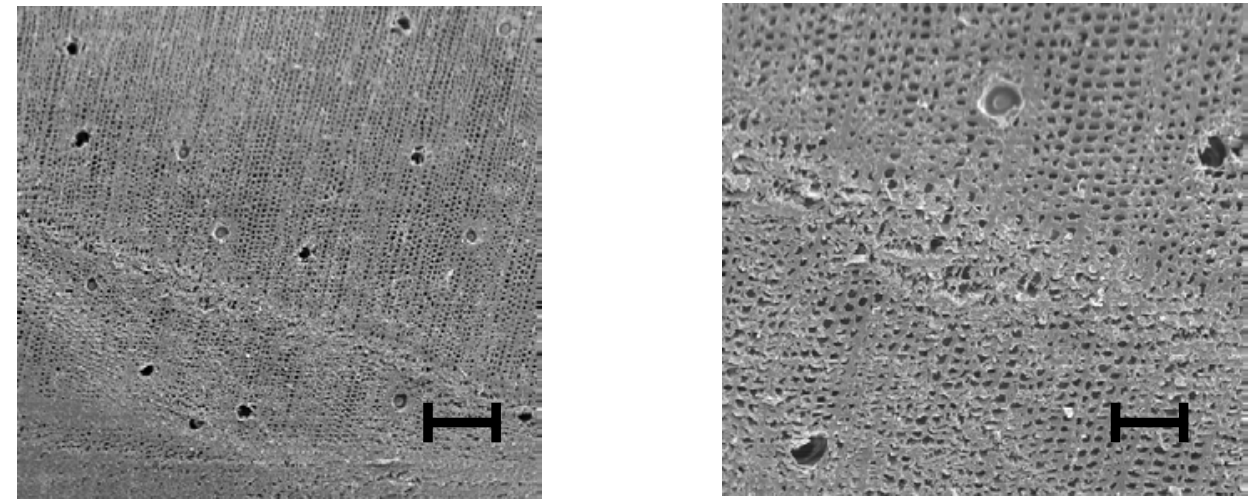

Figura 4.19 - Corte transversal do PL com os elementos anatômicos desobstruídos, com aumento de vinte e cinqüenta vezes. 

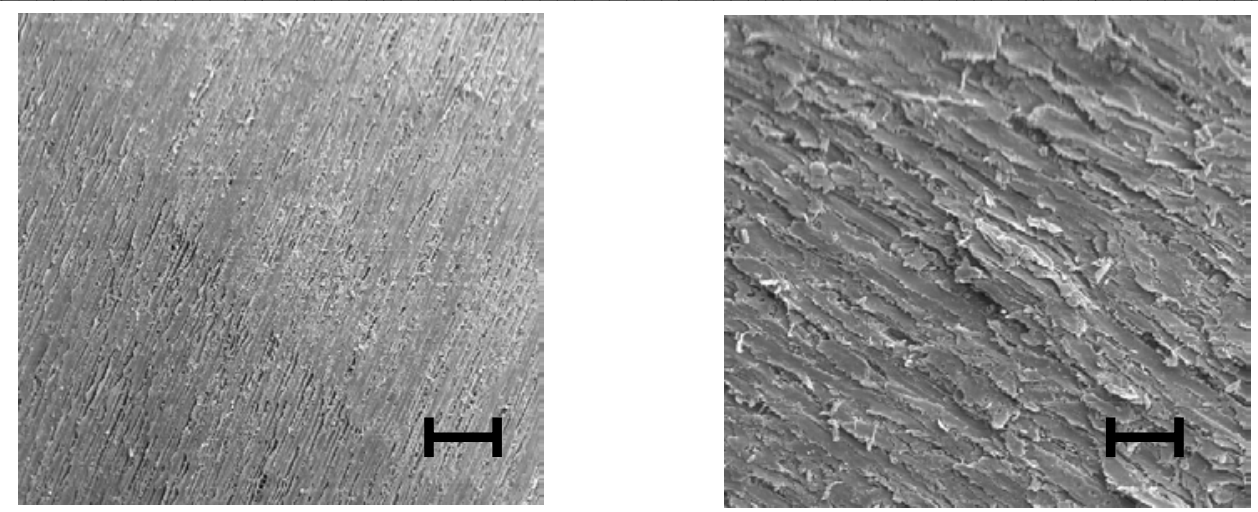

Figura 4.20 - Corte radial do PT com os elementos anatômicos obstruídos, com aumento de vinte e cem vezes.

Na Figura 4.21 é visto traqueídeos longitudinais aberto ao meio, visto que se trata de uma conífera.
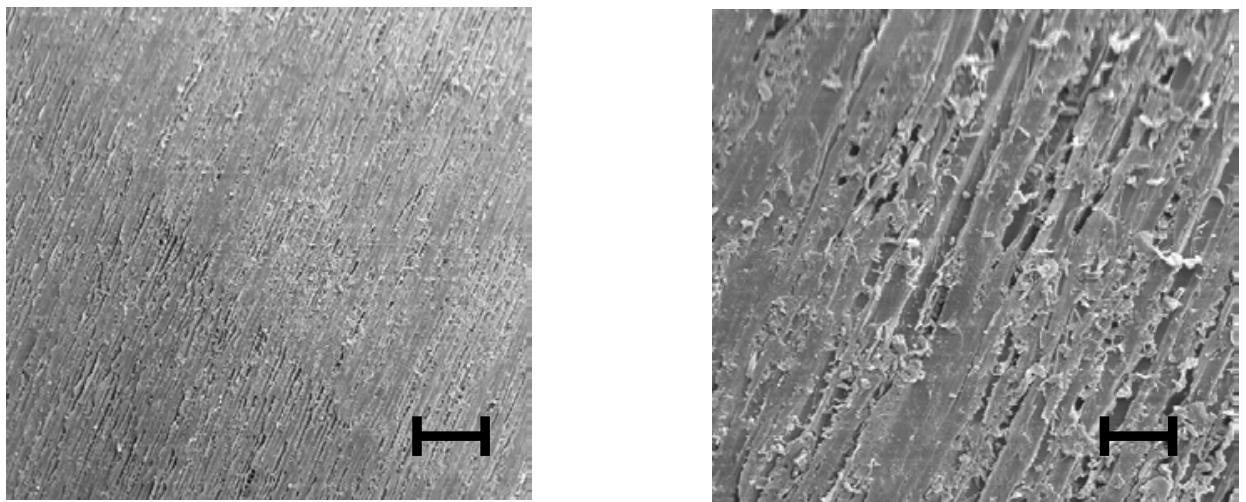

Figura 4.21 - Corte radial do PL com os elementos anatômicos desobstruídos, com aumento de vinte e cem vezes.

Através da microscopia eletrônica de varredura, foi possível determinar a quantidade de vasos nas dicotiledôneas, traqueídeos nas coníferas e, o diâmetro médio destes elementos anatômicos. O alburno do E. citriodora, na direção longitudinal às fibras, apresenta em média 295 vasos por $\mathrm{cm}^{2}$ com diâmetro médio de 0,093 $\mathrm{mm}$; o alburno do E. grandis, na direção longitudinal às fibras, apresenta em média 160 vasos por $\mathrm{cm}^{2}$ com diâmetro médio de $0,18 \mathrm{~mm}$ e para o Pinus elliottii, tem-se 1221 traqueídeos por $\mathrm{cm}^{2}$ com diâmetro médio de $0,020 \mathrm{~mm}$. 


\section{2 - Resultados da análise da química}

Amostras de madeira de Pinus e Eucalyptus foram submetidas a vários processos para se determinar o teor de extrativos, expresso como a somatória dos compostos solúveis em solventes orgânicos (etanol e ciclo-hexano) e água; a fração inorgânica foi denominada como cinzas e também se determinou o teor de lignina e polissacarídeos polioses e celulose - de acordo com Fengel (1989) e Sjostrom (1981).

Os resultados da análise química da madeira para cada amostra estão apresentados na Tabela 2, onde alburno 1 e alburno 2 juntamente com cerne 1 e cerne 2 representam a primeira e segunda amostra da análise química que foi realizada em duplicata.

Tabela 2 - Composição química dos principais constituintes da madeira.

\begin{tabular}{|c|c|c|c|c|c|c|}
\hline Espécie & C.P. & Cinzas (\%) & Extrativos (\%) & Lignina* (\%) & Celulose (\%) & Polioses (\%) \\
\hline \multirow{4}{*}{ E. citriodora } & Alburno-1 & 0,33 & 3,25 & 31,41 & 45,34 & 19,54 \\
\cline { 2 - 7 } & Alburno-2 & 0,31 & 3,33 & 30,87 & 46,76 & 19,25 \\
\cline { 2 - 7 } & Cerne-1 & 0,18 & 14,61 & 31,78 & 45.27 & 18,41 \\
\cline { 2 - 7 } & Cerne-2 & 0,19 & 14,32 & 31,82 & 43,74 & 18,46 \\
\hline \multirow{5}{*}{ E. grandis } & Alburno-1 & 0,35 & 7,82 & 33,74 & 50,50 & 15,33 \\
\cline { 2 - 7 } & Alburno-2 & 0,34 & 8,12 & 34,06 & 46,96 & 15,96 \\
\cline { 2 - 7 } & Cerne-1 & 0,05 & 5.73 & 33,11 & 46,42 & 16,69 \\
\cline { 2 - 7 } & Cerne-2 & 0,06 & 7,42 & 33,05 & 45,60 & 15,41 \\
\hline \multirow{2}{*}{ Pinus elliotti } & $* *-1$ & 0,26 & 16,06 & 28,73 & 46.22 & 20,42 \\
\cline { 2 - 7 } & $* *-2$ & 0,28 & 15,06 & 30,33 & 43.78 & 21,58 \\
\hline \multicolumn{7}{|c|}{$*$ Lignina (\%) é a somatória da lignina insolúvel e lignina solúvel. } \\
\hline \multirow{7}{*}{ ** indica que não houve diferenciação em relação à parte do lenho de que foi retirado o C.P. } \\
\hline
\end{tabular}

A Tabela 3, Tabela 4 e Tabela 5 apresentam os resultados estatísticos dos principais constituintes da madeira para as espécies de E. citriodora, E. grandis e Pinus elliottii; onde $\mathrm{n}$ é a quantidade de amostras em que foi realizada a análise química (duplicata), u é a média das amostras analisadas, $\mathrm{S}$ é o desvio padrão e CV é o coeficiente de variação. 
Tabela 3 - Medidas estatísticas dos resultados da análise química do E. citriodora.

\begin{tabular}{|c|c|c|c|c|c|c|c|c|}
\hline \multirow{2}{*}{ Componentes (\%) } & \multicolumn{5}{|c|}{ Alburno } & \multicolumn{4}{c|}{ Cerne } \\
\cline { 2 - 8 } & $n$ & $\mu$ & $S$ & $\mathrm{CV}$ & $n$ & $\mu$ & $S$ & $\mathrm{CV}$ \\
\hline Cinzas & 2 & 0,322 & 0,018 & 5,46 & 2 & 0,183 & 0,005 & 2,51 \\
\hline Lignina & 2 & 31,14 & 0,38 & 1,23 & 2 & 31,80 & 0,03 & 0,09 \\
\hline Celulose & 2 & 46,05 & 1,00 & 2,18 & 2 & 44,50 & 1,08 & 2,43 \\
\hline Polioses & 2 & 19,39 & 0,21 & 1,06 & 2 & 18,43 & 0.03 & 0.18 \\
\hline Extrativos & 2 & 3,29 & 0,06 & 1,68 & 2 & 14,46 & 0,20 & 1,38 \\
\hline
\end{tabular}

Tabela 4 - Medidas estatísticas dos resultados da análise química do E.grandis.

\begin{tabular}{|c|c|c|c|c|c|c|c|c|}
\hline \multirow{2}{*}{ Componentes (\%) } & \multicolumn{4}{|c|}{ Alburno } & \multicolumn{4}{c|}{ Cerne } \\
\cline { 2 - 9 } & $n$ & $\mu$ & $S$ & $\mathrm{CV}$ & $n$ & $\mu$ & $S$ & $\mathrm{CV}$ \\
\hline Cinzas & 2 & 0.346 & 0,009 & 2,69 & 2 & 0,055 & 0,007 & 12,85 \\
\hline Lignina & 2 & 33,90 & 0,23 & 0,67 & 2 & 33,08 & 0,04 & 0,13 \\
\hline Celulose & 2 & 48,73 & 2,50 & 5,14 & 2 & 46,01 & 0,58 & 1.26 \\
\hline Polioses & 2 & 15,65 & 0,45 & 2,85 & 2 & 16,05 & 0,91 & 5,64 \\
\hline Extrativos & 2 & 7,97 & 0,21 & 2,60 & 2 & 6,57 & 1,20 & 18,23 \\
\hline
\end{tabular}

Tabela 5 - Medidas estatísticas dos resultados da análise química do Pinus elliottii.

\begin{tabular}{|c|c|c|c|c|}
\hline Componentes (\%) & $n$ & $\mu$ & $S$ & CV \\
\hline Cinzas & 2 & 0,27 & 0.014 & 5.24 \\
\hline Lignina & 2 & 15,56 & 1,131 & 3,83 \\
\hline Celulose & 2 & 29,53 & 1,725 & 3,83 \\
\hline Polioses & 2 & 45 & 0,820 & 3,91 \\
\hline Extrativos & 2 & 21 & 0,707 & 4,54 \\
\hline
\end{tabular}

A lignina é uma macromolécula de natureza aromática e tridimensional, com alto peso molecular. Encontra-se intimamente associada aos polissacarídeos (celulose e polioses), não somente através de entrelaçamento físico, mas também através de ligações químicas. A lignina se apresenta como o componente mais hidrofóbico da madeira, atuando como material cimentante ou adesivo entre as fibras, além de conferir dureza e rigidez à parede celular. Os teores de lignina variam de $23 \%$ a $33 \%$ de acordo com Sjostrom (1981) e Miller (1999). Dos teores de lignina, Tabela 2, observa-se que os 
dados obtidos para as diferentes espécies de madeira diferem entre si, possuindo o $E$. grandis valores superiores ao do E. citriodora e Pinus elliottii e sendo assim, o alto teor de lignina do E. grandis, indica uma maior permeabilidade em relação ao E.citriodora.

O teor de cinzas fornece informações da quantidade de substâncias inorgânicas, provenientes principalmente da seiva bruta. As cinzas são constituídas basicamente por sulfatos, oxalatos, carbonatos e silicatos; como contra-íons mais comuns têm cálcio, potássio, magnésio e manganês. Nas árvores, o conteúdo de minerais varia com a espécie, a disponibilidade no solo, a necessidade individual e a época do ano. O teor de cinzas, normalmente pequeno, raramente é menor que $0,2 \%$ ou maior que $1 \%$ do peso seco das madeiras, de acordo com Miller (1999) e Mori et al (2003). Especificamente para a madeira do gênero Eucalyptus, o teor de cinzas raramente chega a $1 \%$ do seu peso seco, segundo Barrichelo (1985). Na Tabela 2, observa-se que o E. citriodora possui um teor de cinzas superior ao E. grandis e Pinus elliottii, sendo que o último apresenta o menor percentual em cinzas. Comparando o alburno e o cerne do E. citriodora, verificase que o teor de cinzas no alburno, é em média o dobro ou mais do teor de cinzas no cerne. O mesmo acontece com o E. grandis e sendo assim, em relação às espécies de dicotiledôneas analisadas, o elevado teor de cinzas do alburno indica uma maior permeabilidade em relação ao cerne.

Quase todos os resultados de extrativos apresentados para o Eucalyptus grandis e Eucalyptus citriodora estão de acordo com a literatura, segundo Sjostrom (1981) e Miller (1999), com exceção apenas do cerne do Eucalyptus citriodora, que apresenta valor elevado.

A extração com solventes orgânicos (etanol e ciclohexano) tem por finalidade a remoção, para posterior quantificação, de substâncias de baixa polaridade, tais como terpenos, resina, ácidos graxos, ésteres, ceras e materiais corantes. A extração em água retira sais inorgânicos, açúcares e algumas substâncias fenólicas.

Considera-se que as substâncias que constituem os extrativos ocupam uma parte do espaço da parede celular que normalmente seria ocupado pela água. Os extrativos podem constituir até $8 \%$ do peso seco de madeiras de espécies de clima temperado, podendo chegar a até $20 \%$ em madeiras de espécies de clima tropical, de acordo com Araújo (2000). 
De acordo com Lepage (1986), de uma forma geral o cerne não é receptível a tratamento preservativo, que ocorre pela deposição de extrativo no cerne que acentua a aspiração das pontuações além de ocluir o tórus das mesmas.

Segundo Mori et al (2003) e Sjostrom (1981), a presença de tiloses na madeira faz com que ela tenha pouca permeabilidade a líquido. A presença de tilose está associada com à presença de extrativos na madeira, uma vez que os vasos são obstruídos por tiloses e perdem sua atividade fisiológica nos tecidos próximos ao cerne. Consequentemente grande quantia de extrativos são gerados e que penetram ao longo do cerne.

Da Tabela 2 observa-se que o teor de extrativos é bastante variável para as diferentes espécies de madeira, apresentando o Pinus elliottii teor de extativos um pouco maior que o E. citriodora, enquanto a madeira de E. grandis apresenta a menor quantidade de extrativos. O alburno do E. citriodora possui um valor bem inferior de extrativos em relação ao cerne, ao passo que para o E. grandis o teor de extrativos para o alburno e cerne estão muito próximos.

A quantidade de extrativos presentes no cerne do E. citriodora é em média o dobro ou mais da quantidade de extrativos presentes no alburno do E. citriodora, alburno do $E$. grandis e cerne do E. grandis. Sendo assim, a nula permeabilidade no cerne do $E$. citriodora esta associada com a presença alta de extrativos.

De acordo com Sjostrom (1981) e Miller (1999), os teores de celulose podem variar de $40 \%$ a $50 \%$. A celulose é o principal componente da parede celular dos vegetais e o mais abundante composto orgânico da natureza. Apresenta-se sob a forma de fibras Observa-se na Tabela 2, que o E. grandis apresenta teor de celulose um pouco maior que o E. citriodora e bem superior em relação ao Pinus elliottii. Nas dicotiledôneas, madeiras com alto teor de celulose são mais permeáveis que madeiras com baixo teor de celulose.

Em relação às polioses ou (hemiceluloses), seus teores encontram-se dentro de um intervalo de 20\% a 40\%, segundo Mori et al (2003) e Sjostrom (1981). As polioses são os principais polissacarídeos não celulósicos da madeira, estando sempre associadas à lignina e a celulose. $O$ teor de polioses se apresenta ao inverso do teor de celulose onde o Pinus elliottii tem um valor bem elevado de polioses em relação ao E. citriodora e 
E. grandis, que apresentam teores de polioses bem próximos. Sendo assim, constatou-se que, tanto para o Eucalyptus grandis quanto para o Eucalyptus citriodora, os valores encontrados para as polioses estão abaixo do descrito pela literatura e para o Pinus elliottii estão acima do descrito pela literatura. Com tudo, para às dicotiledôneas estudadas, o baixo teor de polioses indica uma maior permeabilidade destas madeiras em relação ao Pinus elliottii.

\section{3 - Resultados da permeabilidade em função do fluxo e resultados da análise estatística.}

A Tabela 6 apresenta os resultados estatísticos da permeabilidade a gás e a líquido, para as espécies de E. citriodora, E. grandis e Pinus elliottii; onde u é a média das amostras analisadas em $\mathrm{cm}^{3} / \mathrm{cm}$.atm.s, S é o desvio padrão e $\mathrm{CV}$ é o coeficiente de variação. Para análise dos resultados apresentados na Tabela 6, foram ensaiados 20 corpos-de-prova, com exceção para permeabilidade a líquido do GAL com 11 corposde-prova; do GCL com 15 corpos-de-prova, e do PL com 16 corpos-de-prova.

Tabela 6 - Resultados estatísticos de permeabilidade para as amostras que apresentaram vazão a umidade de $12 \%$.

\begin{tabular}{|c|c|c|c|c|c|c|c|c|c|}
\hline & \multicolumn{4}{|c|}{ Gás } & \multicolumn{3}{c|}{ Água destilada } & \multicolumn{3}{c|}{ Emulsão de óleo de Neen } \\
\hline C.P. & $\mu$ & $S$ & CV & $M$ & $S$ & CV & $\mu$ & $S$ & CV \\
\hline CAL & 611,91 & 26,72 & 4,37 & 346,86 & 66,89 & 19,28 & 410,17 & 108,93 & 26,56 \\
\hline GAL & 681,53 & 74,50 & 10,93 & 470,57 & 121,89 & 25,90 & 313,26 & 156,11 & 49,84 \\
\hline GCL & 24,58 & 4,15 & 16,87 & 0,420 & 0,257 & 61,14 & 0,126 & 0,039 & 31,01 \\
\hline PL & 141,71 & 14,44 & 10,19 & 5,46 & 2,54 & 46,59 & 4,13 & 1,89 & 45,67 \\
\hline PT & 23,52 & 6,07 & 25,79 & $* *$ & $* *$ & $* *$ & $* *$ & $* *$ & $* *$ \\
\hline ** significa amostras que não apresentaram fluxo.
\end{tabular}

Significado das siglas:

- $\mathrm{CAL}=$ Eucalyptus citriodora alburno longitudinal;

- GAL = Eucalyptus grandis alburno longitudinal;

- GCL = Eucalyptus grandis cerne longitudinal;

- PL = Pinus elliottii longitudinal; 
-PT = Pinus elliottii transversal.

Quase todos os resultados do CV para permeabilidade a gás se mostraram dentro de uma faixa aceitável para a madeira, que é de $18 \%$. Somente o P. eliottii na direção transversal apresentou um CV muito alto em relação às demais amostras.

Em relação à permeabilidade a líquido temos um $\mathrm{CV}$ variando de duas a quatro vezes a mais em relação à permeabilidade gasosa.

Para a permeabilidade a líquida, de acordo com Lepage (1986), a viscosidade é uma das propriedades de grande influência. Admitindo a equação de Poiseuille como válida, infere-se que a permeabilidade é inversamente proporcional a viscosidade. Sendo assim, a viscosidade da água destilada, segundo Rosa (2005), é de $0,98 \mathrm{mPas}$ a $25^{\circ} \mathrm{C}$ e para a emulsão de óleo de Neen, a viscosidade à temperatura ambiente é de $4 \mathrm{mPas}$, o que justifica os resultados superiores da permeabilidade com água destilada em relação à permeabilidade com preservativo à base de óleo de Neen. Mas, os resultados apresentados na Tabela 6 para permeabilidade a líquido à base de água destilada e preservativo à base de óleo de Neen, no alburno do E. citriodora, apresentam resultados contrários a Lei de Poiseuille, ou seja, o preservativo á base de óleo de Neen se mostrou mais permeável que água destilada. Este fato pode ter ocorrido devido os corpos-deprova do alburno do E. citriodora serem fabricados um ano após os corpos-de-prova utilizados para determinar a permeabilidade a líquido a base de água destilada.

$\mathrm{Na}$ Tabela 7 são apresentados os valores de permeabilidade gasosa $\left(\mathrm{K}_{\mathrm{g}}=\mathrm{cm}^{3} / \mathrm{cm}\right.$.atm.s) na direção longitudinal, os postos destes valores por tratamento e os valores de $\mathrm{R}_{\mathrm{j}}$ (soma dos postos), $\mathrm{H}$ (estatística) e $\mathrm{p}$ (probabilidade do teste), respectivamente, para o Eucalyptus citriodora no alburno (A), Eucalyptus grandis no alburno (A) e no cerne (C), e para o Pinus elliottii.

Analisando a Tabela 7, pode-se observar que para $\mathrm{K}_{\mathrm{g}}, \mathrm{p}<0,0001<0,05$. Sendo assim, os dados apresentados na Tabela 7 não são estatisticamente equivalentes e utilizase o método de Dunn para descobrir quais são os grupos que diferem entre si. 
Tabela 7 - Resultados da $\mathrm{K}_{\mathrm{g}} \mathrm{em} \mathrm{cm}^{3} / \mathrm{cm}$.atm.s, Rj, $\mathrm{H}$ e $\mathrm{p}$, na direção longitudinal às fibras.

\begin{tabular}{|c|c|c|c|c|}
\hline CP & E. citriodora $-\mathrm{A}$ & E. grandis $-\mathrm{A}$ & E. grandis $-\mathrm{C}$ & P. elliottii \\
\hline 01 & 583 & 761 & 29 & 136 \\
\hline 02 & 545 & 703 & 30 & 159 \\
\hline 03 & 638 & 712 & $* *$ & 146 \\
\hline 04 & 605 & 625 & 21 & 174 \\
\hline 05 & 613 & 677 & 24 & 124 \\
\hline 06 & 614 & 751 & 24 & 128 \\
\hline 07 & 626 & 647 & 22 & 138 \\
\hline 08 & 578 & 763 & 30 & 134 \\
\hline 09 & 609 & 792 & 21 & 138 \\
\hline 10 & 574 & 522 & $* *$ & 141 \\
\hline 11 & 655 & 568 & 20 & 172 \\
\hline 12 & 611 & 754 & 28 & 142 \\
\hline 13 & 607 & 633 & 26 & 156 \\
\hline 14 & 623 & 742 & 18 & 121 \\
\hline 15 & 603 & 581 & 19 & 151 \\
\hline 16 & 606 & 695 & 26 & 136 \\
\hline 17 & 635 & 657 & 22 & 130 \\
\hline 18 & 638 & 751 & 31 & 129 \\
\hline 19 & 639 & 617 & 26 & 147 \\
\hline 20 & 638 & 679 & 27 & 131 \\
\hline $\mathrm{R}_{\mathrm{i}}$ & 1048 & 1292 & 171 & 570 \\
\hline $\mathrm{H}$ & & & & \\
\hline $\mathrm{p}$ & & & & \\
\hline & & & & \\
\hline
\end{tabular}

A Tabela 8 apresenta a diferença entre os postos para o método de Dunn e quais grupos diferem entre si pela média da soma dos postos, para os resultados da $\mathrm{K}_{\mathrm{g}}$ na direção longitudinal às fibras.

Tabela 8 - Diferença entre a média dos postos pelo método de Dunn para $\mathrm{K}_{\mathrm{g}}$ na direção longitudinal às fibras

\begin{tabular}{|c|c|c|c|c|}
\hline Comparações (método de Dunn) & Dif. Postos & $\mathrm{z}$ calculado & $\mathrm{z}$ crítico & $\mathrm{p}$ \\
\hline Postos médios 1 e 2 & 12.2 & 1.7025 & 2.635 & $\mathrm{~ns}$ \\
\hline Postos médios 1 e 3 & 42.9 & 5.827 & 2.635 & $<0.05$ \\
\hline Postos médios 1 e 4 & 23.9 & 3.3352 & 2.635 & $<0.05$ \\
\hline Postos médios 2 e 3 & 55.1 & 7.4841 & 2.635 & $<0.05$ \\
\hline Postos médios 2 e 4 & 36.1 & 5.0378 & 2.635 & $<0.05$ \\
\hline Postos médios 3 e 4 & 19 & 2.5807 & 2.635 & $\mathrm{~ns}$ \\
\hline
\end{tabular}


Analisando os resultados apresentados na Tabela 8, utilizando o método de Dunn, concluiu-se que os grupos que são estatisticamente equivalentes são: alburno do $E$. citriodora (grupo 1) com alburno do E. grandis (grupo 2); e o cerne do E. grandis (grupo 3) com o Pinus elliotti (grupo 4). Os demais grupos não são considerados estatisticamente equivalentes, sendo eles: alburno do E. citriodora (grupo 1) com cerne do E. grandis (grupo 3); alburno do E. citriodora (grupo 1) com Pinus elliotti (grupo 4); alburno do E. grandis (grupo 2) com cerne do E. grandis (grupo 3) e alburno do $E$. grandis (grupo 2) com Pinus elliotti (grupo 4).

Os resultados obtidos para $\mathrm{K}_{\mathrm{g}}$ na direção longitudinal, por este método estatístico demonstrando quais grupos são e não são estatisticamente equivalentes podem ser melhor compreendidos com o auxílio de um box-plot, Figura 4.22.

\section{Box-plot de permeabilidade gasosa}

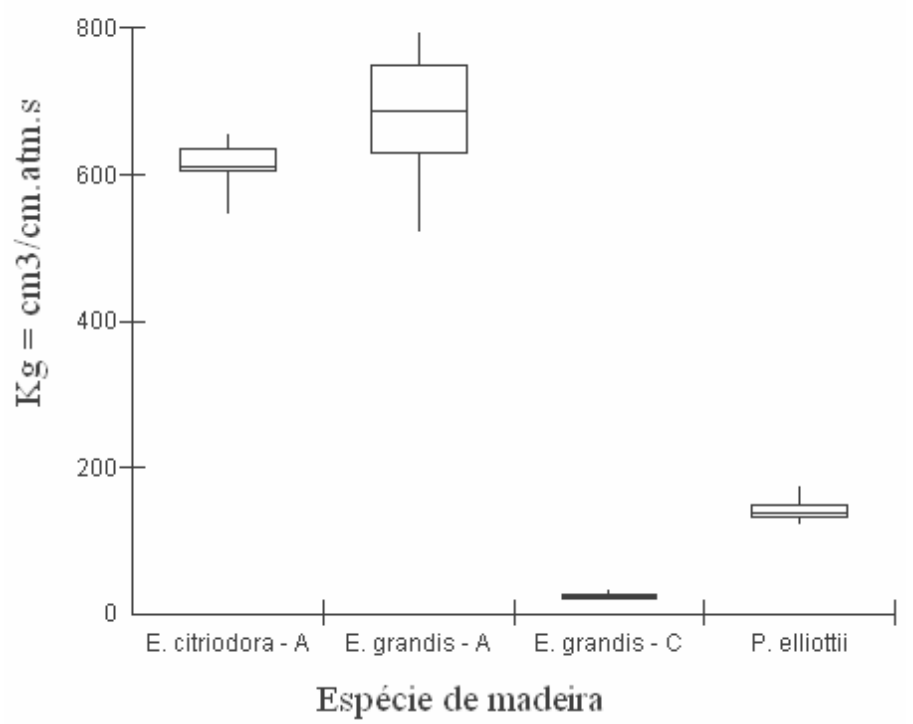

Figura 4.22 - Box-Plot de permeabilidade gasosa na direção longitudinal às fibras.

A Tabela 9 e Tabela 10 apresentam os resultados de permeabilidade a líquido $\left(\mathrm{K}=\mathrm{cm}^{3} / \mathrm{cm}\right.$.atm.s) com água destilada e preservativo à base de óleo de Neen na direção longitudinal às fibras, os valores de $\mathrm{R}_{\mathrm{j}}$ (soma dos postos), $\mathrm{H}$ (estatística) $\mathrm{e} p$ (probabilidade do teste), respectivamente, para o Eucalyptus citriodora no alburno (A), Eucalyptus grandis no alburno (A) e no cerne (C), e para o Pinus elliottii. 
Tabela 9 - Resultados da $\mathrm{K} \mathrm{em} \mathrm{cm}$ / $\mathrm{cm}$.atm.s com água destilada, Rj, $\mathrm{H}$ e p, na direção longitudinal às fibras.

\begin{tabular}{|c|c|c|c|c|}
\hline $\mathrm{CP}$ & E. citriodora - A & E. grandis - A & E. grandis - C & P. elliottii \\
\hline 01 & 364 & 429 & 0.351 & 5 \\
\hline 02 & 263 & 458 & 0.27 & $* *$ \\
\hline 03 & 380 & 466 & 0.715 & 4 \\
\hline 04 & 304 & 262 & 0.272 & 8 \\
\hline 05 & 295 & 548 & 0.785 & 1 \\
\hline 06 & 329 & 524 & 0.29 & 6 \\
\hline 07 & 317 & 369 & 0.103 & 4 \\
\hline 08 & 332 & 585 & 0.814 & 7 \\
\hline 09 & 377 & 685 & 0.858 & 4 \\
\hline 10 & 330 & 526 & $* *$ & 11 \\
\hline 11 & 274 & 323 & 0.137 & 8 \\
\hline 12 & 350 & $*$ & 0.341 & 5 \\
\hline 13 & 333 & $*$ & 0.253 & 5 \\
\hline 14 & 293 & $*$ & 0.327 & 2 \\
\hline 15 & 324 & $*$ & 0.37 & 4 \\
\hline 16 & 294 & $*$ & $*$ & 7 \\
\hline 17 & 539 & $*$ & $*$ & $*$ \\
\hline 18 & 346 & $*$ & $*$ & $*$ \\
\hline 19 & 423 & $*$ & $*$ & $*$ \\
\hline 20 & 469 & $*$ & $*$ & $*$ \\
\hline $\mathrm{R}_{\mathrm{j}}$ & 836 & 559 & 105 & 330 \\
\hline $\mathrm{H}$ & \multicolumn{4}{|c|}{51.0973} \\
\hline $\mathrm{p}$ & \multicolumn{4}{|c|}{$<0.0001$} \\
\hline \multicolumn{5}{|c|}{ Obs: * indica que não havia o corpo-de-prova } \\
\hline \multicolumn{5}{|c|}{ Obs: ** indica corpo-de-prova que não apresentou vazão } \\
\hline
\end{tabular}


Tabela 10 - Resultados da $\mathrm{K}$ em $\mathrm{cm}^{3} / \mathrm{cm}$.atm.s, com preservativo à base de óleo de Neen, Rj, H $\mathrm{e} p$, na direção longitudinal às fibras.

\begin{tabular}{|c|c|c|c|c|}
\hline $\mathrm{CP}$ & E. citriodora-A & E. grandis - A & E. grandis - C & P. elliottii \\
\hline 1 & 487 & 424 & 0.088 & 4 \\
\hline 2 & 396 & 283 & 0.168 & 2 \\
\hline 3 & 230 & 496 & 0.187 & $* *$ \\
\hline 4 & 381 & 249 & 0.183 & 5 \\
\hline 5 & 316 & 385 & 0.079 & 2 \\
\hline 6 & 364 & 291 & $* *$ & 5 \\
\hline 7 & 403 & 519 & 0.114 & 2 \\
\hline 8 & 392 & 362 & 0.101 & 3 \\
\hline 9 & 427 & 313 & 0.093 & 3 \\
\hline 10 & 439 & 315 & 0.138 & 7 \\
\hline 11 & 265 & 203 & 0.167 & 5 \\
\hline 12 & 449 & $*$ & 0.084 & 2 \\
\hline 13 & 369 & $*$ & 0.153 & 4 \\
\hline 14 & 360 & $*$ & 0.093 & 4 \\
\hline 15 & 433 & * & 0.112 & 5 \\
\hline 16 & 181 & $*$ & $*$ & $* *$ \\
\hline 17 & 373 & * & * & 8 \\
\hline 18 & 389 & $*$ & $*$ & $*$ \\
\hline 19 & 318 & $*$ & $*$ & $*$ \\
\hline 20 & 333 & $*$ & $*$ & $*$ \\
\hline$R_{j}$ & 922 & 473 & 105 & 330 \\
\hline $\mathrm{H}$ & \multicolumn{4}{|c|}{49.4299} \\
\hline $\mathrm{p}$ & \multicolumn{4}{|c|}{$<0.0001$} \\
\hline \multicolumn{5}{|c|}{ Obs: * indica que não havia o corpo-de-prova } \\
\hline bs: * & dica corpo-de-p & que não apre & u vazão & \\
\hline
\end{tabular}

As Tabelas 11 e 12 apresentam as diferenças entre os postos para o método de Dunn e quais grupos diferem para a permeabilidade $\mathrm{K}$ à base de água destilada e óleo de Neen.

Tabela 11 - Diferença entre a média dos postos pelo método de Dunn para os resultados de K à base de água destilada na direção longitudinal às fibras.

\begin{tabular}{|c|c|c|c|c|}
\hline Comparações (método de Dunn) & Dif. Postos & z calculado & z crítico & $\mathrm{p}$ \\
\hline Postos médios1 e 2 & 9.018 & 1.3756 & 2.635 & $\mathrm{~ns}$ \\
\hline Postos médios 1 e 3 & 34.300 & 5.6362 & 2.635 & $<0.05$ \\
\hline Postos médios 1 e 4 & 19.800 & 3.3193 & 2.635 & $<0.05$ \\
\hline Postos médios 2 e 3 & 43.318 & 6.1562 & 2.635 & $<0.05$ \\
\hline Postos médios 2 e 4 & 28.818 & 4.1569 & 2.635 & $<0.05$ \\
\hline Postos médios 3 e 4 & 14.500 & 2.2342 & 2.635 & $\mathrm{~ns}$ \\
\hline
\end{tabular}


Com os resultados apresentados para $\mathrm{K}$ à base de água destilada na Tabela 11, e utilizando-se o método de Dunn, conclui-se que os grupos que são considerados estatisticamente equivalentes são: alburno do E. citriodora (grupo 1) com alburno do $E$. grandis (grupo 2); e o cerne E. grandis (grupo 3) com o Pinus elliottii (grupo 4). Os demais grupos não são considerados estatisticamente equivalentes, sendo eles: alburno do E. citriodora (grupo 1) com cerne do E. grandis (grupo 3); alburno do E. citriodora (grupo 1) com Pinus elliottii (grupo 4); alburno do E. grandis (grupo 2) com cerne do E. grandis (grupo 3) e alburno do E. grandis (grupo 2) com Pinus elliotti (grupo 4).

A Figura 4.23 representa os resultados obtidos para permeabilidade líquida com água destilada através de um box-plot. Os resultados obtidos para a permeabilidade líquida no cerne do E. grandis e Pinus elliottii, não aparecem no box-plot da Figura 4.23, Figura 4.24 e Figura 4.25, pois estes resultados se encontram em cima do eixo das abcissas, devido os valores obtidos para $\mathrm{K}$ serem muito baixos em relação às demais espécies analisadas e a escala que o Bioestat utilizou para compor o box-plot.

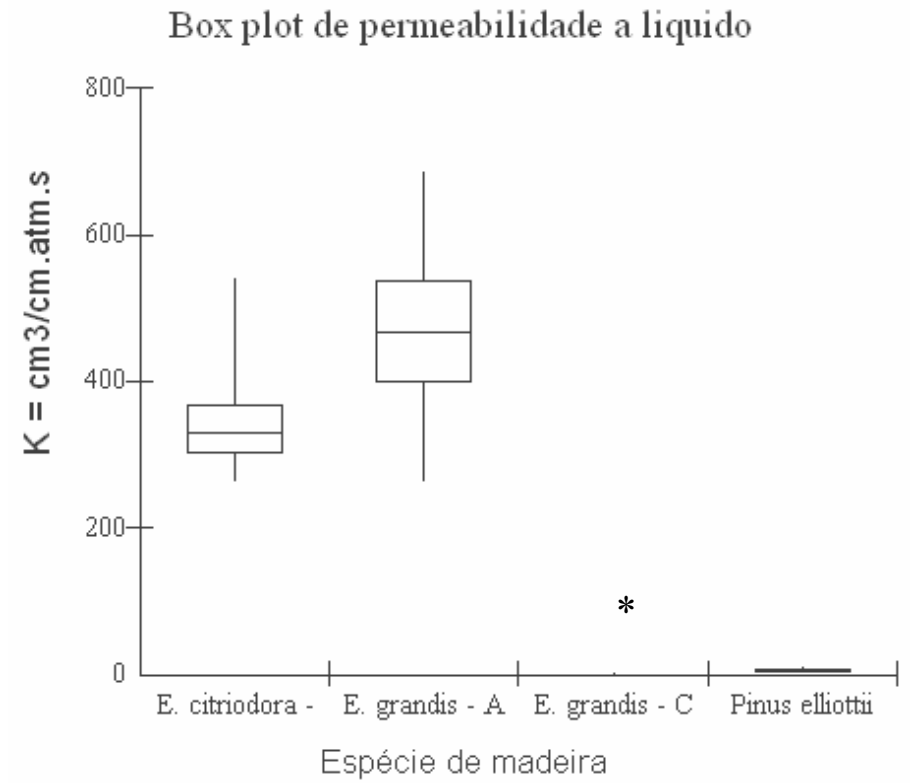

Obs: * indica que a caixa do box-plot não aparece, devido os resultados da espécie analisada serem bem inferiores em relação aos demais.

Figura 4.23 - Box-plot de permeabilidade líquida com água destilada na direção longitudinal às fibras. 
Tabela 12 - Diferença entre a média dos postos pelo método de Dunn para os resultados de k com preservativo à base de óleo de Neen na direção longitudinal às fibras.

\begin{tabular}{|c|c|c|c|c|}
\hline Comparações (método de Dunn) & Dif. Postos & $\mathrm{z}$ calculado & $\mathrm{z}$ crítico & $\mathrm{p}$ \\
\hline Postos médios 1 e 2 & 3.1 & 0.4729 & 2.635 & $\mathrm{~ns}$ \\
\hline Postos médios 1 e 3 & 38.6 & 6.3427 & 2.635 & $<0.05$ \\
\hline Postos médios 1 e 4 & 24.1 & 4.0401 & 2.635 & $<0.05$ \\
\hline Postos médios 2 e 3 & 35.5 & 5.0451 & 2.635 & $<0.05$ \\
\hline Postos médios 2 e 4 & 21 & 3.0292 & 2.635 & $<0.05$ \\
\hline Postos médios 3 e 4 & 14.5 & 2.2342 & 2.635 & $\mathrm{~ns}$ \\
\hline
\end{tabular}

Pelos resultados apresentados para K com preservativo à base de óleo de Neen na Tabela 12, utilizando o método de Dunn, conclui-se que os grupos que são estatisticamente equivalentes são: alburno do E. citriodora (grupo 1) com alburno do $E$. grandis (grupo 2); e cerne do E. grandis (grupo 3) com Pinus elliottii (grupo 4). Os demais grupos não são considerados estatisticamente equivalentes, sendo eles: alburno do E. citriodora (grupo 1) com cerne do E. grandis (grupo 3); alburno do E. citriodora (grupo 1) com Pinus elliottii (grupo 4); alburno do E. grandis (grupo 2) com cerne do E. grandis (grupo 3) e alburno do E. grandis (grupo 2) com Pinus elliottii (grupo 4).

A Figura 4.24 representa os resultados obtidos para permeabilidade líquida com preservativo à base de óleo de Neen através de um box-plot.

Box plot de permeabilidade a liquido

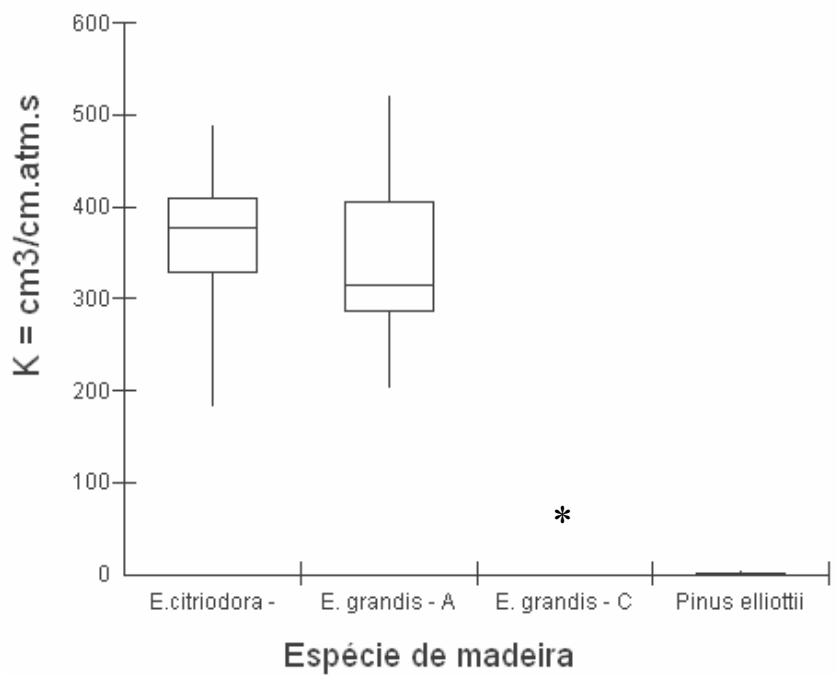

Obs: * indica que a caixa do box-plot não aparece, devido os resultados da espécie analisada serem bem inferiores em relação aos demais.

Figura 4.24 - Box-plot de permeabilidade líquida com óleo de Neen na direção longitudinal às fibras. 
A Tabela 14 apresenta a diferença entre os postos para o método de Dunn e quais grupos diferem entre si para os resultados de $\mathrm{K}$ com água destilada e preservativo natural à base de óleo de Neen juntos.

A Tabela 13 apresenta os resultados de permeabilidade a líquido $\left(\mathrm{K}=\mathrm{cm}^{3} / \mathrm{cm}\right.$.atm.s) com água destilada e preservativo à base de óleo de Neen na direção longitudinal às fibras, os valores $\mathrm{R}_{\mathrm{j}}$ (soma dos postos), $\mathrm{H}$ (estatística) e $\mathrm{p}$ (probabilidade do teste).

Tabela 13 - Resultados da $\mathrm{K}$ em $\mathrm{cm}^{3} / \mathrm{cm}$.atm.s, com água destilada (Água) e preservativo à base de óleo de Neen (Neen), Rj, H e p, na direção longitudinal às fibras.

\begin{tabular}{|c|c|c|c|c|c|c|c|c|}
\hline $\mathrm{CP}$ & $C A L$-Água & $G A L$ - Água & $G C L$ - Água & $P L-$ Água & $C A L$ - Neen & $G A L$ - Neen & $G C L$ - Neen & $P L-$ Neen \\
\hline 1 & 364 & 429 & 0.351 & 5 & 487 & 424 & 0.088 & 4 \\
\hline 2 & 263 & 458 & 0.27 & $* *$ & 396 & 283 & 0.168 & 2 \\
\hline 3 & 380 & 466 & 0.715 & 4 & 230 & 496 & 0.187 & $* *$ \\
\hline 4 & 304 & 262 & 0.272 & 8 & 381 & 249 & 0.183 & 5 \\
\hline 5 & 295 & 548 & 0.785 & 1 & 316 & 385 & 0.079 & 2 \\
\hline 6 & 329 & 524 & 0.29 & 6 & 364 & 291 & $* *$ & 5 \\
\hline 7 & 317 & 369 & 0.103 & 4 & 403 & 519 & 0.114 & 2 \\
\hline 8 & 332 & 585 & 0.814 & 7 & 392 & 362 & 0.101 & 3 \\
\hline 9 & 377 & 685 & 0.858 & 4 & 427 & 313 & 0.093 & 3 \\
\hline 10 & 330 & 526 & $* *$ & 11 & 439 & 315 & 0.138 & 7 \\
\hline 11 & 274 & 323 & 0.137 & 8 & 265 & 203 & 0.167 & 5 \\
\hline 12 & 350 & $*$ & 0.341 & 5 & 449 & $*$ & 0.084 & 2 \\
\hline 13 & 333 & $*$ & 0.253 & 5 & 369 & $*$ & 0.153 & 4 \\
\hline 14 & 293 & $*$ & 0.327 & 2 & 360 & $*$ & 0.093 & 4 \\
\hline 15 & 324 & $*$ & 0.37 & 4 & 433 & $*$ & 0.112 & 5 \\
\hline 16 & 294 & $*$ & $*$ & 7 & 181 & $*$ & $*$ & $* *$ \\
\hline 17 & 539 & * & * & * & 373 & * & $*$ & 8 \\
\hline 18 & 346 & $*$ & $*$ & $*$ & 389 & $*$ & $*$ & $*$ \\
\hline 19 & 423 & $*$ & $*$ & $*$ & 318 & $*$ & $*$ & $*$ \\
\hline 20 & 469 & $*$ & $*$ & $*$ & 333 & $*$ & $*$ & $*$ \\
\hline $\mathrm{R}_{\mathrm{i}}$ & 1673 & 1145 & 297 & 750 & 1812 & 919 & 119 & 545 \\
\hline $\mathrm{H}$ & \multicolumn{8}{|c|}{103,6862} \\
\hline $\mathrm{P}$ & \multicolumn{8}{|c|}{$<0,0001$} \\
\hline bs: * & ica que nầ & avia o cor & o-de-prova & & & & & \\
\hline
\end{tabular}

Significado das siglas:

- CAL = Eucalyptus citriodora alburno longitudinal;

- GAL = Eucalyptus grandis alburno longitudinal; 
- GCL = Eucalyptus grandis cerne longitudinal;

- PL = Pinus elliottii longitudinal.

Tabela 14 - Diferença entre a média dos postos pelo método de Dunn para os resultados de $\mathrm{k}$ com água destilada e preservativo à base de óleo de Neen, na direção longitudinal às fibras.

\begin{tabular}{|c|c|c|c|c|}
\hline Comparações (método de Dunn) & Dif. Postos & $\mathrm{z}$ calculado & $\mathrm{z}$ crítico & $\mathrm{p}$ \\
\hline Postos médios 1 e 2 & 20.4409 & 1.5654 & 3.125 & $\mathrm{~ns}$ \\
\hline Postos médios 1 e 3 & 62.4357 & 5.1509 & 3.125 & $<0.05$ \\
\hline Postos médios 1 e 4 & 33.65 & 2.8322 & 3.125 & $\mathrm{~ns}$ \\
\hline Postos médios 1 e 5 & 6.95 & 0.6318 & 3.125 & $\mathrm{~ns}$ \\
\hline Postos médios 1 e 6 & 0.1045 & 0.008 & 3.125 & $\mathrm{~ns}$ \\
\hline Postos médios 1 e 7 & 75.15 & 6.1998 & 3.125 & $<0.05$ \\
\hline Postos médios 1 e 8 & 47.3167 & 3.9824 & 3.125 & $<0.05$ \\
\hline Postos médios 2 e 3 & 82.8766 & 5.9133 & 3.125 & $<0.05$ \\
\hline Postos médios 2 e 4 & 54.0909 & 3.9173 & 3.125 & $<0.05$ \\
\hline Postos médios 2 e 5 & 13.4909 & 1.0332 & 3.125 & $\mathrm{~ns}$ \\
\hline Postos médios 2 e 6 & 20.5455 & 1.3852 & 3.125 & $\mathrm{~ns}$ \\
\hline Postos médios 2 e 7 & 95.5909 & 6.8205 & 3.125 & $<0.05$ \\
\hline Postos médios 2 e 8 & 67.7576 & 4.907 & 3.125 & $<0.05$ \\
\hline Postos médios 3 e 4 & 28.7857 & 2.2269 & 3.125 & $\mathrm{~ns}$ \\
\hline Postos médios 3 e 5 & 69.3857 & 5.7242 & 3.125 & $<0.05$ \\
\hline Postos médios 3 e 6 & 62.3312 & 4.4474 & 3.125 & $<0.05$ \\
\hline Postos médios 3 e 7 & 12.7143 & 0.967 & 3.125 & $\mathrm{~ns}$ \\
\hline Postos médios 3 e 8 & 15.119 & 1.1696 & 3.125 & $\mathrm{~ns}$ \\
\hline Postos médios 4 e 5 & 40.6 & 3.4171 & 3.125 & $<0.05$ \\
\hline Postos médios 4 e 6 & 33.5455 & 2.4294 & 3.125 & $\mathrm{~ns}$ \\
\hline Postos médios 4 e 7 & 41.5 & 3.2105 & 3.125 & $<0.05$ \\
\hline Postos médios 4 e 8 & 13.6667 & 1.076 & 3.125 & $\mathrm{~ns}$ \\
\hline Postos médios 5 e 6 & 7.0545 & 0.5403 & 3.125 & $\mathrm{~ns}$ \\
\hline Postos médios 5 e 7 & 82.1 & 6.7731 & 3.125 & $<0.05$ \\
\hline Postos médios 5 e 8 & 54.2667 & 4.5674 & 3.125 & $<0.05$ \\
\hline Postos médios 6 e 7 & 75.0455 & 5.3545 & 3.125 & $<0.05$ \\
\hline Postos médios 6 e 8 & 47.2121 & 3.4191 & 3.125 & $<0.05$ \\
\hline Postos médios 7 e 8 & 27.8333 & 2.1532 & 3.125 & $\mathrm{~ns}$ \\
\hline
\end{tabular}


Com os resultados obtidos na Tabela 14 é possível verificar se há equivalência estatística entre os resultados obtidos na K com água destilada e na K com óleo de Neen.

Sendo assim, os grupos que são estatisticamente equivalentes são:

- Alburno do E. citriodora (água destilada, grupo 1) com alburno do E. grandis (água destilada, grupo 2; óleo de Neen, grupo 6), Pinus elliottii (água destilada, grupo 4) e alburno E. citriodora (óleo de Neen, grupo 5).

- Alburno E. grandis (água destilada, grupo 2) com alburno do E. citriodora (óleo de Neen, grupo 5) e alburno do E. grandis (óleo de Neen, grupo 6).

- Cerne do E. grandis (água destilada, grupo 3) com Pinus elliottii (água destilada, grupo 4; óleo de Neen, grupo 8), cerne do E. grandis (óleo de Neen, grupo 7).

- Pinus elliottii (água destilada, grupo 4) com alburno do E. grandis (óleo de Neen, grupo 6) e Pinus elliottii (óleo de Neen, grupo 8).

- Alburno do E. citriodora (óleo de Neen, grupo 5) com alburno do E. grandis (óleo de Neen, grupo 6).

- Cerne do E. grandis (óleo de Neen, grupo 7) com Pinus elliottii (óleo de Neen, grupo 8).

Os demais grupos não mostraram equivalência estatística por apresentarem um valor de $\mathrm{p}<0,05$.

Os resultados obtidos com o cruzamento dos resultados obtidos para os dois fluidos analisados (água destilada e preservativo á base de óleo de Neen) são apresentado no box-plot da Figura 4.25.

Analisando individualmente cada espécie e a parte específica do tronco de que foi retirado o corpo-de-prova, nota-se que, se compararmos os dois fluidos analisados, não há diferença estatística para estes grupos, apesar da diferença de viscosidade dos fluidos, são eles: grupo 1 e 5 ; grupo 2 e 6; grupo 3 e 7 e grupo 4 e 8 . 


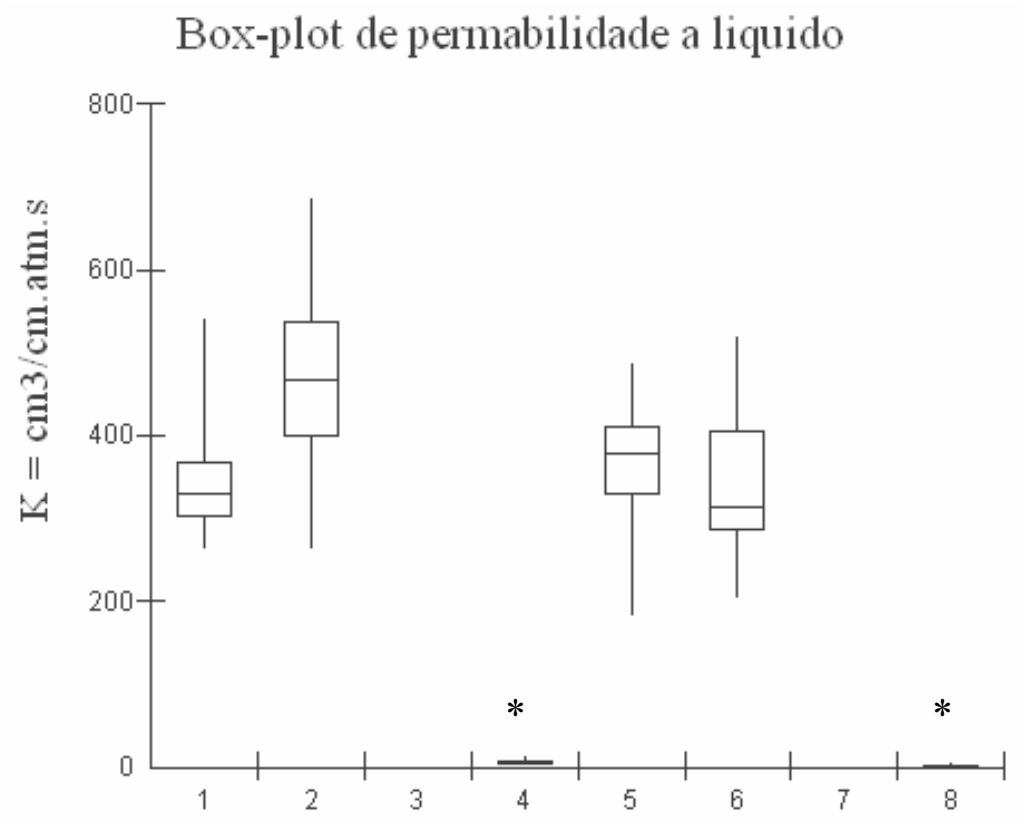

Espécie de madeira representada por grupos

Obs: * indica que a caixa do box-plot não aparece, devido os resultados da espécie analisada serem bem inferiores em relação aos demais.

Figura 4.25 - Box-plot de permeabilidade líquida para os dois tipos de fluidos analisados na direção longitudinal às fibras.

Em relação à permeabilidade na direção transversal às fibras, a única amostra que apresentou fluxo é a de Pinus elliottii. Esta espécie é permeável apenas a gás (ar atmosférico) e sendo assim não foi possível comparar estatisticamente sua permeabilidade com as demais. Os resultados para permeabilidade a gás para o Pinus elliottii na direção transversal são apresentado na tabela 14.

Tabela 15 - Resultados da $\mathrm{K}_{\mathrm{g}} \mathrm{em} \mathrm{cm}^{3} / \mathrm{cm}$.atm.s na direção longitudinal às fibras.

\begin{tabular}{|c|c|c|c|c|c|c|c|}
\hline C.P. & P. elliottii & C.P. & P. elliottii & C.P. & P. elliottii & C.P. & P. elliottii \\
\hline 01 & 18 & 06 & $* *$ & 11 & 24 & 16 & 29 \\
\hline 02 & 26 & 07 & 14 & 12 & 21 & 17 & $* *$ \\
\hline 03 & 16 & 08 & 28 & 13 & 31 & 18 & 15 \\
\hline 04 & 21 & 09 & 26 & 14 & 16 & 19 & 22 \\
\hline 05 & 24 & 10 & 32 & 15 & 29 & 20 & 31 \\
\hline
\end{tabular}


As amostras ensaiadas que não apresentaram permeabilidade a líquido e a gás são: alburno e cerne do Eucalyptus citriodora e Eucalyptus grandis na direção transversal, o cerne do Eucalyptus citriodora na direção longitudinal. O Pinus elliotti, não apresentou vazão na direção transversal para permeabilidade a líquido.

Com a finalidade de se encontrar um modelo matemático, que represente o comportamento para a propriedade de permeabilidade, das espécies estudadas, foram realizados testes de regressão linear, considerando as seguintes variáveis:

- permeabilidade e área da base do cilindro;

- permeabilidade e densidade;

- permeabilidade e volume do cilindro;

- permeabilidade e porosidade.

Os resultados obtidos demonstram que não há correlação entre os parâmetros analisados, onde o valor de $\mathrm{R}^{2}$ se mostrou sempre abaixo de 0,3 .

\section{4 - Caracterização simplificada}

Os ensaios de caracterização simplificada foram realizados no alburno e cerne das dicotiledôneas, porque o fluxo foi determinado em partes específicas da árvore.

Na Tabela 16 são apresentados as principais propriedades mecânicas da madeira, que são: os valores médios de compressão paralela às fibras $\left(f_{\mathrm{co}, \mathrm{m}}\right)$, módulo de elasticidade $\left(\mathrm{E}_{\mathrm{co}, \mathrm{m}}\right)$; densidade básica $\left(\rho_{\mathrm{bas}}\right)$, densidade aparente $\left(\rho_{\mathrm{ap}}\right)$, umidade $(\mathrm{U})$ e porosidade $\left(\mathrm{V}_{\mathrm{a}}\right)$.

Tabela 16 - Principais propriedades físicas da madeira.

\begin{tabular}{|c|c|c|c|c|c|c|c|}
\hline Espécie & Parte do lenho & fco,m (Mpa) & Eco,m $(\mathrm{MPa})$ & $\rho_{\text {bas }}\left(\mathrm{kg} / \mathrm{m}^{3}\right)$ & $\rho_{\mathrm{ap}}\left(\mathrm{kg} / \mathrm{m}^{3}\right)$ & $\mathrm{U}(\%)$ & $\mathrm{Va}(\%)$ \\
\hline \multirow{2}{*}{ E. citriodora } & Alburno & 67 & 7183 & 790 & 950 & 20 & 29.25 \\
\hline & Cerne & 73 & 23912 & 866 & 1076 & 25 & 20.56 \\
\hline \multirow{2}{*}{ E. grandis } & Alburno & 50 & 5357 & 603 & 723 & 21 & 41.35 \\
\hline & Cerne & 55 & 19175 & 556 & 720 & 29 & 39.60 \\
\hline Pinus elliottii & - & 39 & 6395 & 460 & 460 & 11 & 57.99 \\
\hline
\end{tabular}

Obs: - significa que não há diferença na parte do lenho. 
Dentre as propriedades físicas estudadas, a mais importante é a porosidade (fração de vazios), pois esta propriedade vem de encontro com a permeabilidade que se correlaciona bem com sua tratabilidade, Lepage (1986).

Em relação às dicotiledôneas, o alburno do E. grandis é a madeira de maior permeabilidade, em seguida temos o alburno do E. citriodora. Estes dados estão de acordo com a porosidade apresentada na Tabela 16. Apesar da alta porosidade do cerne do E. grandis, o mesmo apresenta baixa permeabilidade devido à presença de extrativos e tilas, que, mesmo em baixa quantidade, Tabela 2, obstruíram parcialmente esta espécie. Em relação ao cerne do E. citriodora, a permeabilidade nula é devido à alta quantidade de extrativos apresentado na análise química, Tabela 2.

O Pinus elliottii apresenta a maior porosidade dentre as espécies analisadas, mas sua permeabilidade na direção longitudinal é menor em relação ao alburno das dicotiledôneas, isto se deve ao fato que o fator determinante para permeabilidade das coníferas é a abertura das pontuações e não o diâmetro médio dos traqueídeos.

Das demais propriedades físicas apresentadas, quase todas estão de acordo com o NBR 7190/1997, com exceção do módulo de elasticidade médio para o alburno, que se encontra bem abaixo dos valores normativos. Estes resultados são explicados pelo fato de que, quando a norma foi composta, não houve diferenciação entre o alburno e cerne nos corpos-de-prova e sim em obter apenas os valores médios. 


\section{5 - CONCLUSÕES}

Do estudo teórico e experimental realizados, podemos concluir que:

- para realização dos ensaios de permeabilidade recomenda-se a desobstrução dos elementos anatômicos para determinação do fluxo, que pode ser evidenciado claramente com a microscopia eletrônica de varredura. A desobstrução dos elementos anatômicos seria mais significativa nas coníferas utilizando um micrótono, devido aos traqueídeos que foram colapsados;

- o alto teor de extrativo presente no cerne das dicotiledôneas é um fator determinante para sua permeabilidade, onde o cerne do E. citriodora apresenta o dobro de extrativos em relação ao cerne do E. grandis e, sua permeabilidade é nula;

- a diferença obtida nos resultados de permeabilidade está relacionada à particularidade anatômica de cada espécie, da parte específica do lenho de que foi retirado o corpo-de-prova e à idade da árvore. Na direção longitudinal, para permeabilidade a lìquido e a gás, o alburno do $E$ grandis se mostrou mais permeável que o alburno do E. citriodora, seguido do Pinus elliottii e cerne do E grandis. A única espécie que apresentou permeabilidade a gás na direção transversal foi a de Pinus elliottii e, para permeabilidade a líquido na direção transversal, nenhuma das espécies se mostrou permeável;

- analisando a permeabilidade a líquido em relação aos dois fluidos utilizados e a parte do lenho de que foi retirado o corpo-de-prova para a mesma espécie, conclui-se que a viscosidade não foi fator determinante para os resultados obtidos, pois os grupos são estatisticamente equivalentes;

- o cerne do E. grandis apresentou baixa vazão para os fluidos analisados. Este fato se deve à presença de tilas e à pressão que foi utilizada de $0,9 \mathrm{kgf} / \mathrm{cm}^{2}$. Sendo assim, para as dicotiledôneas, o E. grandis se mostrou mais viável para tratamento químico pelo fato de o cerne ser pouco permeável;

- das espécies analisadas todas apresentam um bom potencial para tratamento químico onde a espécie de Pinus elliottii não é a madeira mais permeável, mas é a única 
que apresentou vazão na direção transversal e sendo assim seria a mais indicada para receber tratamento químico;

- em relação às dicotiledôneas, apesar do alburno E citriodora, ter uma quantidade maior de vasos por $\mathrm{cm}^{2}$, o mesmo não apresenta à maior permeabilidade, devido o diâmetro médio dos vasos do alburno do E grandis, serem em média o dobro do diâmetro médio dos vasos do E citriodora;

- a porosidade não é fator determinante na permeabilidade, visto que os elementos anatômicos podem estar obstruídos por tilas;

- o equipamento apresentado se mostrou de fácil construção, baixo custo e apresenta resultados satisfatórios na determinação da permeabilidade a líquido e a gás. Se o objetivo for apenas determinar a permeabilidade a gás, pode-se optar por montar apenas o conjunto de rolhas juntamente com a mangueira cristal;

- o ensaio com gás, se mostrou mais viável na determinação da permeabilidade, porque a madeira é um material hidrófilo e, os fluidos líquidos aquosos utilizados tendem a se interagir com a parede celular pela devido a sua polaridade;

- as análises de correlações realizadas, considerando os parâmetros de permeabilidade x área da base do cilindro, densidade, volume do cilindro e porosidade, não apresentaram resultados satisfatórios para o comportamento das propriedades de permeabilidade.

Para continuidade desta pesquisa, recomenda-se:

- determinar o parâmetro mais importante relacionado a permeabilidade, para uma proposta de um modelo matemático que explique o comportamento da propriedade de permeabilidade;

- desenvolvimento de uma normalização para os ensaios de permeabilidade;

- composição de uma tabela de permeabilidade para as madeiras brasileiras. 


\section{6 - REFERÊNCIAS}

ARAujO, L. V. C.; RODRIGUEZ, L. C. E.; PAES, J. B.; Características físicoquímicas e energéticas da madeira de nim indiano. Scientia Forestalis, v. , n.57, p.153$159,2000$.

ASSOCIAÇÃO BRASILEIRA DE NORMAS TÉCNICAS. NBR 7190 : projeto de estruturas de madeira. Rio de Janeiro: ABNT,1997.

BARRICHELO, L. E. G.; BRITO, J. O.; Química da madeira. Piracicaba: Esalq, 1985. $125 \mathrm{p}$.

CALIL, C.J.; ROCCO, F.A.; DIAS, A.A. Dimensionamento de elementos estruturais de madeira. São Carlos: Editora Manole, 2003, 152 p.

CAMPOS, H. Estatística experimental não-paramétrica 3ed. Piracicaba: Esalq, 1979. cap. 7.

FENGEL, Dietrich; Wood - chemistry, ultrastructure, reactions. New York: Walter de Gruyter, 1989.p.613

DÉON, G. Manual de preservação das madeiras em clima tropical. Tradução. de Antonio Carlos Mascarenhas. Salvador: ITTO,1989. 116p. (Série Técnica 3)

HANSMANN, C. Permeability of wood - a review. Drevarsky Vyskum, v.47 ,n.4, p.1$16,2002$.

HELLMEISTER, J.C. Sobre a determinação das características físicas da madeira. 1973. 161p. Tese (Doutorado em engenharia) - Escola de Engenharia de São Carlos, Universidade de São Paulo, São Carlos, 1973. 
ILMARI, A et al. Modeling fundamental properties of wood products. In: International Wood Engineering Conference - IWEC, New Orleans, Louisiana, USA, 1996.

JANKOWSKY, I.P. Potencialidade do creosoto de eucalyptus ssp como preservativo para madeiras. 1986. 159p Tese (Doutorado em engenharia) Escola Politécnica de São Paulo - Universidade de São Paulo, São Paulo, 1986.

KRABBENHOFT, K.; DAMKILDE, L. Double porosity models for the description of water infiltration in wood. Wood Science Technology, v.38, n.8, p.641-659, Dec 2004.

LEPAGE, E.N. (Coord.). Manual de preservação de madeiras. São Paulo: IPT, 1986.708p. (Publicação IPT n. ${ }^{\circ}$ 1637, v.I-II)

LATORRACA, J.V.F.; ALBUQUERQUE, C.E.C. Colagem varia de acordo com as propriedades da madeira. Rev. da Madeira, ano 15, n.88, p. 28-32, 2005.

MACHADO, G.O.;et al. Preservativo para madeira á base de óleo de Neen. In: Encontro Brasileiro em Madeiras e em Estruturas de Madeira, 10, São Pedro, 2006. Anais, São Pedro, 2006.

MAGALHÃES, W.L.E. Tratamento mecânico visando o aumento da permeabilidade em madeira de Pinus elliottii Engelm Var.elliotti. In: Encontro Brasileiro em Madeiras e em Estruturas de Madeira, 9, Cuiabá, 2004. Anais, Cuiabá, 2004.

MILLER, R.B. Wood handbook: wood as an engineering material. Madison, Wisconsin, Forest Products Laboratory - FPL, 1999. 463p. 
MINISTÉRIO DA AGRICULTURA. Boletins meteorológicos mensais:período de 1970 a 1993. Disponível em: < http://extranet.cppse.embrapa.br:8080/extranet/servicos/dados-meteorologicos > Acesso em: 15 jan. 2007.

MORALES, E.A.M. Determinação do módulo de elasticidade da madeira: proposta para simplificação de procedimentos metodológicos. 2002. 86p. Dissertação (Mestrado em Ciências e Engenharia de Materiais) - Escola de Engenharia de São Carlos, Universidade de São Paulo, São Carlos, 2002.

MORI, F. A. et al. Utilização de eucaliptos e de madeiras nativas no armazenamento da aguardente de cana-de-açúcar. Ci. Tecnol. Aliment. Campinas, v. 23, n. 3, 2003.

SIAU, J.F. Flow in wood. Syracuse, Syracuse University Press, 1971. 131 p.

SJOSTROM, S. Wood chemistry: fundamentals and applications. London: Academic Press, Inc., 1981.

TAPPI STANDARD METHODS. Ash in wood and pulp: T 211 om-85. Atlanta, TAPPI PRESS, 1991. v.1.

TAPPI STANDARD METHODS. Acid-insoluble lignin in wood and pulp: T 222 om98. Atlanta, TAPPI PRESS, 1999.

TAPPI STANDARD METHODS. Preparation of wood for chemical analysis: T 264 cm-97. Atlanta, TAPPI PRESS ,1999.

TAYLOR, G. LA MADERA. Barcelona:Ed. Blume, 1978. 272 p. 


\section{ANEXO I}

\section{DADOS DOS ENSAIOS REALIZADOS}

Abaixo estão as tabelas das considerações e resultados para as espécies que apresentaram vazão, o sentido em relação às fibras e a parte do lenho em que o corpode-prova foi ensaiado. Foram a partir destes resultados que se calculou a permeabilidade.

\section{Significado das siglas para as tabelas abaixo:}

$\mathrm{CP}=$ corpo-de-prova;

$\mathrm{U} \%=$ porcentagem de umidade verde;

$\mathrm{P}_{\mathrm{v}}=$ peso verde;

$\mathrm{P}_{\mathrm{s}}=$ peso $\operatorname{seco}-(\mathrm{U}=12 \%)$;

$\mathrm{D}=$ seção do corpo-de-prova com elementos anatômicos desobstruídos;

$\mathrm{O}=$ seção do corpo-de-prova com elementos anatômicos obstruídos;

$\mathrm{Q}=$ fluxo;

$\mathrm{P}_{1}=$ pressão de saída no corpo-de-prova;

$1=$ comprimento;

$\varnothing=$ diâmetro;

$\mathrm{s}=$ segundo;

$\min =$ minuto;

$\mathrm{P}_{\mathrm{f}}=$ peso final;

atm $=$ pressão atmosférica. 
Anexo I-Permeabilidade

Tabela 01 - Considerações e resultados para os corpos-de-prova de E. citriodora no alburno para ensaio a gás na direção longitudinal às fibras.

\begin{tabular}{|c|c|c|c|c|c|c|c|c|c|c|c|c|}
\hline \multirow{2}{*}{$\mathrm{CP}$} & \multirow{2}{*}{$\mathrm{U}(\%)$} & \multirow{2}{*}{$P_{v}(g)$} & \multirow{2}{*}{$P_{s}(g)$} & \multirow{2}{*}{$\begin{array}{c}\text { Situação da } \\
\text { seção }\end{array}$} & \multicolumn{2}{|c|}{$\mathrm{Q}(\mathrm{L} / \mathrm{h})$} & \multirow{2}{*}{$\begin{array}{c}\mathrm{P}_{1} \\
(\mathrm{~atm})\end{array}$} & \multicolumn{2}{|c|}{$\mathrm{Q}(\mathrm{L} / \mathrm{h})$ na inversão } & \multirow{2}{*}{$\begin{array}{c}\mathrm{P}_{1} \\
(\mathrm{~atm})\end{array}$} & \multirow{2}{*}{$\begin{array}{c}1(\mathrm{~mm}) \\
\text { a } 12 \% \mathrm{U}\end{array}$} & \multirow{2}{*}{$\begin{array}{l}\varnothing(\mathrm{mm}) \\
\text { a } 12 \% \mathrm{U}\end{array}$} \\
\hline & & & & & Após 1min & Após $2 \mathrm{~min}$ & & Após $1 \mathrm{~min}$ & Após $2 \mathrm{~min}$ & & & \\
\hline CAL - 01 & 20 & 16,8 & 15,68 & $\mathrm{D}$ & 570 & 570 & 0,237 & 570 & 570 & 0,237 & 50,68 & 20,39 \\
\hline CAL - 02 & 20 & 16,9 & 15,77 & $\mathrm{D}$ & 500 & 500 & 0,316 & 500 & 500 & 0,316 & 51,01 & 20,40 \\
\hline CAL - 03 & 20 & 16 & 14,93 & $\mathrm{D}$ & 525 & 525 & 0,263 & 525 & 525 & 0,263 & 50,80 & 18,88 \\
\hline CAL - 04 & 20 & 16,1 & 15,03 & $\mathrm{D}$ & 555 & 555 & 0,276 & 555 & 555 & 0,276 & 51,23 & 20,12 \\
\hline CAL - 05 & 20 & 14,4 & 13,44 & $\mathrm{D}$ & 560 & 560 & 0,263 & 560 & 560 & 0,263 & 51,38 & 20,01 \\
\hline CAL - 06 & 20 & 16,3 & 15,21 & $\mathrm{D}$ & 575 & 575 & 0,257 & 575 & 575 & 0,257 & 51,20 & 20,18 \\
\hline CAL - 08 & 20 & 16,2 & 15,12 & $\mathrm{D}$ & 500 & 500 & 0,289 & 500 & 500 & 0,289 & 51,32 & 19,65 \\
\hline CAL - 09 & 20 & 16,1 & 15,03 & $\mathrm{D}$ & 525 & 525 & 0,276 & 525 & 525 & 0,276 & 51,30 & 19,52 \\
\hline CAL - 10 & 20 & 17,3 & 16,15 & $\mathrm{D}$ & 550 & 550 & 0,243 & 550 & 550 & 0,243 & 51,26 & 20,33 \\
\hline CAL - 11 & 20 & 15,1 & 14,09 & $\mathrm{D}$ & 575 & 575 & 0,237 & 575 & 575 & 0,237 & 51,11 & 19,40 \\
\hline CAL - 12 & 20 & 14,9 & 13,91 & $\mathrm{D}$ & 500 & 500 & 0,329 & 500 & 500 & 0,329 & 51,14 & 19,41 \\
\hline CAL - 13 & 20 & 13,2 & 12,32 & $\mathrm{D}$ & 550 & 550 & 0,263 & 550 & 550 & 0,263 & 47,17 & 19,09 \\
\hline CAL - 14 & 20 & 14,3 & 13,35 & $\mathrm{D}$ & 475 & 475 & 0,355 & 475 & 475 & 0,355 & 51,28 & 18,99 \\
\hline CAL - 16 & 20 & 15,1 & 14,09 & $\mathrm{D}$ & 500 & 500 & 0,316 & 500 & 500 & 0,316 & 50,78 & 19,31 \\
\hline CAL - 17 & 20 & 13,6 & 12,69 & $\mathrm{D}$ & 500 & 500 & 0,329 & 500 & 500 & 0,329 & 50,55 & 18,93 \\
\hline CAL - 18 & 20 & 13,8 & 12,88 & $\mathrm{D}$ & 475 & 475 & 0,382 & 475 & 475 & 0,382 & 50,05 & 18,82 \\
\hline CAL - 19 & 20 & 14,7 & 13,72 & $\mathrm{D}$ & 600 & 600 & 0,211 & 600 & 600 & 0,211 & 51,25 & 19,94 \\
\hline CAL - 20 & 20 & 15,7 & 14,65 & $\mathrm{D}$ & 625 & 625 & 0,171 & 625 & 625 & 0,171 & 51,77 & 20,27 \\
\hline
\end{tabular}

\begin{tabular}{|c|c|c|c|c|c|c|c|c|c|c|c|c|}
\hline CAL - 04 & 20 & 16,1 & 15,03 & $\mathrm{O}$ & 175 & 175 & 0,632 & 175 & 175 & 480 & 52,23 & 20,12 \\
\hline CAL - 05 & 20 & 14,4 & 13,44 & $\mathrm{O}$ & 155 & 155 & 0,658 & 155 & 155 & 500 & 52,38 & 20,01 \\
\hline CAL - 06 & 20 & 16,3 & 15,21 & $\mathrm{O}$ & 180 & 180 & 0,605 & 180 & 180 & 460 & 52,20 & 20,18 \\
\hline CAL - 07 & 20 & 15,6 & 14,56 & $\mathrm{O}$ & 100 & 100 & 0,724 & 100 & 100 & 550 & 52,27 & 19,24 \\
\hline CAL - 08 & 20 & 16,2 & 15,12 & $\mathrm{O}$ & 275 & 275 & 0,553 & 275 & 275 & 420 & 52,32 & 19,65 \\
\hline CAL - 09 & 20 & 16,1 & 15,03 & $\mathrm{O}$ & 225 & 225 & 0,579 & 225 & 225 & 440 & 52,30 & 19,52 \\
\hline CAL - 10 & 20 & 17,3 & 16,15 & $\mathrm{O}$ & 175 & 175 & 0,632 & 175 & 175 & 480 & 52,26 & 20,33 \\
\hline
\end{tabular}


Anexo I-Permeabilidade

Tabela 02 - Considerações e resultados para os corpos-de-prova de E.grandis no alburno para ensaio a gás na direção longitudinal às fibras.

\begin{tabular}{|c|c|c|c|c|c|c|c|c|c|c|c|c|}
\hline \multirow{2}{*}{$\mathrm{CP}$} & \multirow{2}{*}{$\mathrm{U}(\%)$} & \multirow{2}{*}{$\left.P_{v}(g)\right)$} & \multirow{2}{*}{$P_{s}(g)$} & \multirow{2}{*}{$\begin{array}{c}\text { Situação da } \\
\text { seção } \\
\end{array}$} & \multicolumn{2}{|c|}{$\mathrm{Q}(\mathrm{L} / \mathrm{h})$} & \multirow{2}{*}{$\begin{array}{c}\mathrm{P}_{1} \\
(\mathrm{~atm})\end{array}$} & \multicolumn{2}{|c|}{$\mathrm{Q}(\mathrm{L} / \mathrm{h})$ na inversão } & \multirow{2}{*}{$\begin{array}{c}\mathrm{P}_{1} \\
(\mathrm{~atm})\end{array}$} & \multirow{2}{*}{$\begin{array}{l}1(\mathrm{~mm}) \\
\text { a } 12 \% \mathrm{U}\end{array}$} & \multirow{2}{*}{$\begin{array}{l}\varnothing(\mathrm{mm}) \\
\text { a } 12 \% \mathrm{U}\end{array}$} \\
\hline & & & & & Após 1min & Após $2 \mathrm{~min}$ & & Após $1 \mathrm{~min}$ & Após 2 min & & & \\
\hline GAL - 01 & 20,8 & 11,9 & 11,03 & $\mathrm{D}$ & 675 & 675 & 0,112 & 675 & 675 & 0,112 & 50,80 & 18,90 \\
\hline GAL - 02 & 20,8 & 12,1 & 11,22 & $\mathrm{D}$ & 625 & 625 & 0,184 & 625 & 625 & 0,184 & 50,90 & 19,20 \\
\hline GAL - 04 & 20,8 & 16,2 & 15,02 & $\mathrm{D}$ & 525 & 525 & 0,316 & 525 & 525 & 0,316 & 50,90 & 19,5 \\
\hline GAL - 05 & 20,8 & 16,6 & 15,39 & $\mathrm{D}$ & 650 & 650 & 0,151 & 650 & 650 & 0,151 & 51,05 & 19,84 \\
\hline GAL - 06 & 20,8 & 11,7 & 10,85 & $\mathrm{D}$ & 575 & 575 & 0,263 & 575 & 575 & 0,263 & 51,53 & 18,34 \\
\hline GAL - 08 & 20,8 & 11,8 & 10,94 & $\mathrm{D}$ & 625 & 625 & 0,171 & 625 & 625 & 0,171 & 51,24 & 18,44 \\
\hline GAL - 09 & 20,8 & 12,2 & 11,31 & $\mathrm{D}$ & 700 & 700 & 0,099 & 700 & 700 & 0,099 & 51,00 & 18,88 \\
\hline GAL - 10 & 20,8 & 11,7 & 10,85 & $\mathrm{D}$ & 325 & 325 & 0,461 & 325 & 325 & 0,461 & 51,00 & 18,30 \\
\hline GAL - 11 & 20,8 & 15,8 & 14,6 & $\mathrm{D}$ & 500 & 500 & 0,316 & 500 & 500 & 0,316 & 51,06 & 19,99 \\
\hline GAL - 12 & 20,8 & 11,4 & 10,5 & $\mathrm{D}$ & 690 & 690 & 0,118 & 690 & 690 & 0,118 & 50,58 & 19,18 \\
\hline GAL - 13 & 20,8 & 11,6 & 10,7 & $\mathrm{D}$ & 525 & 525 & 0,316 & 525 & 525 & 0,316 & 50,84 & 19,36 \\
\hline GAL - 14 & 20,8 & 11,3 & 10,4 & $\mathrm{D}$ & 675 & 675 & 0,145 & 675 & 675 & 0,145 & 51,00 & 19,28 \\
\hline GAL - 17 & 20,8 & 11,3 & 10,4 & $\mathrm{D}$ & 550 & 550 & 0,263 & 550 & 550 & 0,263 & 50,58 & 19,01 \\
\hline GAL - 18 & 20,8 & 11,4 & 10,5 & $\mathrm{D}$ & 690 & 690 & 0,118 & 690 & 690 & 0,118 & 51,05 & 19,31 \\
\hline GAL - 19 & 20,8 & 15,7 & 14,5 & $\mathrm{D}$ & 625 & 625 & 0,171 & 625 & 625 & 0,171 & 50,89 & 20,43 \\
\hline GAL - 20 & 20,8 & 11,1 & 10,2 & $\mathrm{D}$ & 560 & 560 & 0,263 & 560 & 560 & 0,263 & 50,68 & 18,88 \\
\hline
\end{tabular}

\begin{tabular}{|c|c|c|c|c|c|c|c|c|c|c|c|c|}
\hline GAL - 06 & 20,8 & 11,7 & 10,85 & $\mathrm{O}$ & 175 & 175 & 0,724 & 175 & 175 & 0,724 & 52,53 & 18,34 \\
\hline GAL - 07 & 20,8 & 12,5 & 11,59 & $\mathrm{O}$ & 225 & 225 & 0,658 & 225 & 225 & 0,658 & 52,25 & 19,02 \\
\hline GAL - 08 & 20,8 & 11,8 & 10,94 & $\mathrm{O}$ & 150 & 150 & 0,737 & 150 & 150 & 0,737 & 52,24 & 18,44 \\
\hline GAL - 09 & 20,8 & 12,2 & 11,31 & $\mathrm{O}$ & 250 & 250 & 0,539 & 250 & 250 & 0,539 & 52,00 & 18,88 \\
\hline
\end{tabular}


Tabela 03 - Considerações e resultados para os corpos-de-prova de E. grandis no cerne para ensaio a gás na direção longitudinal às fibras.

\begin{tabular}{|c|c|c|c|c|c|c|c|c|c|c|c|c|c|}
\hline \multirow{2}{*}{$\mathrm{CP}$} & \multirow{2}{*}{$\mathrm{U}(\%)$} & \multirow{2}{*}{$\left.P_{v}(g)\right)$} & \multirow{2}{*}{$P_{s}(g)$} & \multirow{2}{*}{$\begin{array}{l}\text { Situação da } \\
\text { seção }\end{array}$} & \multicolumn{2}{|c|}{$\mathrm{Q}(\mathrm{L} / \mathrm{h})$} & \multirow{2}{*}{$\begin{array}{c}\mathrm{P}_{1} \\
(\mathrm{~atm})\end{array}$} & \multirow{2}{*}{$\begin{array}{c}\text { Média da } \\
\text { diferença }\end{array}$} & \multicolumn{2}{|c|}{$\mathrm{Q}(\mathrm{ml} / \mathrm{m})$ na inversão } & \multirow{2}{*}{$\begin{array}{c}\mathrm{P}_{1} \\
(\mathrm{~atm})\end{array}$} & \multirow{2}{*}{$\begin{array}{c}1(\mathrm{~mm}) \\
\text { a } 12 \% \mathrm{U}\end{array}$} & \multirow{2}{*}{$\begin{array}{l}\varnothing(\mathrm{mm}) \\
\mathrm{a} 12 \% \mathrm{U}\end{array}$} \\
\hline & & & & & Após 1min & Após $2 \mathrm{~min}$ & & & Após $1 \mathrm{~min}$ & Após $2 \mathrm{~min}$ & & & \\
\hline GCL - 01 & 28,9 & 9,4 & 8,17 & $\mathrm{D}$ & 47 & 47 & 0,855 & 44 & 40 & 40 & 0,868 & 48,80 & 17,84 \\
\hline GCL - 02 & 28,9 & 9,2 & 7,99 & $\mathrm{D}$ & 47 & 47 & 0,855 & 47 & 47 & 47 & 0,855 & 47,30 & 17,70 \\
\hline GCL - 03 & 28,9 & 10 & 8,69 & $\mathrm{D}$ & $*$ & $*$ & 0,868 & $*$ & $*$ & $*$ & 0,868 & 47,02 & 18,79 \\
\hline GCL - 04 & 28,9 & 10,3 & 8,95 & $\mathrm{D}$ & 85 & 85 & 0,803 & 70 & 55 & 55 & 0,842 & 49,25 & 19,02 \\
\hline GCL - 05 & 28,9 & 9,1 & 7,91 & $\mathrm{D}$ & 35 & 35 & 0,868 & 30 & 25 & 25 & 0,868 & 47,88 & 18,46 \\
\hline GCL - 06 & 28,9 & 10,5 & 9,12 & $\mathrm{D}$ & 32 & 32 & 0,868 & 30 & 28 & 28 & 0,868 & 49,70 & 18,94 \\
\hline GCL - 08 & 28,9 & 9,6 & 8,34 & $\mathrm{D}$ & 35 & 35 & 0,868 & 35 & 35 & 35 & 0,868 & 48,01 & 17,76 \\
\hline GCL - 09 & 28,9 & 9,6 & 8,34 & $\mathrm{D}$ & 25 & 25 & 0,868 & 24 & 22 & 22 & 0,868 & 47,61 & 17,70 \\
\hline GCL - 10 & 28,9 & 12 & 10,43 & $\mathrm{D}$ & $*$ & $*$ & 0,868 & $*$ & $*$ & $*$ & 0,868 & 50,47 & 18,23 \\
\hline GCL - 11 & 28,9 & 9,6 & 8,3 & $\mathrm{D}$ & 30 & 30 & 0,868 & 27 & 25 & 25 & 0,868 & 48,19 & 19,48 \\
\hline GCL - 12 & 28,9 & 9,6 & 8,3 & $\mathrm{D}$ & 42 & 42 & 0,862 & 42 & 42 & 42 & 0,862 & 49,22 & 19,22 \\
\hline GCL - 13 & 28,9 & 10 & 8,6 & $\mathrm{D}$ & 55 & 55 & 0,842 & 55 & 55 & 55 & 0,842 & 50,14 & 19,14 \\
\hline GCL - 14 & 28,9 & 9,6 & 8,3 & $\mathrm{D}$ & 23 & 23 & 0,868 & 21 & 18 & 18 & 0,868 & 50,02 & 18,13 \\
\hline GCL - 16 & 28,9 & 9,8 & 8,5 & $\mathrm{D}$ & 47 & 47 & 0,855 & 47 & 47 & 47 & 0,855 & 49,29 & 19,50 \\
\hline GCL - 17 & 28,9 & 9,6 & 8,3 & $\mathrm{D}$ & 55 & 55 & 0,842 & 50 & 45 & 45 & 0,862 & 46,63 & 19,30 \\
\hline GCL - 18 & 28,9 & 8,8 & 7,6 & $\mathrm{D}$ & 40 & 40 & 0,868 & 38 & 25 & 25 & 0,868 & 49,25 & 18,56 \\
\hline GCL - 19 & 28,9 & 9,5 & 8,2 & $\mathrm{D}$ & 35 & 35 & 0,868 & 34 & 32 & 32 & 0,868 & 48,26 & 19,06 \\
\hline GCL - 20 & 28,9 & 8 & 6,9 & $\mathrm{D}$ & 37 & 37 & 0,868 & 35 & 32 & 32 & 0,868 & 45,05 & 18,36 \\
\hline
\end{tabular}

\begin{tabular}{|c|c|c|c|c|c|c|c|c|c|c|c|c|c|}
\hline GCL - 06 & 28,9 & 10,5 & 9,12 & $\mathrm{O}$ & 30 & 30 & 0,868 & 31 & 32 & 32 & 0,868 & 50,70 & 18,94 \\
\hline GCL - 07 & 28,9 & 11,3 & 9,82 & $\mathrm{O}$ & 47 & 47 & 0,855 & 38 & 30 & 30 & 0,868 & 51,40 & 19,96 \\
\hline GCL - 08 & 28,9 & 9,6 & 8,34 & $\mathrm{O}$ & 35 & 35 & 0,868 & 33 & 30 & 30 & 0,868 & 49,01 & 17,76 \\
\hline GCL - 09 & 28,9 & 9,6 & 8,34 & $\mathrm{O}$ & 25 & 25 & 0,868 & 20 & 15 & 15 & 0,868 & 48,61 & 17,70 \\
\hline
\end{tabular}


Anexo I-Permeabilidade

Tabela 04 - Considerações e resultados para os corpos-de-prova de $P$. elliottii para ensaio a gás na direção longitudinal às fibras.

\begin{tabular}{|c|c|c|c|c|c|c|c|c|c|c|c|c|}
\hline \multirow{2}{*}{$\mathrm{CP}$} & \multirow{2}{*}{$\mathrm{U}(\%)$} & \multirow{2}{*}{$P_{v}(g)$} & \multirow{2}{*}{$P_{s}(g)$} & \multirow{2}{*}{$\begin{array}{c}\text { Situação da } \\
\text { seção }\end{array}$} & \multicolumn{2}{|c|}{$\mathrm{Q}(\mathrm{L} / \mathrm{h})$} & \multirow{2}{*}{$\begin{array}{c}\mathrm{P}_{1} \\
(\mathrm{~atm})\end{array}$} & \multicolumn{2}{|c|}{$\mathrm{Q}(\mathrm{L} / \mathrm{h})$ na inversão } & \multirow{2}{*}{$\begin{array}{c}\mathrm{P}_{1} \\
(\mathrm{~atm})\end{array}$} & \multirow{2}{*}{$\begin{array}{c}1(\mathrm{~mm}) \\
\text { a } 12 \% \mathrm{U}\end{array}$} & \multirow{2}{*}{$\begin{array}{l}\varnothing(\mathrm{mm}) \\
\text { a } 12 \% \mathrm{U}\end{array}$} \\
\hline & & & & & Após $1 \mathrm{~min}$ & Após $2 \mathrm{~min}$ & & Após $1 \mathrm{~min}$ & Após $2 \mathrm{~min}$ & & & \\
\hline PL - 01 & 10,65 & 8,6 & 8,6 & $\mathrm{D}$ & 34 & 34 & 0,803 & 34 & 34 & 0,803 & 49,90 & 21,35 \\
\hline PL - 02 & 10,65 & 8,8 & 8,8 & $\mathrm{D}$ & 32 & 32 & 0,816 & 32 & 32 & 0,816 & 49,05 & 20,22 \\
\hline PL - 03 & 10,65 & 7,2 & 7,2 & $\mathrm{D}$ & 49 & 49 & 0,763 & 49 & 49 & 0,763 & 48,86 & 21,02 \\
\hline PL - 04 & 10,65 & 7,6 & 7,6 & $\mathrm{D}$ & 52 & 52 & 0,763 & 52 & 52 & 0,763 & 48,95 & 19,85 \\
\hline PL - 05 & 10,65 & 7,2 & 7,2 & $\mathrm{D}$ & 26 & 26 & 0,816 & 26 & 26 & 0,816 & 49,28 & 20,64 \\
\hline PL - 06 & 10,65 & 8 & 8 & $\mathrm{D}$ & 44 & 44 & 0,750 & 44 & 44 & 0,750 & 49,28 & 20,49 \\
\hline PL - 08 & 10,65 & 7,2 & 7,2 & $\mathrm{D}$ & 50 & 50 & 0,724 & 50 & 50 & 0,724 & 49,28 & 19,90 \\
\hline PL - 09 & 10,65 & 8,3 & 8,3 & $\mathrm{D}$ & 63 & 63 & 0,684 & 63 & 63 & 0,684 & 49,24 & 20,18 \\
\hline PL - 10 & 10,65 & 8 & 8 & $\mathrm{D}$ & 28 & 28 & 0,816 & 28 & 28 & 0,816 & 48,74 & 20,00 \\
\hline PL - 11 & 10,65 & 6,2 & 6,2 & $\mathrm{D}$ & 33 & 33 & 0,816 & 33 & 33 & 0,816 & 50,10 & 19,97 \\
\hline PL - 12 & 10,65 & 9,5 & 9,5 & $\mathrm{D}$ & 28 & 28 & 0,816 & 28 & 28 & 0,816 & 50,51 & 20,29 \\
\hline PL - 13 & 10,65 & 6,8 & 6,8 & $\mathrm{D}$ & 31 & 31 & 0,816 & 31 & 31 & 0,816 & 50,11 & 20,31 \\
\hline PL - 14 & 10,65 & 6,5 & 6,5 & $\mathrm{D}$ & 17 & 17 & 0,842 & 17 & 17 & 0,842 & 50,92 & 20,27 \\
\hline PL - 16 & 10,65 & 7,3 & 7,3 & $\mathrm{D}$ & 27 & 27 & 0,816 & 27 & 27 & 0,816 & 50,07 & 20,28 \\
\hline PL - 17 & 10,65 & 9,4 & 9,4 & $\mathrm{D}$ & 26 & 26 & 0,816 & 26 & 26 & 0,816 & 50,18 & 20,26 \\
\hline PL - 18 & 10,65 & 6,8 & 6,8 & $\mathrm{D}$ & 22 & 22 & 0,829 & 22 & 22 & 0,829 & 49,33 & 20,08 \\
\hline PL - 19 & 10,65 & 9,6 & 9,6 & $\mathrm{D}$ & 25 & 25 & 0,829 & 25 & 25 & 0,829 & 50,49 & 20,32 \\
\hline PL - 20 & 10,65 & 6,7 & 6,7 & $\mathrm{D}$ & 18 & 18 & 0,842 & 18 & 18 & 0,842 & 50,00 & 19,81 \\
\hline
\end{tabular}

\begin{tabular}{|l|l|l|l|l|l|l|l|l|l|l|l|l|}
\hline PL - 11 & 10,65 & 6,2 & 6,2 & O & 26 & 26 & 0,816 & 26 & 26 & 0,816 & 50,25 & 19,97 \\
\hline PL - 12 & 10,65 & 9,5 & 9,5 & O & 20 & 20 & 0,855 & 20 & 20 & 0,855 & 50,64 & 20,29 \\
\hline PL - 13 & 10,65 & 6,8 & 6,8 & O & 22 & 22 & 0,829 & 22 & 22 & 0,829 & 50,26 & 20,31 \\
\hline PL - 14 & 10,65 & 6,5 & 6,5 & O & 12 & 12 & 0,842 & 12 & 12 & 0,842 & 51,10 & 20,27 \\
\hline PL - 15 & 10,65 & 6,2 & 6,2 & O & 20 & 20 & 0,855 & 20 & 20 & 0,855 & 50,44 & 19,91 \\
\hline
\end{tabular}


Tabela 05 - Considerações e resultados para os corpos-de-prova de $P$. elliottii para ensaio a gás na direção transversal às fibras.

\begin{tabular}{|c|c|c|c|c|c|c|c|c|c|c|c|c|c|}
\hline \multirow{2}{*}{$\mathrm{CP}$} & \multirow{2}{*}{$U(\%)$} & \multirow{2}{*}{$P_{v}(g)$} & \multirow{2}{*}{$P_{s}(g)$} & \multirow{2}{*}{$\begin{array}{c}\text { Situação da } \\
\text { seção }\end{array}$} & \multicolumn{2}{|c|}{$\mathrm{Q}(\mathrm{L} / \mathrm{h})$} & \multirow{2}{*}{$\begin{array}{c}\mathrm{P}_{1} \\
(\mathrm{~atm})\end{array}$} & \multirow{2}{*}{$\begin{array}{l}\text { Média da } \\
\text { diferença }\end{array}$} & \multicolumn{2}{|c|}{$\mathrm{Q}(\mathrm{ml} / \mathrm{m})$ na inversão } & \multirow{2}{*}{$\begin{array}{c}\mathrm{P}_{1} \\
(\mathrm{~atm})\end{array}$} & \multirow{2}{*}{$\begin{array}{c}1(\mathrm{~mm}) \\
\text { a } 12 \% \mathrm{U}\end{array}$} & \multirow{2}{*}{$\begin{array}{l}\varnothing(\mathrm{mm}) \\
\text { a } 12 \% \mathrm{U}\end{array}$} \\
\hline & & & & & Após $1 \mathrm{~min}$ & Após 2 min & & & Após $1 \mathrm{~min}$ & Após $2 \mathrm{~min}$ & & & \\
\hline PT - 01 & 10,65 & 8,2 & 8,2 & $\mathrm{D}$ & 30 & 30 & 0,868 & 26 & 22 & 22 & 0,868 & 48,48 & 20 \\
\hline $\mathrm{PT}-02$ & 10,65 & 7,9 & 7,9 & $\mathrm{D}$ & 42 & 42 & 0,862 & 42 & 42 & 42 & 0,862 & 49,5 & 20,01 \\
\hline $\mathrm{PT}-03$ & 10,65 & 7,5 & 7,5 & $\mathrm{D}$ & 25 & 25 & 0,868 & 24 & 22 & 22 & 0,868 & 49,04 & 20,57 \\
\hline $\mathrm{PT}-04$ & 10,65 & 7,6 & 7,6 & $\mathrm{D}$ & 30 & 30 & 0,868 & 30 & 30 & 30 & 0,868 & 49,41 & 20,18 \\
\hline PT - 05 & 10,65 & 7,9 & 7,9 & $\mathrm{D}$ & 55 & 55 & 0,855 & 47 & 40 & 40 & 0,855 & 48,84 & 20,09 \\
\hline PT - 06 & 10,65 & 7,3 & 7,3 & $\mathrm{D}$ & $*$ & $*$ & 0,868 & $*$ & $*$ & $*$ & 0,868 & 49,48 & 19,65 \\
\hline PT - 08 & 10,65 & 8,4 & 8,4 & $\mathrm{D}$ & 50 & 50 & 0,862 & 50 & 50 & 50 & 0,862 & 48,95 & 20,66 \\
\hline PT - 09 & 10,65 & 7,7 & 7,7 & $\mathrm{D}$ & 50 & 50 & 0,862 & 43 & 35 & 35 & 0,862 & 49,55 & 20,16 \\
\hline $\mathrm{PT}-10$ & 10,65 & 7,9 & 7,9 & $\mathrm{D}$ & 52 & 52 & 0,862 & 51 & 50 & 50 & 0,862 & 49,5 & 19,8 \\
\hline $\mathrm{PT}-11$ & 10,65 & 7,1 & 7,1 & $\mathrm{D}$ & 65 & 65 & 0,855 & 49 & 32 & 32 & 0,855 & 49,25 & 20,17 \\
\hline $\mathrm{PT}-12$ & 10,65 & 7,7 & 7,7 & $\mathrm{D}$ & 35 & 35 & 0,868 & 31 & 27 & 27 & 0,868 & 49,18 & 20,49 \\
\hline $\mathrm{PT}-13$ & 10,65 & 7,1 & 7,1 & $\mathrm{D}$ & 52 & 52 & 0,862 & 52 & 52 & 52 & 0,862 & 48,3 & 20,04 \\
\hline $\mathrm{PT}-14$ & 10,65 & 7 & 7 & $\mathrm{D}$ & 22 & 22 & 0,868 & 22 & 22 & 22 & 0,868 & 49,2 & 19,9 \\
\hline PT - 16 & 10,65 & 7,5 & 7,5 & $\mathrm{D}$ & 57 & 57 & 0,855 & 57 & 57 & 57 & 0,855 & 50,77 & 20,55 \\
\hline PT - 17 & 10,65 & 8 & 8 & $\mathrm{D}$ & $*$ & $*$ & 0,868 & $*$ & $*$ & $*$ & 0,868 & 50,63 & 20,69 \\
\hline PT - 18 & 10,65 & 8 & 8 & $\mathrm{D}$ & 22 & 22 & 0,868 & 22 & 22 & 22 & 0,868 & 50,96 & 20,48 \\
\hline PT - 19 & 10,65 & 6,7 & 6,7 & $\mathrm{D}$ & 42 & 42 & 0,862 & 35 & 27 & 27 & 0,862 & 50,92 & 20,18 \\
\hline $\mathrm{PT}-20$ & 10,65 & 7,6 & 7,6 & $\mathrm{D}$ & 67 & 67 & 0,855 & 59 & 52 & 52 & 0,855 & 50,83 & 20,24 \\
\hline
\end{tabular}

\begin{tabular}{|c|c|c|c|c|c|c|c|c|c|c|c|c|c|}
\hline PT - 06 & 10,65 & 7,3 & 7,3 & $\mathrm{O}$ & $*$ & $*$ & 0,868 & $*$ & $*$ & $*$ & 0,868 & 49,6 & 19,65 \\
\hline PT - 07 & 10,65 & 7,6 & 7,6 & $\mathrm{O}$ & 20 & 20 & 0,868 & 20 & 20 & 20 & 0,868 & 49,03 & 19,83 \\
\hline PT - 08 & 10,65 & 8,4 & 8,4 & $\mathrm{O}$ & 47 & 47 & 0,862 & 47 & 47 & 47 & 0,862 & 49,1 & 20,66 \\
\hline PT - 09 & 10,65 & 7,7 & 7,7 & $\mathrm{O}$ & 47 & 47 & 0,862 & 47 & 47 & 47 & 0,862 & 49,65 & 20,16 \\
\hline PT - 10 & 10,65 & 7,9 & 7,9 & $\mathrm{O}$ & 50 & 50 & 0,862 & 49 & 47 & 47 & 0,862 & 49,6 & 19,8 \\
\hline PT - 11 & 10,65 & 7,1 & 7,1 & $\mathrm{O}$ & 60 & 60 & 0,855 & 60 & 60 & 60 & 0,855 & 49,3 & 20,17 \\
\hline PT - 12 & 10,65 & 7,7 & 7,7 & $\mathrm{O}$ & 30 & 30 & 0,868 & 33 & 35 & 35 & 0,868 & 49,25 & 20,49 \\
\hline
\end{tabular}


Anexo I-Permeabilidade

Tabela 05 - Considerações e resultados para os corpos-de-prova de $P$. elliottii para ensaio a gás na direção transversal às fibras.

\begin{tabular}{|c|c|c|c|c|c|c|c|c|c|c|c|c|c|}
\hline \multicolumn{14}{|c|}{ Contınuaçao } \\
\hline PT - 13 & 10,65 & 7,1 & 7,1 & $\mathrm{O}$ & 52 & 52 & 0,862 & 49 & 47 & 47 & 0,862 & 48,5 & 20,04 \\
\hline PT - 14 & 10,65 & 7 & 7 & $\mathrm{O}$ & 22 & 22 & 0,868 & 22 & 22 & 22 & 0,868 & 49,3 & 19,9 \\
\hline PT - 15 & 10,65 & 7,2 & 7,2 & $\mathrm{O}$ & 50 & 50 & 0,862 & 41 & 32 & 32 & 0,862 & 48,8 & 20,42 \\
\hline
\end{tabular}

Tabela 06 - Considerações e resultados para os corpos-de-prova de E. citriodora no alburno para ensaio a líquido com água destilada na direção longitudinal às fibras.

\begin{tabular}{|c|c|c|c|c|c|c|c|c|c|c|c|}
\hline $\mathrm{CP}$ & $U(\%)$ & $P_{v}(g)$ & $P_{s}(g)$ & $\begin{array}{c}\mathrm{P}_{\mathrm{f}}(\mathrm{g}) \\
\text { pós ensaio }\end{array}$ & $\begin{array}{l}\% \text { ganho } \\
\text { em massa }\end{array}$ & $\begin{array}{c}\text { Tempo (s) } \\
\text { para Q de } 30 \mathrm{ml}\end{array}$ & $\begin{array}{c}\mathrm{P}_{1} \\
(\mathrm{~atm})\end{array}$ & $\begin{array}{c}1(\mathrm{~mm}) \\
\text { a } 12 \% \mathrm{U}\end{array}$ & $\begin{array}{c}\varnothing(\mathrm{mm}) \\
\text { a } 12 \% \mathrm{U}\end{array}$ & $\begin{array}{c}1(\mathrm{~mm}) \\
\text { pós ensaio }\end{array}$ & $\begin{array}{c}\varnothing(\mathrm{mm}) \\
\text { pós ensaio }\end{array}$ \\
\hline CAL - 01 & 20 & 16,8 & 15,68 & 17,30 & 10,33 & 3,37 & 0,868 & 50,68 & 20,39 & 50,75 & 21,2 \\
\hline CAL - 02 & 20 & 16,9 & 15,77 & 16,60 & 5,24 & 4,68 & 0,868 & 51,01 & 20,4 & 51,05 & 20,68 \\
\hline CAL - 03 & 20 & 16 & 14,93 & 16,20 & 8,48 & 3,77 & 0,868 & 50,8 & 18,88 & 50,93 & 20,27 \\
\hline CAL - 04 & 20 & 16,1 & 15,03 & 16,30 & 8,47 & 4,18 & 0,868 & 51,23 & 20,12 & 51,4 & 20,2 \\
\hline CAL - 05 & 20 & 14,4 & 13,44 & 15,40 & 14,58 & 4,38 & 0,868 & 51,38 & 20,01 & 51,6 & 20,09 \\
\hline CAL - 06 & 20 & 16,3 & 15,21 & 16,70 & 9,77 & 3,84 & 0,868 & 51,2 & 20,18 & 51,3 & 20,66 \\
\hline CAL - 08 & 20 & 16,2 & 15,12 & 16,50 & 9,13 & 4,03 & 0,868 & 51,32 & 19,65 & 51,39 & 20,05 \\
\hline CAL - 09 & 20 & 16,1 & 15,03 & 16,00 & 6,48 & 3,59 & 0,868 & 51,3 & 19,52 & 51,4 & 19,66 \\
\hline CAL - 10 & 20 & 17,3 & 16,15 & 17,00 & 5,28 & 3,78 & 0,868 & 51,26 & 20,33 & 51,36 & 20,34 \\
\hline CAL - 11 & 20 & 15,1 & 14,09 & 14,7 & 4,30 & 4,94 & 0,868 & 50,67 & 19,4 & 51,11 & 19,76 \\
\hline CAL - 12 & 20 & 14,9 & 13,91 & 15,6 & 12,18 & 3,9 & 0,868 & 51,08 & 19,41 & 51,14 & 20,09 \\
\hline CAL - 13 & 20 & 13,2 & 12,32 & 14,1 & 14,45 & 3,9 & 0,868 & 47,13 & 19,09 & 47,17 & 19,59 \\
\hline CAL - 14 & 20 & 14,3 & 13,35 & 15,1 & 13,14 & 4,88 & 0,868 & 51,25 & 18,99 & 51,28 & 19,06 \\
\hline CAL - 16 & 20 & 15,1 & 14,09 & 15,9 & 12,82 & 4,65 & 0,868 & 50,75 & 19,31 & 50,78 & 19,5 \\
\hline CAL - 17 & 20 & 13,6 & 12,69 & 15,3 & 20,54 & 2,63 & 0,868 & 50,53 & 18,93 & 50,55 & 19,37 \\
\hline CAL - 18 & 20 & 13,8 & 12,88 & 14,5 & 12,58 & 4,1 & 0,868 & 50,01 & 18,82 & 50,05 & 19,13 \\
\hline CAL - 19 & 17,9 & 15,9 & 15,10 & 16,5 & 9,24 & 3,06 & 0,868 & 51,22 & 19,94 & 51,25 & 20,09 \\
\hline CAL - 20 & 17,9 & 15,8 & 15,01 & 16,2 & 7,93 & 2,69 & 0,868 & 51,54 & 20,27 & 51,77 & 20,72 \\
\hline
\end{tabular}


Tabela 07 - Considerações e resultados para os corpos-de-prova de E. grandis no alburno para ensaio a líquido com água destilada na direção longitudinal às fibras.

\begin{tabular}{|c|c|c|c|c|c|c|c|c|c|c|c|}
\hline $\mathrm{CP}$ & $\mathrm{U}(\%)$ & $P_{v}(g)$ & $\mathrm{P}_{\mathrm{s}}(\mathrm{g})$ & $\begin{array}{c}\mathrm{P}_{\mathrm{f}}(\mathrm{g}) \\
\text { pós ensaio }\end{array}$ & $\begin{array}{l}\% \text { ganho } \\
\text { em massa }\end{array}$ & $\begin{array}{c}\text { Tempo (s) } \\
\text { para Q de } 30 \mathrm{ml}\end{array}$ & $\begin{array}{c}\mathrm{P}_{1} \\
(\mathrm{~atm})\end{array}$ & $\begin{array}{c}1(\mathrm{~mm}) \\
\text { a } 12 \% \mathrm{U}\end{array}$ & $\begin{array}{l}\varnothing(\mathrm{mm}) \\
\text { a } 12 \% \mathrm{U}\end{array}$ & $\begin{array}{c}1(\mathrm{~mm}) \\
\text { pós ensaio }\end{array}$ & $\begin{array}{c}\varnothing(\mathrm{mm}) \\
\text { pós ensaio }\end{array}$ \\
\hline GAL - 01 & 20,8 & 11,9 & 11,0 & 13,1 & 18,7 & 3,33 & 0,868 & 50,8 & 18,9 & 51,03 & 19,36 \\
\hline GAL - 02 & 20,8 & 12,1 & 11,2 & 14,3 & 27,5 & 3,03 & 0,868 & 50,9 & 19,2 & 51,15 & 19,22 \\
\hline GAL - 03 & 20,8 & 11,8 & 10,9 & 12,7 & 16,1 & 3,08 & 0,868 & 50,8 & 18,87 & 51,06 & 19,21 \\
\hline GAL - 04 & 20,8 & 16,2 & 15,0 & 16,3 & 8,5 & 5,13 & 0,868 & 50,9 & 19,5 & 51,03 & 19,63 \\
\hline GAL - 05 & 20,8 & 16,6 & 15,4 & 16,8 & 9,2 & 2,38 & 0,868 & 51,05 & 19,84 & 51,12 & 19,93 \\
\hline GAL - 06 & 20,8 & 11,7 & 10,8 & 12 & 10,6 & 2,94 & 0,868 & 51,53 & 18,34 & 51,6 & 18,4 \\
\hline GAL - 08 & 20,8 & 11,8 & 10,9 & 11,8 & 7,9 & 2,59 & 0,868 & 51,24 & 18,44 & 51,33 & 18,75 \\
\hline GAL - 09 & 20,8 & 12,2 & 11,3 & 11,8 & 4,3 & 2,1 & 0,868 & 51 & 18,88 & 51,88 & 19,07 \\
\hline GAL - 10 & 20,8 & 11,7 & 10,8 & 11,9 & 9,7 & 2,91 & 0,868 & 51 & 18,3 & 51,34 & 18,5 \\
\hline GAL - 11 & 20,8 & 15,8 & 14,6 & 16 & 9,6 & 4 & 0,868 & 51,06 & 19,95 & 51,14 & 19,99 \\
\hline
\end{tabular}


Tabela 08 - Considerações e resultados para os corpos-de-prova de E. grandis no cerne para ensaio a líquido com água destilada na direção longitudinal às fibras.

\begin{tabular}{|c|c|c|c|c|c|c|c|c|c|c|c|}
\hline $\mathrm{CP}$ & $\mathrm{U}(\%)$ & $\mathrm{Pv}(\mathrm{g})$ & Ps (g) & $\begin{array}{c}\mathrm{P}_{\mathrm{f}}(\mathrm{g}) \\
\text { pós ensaio }\end{array}$ & $\begin{array}{l}\% \text { ganho } \\
\text { em massa }\end{array}$ & $\begin{array}{c}\text { Tempo }(\mathrm{m}) \\
\text { para Q de } 1 / 2 \mathrm{ml}\end{array}$ & $\begin{array}{c}\mathrm{P}_{1} \\
(\mathrm{~atm})\end{array}$ & $\begin{array}{c}1(\mathrm{~mm}) \\
\text { a } 12 \% \mathrm{U}\end{array}$ & $\begin{array}{c}\varnothing(\mathrm{mm}) \\
\text { a } 12 \% \mathrm{U} \\
\end{array}$ & $\begin{array}{c}1(\mathrm{~mm}) \\
\text { pós ensaio }\end{array}$ & $\begin{array}{c}\varnothing(\mathrm{mm}) \\
\text { pós ensaio }\end{array}$ \\
\hline GCL - 01 & 28,9 & 9,4 & 8,2 & 9 & 10,2 & 1,22 & 0,868 & 48,8 & 17,84 & 48,9 & 18,2 \\
\hline GCL - 02 & 28,9 & 9,2 & 8,0 & 8,9 & 11,3 & 1,56 & 0,868 & 47,3 & 17,7 & 47,46 & 18,27 \\
\hline GCL - 03 & 28,9 & 10 & 8,7 & 9,4 & 8,2 & 0,52 & 0,868 & 47,02 & 18,79 & 48,04 & 18,8 \\
\hline GCL - 04 & 28,9 & 10,3 & 8,9 & 9,7 & 8,4 & 1,4 & 0,868 & 49,25 & 19,02 & 49,36 & 19,05 \\
\hline GCL - 05 & 28,9 & 9,1 & 7,9 & 8,7 & 10,0 & 0,5 & 0,868 & 47,88 & 18,46 & 47,99 & 18,64 \\
\hline GCL - 06 & 28,9 & 10,5 & 9,1 & 9,6 & 5,2 & 1,32 & 0,868 & 49,18 & 18,94 & 49,27 & 18,96 \\
\hline GCL - 08 & 28,9 & 9,6 & 8,3 & 9,3 & 11,5 & 0,52 & 0,868 & 47,78 & 17,76 & 47,78 & 18,03 \\
\hline GCL - 09 & 28,9 & 9,6 & 8,3 & 9,1 & 9,1 & 0,49 & 0,868 & 47,13 & 17,7 & 47,18 & 17,98 \\
\hline GCL - 10 & 28,9 & 12 & 10,4 & 10,8 & 3,6 & $*$ & 0,868 & 50,21 & 18,23 & 50,21 & 18,73 \\
\hline GCL - 11 & 28,9 & 9,6 & 8,3 & 8,8 & 6,0 & 2,59 & 0,868 & 48,19 & 19,48 & 48,34 & 20,09 \\
\hline GCL - 12 & 28,9 & 9,6 & 8,3 & 9,3 & 12,0 & 1,09 & 0,868 & 49,22 & 19,22 & 49,41 & 19,23 \\
\hline GCL - 13 & 28,9 & 10 & 8,6 & 9,2 & 7,0 & 1,51 & 0,868 & 50,14 & 19,14 & 50,25 & 19,17 \\
\hline GCL - 14 & 28,9 & 9,6 & 8,3 & 9,2 & 10,8 & 1,3 & 0,868 & 50,02 & 18,13 & 50,15 & 18,29 \\
\hline
\end{tabular}


Tabela 09 - Considerações e resultados para os corpos-de-prova de $P$. elliottii para ensaio liquido com água destilada na direção longitudinal as fibras.

\begin{tabular}{|c|c|c|c|c|c|c|c|c|c|c|c|}
\hline U (\%) & $\mathrm{Pv}(\mathrm{g})$ & $P_{v}(g)$ & $P_{s}(g)$ & $\begin{array}{c}\mathrm{P}_{\mathrm{f}}(\mathrm{g}) \\
\text { pós ensaio }\end{array}$ & $\begin{array}{l}\% \text { ganho } \\
\text { em massa }\end{array}$ & $\begin{array}{c}\text { Tempo }(\mathrm{m}) \\
\text { para Q de } 25 \mathrm{ml}\end{array}$ & $\begin{array}{c}\mathrm{P}_{1} \\
(\mathrm{~atm})\end{array}$ & $\begin{array}{c}1(\mathrm{~mm}) \\
\text { a } 12 \% \mathrm{U}\end{array}$ & $\begin{array}{c}\varnothing(\mathrm{mm}) \\
\text { a } 12 \% \mathrm{U}\end{array}$ & $\begin{array}{c}1(\mathrm{~mm}) \\
\text { pós ensaio }\end{array}$ & $\begin{array}{c}\varnothing(\mathrm{mm}) \\
\text { pós ensaio }\end{array}$ \\
\hline PL - 01 & 10,65 & 8,6 & 8,6 & 9,8 & 13,95 & 3,03 & 0,868 & 49,9 & 21,35 & 49,95 & 21,46 \\
\hline PL - 02 & 10,65 & 8,8 & 8,8 & 11,9 & 35,23 & $*$ & 0,868 & 49,05 & 20,22 & 49,18 & 20,76 \\
\hline PL - 03 & 10,65 & 7,2 & 7,2 & 10,8 & 50,00 & 4,16 & 0,868 & 48,86 & 21,02 & 49,12 & 21,2 \\
\hline PL - 04 & 10,65 & 7,6 & 7,6 & 12,1 & 59,21 & 2,11 & 0,868 & 48,95 & 19,85 & 49 & 20,15 \\
\hline PL - 05 & 10,65 & 7,2 & 7,2 & 11,9 & 65,28 & 14,1 & 0,868 & 49,28 & 20,64 & 49,3 & 20,83 \\
\hline PL - 06 & 10,65 & 8 & 8 & 12,6 & 57,50 & 2,54 & 0,868 & 49,28 & 20,49 & 49,63 & 20,49 \\
\hline PL - 07 & 10,65 & 6,9 & 6,9 & 11 & 59,42 & 4,5 & 0,868 & 48,18 & 20,13 & 48,39 & 20,42 \\
\hline PL - 08 & 10,65 & 7,2 & 7,2 & 11,2 & 55,56 & 2,54 & 0,868 & 49,28 & 19,9 & 49,29 & 20,09 \\
\hline PL - 09 & 10,65 & 8,3 & 8,3 & 13,8 & 66,27 & 4,07 & 0,868 & 49,24 & 20,18 & 49,27 & 20,75 \\
\hline PL - 10 & 10,65 & 8 & 8 & 12,9 & 61,25 & 1,51 & 0,868 & 48,74 & 20 & 48,92 & 20,29 \\
\hline PL - 11 & 10,65 & 6,2 & 6,2 & 8,6 & 38,71 & 2,27 & 0,868 & 50,1 & 19,97 & 50,17 & 20,24 \\
\hline PL - 12 & 10,65 & 9,5 & 9,5 & 11,5 & 21,05 & 3,15 & 0,868 & 50,51 & 20,29 & 50,59 & 21,03 \\
\hline PL - 13 & 10,65 & 6,8 & 6,8 & 9,6 & 41,18 & 3,24 & 0,868 & 50,11 & 20,31 & 50,13 & 20,51 \\
\hline PL - 14 & 10,65 & 6,2 & 6,2 & 8,5 & 37,10 & 8,46 & 0,868 & 50 & 19,91 & 50,25 & 20,2 \\
\hline PL - 15 & 10,65 & 7,3 & 7,3 & 10,2 & 39,73 & 4,04 & 0,868 & 50,07 & 20,28 & 50,2 & 20,51 \\
\hline PL - 16 & 10,65 & 9,4 & 9,4 & 12,1 & 28,72 & 2,59 & 0,868 & 50,18 & 20,26 & 50,34 & 20,47 \\
\hline
\end{tabular}


Tabela 10 - Considerações e resultados para os corpos-de-prova de E. citriodora no alburno para ensaio liquido com preservativo à base de óleo de Neen na direção longitudinal às fibras.

\begin{tabular}{|c|c|c|c|c|c|c|c|c|c|c|c|}
\hline $\mathrm{CP}$ & $U(\%)$ & $P_{v}(g)$ & $P_{s}(g)$ & $\begin{array}{c}\mathrm{P}_{\mathrm{f}}(\mathrm{g}) \\
\text { pós ensaio }\end{array}$ & $\begin{array}{l}\% \text { ganho } \\
\text { em massa }\end{array}$ & $\begin{array}{c}\text { Tempo (s) } \\
\text { para Q de } 30 \mathrm{ml}\end{array}$ & $\begin{array}{c}\mathrm{P}_{1} \\
(\mathrm{~atm})\end{array}$ & $\begin{array}{c}1(\mathrm{~mm}) \\
\text { a } 12 \% \mathrm{U}\end{array}$ & $\begin{array}{c}\varnothing(\mathrm{mm}) \\
\text { a } 12 \% \mathrm{U}\end{array}$ & $\begin{array}{c}1(\mathrm{~mm}) \\
\text { pós ensaio }\end{array}$ & $\begin{array}{c}\varnothing(\mathrm{mm}) \\
\text { pós ensaio }\end{array}$ \\
\hline CAL - 01 & 17,9 & 14,9 & 14,15 & 15,3 & 8,09 & 2,57 & 0,868 & 50,75 & 19,81 & 50,95 & 20,19 \\
\hline CAL - 02 & 17,9 & 15,8 & 15,01 & 16,7 & 11,26 & 3,04 & 0,868 & 51,02 & 20,28 & 51,09 & 20,64 \\
\hline CAL - 03 & 17,9 & 16 & 15,20 & 17,1 & 12,51 & 5,25 & 0,868 & 50,98 & 20,24 & 51 & 20,59 \\
\hline CAL - 04 & 17,9 & 15,6 & 14,82 & 16,5 & 11,34 & 3,32 & 0,868 & 51,21 & 19,83 & 51,29 & 20,18 \\
\hline CAL - 05 & 17,9 & 15,77 & 14,98 & 16,5 & 10,14 & 4 & 0,868 & 51,07 & 19,97 & 51,16 & 20,16 \\
\hline CAL - 06 & 17,9 & 16 & 15,20 & 16,7 & 9,87 & 3,53 & 0,868 & 51,16 & 19,98 & 51,18 & 20 \\
\hline CAL - 07 & 17,9 & 15,8 & 15,01 & 16,7 & 11,26 & 3,19 & 0,868 & 51,45 & 19,94 & 51,52 & 20,05 \\
\hline CAL - 08 & 17,9 & 16 & 15,20 & 16,6 & 9,22 & 3,34 & 0,868 & 52,07 & 19,81 & 52,14 & 20 \\
\hline CAL - 09 & 17,9 & 15,7 & 14,91 & 16,5 & 10,63 & 2,84 & 0,868 & 51,38 & 20,18 & 51,56 & 20,65 \\
\hline CAL - 10 & 17,9 & 15,9 & 15,10 & 16,4 & 8,58 & 2,85 & 0,868 & 51,36 & 20,18 & 51,5 & 20,32 \\
\hline CAL - 11 & 17,9 & 15,8 & 15,01 & 16,2 & 7,93 & 4,63 & 0,868 & 51,04 & 20,17 & 51,06 & 20,47 \\
\hline CAL - 12 & 17,9 & 15 & 14,25 & 15,8 & 10,88 & 2,88 & 0,868 & 50,87 & 19,64 & 50,95 & 19,89 \\
\hline CAL - 13 & 17,9 & 16,4 & 15,58 & 16,7 & 7,19 & 3,44 & 0,868 & 51,44 & 20,11 & 51,52 & 20,2 \\
\hline CAL - 14 & 17,9 & 15,9 & 15,10 & 16,8 & 11,23 & 3,43 & 0,868 & 51,04 & 20,17 & 51,25 & 20,39 \\
\hline CAL - 15 & 17,9 & 15,8 & 15,01 & 16,5 & 9,93 & 2,97 & 0,868 & 51,4 & 19,91 & 51,42 & 20,04 \\
\hline CAL - 16 & 17,9 & 15,4 & 14,63 & 16,4 & 12,10 & 6,6 & 0,868 & 49,52 & 19,92 & 49,58 & 20,4 \\
\hline CAL - 17 & 17,9 & 15,6 & 14,82 & 16,6 & 12,02 & 3,45 & 0,868 & 51,19 & 19,77 & 51,2 & 20 \\
\hline CAL - 18 & 17,9 & 16,1 & 15,29 & 16,7 & 9,19 & 3,16 & 0,868 & 51,36 & 20,17 & 51,42 & 20,5 \\
\hline CAL - 19 & 17,9 & 15,8 & 15,01 & 16,3 & 8,60 & 4 & 0,868 & 51,63 & 20,05 & 51,79 & 20,21 \\
\hline CAL - 20 & 17,9 & 16,4 & 15,58 & 17 & 9,12 & 3,78 & 0,868 & 51,6 & 20,27 & 51,7 & 20,3 \\
\hline
\end{tabular}


Tabela 11 - Considerações e resultados para os corpos-de-prova de E.grandis no alburno para ensaio líquido com preservativo à base de óleo de Neen na direção longitudinal às fibras.

\begin{tabular}{|c|c|c|c|c|c|c|c|c|c|c|c|}
\hline $\mathrm{CP}$ & $\mathrm{U}(\%)$ & $\mathrm{P}_{\mathrm{v}}(\mathrm{g})$ & $\mathrm{P}_{\mathrm{s}}(\mathrm{g})$ & $\begin{array}{c}\mathrm{P}_{\mathrm{f}}(\mathrm{g}) \\
\text { pós ensaio }\end{array}$ & $\begin{array}{c}\% \text { ganho } \\
\text { em massa }\end{array}$ & $\begin{array}{c}\text { Tempo (s) } \\
\text { para Q de 25 ml }\end{array}$ & $\begin{array}{c}\mathrm{P}_{1} \\
(\mathrm{~atm})\end{array}$ & $\begin{array}{c}1(\mathrm{~mm}) \\
\mathrm{a} \mathrm{12 \%} \mathrm{U}\end{array}$ & $\begin{array}{c}\varnothing(\mathrm{mm}) \\
\mathrm{a} 12 \% \mathrm{U}\end{array}$ & $\begin{array}{c}1(\mathrm{~mm}) \\
\text { pós ensaio }\end{array}$ & $\begin{array}{c}\varnothing(\mathrm{mm}) \\
\text { pós ensaio }\end{array}$ \\
\hline GAL - 01 & 20,8 & 11,4 & 10,57 & 12,5 & 18,26 & 2,72 & 0,868 & 50,58 & 19,18 & 50,69 & 19,69 \\
\hline GAL - 02 & 20,8 & 11,6 & 10,75 & 12,8 & 19,01 & 4,01 & 0,868 & 50,84 & 19,36 & 50,86 & 19,52 \\
\hline GAL - 03 & 20,8 & 11,3 & 10,48 & 12,5 & 19,31 & 2,32 & 0,868 & 51 & 19,28 & 51,2 & 19,8 \\
\hline GAL - 04 & 20,8 & 15,6 & 14,46 & 15,7 & 8,55 & 4,28 & 0,868 & 50,76 & 19,98 & 50,79 & 19,99 \\
\hline GAL - 05 & 20,8 & 11,2 & 10,38 & 11,9 & 14,60 & 2,97 & 0,868 & 50,89 & 19,31 & 50,9 & 19,66 \\
\hline GAL - 06 & 20,8 & 11,3 & 10,48 & 12,8 & 22,17 & 4,03 & 0,868 & 50,58 & 19,01 & 50,78 & 19,7 \\
\hline GAL - 07 & 20,8 & 11,4 & 10,57 & 11,9 & 12,59 & 2,21 & 0,868 & 51,05 & 19,31 & 51,11 & 19,48 \\
\hline GAL - 08 & 20,8 & 15,7 & 14,56 & 15,8 & 8,54 & 2,82 & 0,868 & 50,89 & 20,43 & 50,97 & 20,45 \\
\hline GAL - 09 & 20,8 & 11,1 & 10,29 & 11,7 & 13,69 & 3,81 & 0,868 & 50,68 & 18,88 & 50,73 & 19,03 \\
\hline GAL - 10 & 20,8 & 10,6 & 9,83 & 11,5 & 17,01 & 3,87 & 0,868 & 50,84 & 18,7 & 50,93 & 18,97 \\
\hline GAL - 11 & 20,8 & 12,1 & 11,22 & 12,4 & 10,53 & 5,81 & 0,868 & 51,36 & 19,11 & 51,4 & 19,2 \\
\hline
\end{tabular}


Tabela 12 - Considerações e resultados para os corpos-de-prova de E. grandis no cerne para ensaio líquido com preservativo à base de óleo de Neen na direção longitudinal as fibras.

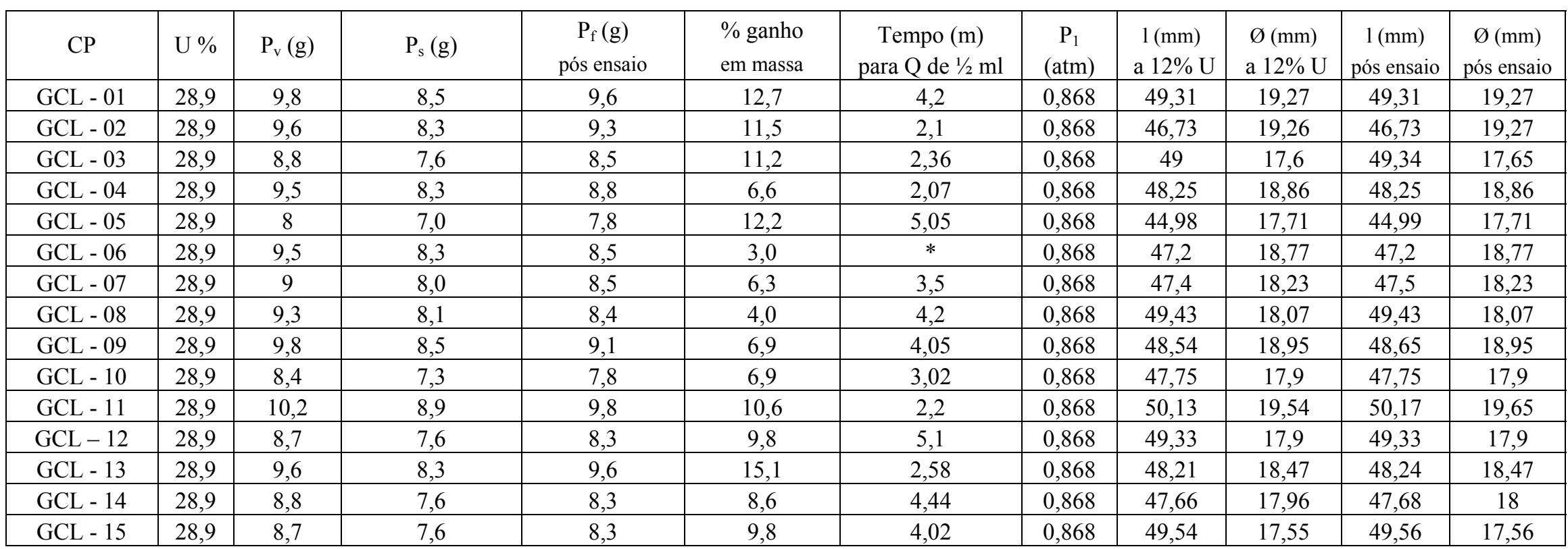


Tabela 13 - Considerações e resultados para os corpos-de-prova de $P$. elliottii para ensaio líquido com preservativo à base de óleo de Neen na direção longitudinal às fibras.

\begin{tabular}{|c|c|c|c|c|c|c|c|c|c|c|c|}
\hline $\mathrm{CP}$ & U (\%) & $\mathrm{P}_{\mathrm{v}}(\mathrm{g})$ & $\mathrm{P}_{\mathrm{s}}(\mathrm{g})$ & $\begin{array}{c}\mathrm{P}_{\mathrm{f}}(\mathrm{g}) \\
\text { pós ensaio }\end{array}$ & $\begin{array}{l}\% \text { ganho } \\
\text { em massa }\end{array}$ & $\begin{array}{c}\text { Tempo }(\mathrm{m}) \\
\text { para Q de } 25 \mathrm{ml}\end{array}$ & $\begin{array}{c}\mathrm{P}_{1} \\
(\mathrm{~atm})\end{array}$ & $\begin{array}{c}1(\mathrm{~mm}) \\
\text { a } 12 \% \mathrm{U}\end{array}$ & $\begin{array}{l}\varnothing(\mathrm{mm}) \\
\text { a } 12 \% \mathrm{U}\end{array}$ & $\begin{array}{c}1(\mathrm{~mm}) \\
\text { pós ensaio }\end{array}$ & $\begin{array}{c}\varnothing(\mathrm{mm}) \\
\text { pós ensaio }\end{array}$ \\
\hline PL - 01 & 10,65 & 6,8 & 6,8 & 8,8 & 29,41 & 4,02 & 0,868 & 49,33 & 20,08 & 49,42 & 20,37 \\
\hline PL - 02 & 10,65 & 9,6 & 9,6 & 10,8 & 12,50 & 8,57 & 0,868 & 50,49 & 20,32 & 50,59 & 20,47 \\
\hline PL - 03 & 10,65 & 6,7 & 6,7 & 8,7 & 29,85 & $*$ & 0,868 & 50 & 19,81 & 50 & 20,16 \\
\hline PL - 04 & 10,65 & 9,5 & 9,5 & 10,5 & 10,53 & 3,23 & 0,868 & 50,4 & 19,99 & 50,47 & 20,35 \\
\hline PL - 05 & 10,65 & 6,3 & 6,3 & 7,9 & 25,40 & 8,21 & 0,868 & 49,53 & 20,27 & 49,6 & 20,53 \\
\hline PL - 06 & 10,65 & 6,9 & 6,9 & 8,2 & 18,84 & 3,11 & 0,868 & 49,84 & 20,29 & 49,93 & 20,36 \\
\hline PL - 08 & 10,65 & 9,7 & 9,7 & 10,9 & 12,37 & 5,38 & 0,868 & 50,49 & 20,08 & 50,62 & 20,73 \\
\hline PL - 09 & 10,65 & 6,4 & 6,4 & 8,1 & 26,56 & 4,58 & 0,868 & 49,51 & 20,25 & 49,62 & 20,48 \\
\hline PL - 10 & 10,65 & 6,8 & 6,8 & 7,8 & 14,71 & 2,56 & 0,868 & 49,86 & 20,18 & 50,06 & 20,51 \\
\hline PL - 11 & 10,65 & 8,9 & 8,9 & 10,4 & 16,85 & 3,4 & 0,868 & 50,8 & 20,36 & 50,92 & 20,43 \\
\hline PL - 12 & 10,65 & 6,6 & 6,6 & 9,1 & 37,88 & 12,29 & 0,868 & 49,82 & 19,98 & 49,92 & 20,27 \\
\hline PL - 13 & 10,65 & 7,2 & 7,2 & 9,8 & 36,11 & 4,13 & 0,868 & 49,81 & 20,35 & 50,07 & 20,38 \\
\hline PL - 14 & 10,65 & 8,3 & 8,3 & 9,7 & 16,87 & 4,4 & 0,868 & 49,64 & 19,83 & 49,79 & 20,18 \\
\hline PL - 16 & 10,65 & 7,6 & 7,6 & 10 & 31,58 & $*$ & 0,868 & 48,69 & 19,6 & 48,71 & 19,79 \\
\hline PL -17 & 10,65 & 6,1 & 6,1 & 7,9 & 29,51 & 2,07 & 0,868 & 48,99 & 20,12 & 49,05 & 20,22 \\
\hline
\end{tabular}




\section{APÊNDICE A}

\section{Exemplo de aplicação do cálculo da permeabilidade de acordo com a Lei}

\section{de Darcy}

É exposto a seguir um exemplo de cálculo para se determinar a permeabilidade gasosa, utilizando os dados apresentados no anexo I. A Tabela 1, do anexo I apresenta a vazão $(\mathrm{L} / \mathrm{h})$, as dimensões (mm) e a pressão atmosférica (atm) na saída do corpo-de-prova na direção longitudinal às fibras para o alburno do $E$. citriodora.

Os cálculos foram efetuados com base nas dimensões de cada corpo-deprova, visto que se fosse adotado uma medida padrão poderia prejudicar os resultados, pois os corpos-de-prova após a secagem na estufa e desobstrução dos elementos anatômicos não apresentavam todos a mesma medida.

A pressa atmosférica adotada para efeito de cálculo, é de 0,906 atm. Está pressão é a média histórica na região de São Carlos, no período de 1970 a 1993, (Ministério da Agricultura), Latitude: $22^{\circ} 01^{\prime} \mathrm{S}$; longitude: $47^{\circ} 54^{\prime} \mathrm{W}$; altitude: $850 \mathrm{~m}$.

Seguindo Lei de Darcy para gases, temos a equação:

$$
K_{g}=\frac{V L P}{t A \Delta P \bar{P}}
$$

Por exemplo, utilizando a amostra CAL - 01, da Tabela 1, do anexo I, temos:

$\mathrm{V}=\mathrm{Q}=570 \mathrm{~L} / \mathrm{h}=158,33 \mathrm{~cm}^{3} / \mathrm{s}$;

$1=5,068 \mathrm{~cm}(12 \% \mathrm{U})$;

$\mathrm{P}=0,906$ atm;

$\mathrm{A}=3,14 .(2,039 / 2)^{2}=3,263 \mathrm{~cm}^{2}$;

$\Delta P=(0,906-0,237)=0,669 \mathrm{~atm} ;$

$\bar{P}=(0,906+0,237) / 2=0,5715 \mathrm{~atm}$.

Substituindo na fórmula, $\mathrm{K}_{\mathrm{g}}=582,63 \mathrm{~cm}^{3} / \mathrm{cm}$.atm.s.

Para líquidos, temos a equação segundo a Lei de Darcy:

$$
\mathrm{K}=\frac{V L}{t A \Delta P}
$$


Por exemplo, utilizando a amostra GAL - 01, da Tabela 6, para água destilada do anexo I, temos:

$\mathrm{V}=\mathrm{Q}=(30 / 3,33)=9,01 \mathrm{~cm}^{3} / \mathrm{s}$

$1=5,08 \mathrm{~cm}$;

$\mathrm{A}=3,14 \cdot(1,89 / 2)^{2}=2,804 \mathrm{~cm}^{2}$;

$\Delta P=(0,906-0,868)=0,038 \mathrm{~atm}$;

Substituindo na fórmula, $\mathrm{K}=429,50 \mathrm{~cm}^{3} / \mathrm{cm}$.atm.s. 


\section{APÊNDICE B}

\section{Exemplo de aplicação do método estatístico não-paramétrico de Kruskal-}

\section{Wallis.}

É exposto a seguir um exemplo de análise utilizando os dados de permeabilidade gasosa $\left(\mathrm{K}_{\mathrm{g}}\right.$ - ar atmosférico), ou seja, a análise de um tipo de fluido nas três espécies estudadas. A Tabela 1 A apresenta os valores de permeabilidade gasosa $\left(\mathrm{K}_{\mathrm{g}} \mathrm{em} \mathrm{cm}^{3} / \mathrm{cm} . \mathrm{atm} . \mathrm{s}\right)$ na direção longitudinal às fibras, os postos destes valores por tratamento e os valores $\mathrm{R}_{\mathrm{j}}, \mathrm{H}$ e p, respectivamente, para o Eucalyptus citriodora no alburno (A), Eucalyptus grandis no alburno (A) e no cerne (C), e para o Pinus elliottii.

Tabela $1 \mathrm{~A}$ - Resultados da $\mathrm{K}_{\mathrm{g}}$ em $\mathrm{cm}^{3} / \mathrm{cm}$.atm.s, os postos destes valores por tratamento e os valores $\mathrm{Rj}, \mathrm{H}$ e p, para as espécies abaixo na direção longitudinal às fibras.

\begin{tabular}{|c|c|c|c|c|c|c|c|c|}
\hline CP & E. citriodora - A & Posto & E. grandis - A & Posto & E. grandis - C & Posto & P. elliottii & Posto \\
\hline 1 & 583 & 45 & 761 & 76 & 29 & 15 & 136 & 26 \\
\hline 2 & 545 & 40 & 703 & 70 & 30 & 16.5 & 159 & 36 \\
\hline 3 & 638 & 62 & 712 & 71 & $* *$ & $* *$ & 146 & 32 \\
\hline 4 & 605 & 47 & 625 & 56 & 21 & 5 & 174 & 38 \\
\hline 5 & 613 & 52 & 677 & 67 & 24 & 9 & 124 & 20 \\
\hline 6 & 614 & 53 & 751 & 74 & 24 & 8 & 128 & 21 \\
\hline 7 & 626 & 57 & 647 & 64 & 22 & 7 & 138 & 28 \\
\hline 8 & 578 & 43 & 763 & 77 & 30 & 16.5 & 134 & 25 \\
\hline 9 & 609 & 50 & 792 & 78 & 21 & 4 & 138 & 29 \\
\hline 10 & 574 & 42 & 522 & 39 & $* *$ & $* *$ & 141 & 30 \\
\hline 11 & 655 & 65 & 568 & 41 & 20 & 3 & 172 & 37 \\
\hline 12 & 611 & 51 & 754 & 75 & 28 & 14 & 142 & 31 \\
\hline 13 & 607 & 49 & 633 & 58 & 26 & 11 & 156 & 35 \\
\hline 14 & 623 & 55 & 742 & 72 & 18 & 1 & 121 & 19 \\
\hline 15 & 603 & 46 & 581 & 44 & 19 & 2 & 151 & 34 \\
\hline 16 & 606 & 48 & 695 & 69 & 26 & 12 & 136 & 27 \\
\hline 17 & 635 & 59 & 657 & 66 & 22 & 6 & 130 & 24 \\
\hline 18 & 638 & 60 & 751 & 73 & 31 & 18 & 129 & 22 \\
\hline 19 & 639 & 63 & 617 & 54 & 26 & 10 & 147 & 33 \\
\hline 20 & 638 & 61 & 679 & 68 & 27 & 13 & 131 & 23 \\
\hline $\mathrm{R}_{\mathrm{i}}$ & & 1048 & & 1292 & & 171 & & 570 \\
\hline $\mathrm{H}$ & & & 67,2811 & & & \\
\hline $\mathrm{p}$ & & & $<0.0001$ & & & \\
\hline
\end{tabular}


Para calcularmos a estatística $\mathrm{H}$, usamos a expressão:

$$
H=\frac{12}{N(N+1)} \sum_{j=1}^{K} \frac{R_{j}^{2}}{n_{j}}-3(N+1)
$$

Por exemplo, para as quatro amostras analisadas, temos: $N=78, \mathrm{R}_{1}=1048$, $\mathrm{R}_{2}=1292, \mathrm{R}_{3}=171, \mathrm{R}_{4}=570$ e $\alpha=0,05$.

Substituindo na fórmula, $\mathrm{H}=67,2811$ com 3 graus de liberdade; a Tabela Quiquadrada nos dá: $\mathrm{h}=7,81$. Os resultados obtidos mostram que $\mathrm{H}$ (estatístico) é maior que o h (calculado), e sendo assim, rejeitamos $\mathrm{H}_{0}$.

Agora são estabelecidas as comparações múltiplas entre os tratamentos para descobrirmos quais são os grupos que diferem entre si.

Os números nas colunas dos postos representam as ordens de classificação conjunta das 78 observações.

Assim tem-se a média dos postos:

$$
\begin{array}{ll}
\bar{R}_{1}=52,4 & \bar{R}_{2}=64,6 \\
\bar{R}_{3}=9,5 & \bar{R}_{4}=28,5
\end{array}
$$

Utilizamos nesse caso, o processo das grandes amostras.

Admitindo, por exemplo, $\alpha=0,05$ tem-se:

$$
\begin{aligned}
z_{\propto /[k(k-1)]}=Z_{0,004} & =2,635, \\
z_{\text {calculado }} & =\frac{\text { diferença }}{\sqrt{\frac{N(N+1)}{12}\left(\frac{1}{\left.n_{1}+\frac{1}{n_{2}}\right)}\right.}}
\end{aligned}
$$

Por exemplo, para os grupos 1 e 2, a diferença é $12,2, \mathrm{~N}=78$ e $\mathrm{n}_{1}=\mathrm{n}_{2}=20$.

Substituindo na fórmula, $z_{\text {calculado }}=1,7025$, que é menor que o $z_{\text {critico }} 2,635$, aceita-se a igualdade.

Os resultados apresentados acima estão de acordo com os resultados apresentados pelo Bioestat, Tabela 2 A. 
Tabela $2 \mathrm{~A}$ - Diferença entre a média dos postos pelo método de Dunn para $\mathrm{K}_{\mathrm{g}}$ na direção longitudinal às fibras.

\begin{tabular}{|c|c|c|c|c|}
\hline Comparações (método de Dunn) & Dif. Postos & $\mathrm{z}$ calculado & $\mathrm{z}$ crítico & $\mathrm{p}$ \\
\hline Postos médios 1 e 2 & 12.2 & 1.7025 & 2.635 & $\mathrm{~ns}$ \\
\hline Postos médios 1 e 3 & 42.9 & 5.827 & 2.635 & $<0.05$ \\
\hline Postos médios 1 e 4 & 23.9 & 3.3352 & 2.635 & $<0.05$ \\
\hline Postos médios 2 e 3 & 55.1 & 7.4841 & 2.635 & $<0.05$ \\
\hline Postos médios 2 e 4 & 36.1 & 5.0378 & 2.635 & $<0.05$ \\
\hline Postos médios 3 e 4 & 19 & 2.5807 & 2.635 & $\mathrm{~ns}$ \\
\hline
\end{tabular}

Também se pode obter este resultados utilizando a d.m.s., que será dada por:

$$
\text { d.m.s } \left.=2,635 \sqrt{\frac{78(78+1)}{12}\left(\frac{1}{20}\right.}+\frac{1}{20}\right)=18,88
$$

Estabelece-e a seguinte tabela de d.m.s.:

\begin{tabular}{cc}
\hline$\left|\overline{R_{i}}-\overline{R_{j}}\right|$ & d.m.s. \\
\hline$\left|\overline{R_{1}}-\overline{R_{2}}\right|=12,2$ & 18,88 \\
$\left|\overline{R_{1}}-\overline{R_{3}}\right|=42,9$ & 19,34 \\
$\left|\overline{R_{1}}-\overline{R_{4}}\right|=23,9$ & 18,88 \\
$\left|\overline{R_{2}}-\overline{R_{3}}\right|=55,1$ & 19,34 \\
$\left|\overline{R_{2}}-\overline{R_{4}}\right|=36,1$ & 18,88 \\
$\left|\overline{R_{3}}-\overline{R_{4}}\right|=19$ & 19,34
\end{tabular}


Concluí à taxa de $5 \%$, que $t_{1}$ difere de $t_{3}$ e de $t_{4}$; e que $t_{2}$ difere de $t_{3}$ e de $t_{4}$, ou seja, a $\mathrm{K}_{\mathrm{g}}$ do alburno do E. citriodora é muito maior que a $\mathrm{K}_{\mathrm{g}}$ do cerne do E. grandis e Pinus elliottii. Ainda temos que a $\mathrm{K}_{\mathrm{g}}$ do alburno do E. grandis também é muito maior que a $\mathrm{K}_{\mathrm{g}}$ do cerne do E. grandis e Pinus elliottii e, sendo assim, esses grupos não são estatisticamente equivalentes. Esquematicamente-se pode representar:

$\begin{array}{ll}\text { alburno do E. citriodora } & \mathrm{a} \\ \text { alburno do E. grandis } & \mathrm{a} \\ \text { cerne do E. grandis } & \mathrm{b} \\ \text { Pinus elliottii } & \mathrm{b}\end{array}$

(letras iguais representam diferenças não significativas; letras diferentes representam diferenças significativas). 


\section{APÊNDICE C}

\section{Tabela dos valores da amplitude $Q$ para o método das comparações múltiplas}

Tabela 1C - Valores da amplitude Q a ser usada nas comparações múltiplas, caso de grandes amostras, com $\mathrm{n}_{1}=\mathrm{n}_{2}=\ldots=\mathrm{n}_{\mathrm{k}}=\mathrm{n},(n \rightarrow \infty)$, onde $\mathrm{k}$ é igual ao número de tratamentos, ou amostras.

\begin{tabular}{|c|c|c|c|c|c|}
\hline $\mathrm{K}$ & 0,20 & 0,105 & 0,05 & 0,01 & 0,001 \\
\hline 2 & 1,812 & 2,326 & 2,772 & 3,643 & 4,654 \\
\hline 3 & 2,424 & 2,902 & 3,314 & 4,120 & 5,063 \\
\hline 4 & 2,784 & 3,240 & 3,633 & 4,403 & 5,309 \\
\hline 5 & 3,037 & 3,478 & 3,858 & 4,603 & 5,484 \\
\hline 6 & 3,232 & 3,661 & 4,030 & 4,757 & 5,619 \\
\hline 7 & 3,389 & 3,808 & 4,170 & 4,882 & 5,730 \\
\hline 8 & 3,520 & 3,931 & 4,286 & 4,987 & 5,823 \\
\hline 9 & 3,632 & 4,037 & 4,386 & 5,078 & 5,903 \\
\hline 10 & 3,730 & 4,129 & 4,474 & 5,157 & 5,973 \\
\hline 11 & 3,817 & 4,211 & 4,552 & 5,227 & 6,036 \\
\hline 12 & 3,895 & 4,285 & 4,622 & 5,290 & 6,092 \\
\hline 13 & 3,966 & 4,351 & 4,685 & 5,348 & 6,144 \\
\hline 14 & 4,030 & 4,412 & 4,743 & 5,400 & 6,191 \\
\hline 15 & 4,089 & 4,468 & 4,796 & 5,448 & 6,234 \\
\hline 16 & 4,144 & 4,519 & 4,845 & 5,493 & 6,274 \\
\hline 17 & 4,195 & 4,568 & 4,891 & 5,535 & 6,312 \\
\hline 18 & 4,242 & 4,612 & 4,934 & 5,574 & 6,347 \\
\hline 19 & 4,287 & 4,654 & 4,974 & 5,611 & 6,380 \\
\hline 20 & 4,328 & 4,694 & 5,012 & 5,645 & 6,411 \\
\hline 22 & 4,405 & 4,767 & 5,081 & 5,709 & 6,468 \\
\hline 24 & 4,474 & 4,832 & 5,144 & 5,766 & 6,520 \\
\hline 26 & 4,537 & 4,892 & 5,201 & 5,818 & 6,568 \\
\hline 28 & 4,595 & 4,947 & 5,253 & 5,866 & 6,611 \\
\hline 30 & 4,648 & 4,997 & 5,301 & 5,910 & 6,651 \\
\hline 32 & 4,697 & 5,044 & 5,346 & 5,952 & 6,688 \\
\hline 34 & 4,793 & 5,087 & 5,388 & 5,990 & 6,723 \\
\hline 36 & 4,786 & 5,128 & 5,427 & 6,026 & 6,756 \\
\hline 38 & 4,826 & 5,166 & 5,463 & 6,060 & 6,787 \\
\hline 40 & 4,854 & 5,202 & 5,498 & 6,092 & 6,816 \\
\hline 50 & 5,026 & 5,357 & 5,646 & 6,228 & 6,940 \\
\hline 60 & 5,155 & 5,480 & 5,764 & 6,338 & 7,041 \\
\hline 70 & 5,262 & 5,582 & 5,863 & 6,429 & 7,124 \\
\hline 80 & 5,353 & 5,669 & 5,947 & 6,507 & 7,198 \\
\hline 90 & 5,433 & 5,745 & 6,020 & 6,575 & 7,258 \\
\hline 100 & 5,503 & 5,812 & 6,085 & 6,636 & 7,314 \\
\hline
\end{tabular}

Tabela adaptada de: HARTER, H.L., 1960. Tables of Range and Studentized Range. Annals of Mathematical Statiatical 31: 1122-47, apud CAMPOS, H., 1983. 